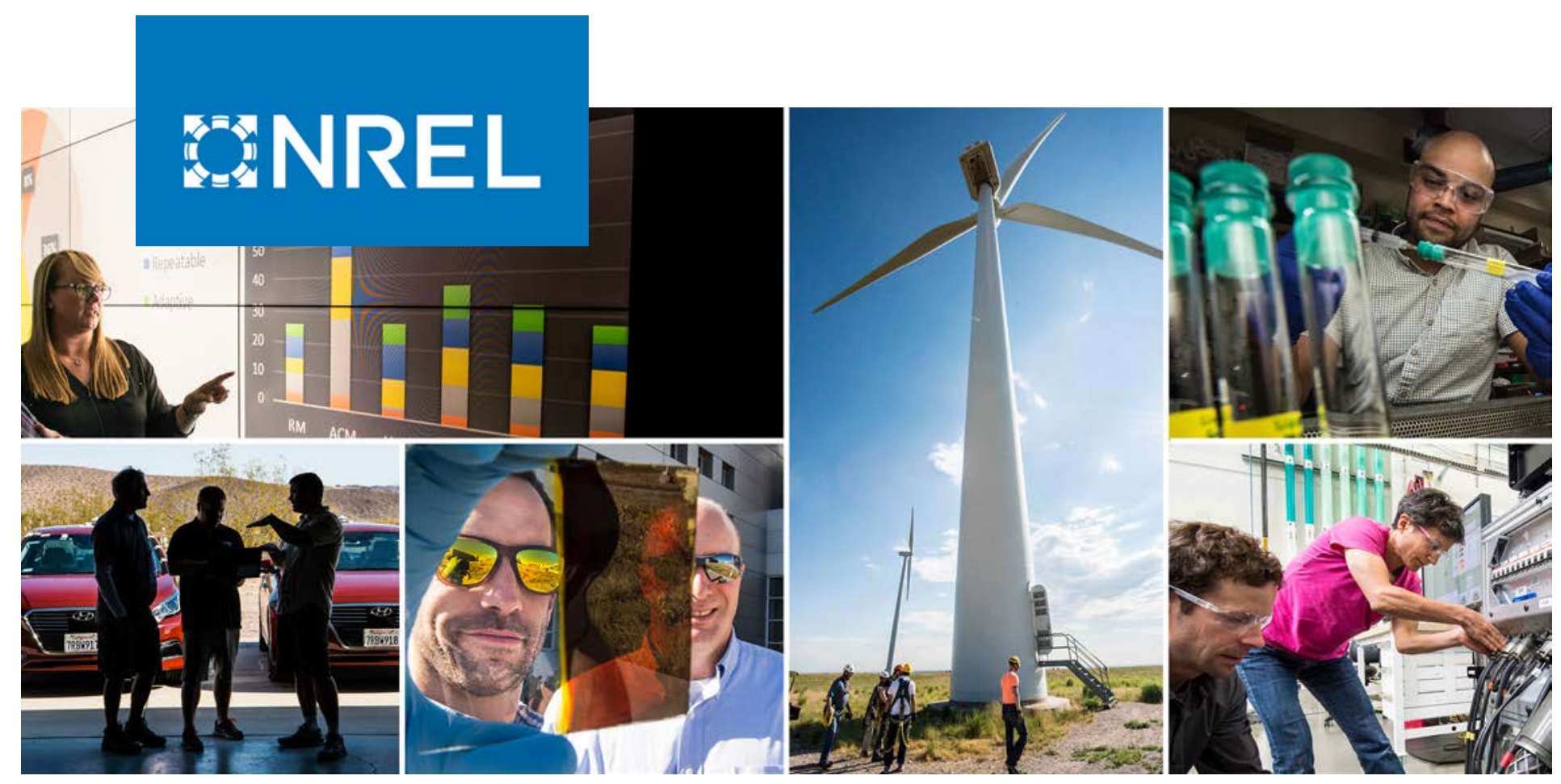

\title{
Regional Energy Deployment System (ReEDS) Model Documentation: Version 2018
}

Stuart Cohen, Jon Becker, Dave Bielen, Maxwell Brown, Wesley Cole, Kelly Eurek, Will Frazier, Bethany Frew, Pieter Gagnon, Jonathan Ho, Paige Jadun, Trieu Mai, Matthew Mowers, Caitlin Murphy, Andrew Reimers, James Richards, Nicole Ryan, Evangelia Spyrou, Daniel Steinberg, Yinong Sun, Nina Vincent, and Matthew Zwerling

National Renewable Energy Laboratory

NREL is a national laboratory of the U.S. Department of Energy Office of Energy Efficiency \& Renewable Energy

Operated by the Alliance for Sustainable Energy, LLC

This report is available at no cost from the National Renewable Energy Laboratory (NREL) at www.nrel.gov/publications.
Technical Report

NREL/TP-6A20- 72023

April 2019 


\section{GANREL}

\section{Regional Energy Deployment System (ReEDS) Model Documentation: Version 2018}

Stuart Cohen, Jon Becker, Dave Bielen, Maxwell Brown, Wesley Cole, Kelly Eurek, Will Frazier, Bethany Frew, Pieter Gagnon, Jonathan Ho, Paige Jadun, Trieu Mai, Matthew Mowers, Caitlin Murphy, Andrew Reimers, James Richards, Nicole Ryan, Evangelia Spyrou, Daniel Steinberg, Yinong Sun, Nina Vincent, and Matthew Zwerling

National Renewable Energy Laboratory

\section{Suggested Citation}

Cohen, Stuart, Jon Becker, Dave Bielen, Maxwell Brown, Wesley Cole, Kelly Eurek, Will Frazier, et al. 2019. Regional Energy Deployment System (ReEDS) Model Documentation: Version 2018. Golden, CO: National Renewable Energy Laboratory. NREL/TP-6A20-72023. https://www.nrel.gov/docs/fy19osti/72023.pdf.

NREL is a national laboratory of the U.S. Department of Energy Office of Energy Efficiency \& Renewable Energy Operated by the Alliance for Sustainable Energy, LLC

This report is available at no cost from the National Renewable Energy Laboratory (NREL) at www.nrel.gov/publications.

Contract No. DE-AC36-08G028308
Technical Report NREL/TP-6A20-72023 April 2019

National Renewable Energy Laboratory 15013 Denver West Parkway Golden, CO 80401

303-275-3000 • www.nrel.gov 


\section{NOTICE}

This work was authored by the National Renewable Energy Laboratory, operated by Alliance for Sustainable Energy, LLC, for the U.S. Department of Energy (DOE) under Contract No. DE-AC36-08G028308. Funding provided by the U.S. Department of Energy Office of Energy Efficiency and Renewable Energy, Strategic Programs. The views expressed herein do not necessarily represent the views of the DOE or the U.S. Government.

This report is available at no cost from the National Renewable Energy Laboratory (NREL) at www.nrel.gov/publications.

U.S. Department of Energy (DOE) reports produced after 1991 and a growing number of pre-1991 documents are available free via www.OSTI.gov.

Cover Photos by Dennis Schroeder: (clockwise, left to right) NREL 51934, NREL 45897, NREL 42160, NREL 45891, NREL 48097, NREL 46526.

NREL prints on paper that contains recycled content. 


\section{Acknowledgments}

We gratefully acknowledge the many people whose efforts contributed to this report. The ReEDS modeling and analysis team at the National Renewable Energy Laboratory (NREL) was active in developing and testing the ReEDS model v.2018. We also acknowledge the vast number of current and past NREL employees on and beyond the ReEDS team who have participated in data and model development, testing, and analysis. We are especially grateful to Walter Short who first envisioned and developed the Wind Deployment System (WinDS) and ReEDS models. We thank Walter Short, Ella Zhou, Owen Zinaman, Laura Vimmerstedt, Jeffrey Logan, Cara Marcy, Gokul Iyer, and Mike Meshek for their comments and improvements on successive versions of this report. Finally, we are grateful to all those who helped sponsor ReEDS model development and analysis, particularly supporters from the U.S. Department of Energy (DOE) but also others who have funded our work over the years. This report was funded by the DOE Office of Energy Efficiency and Renewable Energy under contract number DEAC36-08GO28308. Any errors or omissions are the sole responsibility of the authors.

\section{ReEDS Team Members}

Jon Becker

Dave Bielen

Maxwell Brown

Stuart Cohen

Wesley Cole

Kelly Eurek

Will Frazier

Bethany Frew

$\begin{array}{ll}\text { Pieter Gagnon } & \text { James Richards } \\ \text { Jonathan Ho } & \text { Nicole Ryan } \\ \text { Paige Jadun } & \text { Evangelia Spyrou } \\ \text { Trieu Mai } & \text { Daniel Steinberg } \\ \text { Matthew Mowers } & \text { Yinong Sun } \\ \text { Caitlin Murphy } & \text { Nina Vincent } \\ \text { Andrew Reimers } & \text { Matthew Zwerling }\end{array}$




\section{List of Abbreviations and Acronyms}

$\mathrm{AC}$

AEO

AFY

ATB

BA

CAES

CAIR

$\mathrm{CC}$

CCS

$\mathrm{CF}$

$\mathrm{CO}_{2}$

CMIP

CPP

CPUC

CSAPR

CSP

$\mathrm{CT}$

$\mathrm{CV}$

DC

DNI

DOE

DSIRE

DUPV

EAC

EGR

EGS

EIA

ELCC

EOR

EPA

ERC

ERCOT

FERC

GCM

GHG

GIS

GW

HMI

HSIP

HVDC

IGCC

IOU

IPM

IPP

ISO alternating current

Annual Energy Outlook

acre-feet per year

Annual Technology Baseline

balancing area

compressed-air energy storage

Clean Air Interstate Rule

combined cycle

carbon capture and sequestration

capacity factor

carbon dioxide

Coupled Model Intercomparison Project

Clean Power Plan

California Public Utilities Commission

Cross-State Air Pollution Rule

concentrating solar power

combustion turbine

capacity value

direct current

direct normal insolation

U.S. Department of Energy

Database of State Incentives for Renewables \& Efficiency

distribution-side utility-scale photovoltaic

early action credit

enhanced gas recovery

enhanced geothermal system

U.S. Energy Information Administration

effective load carrying capability

enhanced oil recovery

U.S. Environmental Protection Agency

emission rate credit

Electric Reliability Council of Texas

Federal Energy Regulatory Commission

general circulation model

greenhouse gas

geographic information systems

gigawatt

U.S. Bureau of Reclamation Hydropower Modernization Initiative

Homeland Security Infrastructure Project

high-voltage direct current

integrated gasification combined cycle

investor-owned utility

U.S. Environmental Protection Agency Integrated Planning Model

independent power producer

independent system operator 


$\begin{array}{ll}\text { IRS } & \text { Internal Revenue Service } \\ \text { ITC } & \text { investment tax credit } \\ \text { JEDI } & \text { Jobs and Economic Development Impact model } \\ \mathrm{km}^{2} & \text { square kilometer } \\ \mathrm{kV} & \text { kilovolt } \\ \mathrm{kW} & \text { kilowatt } \\ \mathrm{kWh} & \text { kilowatt hour } \\ \text { LCOE } & \text { levelized cost of energy } \\ \text { LDC } & \text { load-duration curve } \\ \text { LOLP } & \text { loss of load probability } \\ \text { MACRS } & \text { Modified Accelerated Cost Recovery System } \\ \text { MATS } & \text { Mercury and Air Toxic Standards } \\ \text { MMBtu } & \text { million British thermal units } \\ \text { MPI } & \text { materials price index } \\ \text { MW } & \text { megawatt } \\ \text { MWh } & \text { megawatt hour } \\ \text { NaS } & \text { sodium-sulfur } \\ \text { NEB } & \text { Canadian National Energy Board } \\ \text { NEMS } & \text { National Energy Modeling System } \\ \text { NERC } & \text { North American Electric Reliability Corporation } \\ \text { NG } & \text { natural gas } \\ \text { NHAAP } & \text { National Hydropower Asset Assessment Program } \\ \text { NLDC } & \text { net load-duration curve } \\ \text { NO } & \text { nitrogen oxide } \\ \text { NPD } & \text { non-powered dam } \\ \text { NRC } & \text { Nuclear Regulatory Commission } \\ \text { NREL } & \text { National Renewable Energy Lab } \\ \text { NSD } & \text { new stream-reach development } \\ \text { NSRDB } & \text { National Solar Radiation Database } \\ \text { O\&M } & \text { operation and maintenance } \\ \text { OGS } & \text { oil-gas steam } \\ \text { PCM } & \text { production-cost model } \\ \text { PRODESEN } & \text { Mexican Programa de Desarrollo del Sistema Eléctrico Nacional } \\ \text { PSH } & \text { pumped storage hydropower } \\ \text { PTC } & \text { production tax credit } \\ \text { PV } & \text { photovoltaic } \\ \text { RCP } & \text { representative concentration pathway Advisor Model } \\ \text { REC } & \text { renewable energy certificate } \\ \text { ReEDS } & \text { Regional Energy Deployment System } \\ \text { RGGI } & \text { Regional Greenhouse Gas Initiative } \\ \text { RLDC } & \text { residual load-duration curve } \\ \text { RPS } & \text { renewable portfolio standard } \\ \text { RROE } & \text { rate of return on equity } \\ \text { RTO } & \text { Segional Transmission Organization } \\ \text { SAM } & \text { Secret Mexico } \\ \text { SENER } & \end{array}$




$\begin{array}{ll}\mathrm{SO}_{2} & \text { sulfur dioxide } \\ \text { TDY } & \text { typical direct normal insolation year } \\ \text { TEPPC } & \text { Transmission Expansion Planning Policy Committee } \\ \text { TES } & \text { thermal energy storage } \\ \text { TRG } & \text { techno-resource group } \\ \mathrm{tCO}_{2} & \text { metric ton of carbon dioxide } \\ \mathrm{TW}_{\mathrm{TWh}} & \text { terawatt } \\ \mathrm{UPV} & \text { terawatt hour } \\ \text { VRE } & \text { utility-scale photovoltaic } \\ \text { WACC } & \text { variable renewable energy } \\ \text { WECC } & \text { weighted average cost of capital } \\ \text { WIND } & \text { Western Electricity Coordination Council } \\ \text { WinDS } & \text { Wind Integration National Dataset }\end{array}$




\section{Table of Contents}

1 Introduction

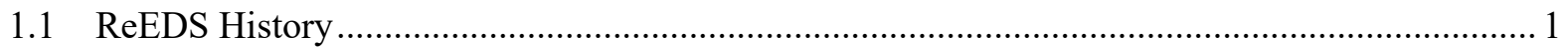

1.2 Qualitative Model Description ............................................................................................ 1

1.3 Linear Program Formulation Description ……………….................................................... 5

1.4 Summary of Caveats .........................................................................................................

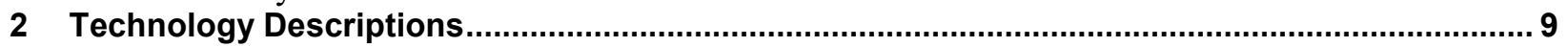

2.1 Renewable Energy Resources and Technologies ………………………………………........ 9

2.1.1 Land-Based Wind........................................................................................

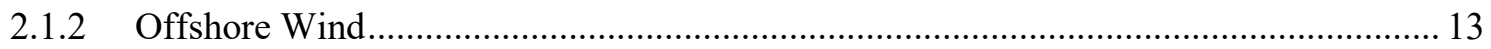

2.1.3 Solar Photovoltaics........................................................................................... 15

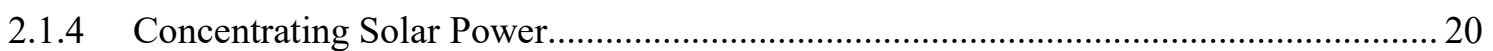

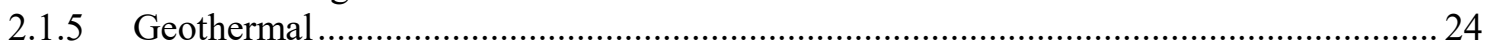

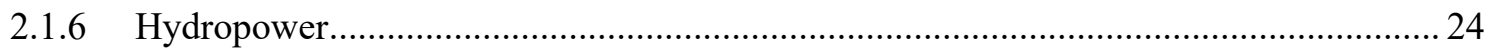

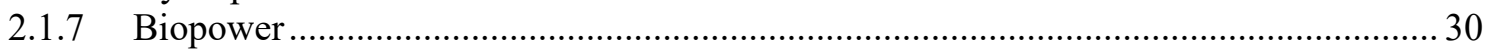

2.1.8 Marine Hydrokinetic Wave ................................................................................... 30

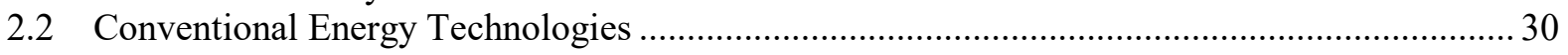

2.3 Storage and Demand-ide Technologies................................................................................. 33

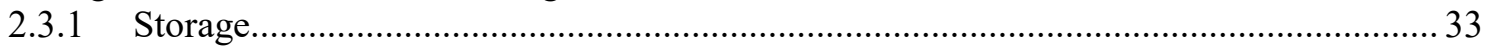

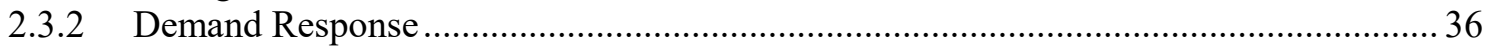

2.3.3 Plug-In Electric Vehicles ...................................................................................... 36

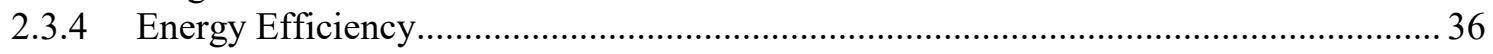

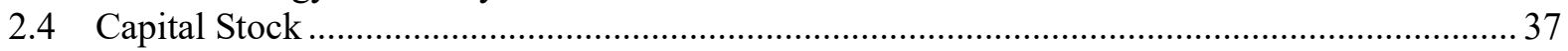

2.4.1 Initial Capital Stock, Prescribed Builds and Restrictions.................................................... 37

2.4.2 Retirements .................................................................................................... 37

2.4.3 Growth Penalties ................................................................................................... 40

2.5 Regional Parameter Variations and Adjustments..................................................................... 41

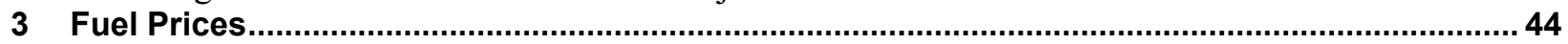

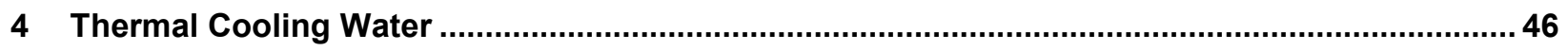

4.1 Cooling System Characteristics............................................................................................ 46

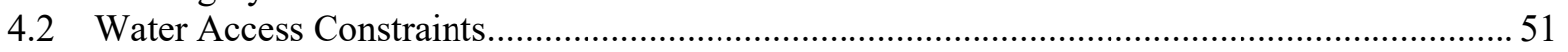

4.3 Cooling Water Availability and Cost ……………………………………………….... 51

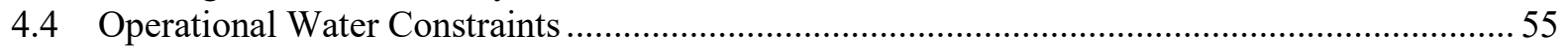

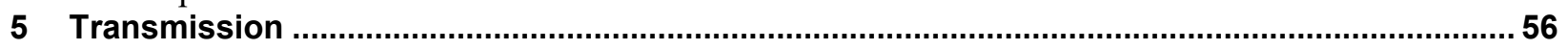

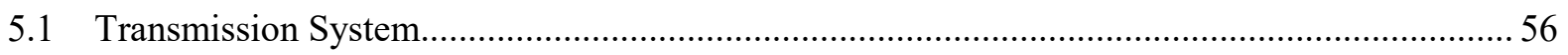

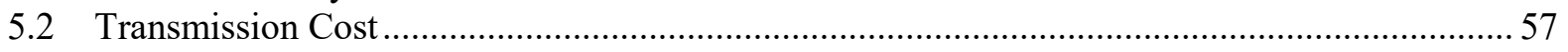

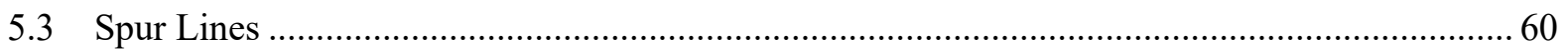

5.4 International Electricity Trade ……………………………………………………………. 60

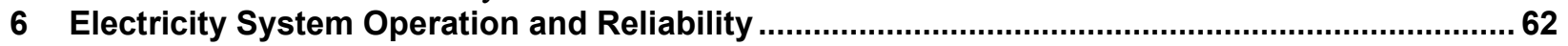

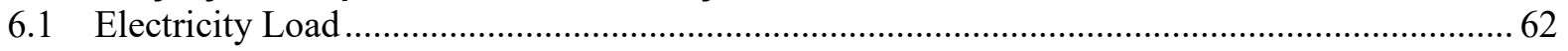

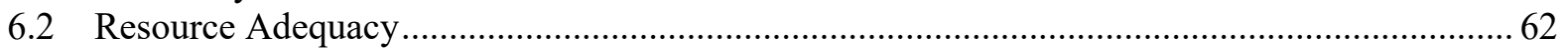

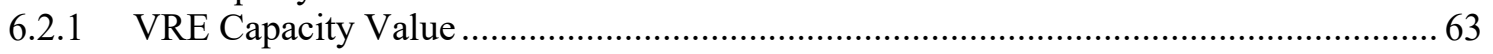

6.2.2 Storage Capacity Value .......................................................................................... 65

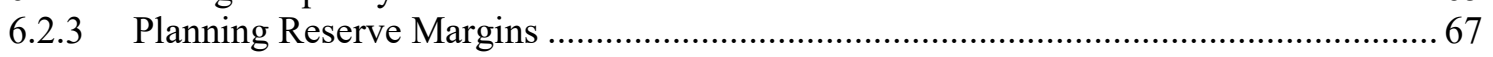

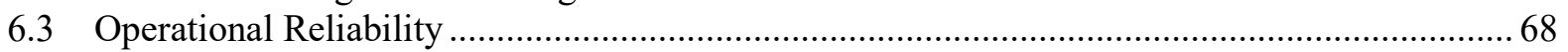

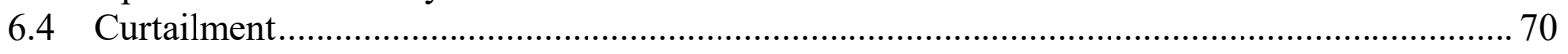

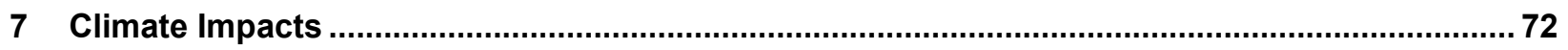

7.1 Temperature Impacts on Load...………………………………………………………. 72

7.2 Temperature Impacts on Power System Performance................................................................ 72

7.3 Precipitation Impacts on Cooling Water Availability ……………………………………...... 73 


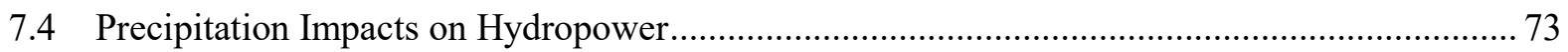

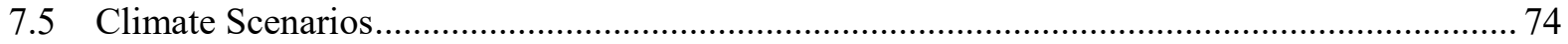

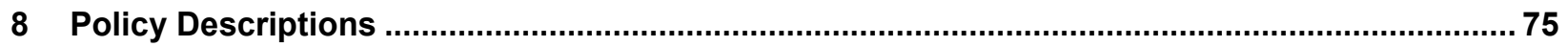

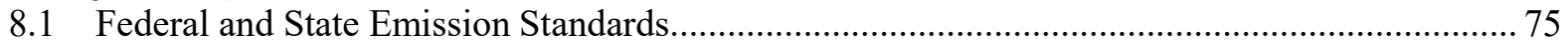

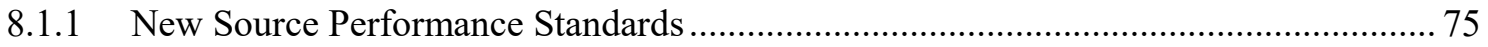

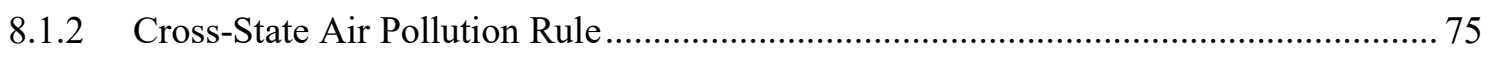

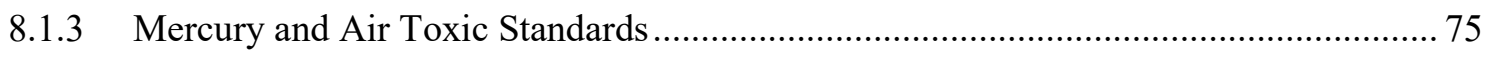

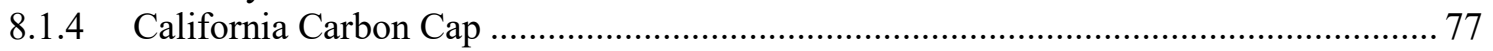

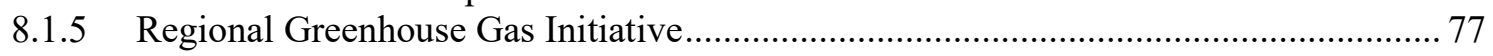

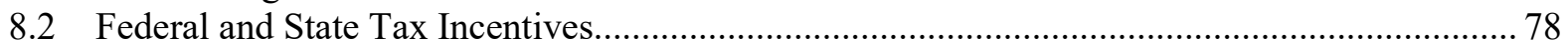

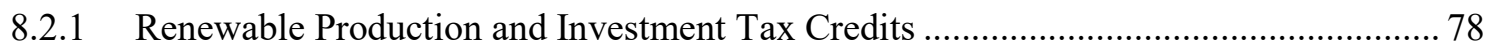

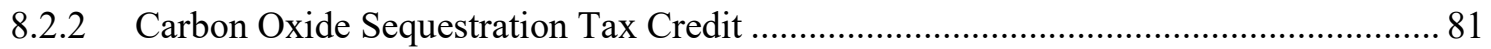

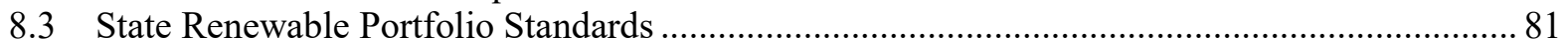

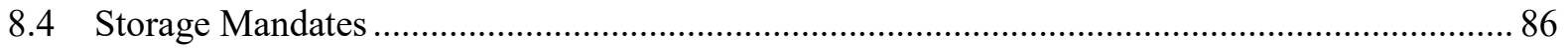

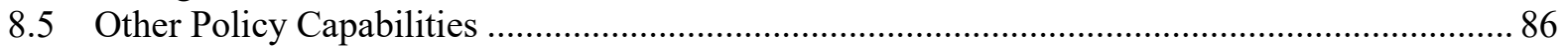

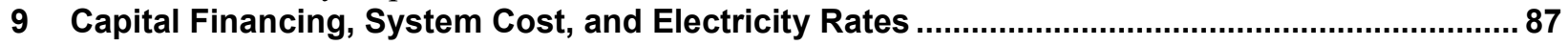

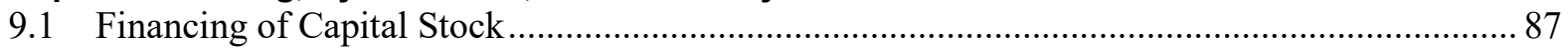

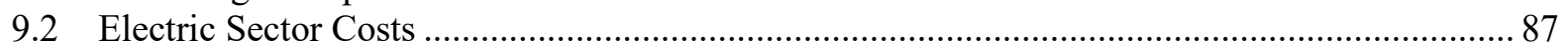

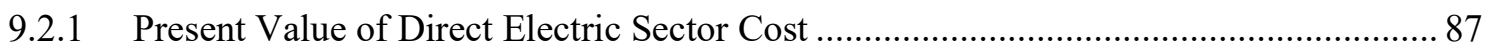

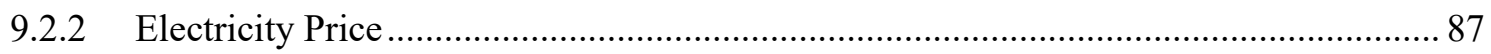

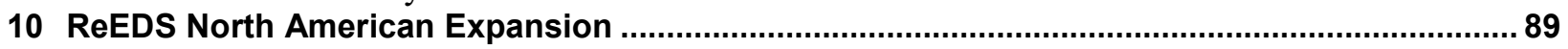

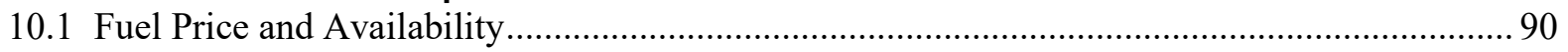

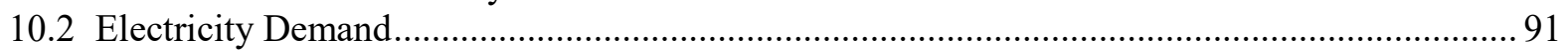

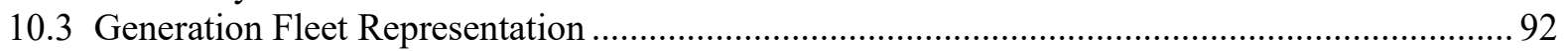

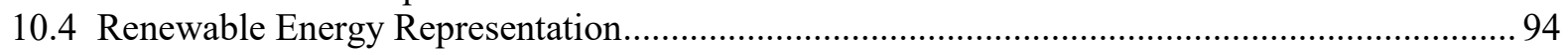

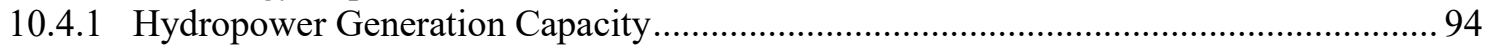

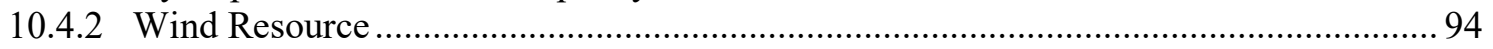

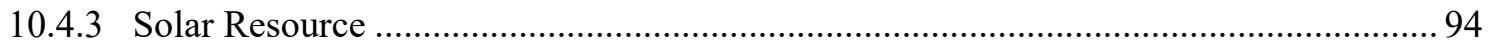

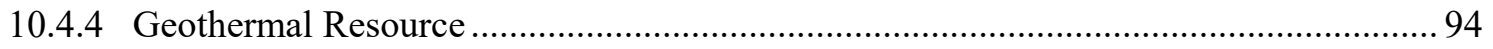

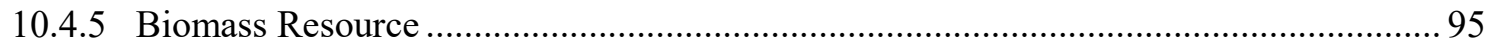

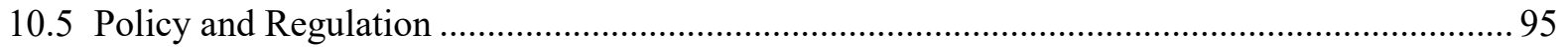

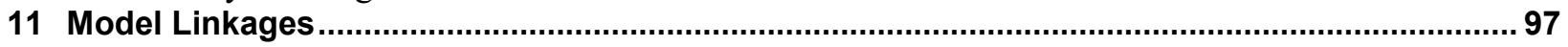

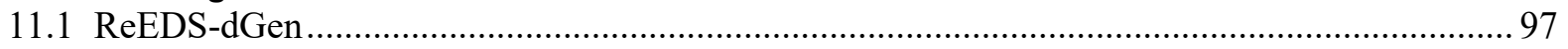

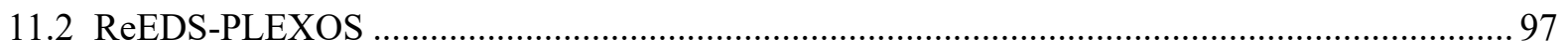

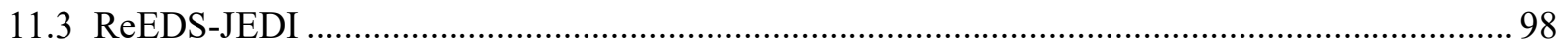

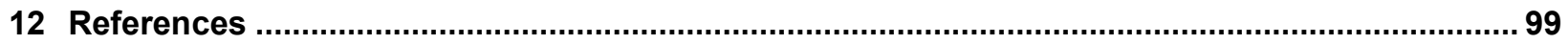

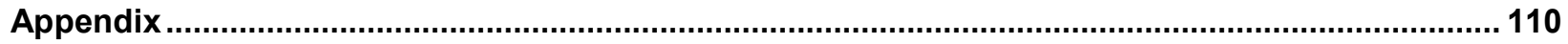

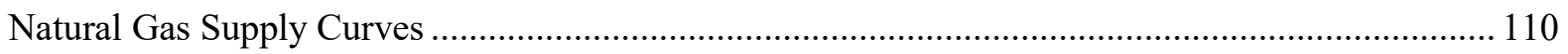

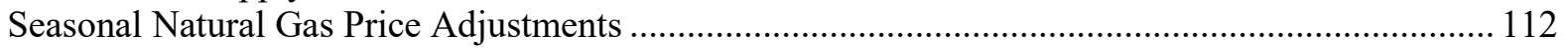

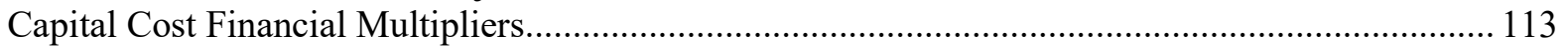

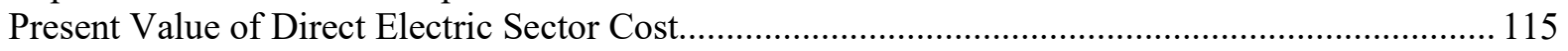

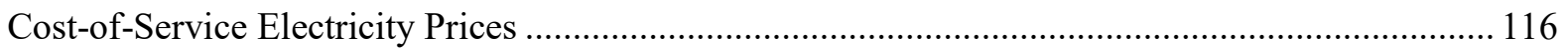

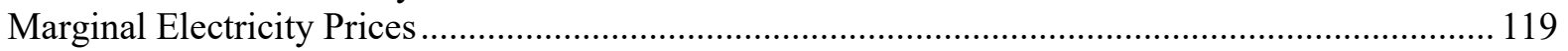

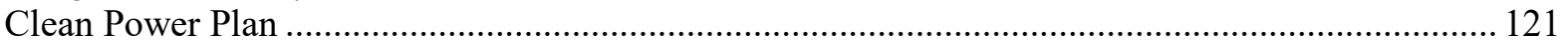

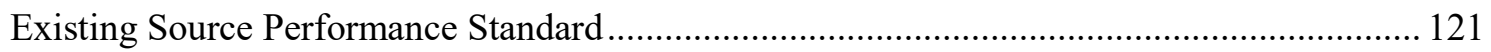

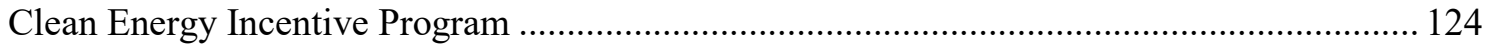




\section{List of Figures}

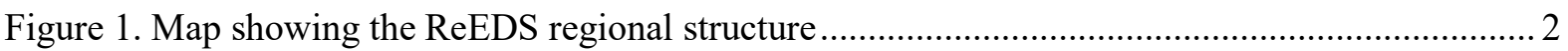

Figure 2. Schematic of the ReEDS model structure ..................................................................... 5

Figure 3. Land-based wind resource map for the contiguous United States ..................................... 12

Figure 4. Estimated wind supply curves of all wind resource modeled in ReEDS (2016\$) ............... 13

Figure 5. Offshore wind resource map for the contiguous United States.......................................... 15

Figure 6. UPV and DUPV resource areas available for development considering land use

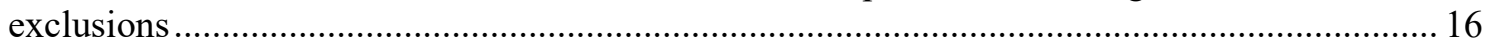

Figure 7. UPV resource availability by ReEDS BA region and resource class................................ 17

Figure 8. DUPV resource availability in each ReEDS region by resource class ............................... 18

Figure 9. Prescribed distributed PV deployment used in the ReEDS as determined by dGen............ 20

Figure 10. CSP resource availability in each ReEDS resource region by 12 resource class............... 22

Figure 11. Demonstration of ReEDS constraints and corresponding feasible space (hashed line) for

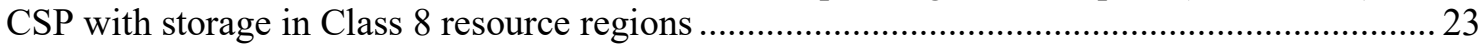

Figure 12. Capacity factor trends versus solar multiple ................................................................. 23

Figure 13. National capital cost supply curves for new identified hydrothermal and near-field EGS

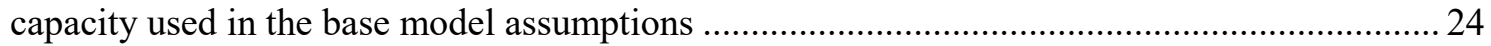

Figure 14. Modeled hydropower upgrade resource potential (DOE 2016b) .................................. 26

Figure 15. Modeled non-powered dam resource potential (DOE 2016b) ......................................... 27

Figure 16. Modeled new stream-reach development resource potential (DOE 2016b) ...................... 28

Figure 17. National hydropower supply curve of capital cost versus cumulative capacity potential... 28

Figure 18. National supply curve for biomass feedstock through the 2012 solve year........................ 30

Figure 19. Modeled new PSH resource potential (DOE 2016b) ..................................................... 35

Figure 20. National PSH supply curve of capital cost versus cumulative capacity potential............... 35

Figure 21. National and regional growth penalty cost curve .......................................................... 40

Figure 22. Maps of regional capital cost multipliers for the various technology types....................... 43

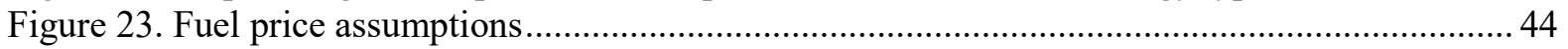

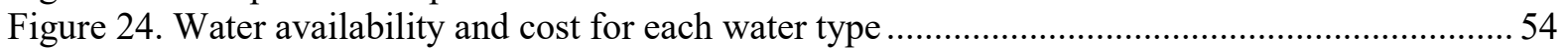

Figure 25. Existing long-distance transmission infrastructure as represented in ReEDS .................. 56

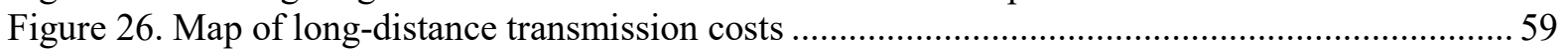

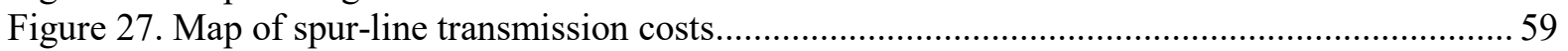

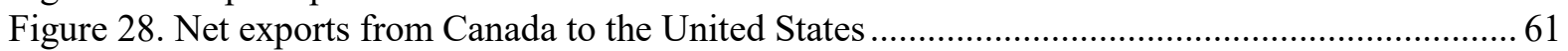

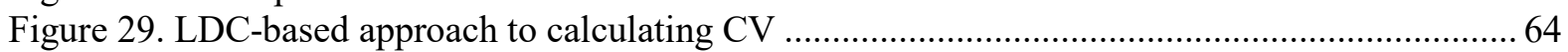

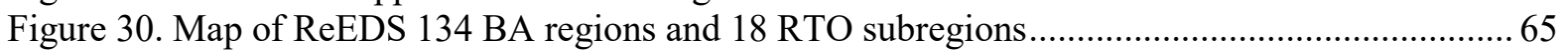

Figure 31. Illustration of the calculation of marginal and existing storage $\mathrm{CV}$ with the functional form

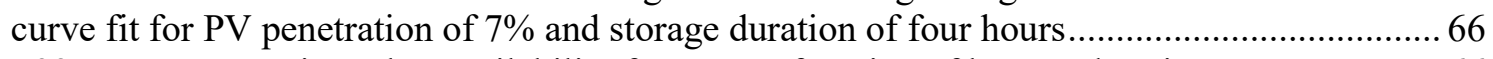

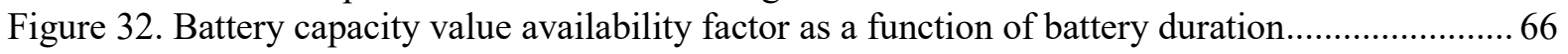

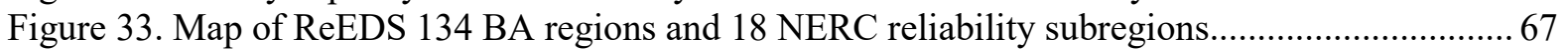

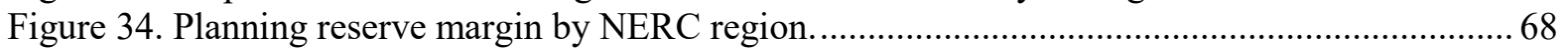

Figure 35. Regions defined in the ReEDS-Canada model ....................................................... 90

Figure 36. Map of EIA Census Division boundaries extended to Canadian provinces........................ 91

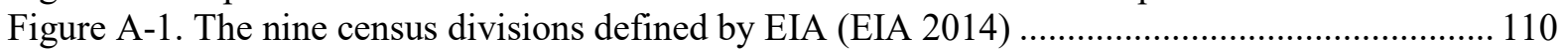

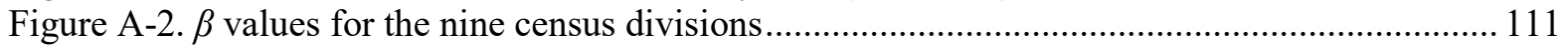

Figure A-3. Natural gas futures prices from the New York Mercantile Exchange for July 10, 2014112

Figure A-4. Natural gas futures prices from Figure A-3 separated by season................................ 113 


\section{List of Tables}

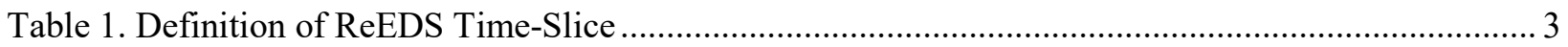

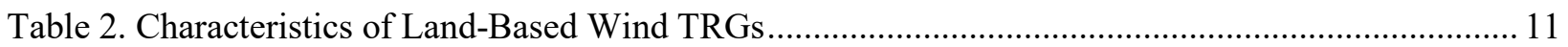

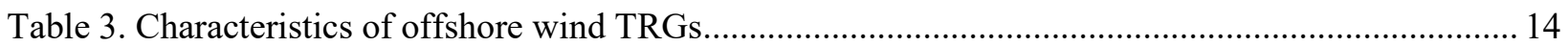

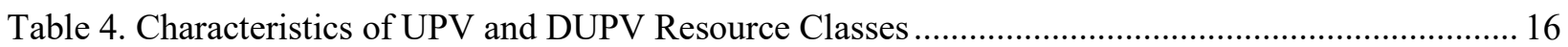

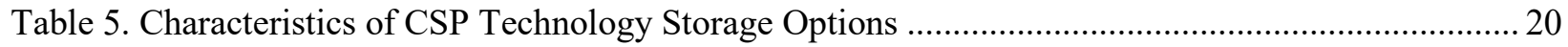

Table 6. Resource Classes for CSP Plants Using a Solar Multiple of 2.4 ............................................. 21

Table 7. Multipliers Applied to Full-Load Heat Rates to Approximate Heat Rates for Part-Load

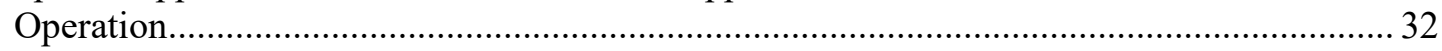

Table 8. Emissions Rate by Generator Type in Pounds per MMBtu ...................................................... 33

Table 9. Lifetimes of Renewable Energy Generators and Batteries ..................................................... 38

Table 10. Most Common Estimated Lifetimes of Conventional Energy Generators (ABB 2018)............ 38

Table 11. Amount of Nuclear Power Plant Capacity (in GW) in Each Bin............................................. 39

Table 12. Nuclear Power Plant Lifetime for Each Scenario by Bin (years) ............................................. 39

Table 13. Minimum Base Values for Assessing Excessive Growth ....................................................... 41

Table 14. Allowed Power and Cooling Technology Combinations in ReEDS ....................................... 47

Table 15. Capital Cost Multipliers for Power-Cooling Technology Combinations .................................. 48

Table 16. Operations and Maintenance Cost Multipliers for Power-Cooling Technology Combinations . 49

Table 17. Heat Rate Multipliers for Power-Cooling Technology Combinations ...................................... 49

Table 18. Water Withdrawal Rates for Power-Cooling Technology Combinations (gal/MWh).............. 50

Table 19. Water Consumption Rates for Power-Cooling Technology Combinations (gal/MWh) ............ 50

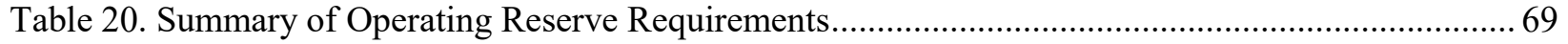

Table 21. Flexibility Parameters of the ReEDS Generation Technologies............................................... 70

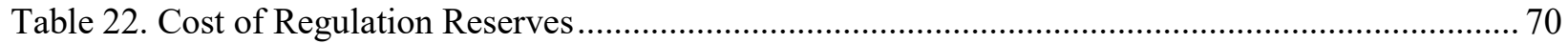

Table 23. Actual and Modeled Schedule of Wind and Solar Tax Credits from the Consolidated

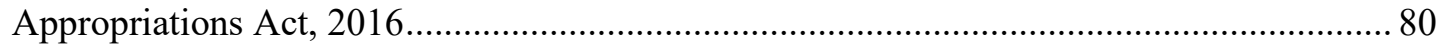

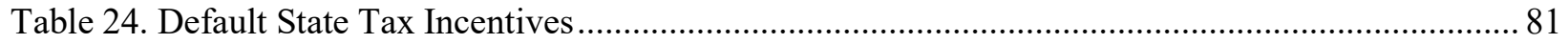

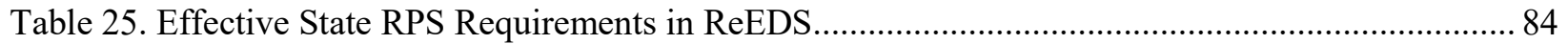

Table 26. Pending Cross-Border Transmission Lines as of January 2016 (DOE 2016a) ......................... 93

Table 27. International REC Trading Rules Implemented in ReEDS ................................................... 96 


\section{Introduction}

The Regional Energy Deployment System (ReEDS) model is a capacity expansion and dispatch model for the contiguous U.S. electric power sector that relies on system-wide least cost optimization to estimate the type and location of future generation and transmission capacity. ${ }^{1}$

\subsection{ReEDS History}

The ReEDS model heritage traces back to National Renewable Energy Laboratory's (NREL's) seminal electric sector capacity expansion model, called the Wind Deployment System (WinDS) model. The WinDS model was developed in 2003 to examine long-term market penetration of wind in the electric power sector (Short et al. 2003). From 2003 to 2008, WinDS was used in a variety of wind-related analyses, including the production of hydrogen from wind power, the impacts of state-level policies on wind deployment, the role plug-in hybrid electric vehicles in wind markets, the impacts of high wind penetration on U.S wind manufacturing, the potential for offshore wind, the benefits of storage to wind power, and the feasibility of producing $20 \%$ of U.S. electricity from wind power by 2030 (DOE 2008). In 2006, a variation of WinDS was developed to analyze concentrating solar power (CSP) potential and its response to state and federal incentives. In 2009, WinDS was recast as ReEDS - a generalized tool for examining the long-term deployment interactions of multiple technologies in the power sector (Short et al. 2009).

Since 2009, ReEDS has been the primary analytical tool in several studies, including the Hydropower Vision (DOE 2016b), Wind Vision (DOE 2015), SunShot Vision (DOE 2012), and Renewable Electricity Futures (NREL 2012). NREL currently uses ReEDS to publish an annual Standard Scenarios report, which provides a U.S. electric sector outlook under a wide range of possible futures (Sullivan et al. 2015b; Cole, Mai, et al. 2016; Cole et al. 2017). ReEDS has also been used to examine impacts of a range of existing and proposed energy policies (Lantz et al. 2014; Mai et al. 2015, 2015; Gagnon et al. 2017). Other recent studies have used ReEDS to examine the role of natural gas, high renewable scenarios, and other important issues for the U.S. electricity sector (Mignone et al. 2012; Logan et al. 2013; Clemmer et al. 2013; Mai et al. 2014; Sullivan et al. 2015a; Cole et al. 2015; Cole, Lewis, et al. 2016; Richards and Cole 2017; Cole et al. 2018). The ReEDS website ${ }^{2}$ includes an up-to-date list of publications that use ReEDS.

\subsection{Qualitative Model Description}

To represent the competition between the many electricity generation, storage, and transmission options, ReEDS identifies the least-cost mix of technologies that meet regional electric power demand requirements, based on grid reliability (reserve) requirements, technology resource constraints, and policy constraints. This cost minimization routine is performed sequentially for two-year periods beginning in 2010. Simulations are typically concluded in the 2050 solve year, but a new input data extension framework now allows ReEDS to run as far as a 2100 solve year. $^{3}$

\footnotetext{
1 “Regional Energy Deployment System Model," NREL, https://www.nrel.gov/analysis/reeds/

2 "Regional Energy Deployment System Model Publications," NREL, https://www.nrel.gov/analysis/reeds/publications.html

${ }^{3}$ By default, all input data are assumed to remain constant after the final available data year except for electricity load. Load growth is extended by extrapolating linearly from the last 10 years of available load data. The data extension framework allows a developer to modify the extension technique to any functional form desired for a given input parameter.
} 
Some of the major outputs of ReEDS include the amount and location of generator capacity, annual generation from each technology, storage capacity expansion, transmission capacity expansion, total electric sector costs, electricity price, fuel demand and prices, and carbon dioxide $\left(\mathrm{CO}_{2}\right)$ emissions.

ReEDS can simulate the contiguous United States, Canada, and Mexico, though the model is typically used to study the contiguous United States. In Section 10, we discuss the model and data requirements for continental simulation. Within the United States, ReEDS serves load and constructs generating capacity in 134 model balancing areas (BAs), shown in Figure 1. The model BAs are not designed to represent or align perfectly with real balancing authority areas; they are county aggregates intended to represent model nodes where electricity supply and demand is balanced. The model's aggregated transmission network connects those BAs and is composed of roughly 300 representative lines across the three asynchronous interconnections: the Western Interconnection, the Eastern Interconnection, and Electric Reliability Council of Texas (ERCOT). The BAs also respect state boundaries, allowing the model to represent individual state regulations and incentives. The BAs are further subdivided into 356 resource regions that describe wind and CSP resource supply and quantity to have more spatial granularity for these resources. Resource regions also consist of one or more counties. All other renewable resources are represented at the BA level of spatial resolution. Additional geographical layers used for defining model characteristics include 3 electricity interconnects, 18 model regional transmission operators designed after existing regional transmission operators, 19 North American Electric Reliability Corporation (NERC) reliability subregions, 9 census divisions as defined by the U.S. Census Bureau, and 48 states. $^{4}$

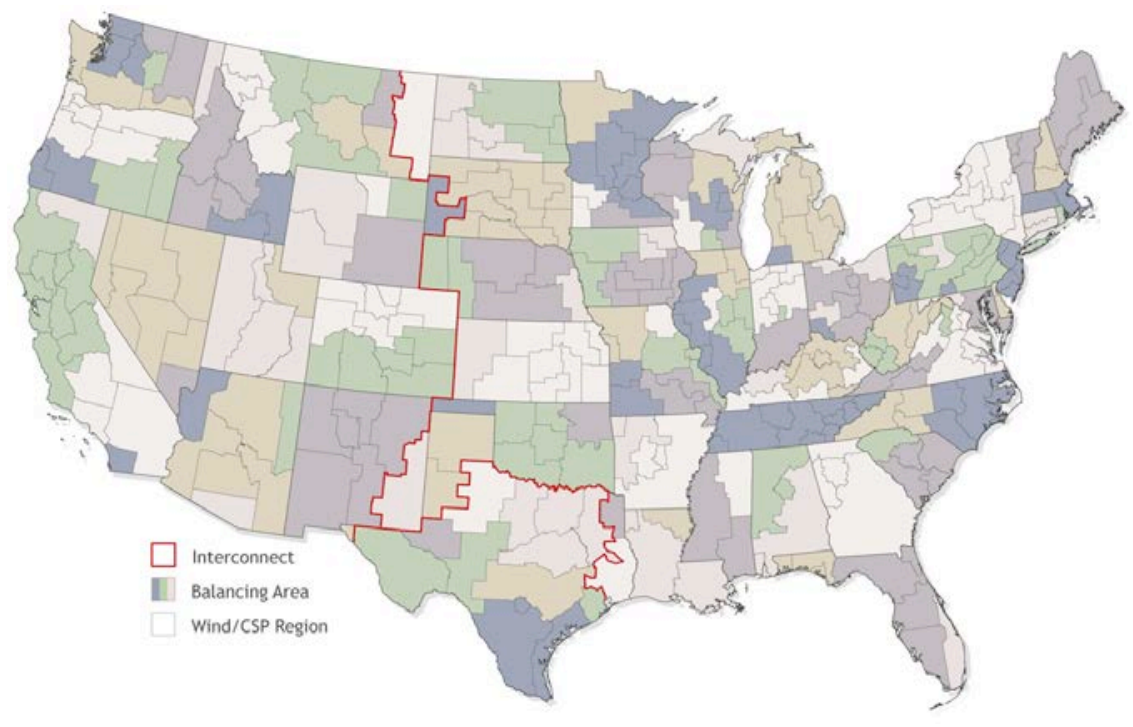

Figure 1. Map showing the ReEDS regional structure

ReEDS includes 3 interconnections, 134 model BAs, and 356 wind and CSP resource regions.

\footnotetext{
${ }^{4}$ These additional geographical layers defined in ReEDS do not necessarily align perfectly with the actual regions, except for state boundaries, which are accurately represented.
} 
Table 1. Definition of ReEDS Time-Slice

\begin{tabular}{lclll}
\hline Time-Slice & Hours/Year & Season & Time of Day & Period \\
\hline H1 & 736 & Summer & Overnight & 10 p.m. to 6 a.m. \\
H2 & 644 & Summer & Morning & 6 a.m. to 1 p.m. \\
H3 & 328 & Summer & Afternoon & 1 p.m. to 5 p.m. \\
H4 & 460 & Summer & Evening & 5 p.m. to 10 p.m. \\
H5 & 488 & Fall & Overnight & 10 p.m. to 6 a.m. \\
H6 & 427 & Fall & Morning & 6 a.m. to 1 p.m. \\
H7 & 244 & Fall & Afternoon & 1 p.m. to 5 p.m. \\
H8 & 305 & Fall & Evening & 5 p.m. to 10 p.m. \\
H9 & 960 & Winter & Overnight & 10 p.m. to 6 a.m. \\
H10 & 840 & Winter & Morning & 6 a.m. to 1 p.m. \\
H11 & 480 & Winter & Afternoon & 1 p.m. to 5 p.m. \\
H12 & 600 & Winter & Evening & 5 p.m. to 10 p.m. \\
H13 & 736 & Spring & Overnight & 10 p.m. to 6 a.m. \\
H14 & 644 & Spring & Morning & 6 a.m. to 1 p.m. \\
H15 & 368 & Spring & Afternoon & 1 p.m. to 5 p.m. \\
H16 & 460 & Spring & Evening & 5 p.m. to 10 p.m. \\
H17 & 40 & Summer & Peak & 40 highest demand hours of \\
& & & H3 \\
\hline
\end{tabular}

ReEDS serves load and maintains operational reliability using a reduced-order dispatch in 17 timeslices within each model year, as defined in Table 1. Each of the four seasons is modeled with a representative day of four chronological time-slices: overnight, morning, afternoon, and evening. ${ }^{5}$ The $17^{\text {th }}$ time-slice is a summer "superpeak" representing the top 40 hours of summer load. Though this schedule does allow the model to capture seasonal and diurnal variations in demand, wind, and solar profiles, it is insufficient to address some of the shorter time-scale challenges associated with unit commitment and economic dispatch, especially under scenarios with high penetration of variable generation (e.g., wind and solar). To more accurately represent how renewable grid integration might affect investment and dispatch decisions, the ReEDS model includes parameters designed to address intra-time-slice variability and uncertainty of wind, solar, and other variable renewable resources. These parameters, including capacity value for system adequacy, forecast error reserve requirements, and curtailment estimates, are each discussed in detail in Section 6.

The major conventional thermal generating technologies represented in ReEDS include simple and combined cycle natural gas, several varieties of coal, oil/gas steam, and nuclear. In addition to representing these technologies, ReEDS characterizes many renewable technologies, including geothermal, hydropower, biopower, wind, and solar. Electricity storage technologies include

\footnotetext{
${ }^{5}$ The modeled load for each time-slice is an average of all hours represented by that time-slice. Therefore, the representative days are non-chronological across seasons.
} 
pumped storage hydropower (PSH), compressed-air energy storage (CAES), batteries, and CSP with thermal storage.

With a system-wide central-planner perspective, ReEDS is not designed to evaluate distributed generation adoption decisions. For this reason, ReEDS analysis is supported by the dGen model (Sigrin et al. 2016) — a market-penetration model well-suited to producing scenarios of market uptake of distributed rooftop photovoltaics (PV). ReEDS uses $\mathrm{dGen}^{6}$ adoption scenarios to exogenously specify the amount and location of new rooftop PV. ${ }^{7}$

ReEDS is structured as a sequence of individual, but interacting ${ }^{8}$ optimization problems, each representing a two-year period from 2010 to a maximum end year of 2100. Each ReEDS scenario launches with an infrastructure base representing installed generation and transmission capacity as of December 31, 2010. New infrastructure that came online from 2011 through the present is prescribed into the ReEDS system in the proper model year, and recently decommissioned units are removed in the same way. Similarly, generators with scheduled online dates are included as prescribed builds in future years, and scheduled retirements are set to be removed from the fleet as appropriate. Additionally, ReEDS inputs include an equipment lifetime for each technology that is used to retire capacity as it ages. In certain types of scenarios, some existing stock can be underutilized due to, for example, high fuel prices or emissions standards. ReEDS facilitates "economic" retirements of underutilized coal capacity if usage (i.e., capacity factor) falls below a certain threshold. Economic coal retirement in ReEDS is applied starting in 2022 with an increasingly stringent threshold of underutilization through $2040 .{ }^{9}$ The model does not include capacity factor-based or economic retirements of any other capacity type. ${ }^{10}$

ReEDS tracks emissions of $\mathrm{CO}_{2}$, sulfur dioxide $\left(\mathrm{SO}_{2}\right)$, nitrogen oxides $\left(\mathrm{NO}_{\mathrm{x}}\right)$, and mercury from both generators and fossil-fueled storage technologies such as CAES. Limits on these emissions can be placed at the national, regional, or state level. Applying a carbon tax instead of a cap is another available policy option; the tax level and trajectory can be defined exogenously.

Annual electric loads and fuel price supply curves are exogenously specified to define the system boundaries for each period of the optimization. The data source for most load and fuel inputs is the most recent Annual Energy Outlook (AEO) from the U.S. Energy Information Administration (EIA). ${ }^{11}$ Coal and uranium fuels are assumed to be price-inelastic; ReEDS can

\footnotetext{
${ }^{6}$ For documentation of the dGen model, see Sigrin et al. (2016).

${ }^{7}$ ReEDS and dGen can interact dynamically, though that capability is not used by default. See Cole, Lewis, et al. (2016) for more information.

${ }^{8}$ Because ReEDS is a sequential model, it is path-dependent, such that solutions in a given solve period inform the starting point of the next optimization year.

${ }^{9}$ The minimum capacity factor threshold is $6 \%$ in 2022 , increases linearly to $50 \%$ by 2040 , and remains flat thereafter. Because ReEDS does not include endogenous economic retirements, this construct is an effort to estimate realistic coal retirement behavior that occurs for a range of reasons including but not exclusive to low capacity factors.

${ }^{10}$ A technology "agnostic" method would be preferred but has not been developed. Nevertheless, we implement this technique for coal because historical and recent market developments have shown coal capacity to be particularly sensitive to reduced capacity factors (Van Atten 2017; Larsen et al. 2018; Jell and Bowman 2018)

${ }^{11}$ Any inputs to ReEDS v.2018 from AEO are sourced from the 2018 edition of the AEO (EIA 2018) or its assumptions (EIA 2017) unless otherwise specified.
} 
demand as much of those fuels as it likes at the AEO-specified price. However, natural gas prices are defined by regional supply curves so that the prices respond to changes in electric sector demand for gas (Section 3).

\subsection{Linear Program Formulation Description}

This section qualitatively describes the basic linear program formulation of ReEDS. The model is recursive-dynamic in that it solves a linear program for each of the 21 two-year periods as it moves successively from 2010 to a maximum of 2100 .

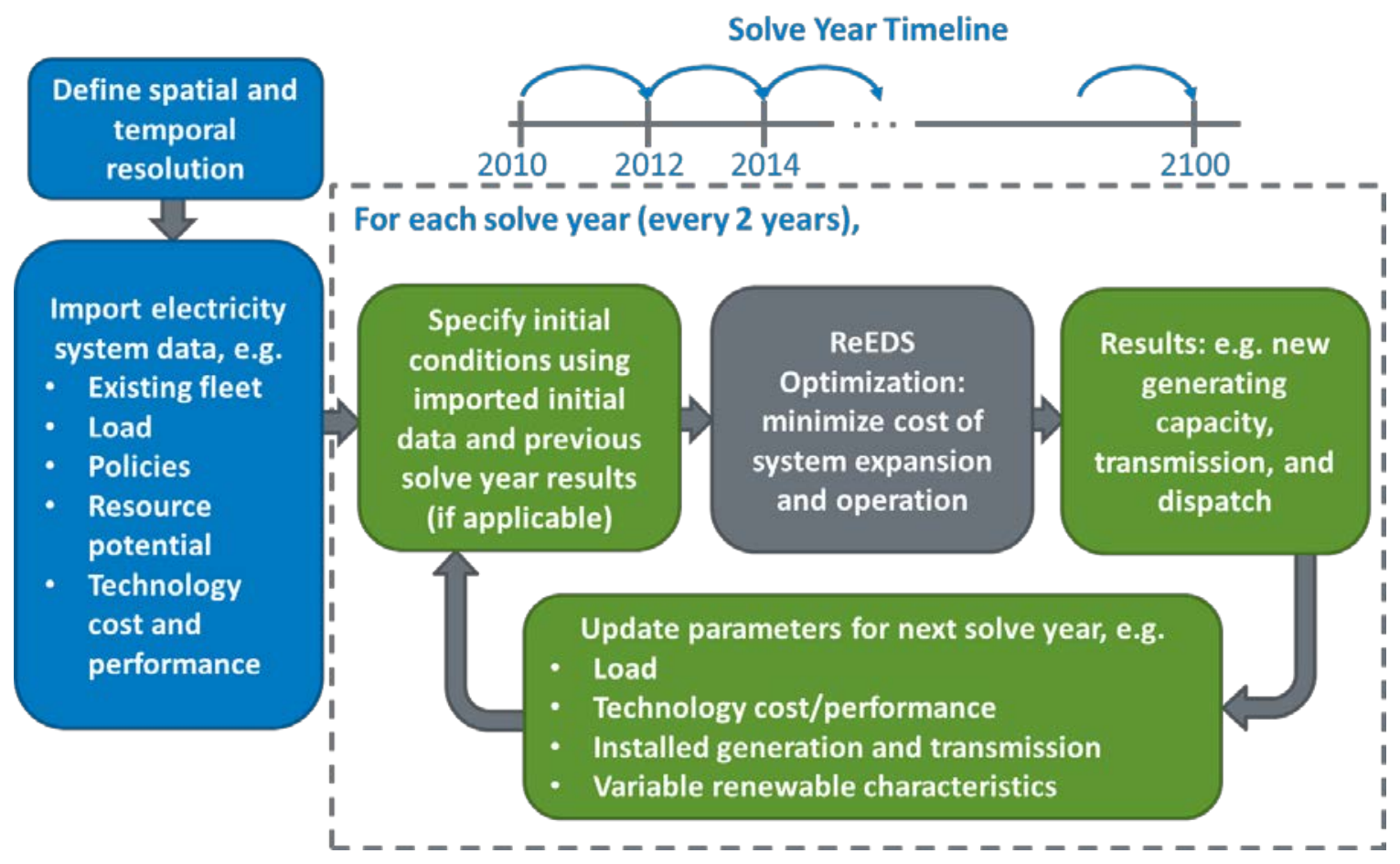

Figure 2. Schematic of the ReEDS model structure

The objective function in the ReEDS linear program is a minimization of both capital and operating costs for the U.S. electric sector, including:

- The net present value of the cost of adding new generation, storage, and transmission capacity

- The present value of operating expenses over the evaluation period ${ }^{12}$ (e.g., expenditures for fuel and operation and maintenance $[\mathrm{O \& M}]$ ) for all installed capacity

- The cost of several categories of ancillary services and storage

- The cost or incentive applied by any policies that directly charge or credit generation or capacity

\footnotetext{
12 The current default is 20 years.
} 
- Penalties for rapid capacity growth as a proxy for manufacturing, supply chain, and siting/permitting limitations

By minimizing these costs and meeting the system constraints (discussed below), the linear program determines the types of new capacity to construct in each region during each period to minimize systemwide cost. Simultaneously, the linear program determines how generation and storage capacity should be dispatched to provide the necessary energy and operating reserves in each of the 17 time-slices. The capacity factor for each dispatchable technology therefore is an output of the model and not an input assumption.

The constraints that govern how ReEDS builds and operates capacity fall into several main categories, including:

- Load constraints: Sufficient power must be generated within or imported by the transmission system to meet the projected load in each of the 134 BAs in each of the 17 time-slices. The annual demand and the time-slice-specific electricity demand in future years are based on projections for each NERC subregion. Within each NERC subregion, the load distribution between BAs and the load shape in each BA is retained for all years.

- Planning reserve constraints: There must be sufficient firm-generating capacity available in each region to meet the forecasted peak demand plus an additional reserve (safety) margin (NERC 2010). Dispatchable technologies contribute their full capacity toward planning reserves. For variable renewable energy (VRE) technologies, ReEDS uses a load-duration curve (LDC) approximation to estimate the effective load-carrying capacity of both existing capacity and potential capacity additions to determine their contribution to meeting the reserve margin. Firm capacity can also be contracted from one region to another if transmission capacity is available. ${ }^{13}$

- Operating reserve constraints: These constraints ensure enough capacity is available to meet unexpected changes in generation and load in each reserve-sharing group (see Section 6.3) and time-slice. ReEDS accounts for the following operating reserve requirements: regulation reserves, spinning reserves, and flexibility reserves.

- Generator operating constraints: Technology-specific constraints bound the minimum and maximum power production and capacity commitment based on physical limitations and assumed average outage rates.

- Transmission constraints: Power transfers among regions are constrained by the nominal carrying capacity of transmission lines that connect the regions and governed by a linearized direct current (DC) power flow representation. Firm power contracts for planning reserves are also subject to transmission limits. A detailed description of the transmission constraints can be found in Section 5.

- Resource constraints: Many renewable technologies, including wind, solar, geothermal, biopower, and hydropower, are spatially heterogeneous and constrained by quantity available at each location. Several of the technologies include cost- and resource-quality considerations in resource supply curves to account for depletion, transmission, and

\footnotetext{
${ }^{13}$ Hydropower's contribution to planning reserves depends on its categorization as dispatchable or non-dispatchable, which is discussed in Section 2.1.6.
} 
competition effects. The resource assessments that seed the supply curves come from various sources and are discussed in Section 2, where characteristics of each technology are also provided.

- Emissions constraints: ReEDS can limit or cap the emissions from fossil-fueled generators for $\mathrm{SO}_{2}, \mathrm{NO}_{x}$, mercury, and $\mathrm{CO}_{2}$. The emission limit and the emission per megawatt-hour by fuel and plant type are inputs to the model. In carbon-constrained scenarios, $\mathrm{CO}_{2}$ can be either capped or taxed, and either a cap or tax can be finely adjusted to match proposed legislation. Alternatively, emissions intensities can also be limited to certain bounds in ReEDS.

- Renewable portfolio standards or clean electricity standards: ReEDS allows users to input renewable portfolio standards (RPSs) or clean electricity standards constraints at the national and state levels. All renewable generation is considered eligible under a national RPS requirement. The renewable generation sources include hydropower, wind, CSP, geothermal, PV, and biopower (including the biomass fraction of co-firing plants). The eligibility of technologies for state RPSs depends on the state's specific requirements and thus varies by state. RPS targets over time are based on an externally defined profile. Penalties for noncompliance can be imposed for each megawatt-hour shortfall occurring in the country or a given state. In the same way, a clean energy standard constraint can be implemented to include non-renewable clean energy resources, such as nuclear, fossil fuels with carbon capture and sequestration (CCS), or natural gas.

\subsection{Summary of Caveats}

Though ReEDS represents many aspects of the U.S. electricity system, it necessitates simplifications, as all models do. We offer a list of some important limitations and caveats that result from these simplifications.

- System-wide optimization: ReEDS takes a system-wide, least-cost perspective that does not necessarily reflect the perspectives of individual decision makers, including specific investors, regional market participants, or corporate or individual consumer choice; nor does it model contractual obligations or noneconomic decisions. In addition, like other optimization models, ReEDS finds the absolute (deterministic) least-cost solution that does not fully reflect real distributions or uncertainties in the parameters; however, the heterogeneity resulting from the high spatial resolution of ReEDS mitigates this effect to some degree.

- Resolution: Though ReEDS has high spatial, temporal, and process resolution for models of its class and scope, it cannot generally represent individual units and transmission lines, and it does not have the temporal resolution to characterize detailed operating behaviors, such as ramp rates and minimum plant runtime. It also does not represent all intra-annual time scales, such as weekly or monthly trends, as ReEDS intraannual time slices are designed to characterize a typical day in each season.

- Foresight and behavior: The model is not inter-temporally optimized, and except for limited foresight of future natural gas prices and $\mathrm{CO}_{2}$ prices (if applicable), model decision-making does not account for anticipated changes to markets and policies. 
For example, ReEDS does not endogenously model banking and borrowing of credits for carbon, renewable, or clean energy policy between solve periods.

- Project pipeline: The model incorporates data of planned or under-construction projects, but these data likely do not include all projects in progress.

- Manufacturing, supply chain, and siting: The model does not explicitly simulate manufacturing, supply chain, or siting and permitting processes. Potential bottlenecks or delays in project development stages for new generation or transmission are not fully reflected in the results. All technologies are assumed to be available at their defined capital cost in any quantity up to their technical resource potential. Penalties for rapid growth are applied in ReEDS; however, these do not fully consider all potential manufacturing or deployment limits. Dates associated with cost inputs in the model reflect project costs for the commercial operation date but not necessarily when equipment is ordered.

- Financing: Though the model can use annually varying financing parameters to capture near-term market conditions and technology-specific financing to account for differences in typical investment strategies across technologies, ReEDS cannot fully represent differences in project financing terms across markets or ownership types and thus does not allow multiple financing options for a given technology.

- Technology learning: Future technology improvements are considered exogenously and thus are not a function of deployment in each scenario.

- Power sector: ReEDS models the only power sector within its defined regional scope (contiguous United States or United States with Canada and/or Mexico), and it does not represent the broader U.S. or global energy economy. For example, competing uses of resources (e.g., natural gas) across sectors are not dynamically represented in ReEDS, and end-use electricity demand is exogenously input into ReEDS.

Notwithstanding these limitations - many of which exist in other similar tools - the modeling approach considers complex interactions among numerous policies and technologies while ensuring electric system reliability requirements are maintained within the resolution and scope of the model. In doing so, ReEDS can comprehensively estimate the system cost and value of a wide range of technology options given a set of assumptions, and we can use the model to generate self-consistent future deployment portfolios. 


\section{Technology Descriptions}

This section describes the electricity generating technologies included in ReEDS. Cost and performance assumptions for these technologies are not included in this report but are taken directly from the 2018 Annual Technology Baseline (ATB) (NREL 2018a). ${ }^{14}$

\subsection{Renewable Energy Resources and Technologies}

Because renewable energy technologies are a primary focus area of the ReEDS model, they are characterized in great detail. Their characterization encompasses resource assessments, ${ }^{15}$ projected technology improvements, grid interconnection costs, and operational implications of integration. Renewable energy technologies modeled include land-based and offshore wind power, solar PV (both distributed and utility), CSP with and without thermal storage, ${ }^{16}$ hydrothermal geothermal, near-field enhanced geothermal systems (EGS), deep EGS, run-of-theriver and traditional hydropower (including upgrades and non-powered dams), dedicated biomass, co-fired biomass, land-fill gas, and marine hydrokinetic wave technologies. The input assumptions, data sources, and treatments of these technologies are discussed in the following sections. Transmission considerations for renewable energy technologies are discussed in Section 5.3. ${ }^{17}$

\subsubsection{Land-Based Wind}

Wind technologies are modeled using representative turbine technologies by region depending on wind resource quality. Details of the wind resource data and technology representation can be found in Appendix H of the Wind Vision study (DOE 2015). In the current version of ReEDS, we have relied on the same data sources and approach; however, we extend the wind resource data to lower-quality wind sites.

Wind turbine models can be classified into three different International Electrotechnical Commission turbine ratings (I-III), which are designed for a range of annual average wind speeds. ${ }^{18}$ The Class I turbines have smaller rotors relative to the size of the generator, or a higher specific power (watts per meter squared, or $\mathrm{W} / \mathrm{m}^{2}$ ), and they are therefore rated to withstand higher winds. In the lowest-speed wind resources, Class III turbines are primarily used to gain the highest capacity factor possible in lower wind speeds. Interpolating cost and performance

\footnotetext{
${ }^{14}$ The Annual Technology Baseline cost projections include the impacts of the PV import tariffs.

${ }^{15}$ All renewable resource assessments are independent and mutually exclusive of each other due to their unique nature and to allow ReEDS to dynamically evaluate cost-optimal capacity expansion without any upstream ranking of which technologies would be preferred at a given site. This implementation ignores any possible land-use conflicts between multiple technologies at the same site, but spatial aggregation and resource heterogeneity is expected to alleviate this limitation.

${ }^{16}$ CSP refers to solar thermal power and not concentrating PV.

${ }^{17}$ Where given in the sections below, renewable energy resource potential values refer to the resource potential represented in ReEDS and not the total technical resource potential. The renewable potential capacity modeled in ReEDS includes exclusions in the pre-processing steps for the model, such as site exclusions, assumed transmission access limits, or a narrower set of technologies considered. Lopez et al. (2012) present renewable technical potential for the United States.

${ }^{18}$ International Electrotechnical Commission Class I turbines are used with an annual average wind speeds of 10 meters $/ \mathrm{second}(\mathrm{m} / \mathrm{s})$ and higher; Class III are used with an annual average wind speed of $7.5 \mathrm{~m} / \mathrm{s}$ and lower. A blend of Class II and Class III turbines is used at annual average wind speeds of $7.5-8.5 \mathrm{~m} / \mathrm{s}$; while a blend of Class II and Class I turbines is used at annual average wind speeds of $8.5-10 \mathrm{~m} / \mathrm{s}$.
} 
across the three International Electrotechnical Commission classes allows monotonic functions of cost and performance by annual average wind speed. Cost and performance assumptions for land-based wind plants are based on expected cost and performance for a turbine (representative or interpolated) appropriate for the average annual wind speed at the site.

The resource assessment for land-based wind starts with a resource map of hourly wind speeds for the United States and offshore areas (for offshore wind, see Section 2.1.2). Land area is filtered to exclude a standard set of areas considered unlikely to be developed for environmental or technical reasons: federal and state protected areas (e.g., parks, wilderness areas, and wildlife sanctuaries), areas covered by water, urban areas, wetlands, airports, and rough terrain. Areas classified as non-ridge-crest forest, non-ridge-crest U.S. Forest Service and U.S. Department of Defense lands, and state forests (where available in geographic information systems [GIS]) are $50 \%$ excluded. The remaining resource totals more than 11,632 gigawatts (GW).

Individual wind sites are grouped into ten resource classes (a.k.a., techno-resource groups or TRGs) for ReEDS, based on estimated levelized cost of energy for present-day technology (Table 2). ${ }^{19}$ The modeling and assessment of individual wind sites was facilitated using NREL's Renewable Energy Potential (reV) tool. The meteorological data for onshore wind are from the Wind Integration National Dataset (WIND) Toolkit, using long-term average data for the resource assessment. Each class includes representative costs (capital and O\&M) and expected output (capacity factor) along with cost and performance improvements over time. Figure 3 shows the land-based wind resource data modeled in ReEDS for all 10 TRGs, where the highestquality wind resources belong to TRG 1 and the lowest to TRG 10. Each TRG is then further differentiated by a supply curve for grid interconnection costs in each region. See Section 5.3 for a discussion of interconnection supply curves for accessing the wind resource. Figure 4 shows estimated 2014 supply curves (levelized cost of energy versus resource) of all wind resources modeled in ReEDS, including land-based and offshore wind.

Distinct wind production profiles are also modeled for each TRG and wind resource region. In addition, to inform the statistical parameterizations for capacity value and curtailment, we use hourly production data and correlations between regions and TRGs. A 2012 weather year is used for the generation of the hourly onshore wind profile data.

\footnotetext{
${ }^{19}$ The wind resource is not evenly binned into the 10 TRGs. The best resource sites (TRGs $1-4$ ) are grouped into smaller bins to improve resolution for sites that are likely to be most competitive.
} 
Table 2. Characteristics of Land-Based Wind TRGs

\begin{tabular}{|c|c|c|c|c|}
\hline $\begin{array}{l}\text { Techno- } \\
\text { Resource } \\
\text { Group (TRG) }\end{array}$ & $\begin{array}{l}\text { Wind Speed } \\
\text { Range }(\mathrm{m} / \mathrm{s})\end{array}$ & $\begin{array}{l}\text { Weighted } \\
\text { Average } \\
\text { Wind Speed } \\
(\mathrm{m} / \mathrm{s})\end{array}$ & $\begin{array}{l}\text { Weighted } \\
\text { Average Net } \\
\text { CF (\%) }\end{array}$ & $\begin{array}{l}\text { Potential Wind } \\
\text { Plant Capacity } \\
\text { (GW) }\end{array}$ \\
\hline TRG1 & $8.2-13.5$ & 8.7 & 47.4 & 100 \\
\hline TRG2 & $8.0-10.9$ & 8.4 & 46.2 & 200 \\
\hline TRG3 & $7.7-11.1$ & 8.2 & 45.0 & 400 \\
\hline TRG4 & $7.5-13.1$ & 7.9 & 43.5 & 800 \\
\hline TRG5 & $6.9-11.1$ & 7.5 & 40.7 & 1,600 \\
\hline TRG6 & $6.1-9.4$ & 6.9 & 36.4 & 1,600 \\
\hline TRG7 & $5.4-8.3$ & 6.2 & 30.8 & 1,600 \\
\hline TRG8 & $4.7-6.9$ & 5.5 & 24.6 & 1,600 \\
\hline TRG9 & $4.0-6.0$ & 4.8 & 18.3 & 1,600 \\
\hline TRG10 & $1.0-5.3$ & 4.0 & 11.1 & 2,132 \\
\hline
\end{tabular}

More information can be found in the NREL Annual Technology Baseline (NREL 2018b). 


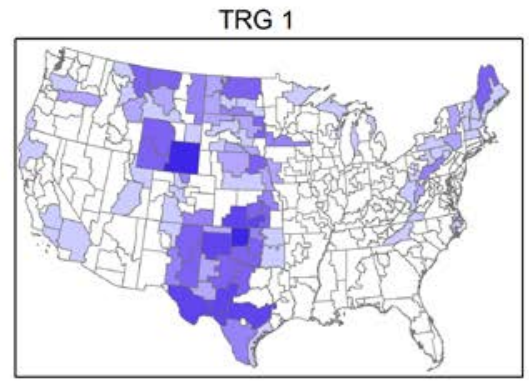

TRG 2

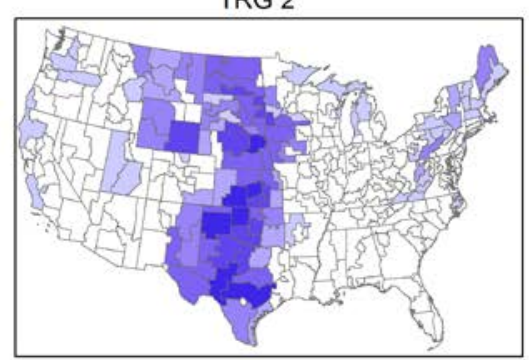

TRG 3

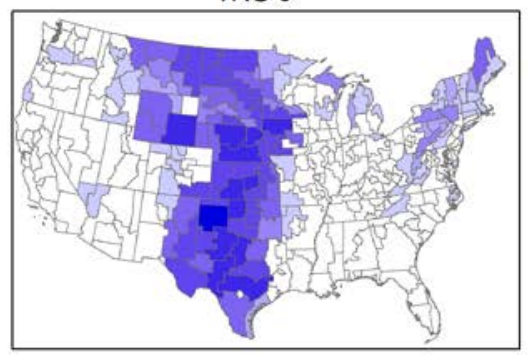

TRG 4
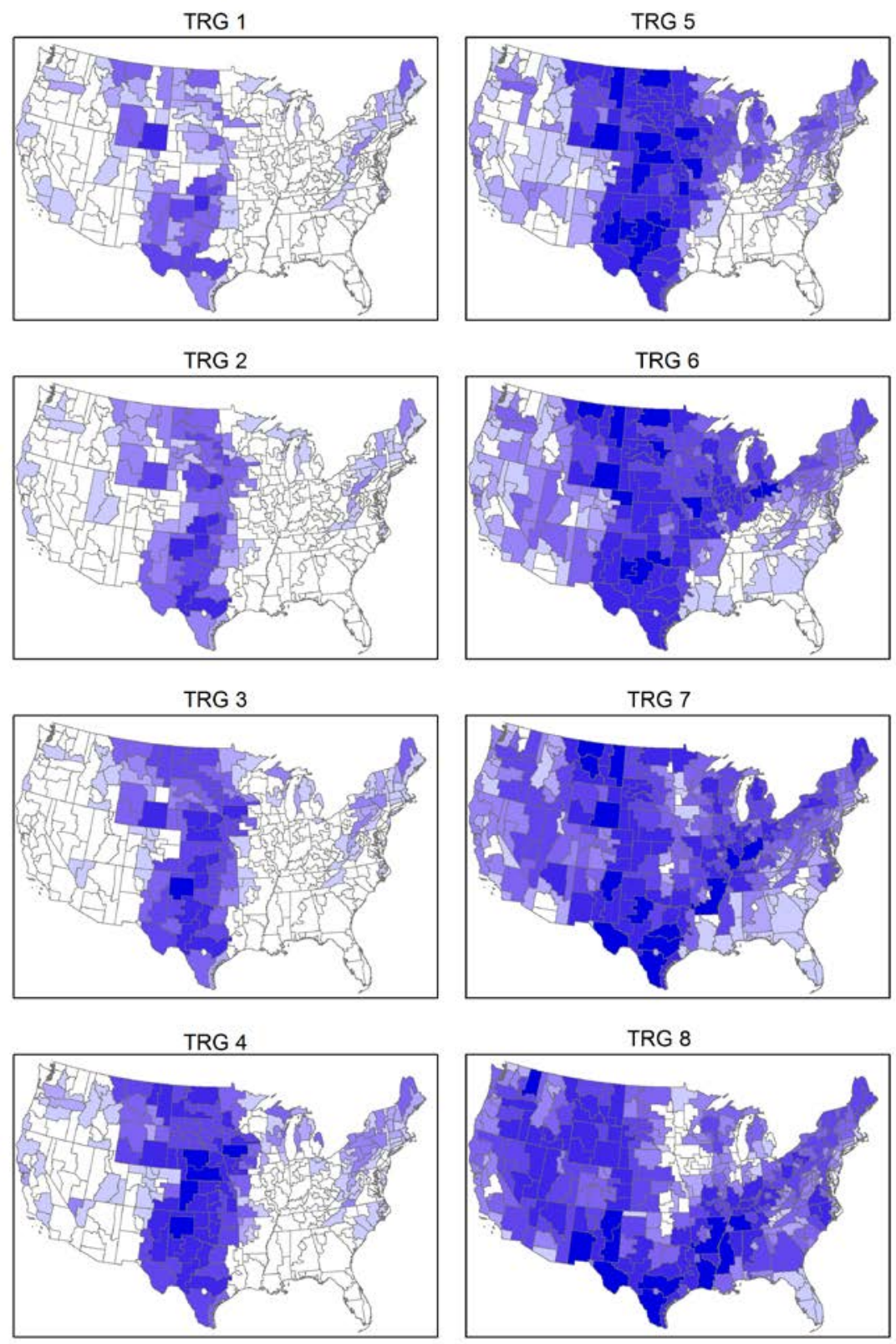

TRG 6

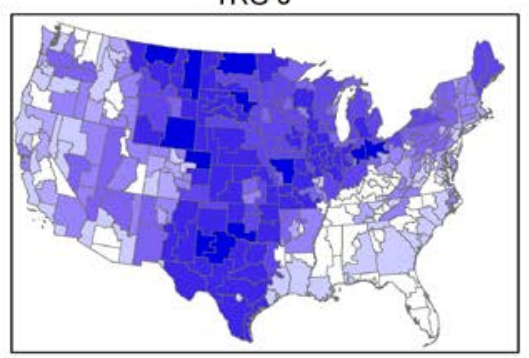

TRG 7

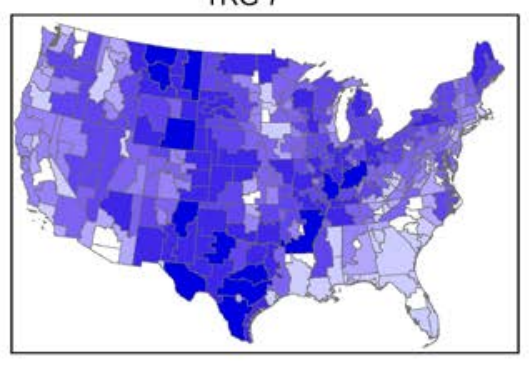

TRG 8

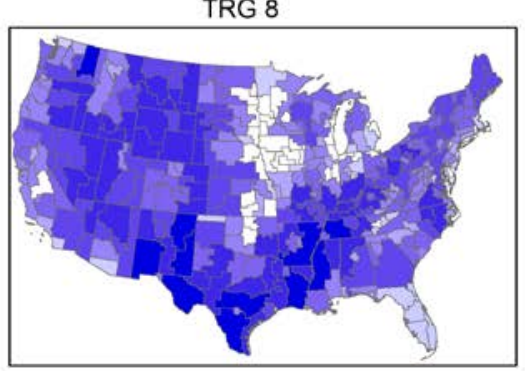

TRG 9

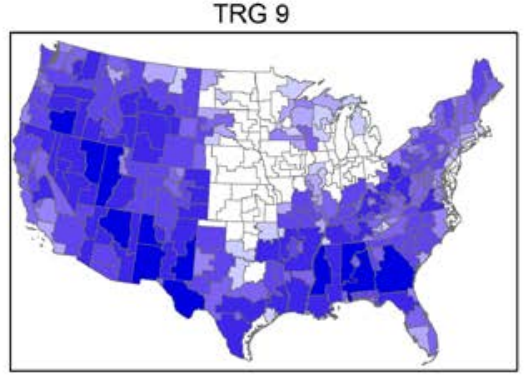

TRG 10

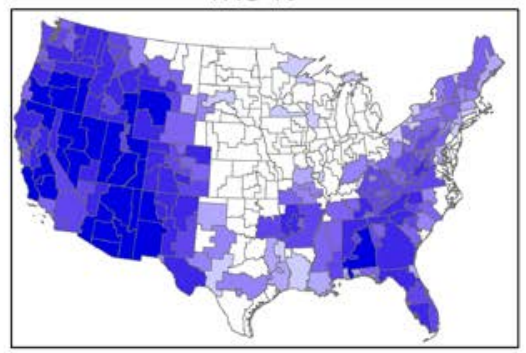

Land Based Wind Capacity (GW)

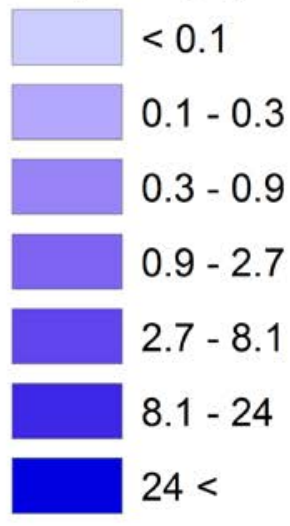

Figure 3. Land-based wind resource map for the contiguous United States 


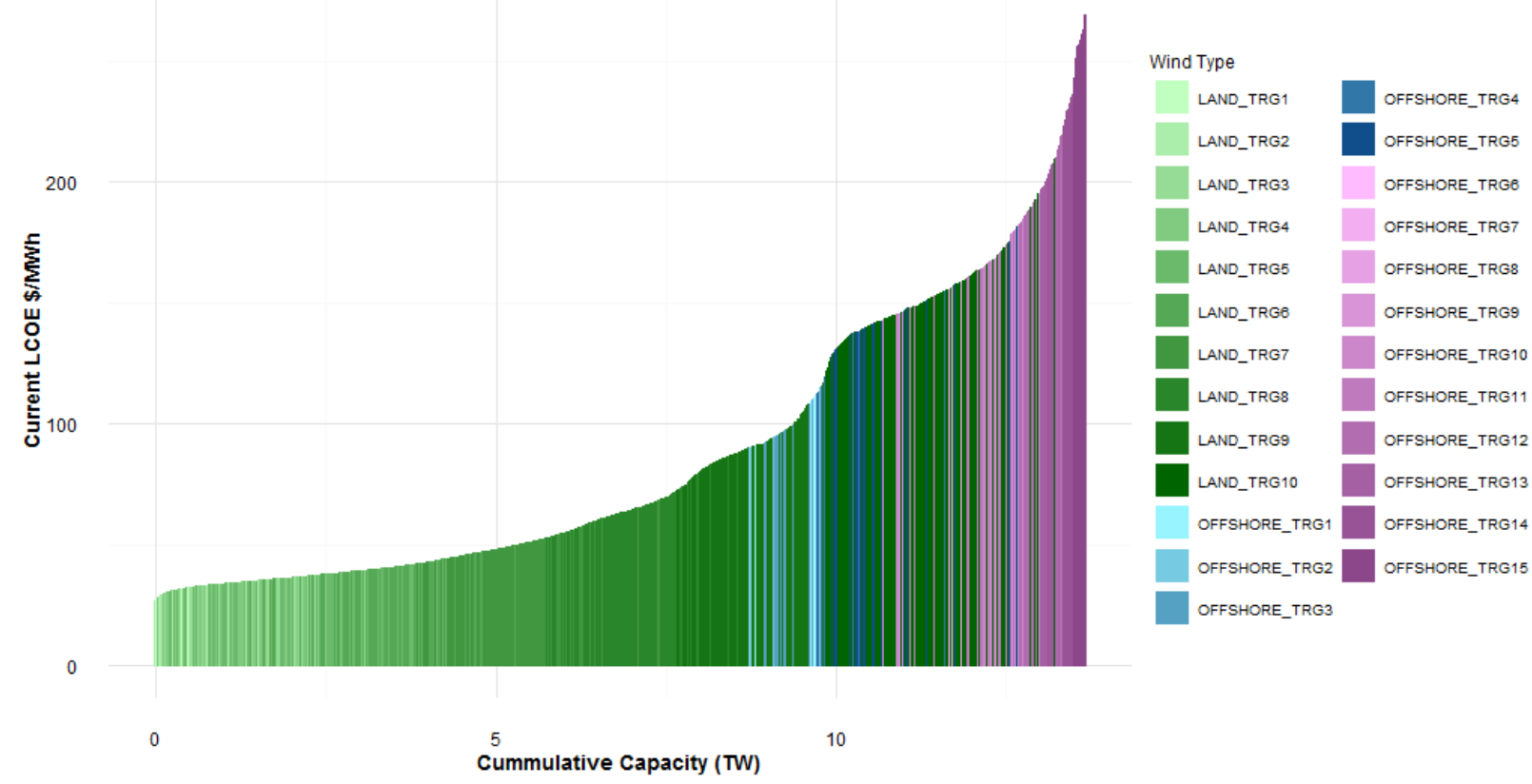

Figure 4. Estimated wind supply curves of all wind resource modeled in ReEDS (2016\$)

\subsubsection{Offshore Wind}

There is substantial diversity in offshore wind generators, in distance from shore, water depth, and resource quality. ReEDS subdivides offshore wind potential into fifteen resource classes: five for fixed-bottom turbine designs and ten for floating designs. Fixed bottom offshore wind development is limited to resources $<60$ meters [m] in depth using either current-technology monopile foundations $(0-30 \mathrm{~m})$; or jacket (truss-style) foundations $(30-60 \mathrm{~m})$. Offshore wind using a floating anchorage could be developed for greater depths and are assumed the only feasible technology for development for resource deeper than $60 \mathrm{~m}$. Within each category, the classes are distinguished by resource quality, and then supply curves differentiate resource by cost of accessing transmission in a similar fashion as land-based wind.

Eligible offshore area for wind development includes open water within the U.S.-exclusive economic zone having a water depth less than 1,000 m, including the Great Lakes. As with landbased resource, offshore zones are filtered to remove areas considered unsuitable for development, including national marine sanctuaries, marine protected areas, wildlife refuges, shipping and towing lanes, offshore platforms, and ocean pipelines. The offshore technology selection is made using the Offshore Wind Cost Model, which selects the most economically feasible technology for developing a wind resource (Beiter and Stehly 2016). More than 2,000 $\mathrm{GW}$ of technical offshore wind potential remain after applying the exclusions.

Current-day cost data are derived from the published data of the global offshore wind industry as well as estimates from recent development activity on the Atlantic Coast of the United States (Tegen et al. 2012; Wiser and Bolinger 2017; NREL 2018b). These data are coupled with engineering assessments and distance-based cost functions (specific to the offshore export cable and incremental construction cost associated with moving farther from shore) to determine expected site-specific costs for technology across a broad range of water depths and distances from shore (Beiter et al. 2017). 
Other aspects of our model representations for offshore wind follow the same methods as those for land-based wind (see Appendix $\mathrm{H}$ of the Wind Vision study [DOE 2015]). Figure 5 shows the offshore wind resource potential modeled in ReEDS using the 15 TRGs. The first five TRGs represent fixed-bottom offshore wind resources with TRG 1 representing the lowest-cost resource based on levelized cost of energy (LCOE). TRGs 6-15 represent floating offshore wind resources with TRG 6 being the lowest cost based on LCOE. The three lowest cost TRGs, for both fixed-bottom and floating-bottom turbines, have smaller bin sizes to capture the highest quality resources with greater resolution.

Table 3. Characteristics of Offshore Wind TRGs

\begin{tabular}{|c|c|c|c|c|c|c|c|}
\hline \multicolumn{2}{|l|}{ TRG } & $\begin{array}{l}\text { Wind } \\
\text { Speed } \\
\text { Range } \\
(\mathrm{m} / \mathrm{s})\end{array}$ & $\begin{array}{l}\text { Weighted } \\
\text { Average } \\
\text { Wind } \\
\text { Speed } \\
(\mathrm{m} / \mathrm{s})\end{array}$ & $\begin{array}{l}\text { Weighted } \\
\text { Water } \\
\text { Depth }(\mathrm{m})\end{array}$ & $\begin{array}{l}\text { Weighted } \\
\text { Distance } \\
\text { Site to } \\
\text { Cable } \\
\text { Landfall } \\
\text { (km) }\end{array}$ & $\begin{array}{l}\text { Weighted } \\
\text { Average } \\
\text { Net CF } \\
(\%)\end{array}$ & $\begin{array}{l}\text { Potential } \\
\text { Wind Plant } \\
\text { Capacity } \\
\text { (GW) }\end{array}$ \\
\hline \multirow{5}{*}{$\begin{array}{l}\text { Fixed- } \\
\text { Bottom }\end{array}$} & TRG 1 & $8.5-9.0$ & 8.6 & 13 & 6 & 45 & 12 \\
\hline & TRG 2 & $8.0-8.5$ & 8.4 & 16 & 9 & 43 & 25 \\
\hline & TRG 3 & $8.0-8.5$ & 8.3 & 19 & 15 & 42 & 50 \\
\hline & TRG 4 & $8.0-8.5$ & 8.3 & 26 & 36 & 41 & 320 \\
\hline & TRG 5 & $7.5-8.0$ & 7.9 & 36 & 72 & 37 & 320 \\
\hline \multirow{10}{*}{ Floating } & TRG 6 & $9.5-10$ & 9.7 & 130 & 24 & 51 & 12 \\
\hline & TRG 7 & $9.5-10$ & 9.7 & 145 & 40 & 50 & 25 \\
\hline & TRG 8 & $9.5-10$ & 9.5 & 139 & 50 & 49 & 50 \\
\hline & TRG 9 & $9.0-9.5$ & 9.4 & 136 & 70 & 48 & 100 \\
\hline & TRG 10 & $9.0-9.5$ & 9.1 & 140 & 94 & 45 & 200 \\
\hline & TRG 11 & $8.5-9.0$ & 8.7 & 323 & 118 & 42 & 200 \\
\hline & TRG 12 & $8.0-8.5$ & 8.1 & 404 & 123 & 37 & 200 \\
\hline & TRG 13 & $7.5-8.0$ & 7.8 & 474 & 138 & 35 & 200 \\
\hline & TRG 14 & $7.0-7.5$ & 7.4 & 615 & 130 & 33 & 200 \\
\hline & TRG 15 & $7.5-8.0$ & 7.5 & 797 & 199 & 31 & 143 \\
\hline
\end{tabular}

More information can be found in the NREL Annual Technology Baseline (NREL 2018b). 


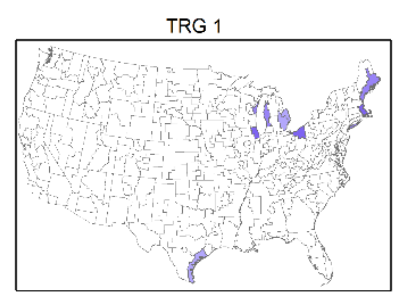

TRG 2

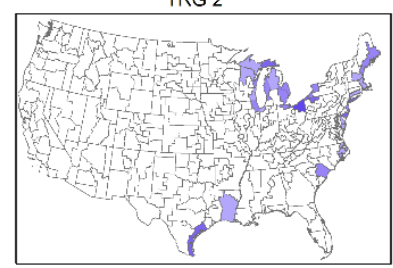

TRG 3
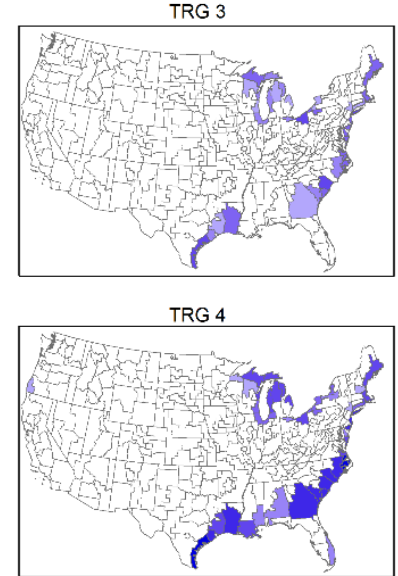

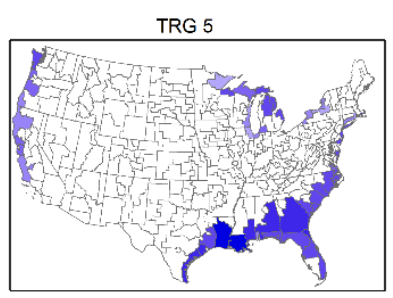

TRG 6

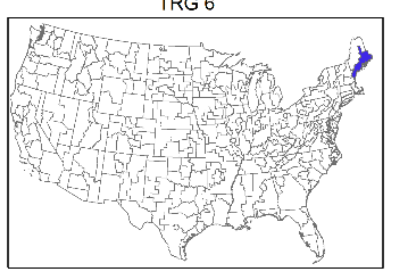

TRG 7

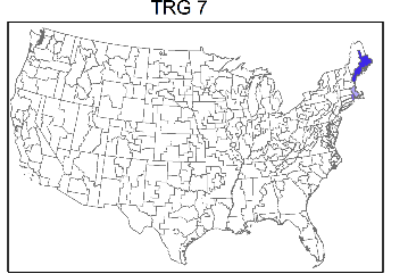

TRG 8

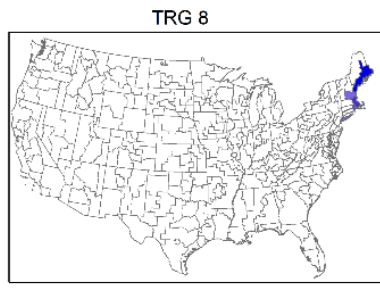

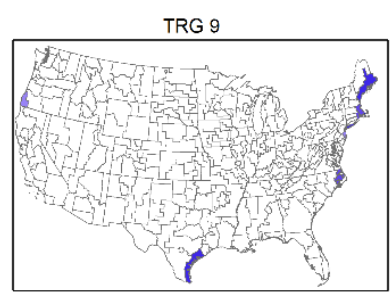

TRG 10

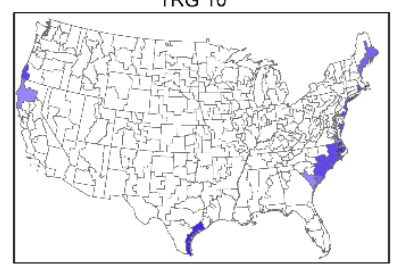

TRG 11

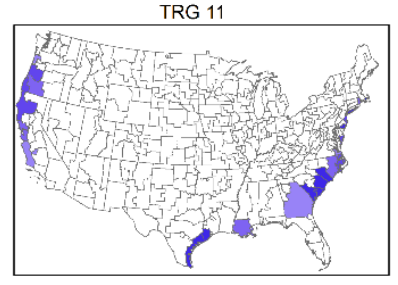

TRG 12

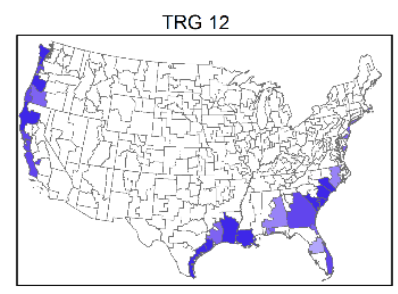

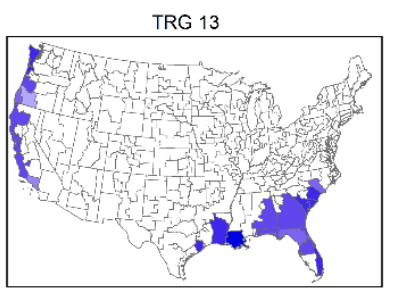

TRG 14

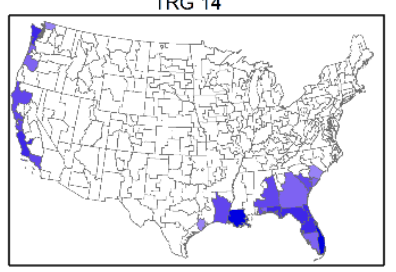

TRG 15

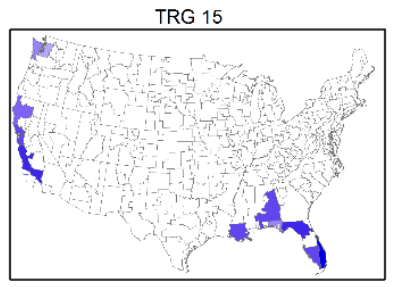

Offshore Wind

Capacity (GW)

$\square<0.1$

$\begin{aligned} & \square \\ & \square\end{aligned} 0.1-0.3$

$0.3-0.9$

$0.9-2.7$

$2.7-8.1$

$2.1-24$
$24<$

Figure 5. Offshore wind resource map for the contiguous United States

\subsubsection{Solar Photovoltaics}

ReEDS differentiates between three solar photovoltaic technologies: large-scale utility PV (UPV), distribution-side utility-scale PV (DUPV), and rooftop PV. Investments in UPV and DUPV are evaluated directly in ReEDS, while rooftop PV deployment and performance are exogenously input into ReEDS from the dGen model.

UPV in ReEDS represents utility-scale single-axis-tracking PV systems with a representative size of 100 megawatts (MW) and an array density of $39 \mathrm{MW}$ per square kilometer (km2) with an inverter loading ratio of 1.3. Resource potential is assumed to be located on large parcels outside urban boundaries, excluding federally protected lands, inventoried "roadless" areas, U.S. Bureau of Land Management areas of critical environmental concern, and areas with slope greater than 5\%. Each eligible UPV site is characterized by a raw hourly $(8,760)$ irradiance profile that is representative of the solar resource within a $10 \mathrm{~km} 2$ contiguous area. Each of these UPV sites are compiled into supply curves for each of the 134 ReEDS BA regions with 9 PV resource classes, which are further differentiated by cost to connect to the transmission network (process described in Section 5.3). The nine resource classes reflect different resource qualities based on the annual average direct normal irradiance (DNI) reported by the latest National Solar Radiation Database (NSRDB), assuming a tilt angle equal to the latitude (Table 2). The UPV supply curves input into ReEDS include 117 terawatts (TW) of potential, which is shown by resource class in Figure 6. 
Table 4. Characteristics of UPV and DUPV Resource Classes

\begin{tabular}{|c|c|c|c|c|c|}
\hline Class & $\begin{array}{l}\text { Irradiance } \\
(\mathrm{kWh} / \mathrm{m} 2 \text { /day) }\end{array}$ & $\begin{array}{l}\text { Potential UPV } \\
\text { Capacity (GW) }\end{array}$ & $\begin{array}{l}\text { Weighted } \\
\text { Average } \\
\text { UPV Capacity } \\
\text { Factor (\%) }\end{array}$ & $\begin{array}{l}\text { Potential DUPV } \\
\text { Capacity (GW) }\end{array}$ & $\begin{array}{l}\text { Weighted } \\
\text { Average } \\
\text { DUPV Capacity } \\
\text { Factor (\%) }\end{array}$ \\
\hline 1 & $3.0-3.5$ & 167 & 12.2 & 14 & 12.6 \\
\hline 2 & $3.5-4.0$ & 16,870 & 16.8 & 184 & 16.7 \\
\hline 3 & $4.0-4.5$ & 30,238 & 18.6 & 434 & 17.9 \\
\hline 4 & $4.5-5.0$ & 37,438 & 19.6 & 511 & 19.1 \\
\hline 5 & $5.0-5.5$ & 20,372 & 21.8 & 222 & 21.1 \\
\hline 6 & $5.5-6.0$ & 11,868 & 23.9 & 116 & 23.8 \\
\hline 7 & $6.0-6.5$ & 332 & 24.4 & 4 & 24.8 \\
\hline 8 & $6.5-7.0$ & 0 & $n / a$ & 0 & $n / a$ \\
\hline 9 & $7.0-7.5$ & 0 & $n / a$ & 0 & $n$ \\
\hline
\end{tabular}

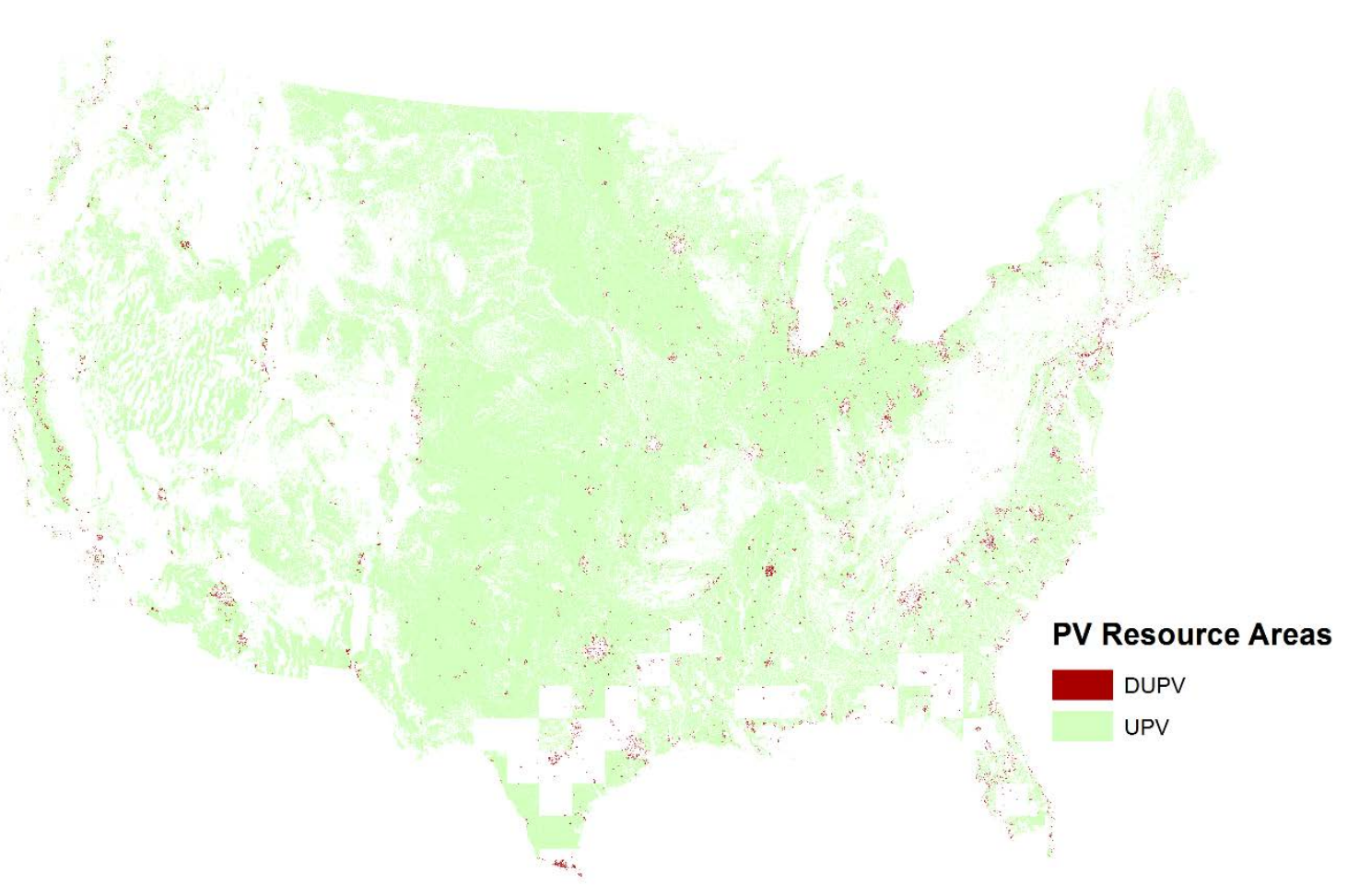

Figure 6. UPV and DUPV resource areas available for development considering land use exclusions 
TRG 1

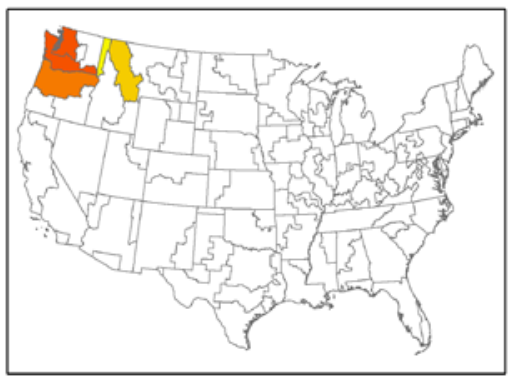

TRG 2

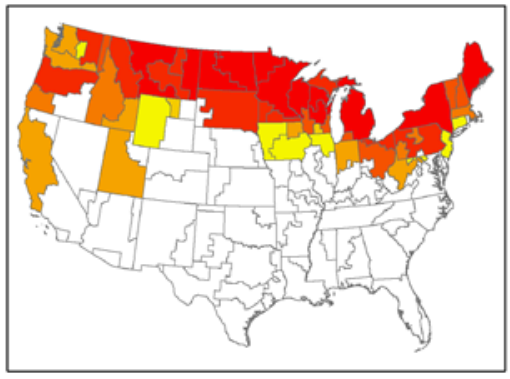

TRG 3

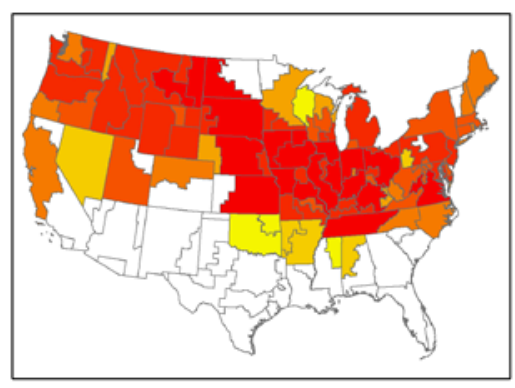

TRG 4

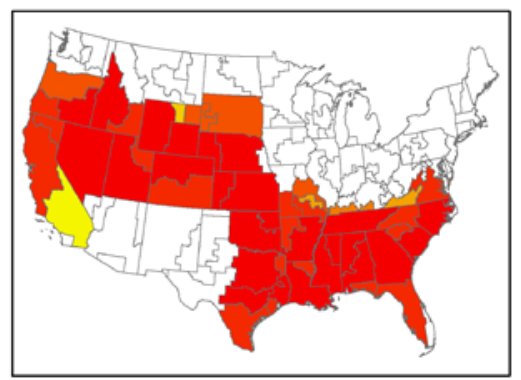

TRG 5

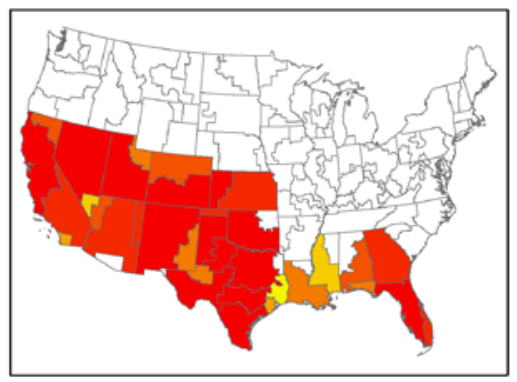

TRG 6

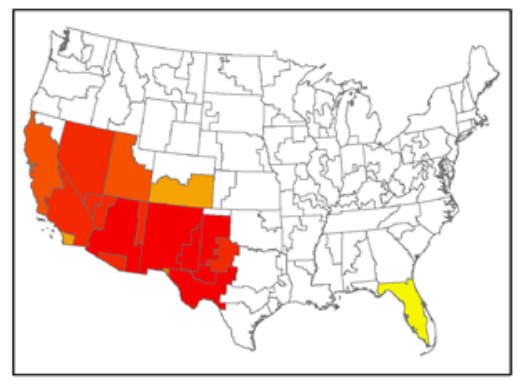

TRG 7

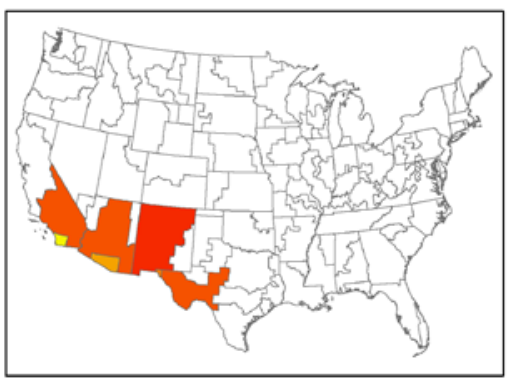

UPV Resource

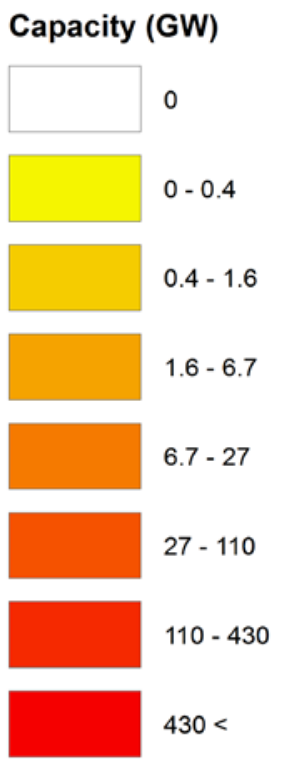

Figure 7. UPV resource availability by ReEDS BA region and resource class

DUPV in ReEDS assumes utility-scale single-axis-tracking systems with a representative size of $1 \mathrm{MW}$ and an array density of $39 \mathrm{MW} / \mathrm{km}^{2}$ with an inverter loading ratio of 1.3 . These systems are located within or are directly connected to distribution networks in urban areas. Resource potential estimates for DUPV are made by defining the eligible area as open space within urban areas and near existing distribution substations. Parking lots, roads, and urbanized areas are excluded by identifying areas with imperviousness greater than or equal to 1\% (Fry et al. 2011). Additional exclusions for landmarks, parks, and water further exclude areas deemed unlikely for development. Each DUPV site within the resulting eligible rural land areas is characterized by a raw hourly $(8,760)$ irradiance profile that is representative of the solar resource within a $10 \mathrm{~km}^{2}$ contiguous area. This process returns an urban DUPV potential of nearly $1.48 \mathrm{TW}$ across the contiguous United States (see Figure 7), with resource potential generally correlated with region size and population, and with higher-quality potential in the Southwest. The two order-ofmagnitude difference in resource capacity relative to UPV is a result of the significantly smaller land area with access to the distribution networks. (Figure 6) Similar to UPV, these values are input into ReEDS as supply curves by BA region and the nine PV resource classes from Table 2. 
TRG 1

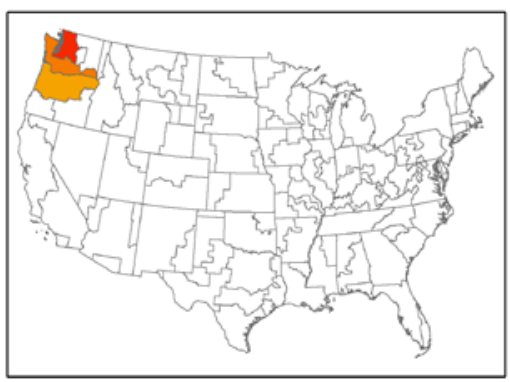

TRG 2

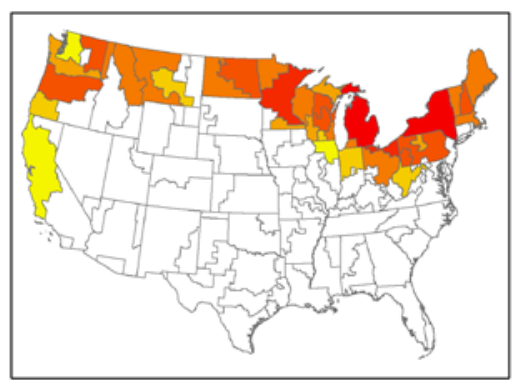

TRG 3

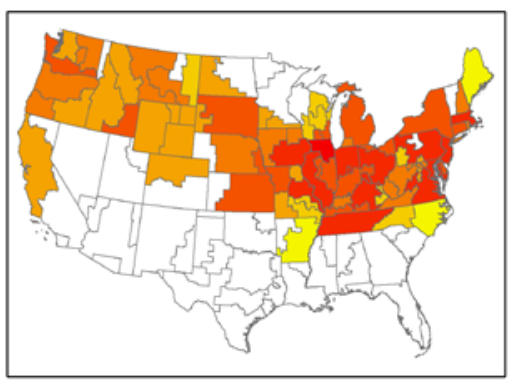

TRG 4

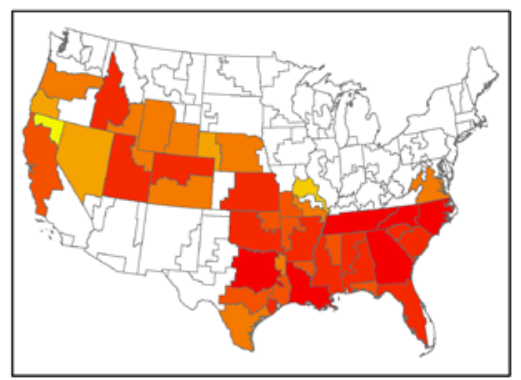

TRG 5

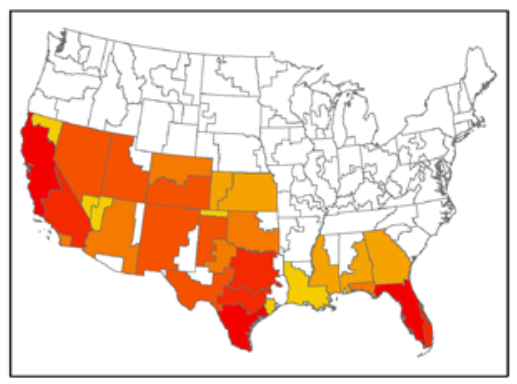

TRG 6

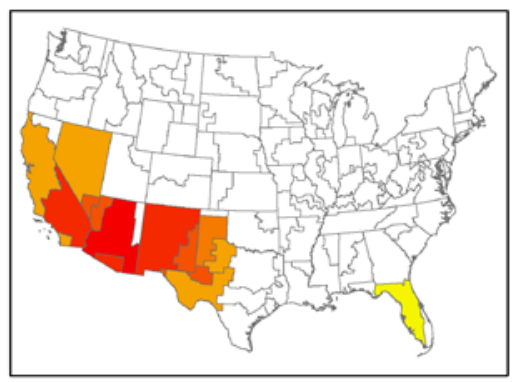

TRG 7

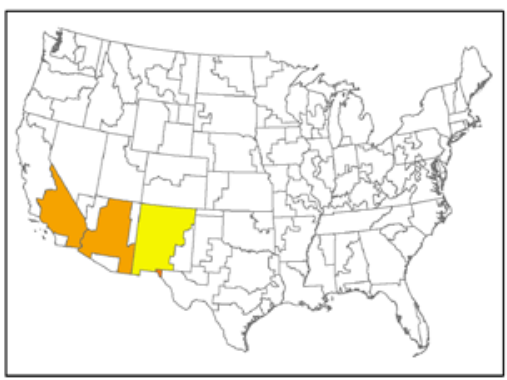

DUPV Resource

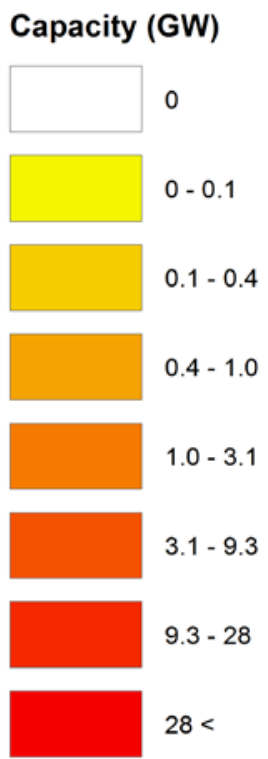

Figure 8. DUPV resource availability in each ReEDS region by resource class

DUPV systems have lower infrastructure requirements than large-scale rural UPV systems; we assume they connect to existing nearby distribution substations at about 13 kilovolts $(\mathrm{kV})$, whereas the representative UPV system connects to a high-voltage bus at $230 \mathrm{kV}$ and may require a spur line several miles long to reach that connection point. The cost of the spur line is handled separately in the accessibility supply curve (Section 5.3), but the additional transformers and power electronics associated with the larger systems and higher-voltage interconnections add cost and losses to the UPV systems. On the other hand, the larger UPV systems benefit from economies of scale. On balance, we assume a per-kW capital cost penalty of $8.7 \%{ }^{20}$ and $3.5 \%$ higher delivered energy (i.e., reduced losses) for DUPV relative to UPV.

\footnotetext{
${ }^{20}$ Represents the average of union and non-union total system cost without transmission between a 10MW (proxy for DUPV) and 100MW (UPV) system (Fu et al. 2015).
} 
Performance characteristics for UPV and DUPV were developed using NREL's Renewable Energy Potential (reV) Tool, using multiyear hourly weather files from the National Solar Radiation Database ${ }^{21}$ at $4-\mathrm{km}$ by $4-\mathrm{km}$ parcels throughout the contiguous United States from 1998 to 2016 . No changes or improvements in capacity factor over time are assumed for PV technologies. For each ReEDS BA region, resource quality classifications were made by averaging across the 1998-2016 period for all available parcels. Hourly generation profiles were taken from 2012. The generation profiles from all the regions in a BA for each resource class were averaged to provide ReEDS with average capacity factors by time-slice and resource class.

To mitigate excessive wheeling of distributed PV generation, ReEDS assumes all power generated by both DUPV and rooftop PV systems is permitted to be exported to neighboring BAs only when total generation in the source region exceeds the load for a given time-slice. UPV-generated electricity, in contrast, can be exported in all time-slices and regions.

Degradation of the efficiency of solar PV capacity over time is also modeled at $0.5 \%$ /year (Jordan and Kurtz 2013). This degradation is modeled by reducing the capacity of PV that generates energy by $0.5 \%$ year.

Rooftop PV includes commercial, industrial, and residential systems. These systems are assumed to have an inverter loading ratio of 1.1. dGen, a consumer adoption model for the contiguous U.S. rooftop PV market, is used to develop future scenarios for rooftop PV capacity, including the capacity deployed by BA and the pre-curtailment energy production by that capacity (Sigrin et al. 2016). The default dGen trajectories used in this version of ReEDS are based on the residential and commercial PV cost projections as described in the 2018 ATB (NREL 2018a). There are 14 unique rooftop PV trajectories available in ReEDS (see Figure 8) that are from the 2018 Standard Scenarios report (W. J. Cole et al. 2018). These trajectories were created by running a ReEDS scenario and feeding the electricity price outputs from ReEDS back into dGen. The trajectories incorporate existing net metering policy as of spring 2018, and they include the investment tax credit (ITC) as discussed in Section 8.2.

${ }^{21}$ https://nsrdb.nrel.gov/ 


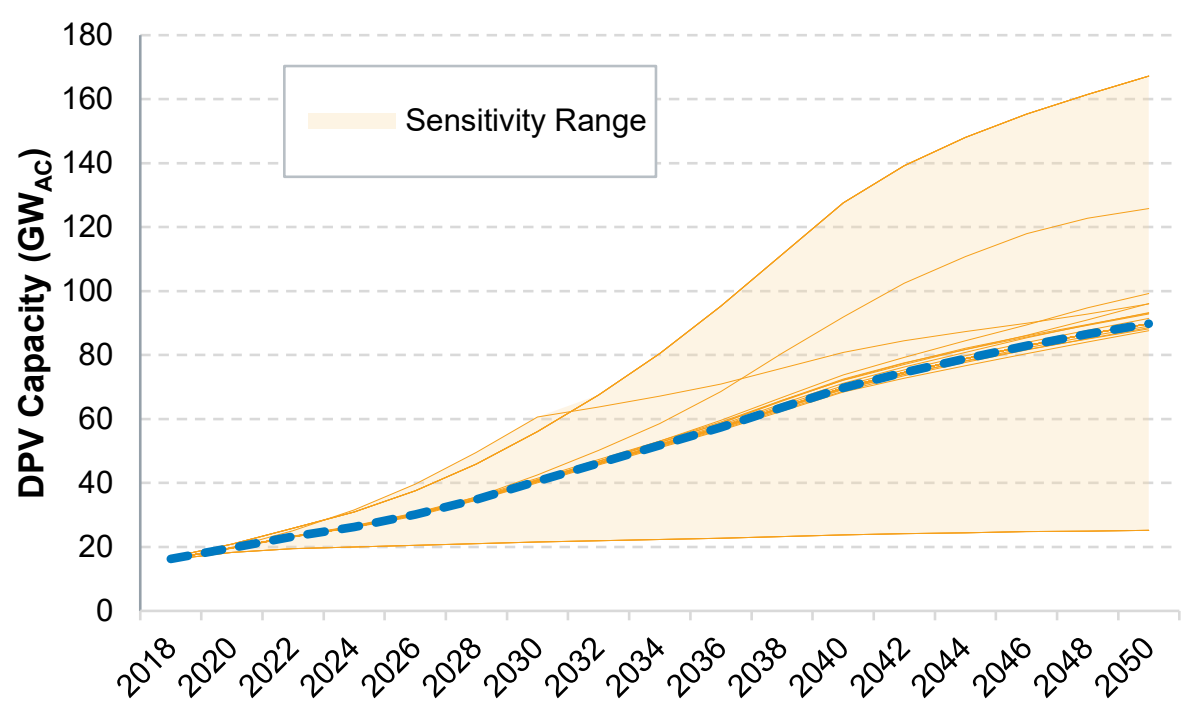

Figure 9. Prescribed distributed PV deployment used in the ReEDS as determined by dGen

For ReEDS simulations beyond 2050, dGen projections are extended to 2100 assuming no changes to input conditions after 2050.

The dashed line shows the Mid-case scenario, while each individual line represents an individual dGen scenario.

\subsubsection{Concentrating Solar Power}

Concentrating solar power (CSP) technology options in ReEDS encompass a subset of possible thermal system configurations, with and without thermal storage, as shown in Table 3 . The two system types access the same resource potential, which is divided into 12 resource classes based on DNI (Table 4). The CSP resource and technical potential is based on the latest version of NSRDB. Details of the CSP resource data and technology representation can be found in Appendix B of Murphy et al. (C. Murphy et al. 2019). By default, recirculating and dry cooling systems are allowed for future CSP plants getting built in ReEDS.

Table 5. Characteristics of CSP Technology Storage Options

\begin{tabular}{lllll}
\hline System & Configuration $^{22}$ & Dispatchability & Capacity Value & Curtailments \\
\hline No Storage & solar multiple: 1.4 & insolation-dependent & variable/ & variable/ \\
With Storage & & & statistical & statistical \\
& $\begin{array}{l}6-12 \text { storage hours, } \\
\text { solar multiple: } 1.6-2.5\end{array}$ & dispatchable & firm & none \\
\hline
\end{tabular}

\footnotetext{
22 The solar multiple is defined as the ratio of the design solar field aperture area to the aperture area required to produce the power cycle design thermal input (and power output) under reference environmental conditions.
} 
The CSP resource classes are defined by power density of DNI, developable land area having been filtered based on land cover type, slope, and protected status. CSP resource in each resource region is therefore represented as a supply curve of $\mathrm{MW}$ of solar collector potential, assuming a power density of $14.9 \mathrm{MW} / \mathrm{km}^{2}$. Performance for each CSP resource class was developed using 2012 hourly resource data (Sengupta et al. 2018) from representative sites of each resource region. The 2012 weather files are processed through the CSP modules of the System Advisor Model (SAM) to develop performance characteristics for each CSP resource class and representative CSP system considered in ReEDS. As with wind and PV technologies, CSP resources are further distinguished by grid accessibility in each resource region (see Section 5.3).

Table 6. Resource Classes for CSP Plants Using a Solar Multiple of 2.4

Resources are then scaled in ReEDS by the ratio of the model-determined solar multiple and 2.4 .

\begin{tabular}{|l|r|r|r|}
\hline $\begin{array}{l}\text { Resource } \\
\text { Class }\end{array}$ & \multicolumn{1}{|l|}{$\begin{array}{l}\text { DNI } \\
\text { (kWh/m²/day) }\end{array}$} & $\begin{array}{l}\text { Weighted Average } \\
\text { Field CF for SM=1 } \\
\text { system (\%) }\end{array}$ & \multicolumn{2}{l|}{$\begin{array}{l}\text { Available Resource } \\
\mathbf{( G W )}\end{array}$} \\
\hline Class1 & $5-5.25$ & 17 & 2,641 \\
\hline Class2 & $5.25-5.5$ & 18 & 1,925 \\
\hline Class3 & $5.5-5.75$ & 19 & 1,495 \\
\hline Class4 & $5.75-6$ & 20 & 1,725 \\
\hline Class5 & $6-6.25$ & 21 & 1,850 \\
\hline Class6 & $6.25-6.5$ & 22 & 1,282 \\
\hline Class7 & $6.5-6.75$ & 23 & 1,252 \\
\hline Class8 & $6.75-7$ & 0.244 & 1,098 \\
\hline Class9 & $7-7.25$ & 0.255 & 1,381 \\
\hline Class10 & $7.25-7.5$ & 0.266 & 1,251 \\
\hline Class11 & $7.5-7.75$ & 0.276 & 114 \\
\hline Class12 & $>7.75$ & 0.285 & 677 \\
\hline
\end{tabular}

a The field capacity factors shown here are from SAM (version 2017.09.05, SDK version 181) simulation assuming a solar multiple $(\mathrm{SM})=1$ system. This field capacity factor is meant to represent the upper limit of corresponding turbine capacity factor for all systems with $S M>1$.

The representative CSP system without storage used to define system performance in ReEDS is a $100 \mathrm{MW}$ trough system with a solar multiple of 1.4. As CSP systems without storage are nondispatchable, output capacity factors are defined directly from SAM results. The average annual capacity factors for the solar fields of these systems range from 20\% (Class 1 resource) to $29 \%$ (Class 12 resource). 


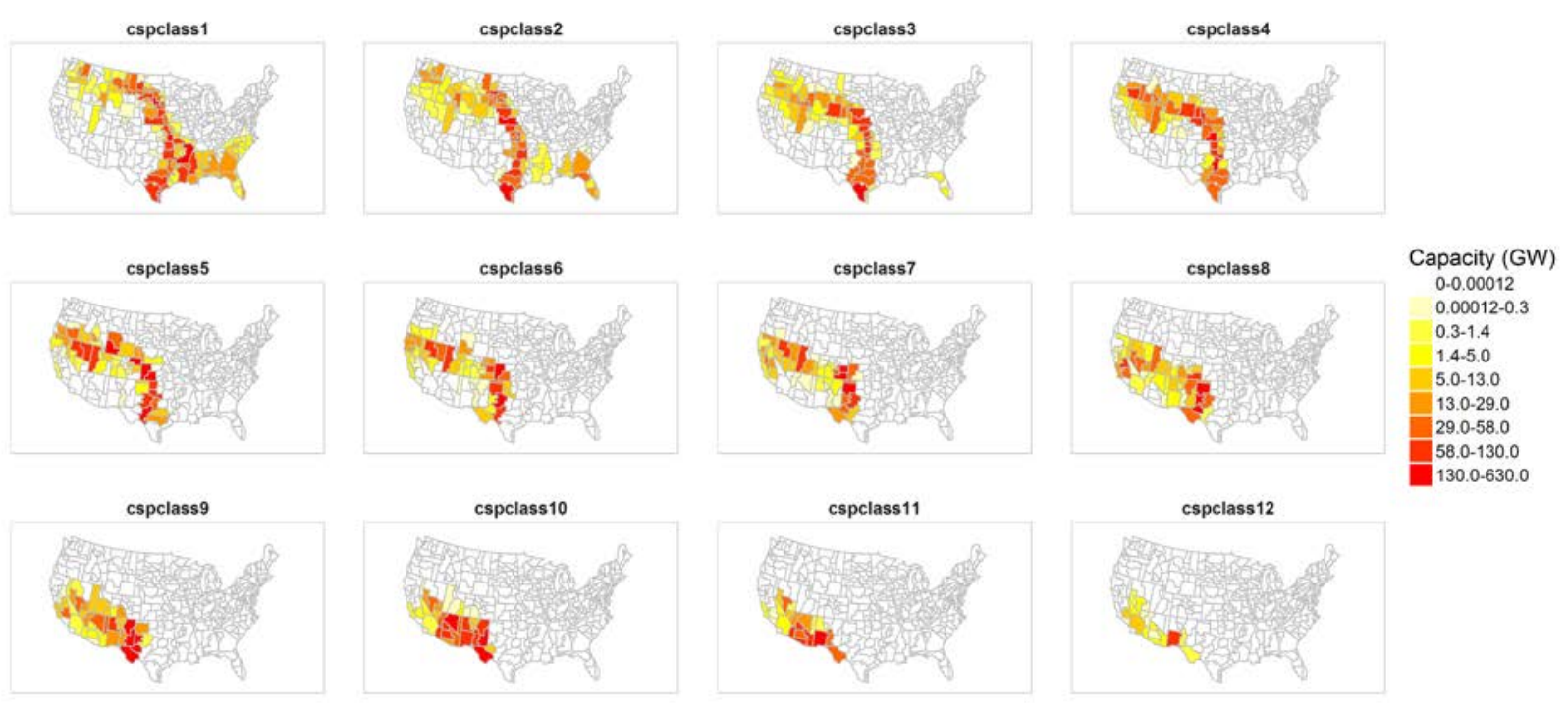

Figure 10. CSP resource availability in each ReEDS resource region by 12 resource class

The representative system for any new CSP with thermal energy storage (TES) is a tower-based configuration with a molten salt heat transfer fluid and a thermal storage tank between the heliostat array and the steam turbine. ${ }^{23}$ CSP with storage is optimally built within ReEDS by considering three major design components (field, turbine, storage) within six constraints as shown in Figure 10. These constraints ensure the systems can be assumed to be fully dispatchable within the energy limitations imposed by the following:

- For a given turbine, the storage tank must hold enough energy for 6-12 hours of rated power output (horizontal lines in Figure 10). ${ }^{24}$

- The maximum allowed solar multiple is 2.5 for tower systems (vertical green line).

- Upper and lower bounds on annual system capacity factor create lower and alternate upper limits on solar multiple (vertical orange and blue lines); ReEDS assumes the array must be sized to produce an average annual capacity factor between $40 \%$ and $65 \%$.

- A minimum storage-to-solar-multiple ratio ensures curtailments are not excessive; in other words, the storage tank size must keep pace with increasing solar multiples to avoid excessive curtailments (diagonal line-derived from the data in Figure 11).

The data in Figure 11 show the turbine capacity factor for a range of CSP system configurations (field, turbine, and storage) as simulated by SAM. The capacity factor erodes for high solar multiple systems due to curtailments arising from insufficient storage. This relationship between storage and solar multiple is used to define the minimum storage to solar multiple ratio constraint in Figure 10 (diagonal line).

${ }^{23}$ Historical and announced trough-based systems are characterized with technology-appropriate characteristics.

24 This limit on storage duration is in not a technical limit, and shorter duration storage has been considered for CSP. 
ReEDS considers CSP-with-storage system configurations within the resulting feasible space (hashed lines in Figure 10). Higher solar multiples result in higher annual average capacity factors, and more storage allows the systems to be more flexible, although both options increase capital costs per kilowatt of installed turbine capacity.

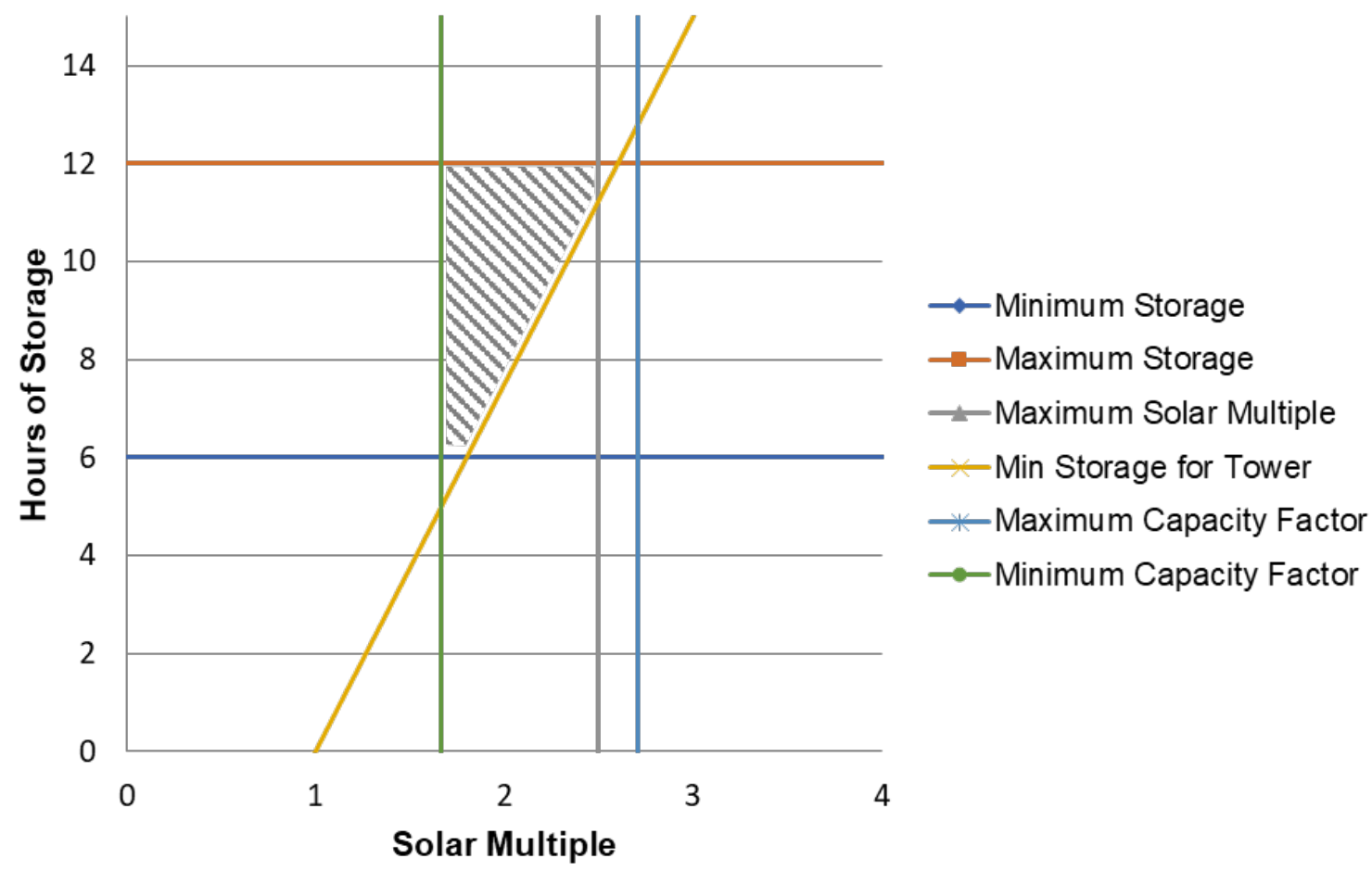

Figure 11. Demonstration of ReEDS constraints and corresponding feasible space (hashed line) for CSP with storage in Class 8 resource regions

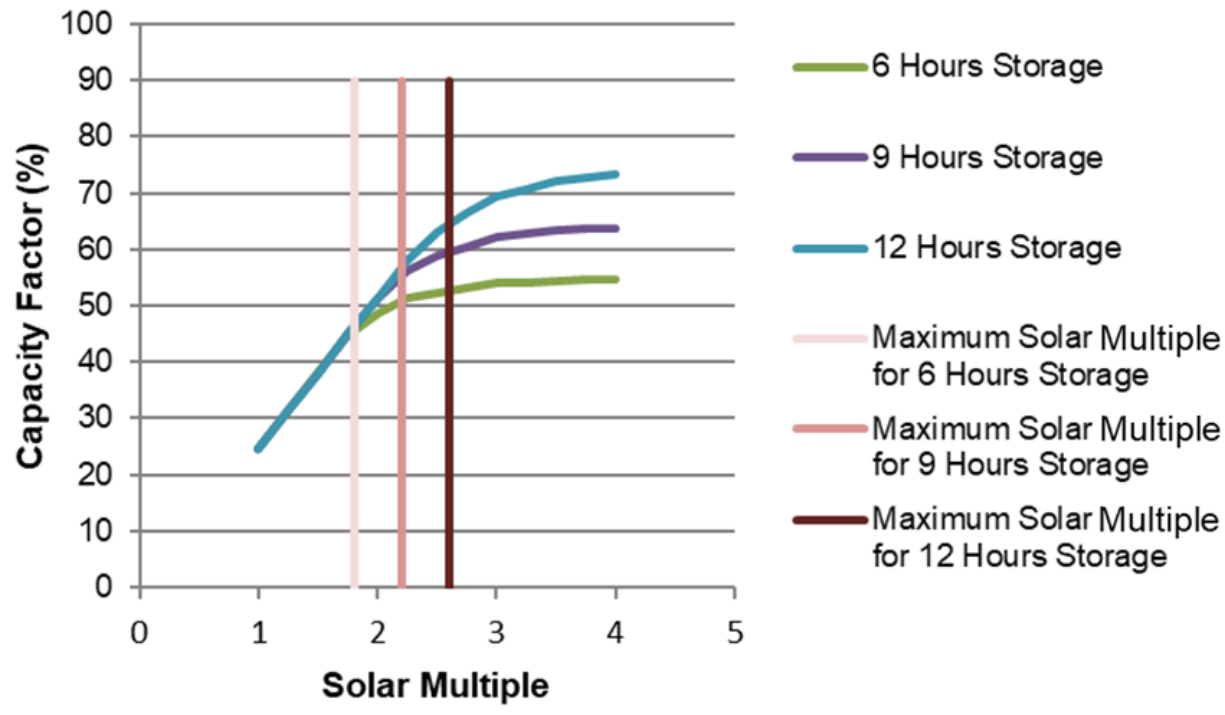

Figure 12. Capacity factor trends versus solar multiple 
For CSP with storage, plant turbine capacity factors by time-slice are an output of the model, not an input, as ReEDS can dispatch collected CSP energy independent of irradiation. Instead, the profile of power input from the collectors (solar field) of the CSP plants are model inputs, based on SAM simulations from the 2012 weather files.

\subsubsection{Geothermal}

Geothermal resource has several subcategories in ReEDS. Hydrothermal resource represents potential sites that involve tapping existing hot water. The hydrothermal potential included in the base supply curve consists of only identified sites, with a separate supply curve for undiscovered hydrothermal resource. EGS sites are geothermal resources that have sufficient temperature but lack the natural permeability, in-situ fluids, or both to be hydrothermal systems. Near-field EGS is a subset of EGS that implies proximity to existing or known hydrothermal sites.

The default geothermal resource assumptions allow for new construction at identified hydrothermal sites and near-hydrothermal-field enhanced geothermal systems (near-field EGS). Though undiscovered hydrothermal and additional deep EGS resources are not allowed under default assumptions due to uncertain feasibility, these geothermal resource categories can be included as additional resource in ReEDS. The identified hydrothermal and near-field EGS supply curves are based on the analysis described in (Augustine 2011) and are shown in Figure 12. The hydrothermal and near-field EGS resource potential is derived from the U.S. Geological Survey's 2008 Geothermal Resource Assessment (Williams, Reed, and Mariner 2008), while the deep EGS resource potential is based on an update of the EGS potential from the Massachusetts Institute of Technology (Tester et al. 2006). As with other technologies, geothermal cost and performance projections are from the ATB (NREL 2018a).
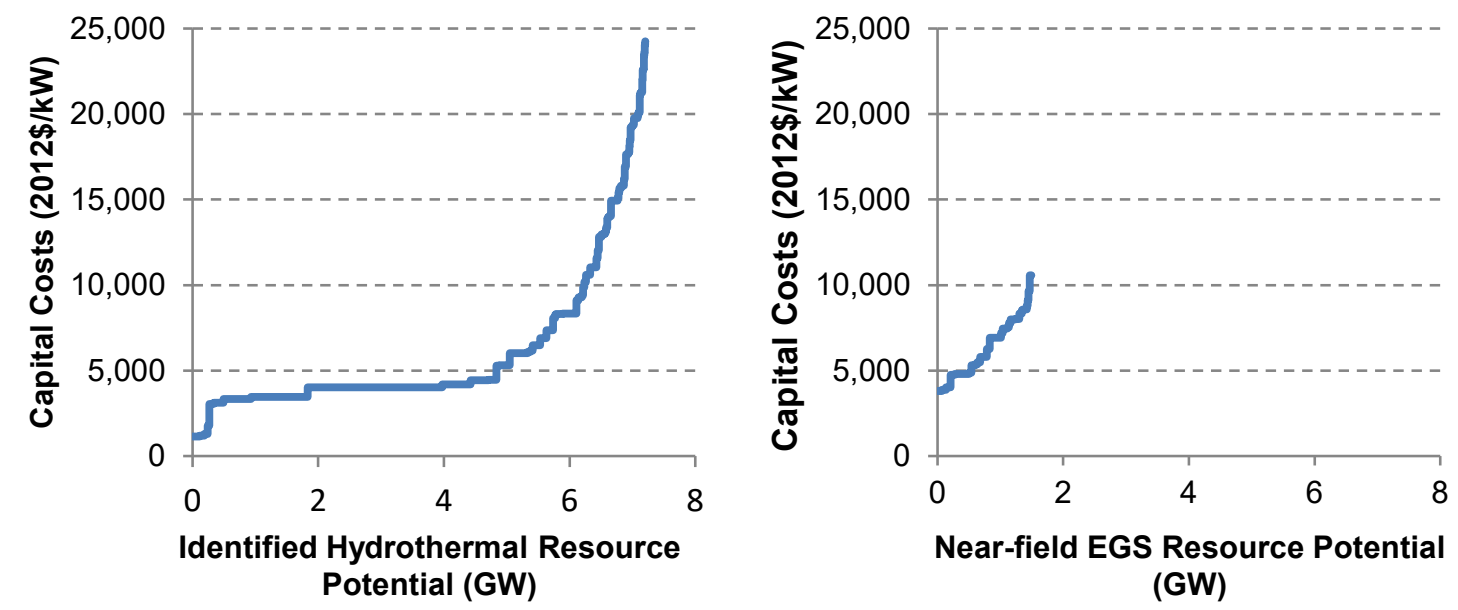

Figure 13. National capital cost supply curves for new identified hydrothermal and near-field EGS capacity used in the base model assumptions

\subsubsection{Hydropower}

The existing hydropower fleet representation is informed by historical performance data. From the nominal hydropower capacity in each BA, seasonal capacity adjustments are used for Western Electricity Coordinating Council (WECC) regions based on data from the Transmission Expansion Planning Policy Committee (TEPPC) 2024 Common Case (WECC 2013, 2015). 
Seasonal capacity adjustments allow more realistic seasonal variations in maximum capacity due to changes in water availability and operating constraints. These data are not available for nonWECC regions. Energy availability for the existing fleet for 2016 and beyond is defined seasonally using region-specific seasonal hydropower capacity factors averaged for 2006-2015 as reported by the National Hydropower Asset Assessment Program (NHAAP), ${ }^{25}$ totaling 270 terawatt hours per year (TWh/yr). Capacity factors for 2010-2014 model years are calibrated so that modeled generation matches historical generation. PSH, both existing and new, is discussed in Section 2.3 on storage technologies.

There are three categories of new hydropower resource potential represented in the model.

1. Upgrade and expansion potential for existing hydropower

2. Potential for powering non-powered dams (NPD)

3. New stream-reach development potential (NSD)

The supply curves for each are discussed in detail in the Hydropower Vision report (DOE 2016b), particularly Chapter 3 and Appendix B.

ReEDS does not currently distinguish between different types of hydropower upgrades, so upgrade potential is represented generically as a potential for capacity growth that is assumed to have the same energy production potential per capacity (i.e., capacity factor) as the corresponding existing hydropower capacity in the region. The quantity of available upgrades is derived from a combination of limited resource assessments and case studies by the U.S. Bureau of Reclamation Hydropower Modernization Initiative (HMI), U.S. Army Corps of Engineers (Corps), and NHAAP Hydropower Advancement Project (Montgomery, Watson, and Harza 2009; Bureau of Reclamation 2011). Upgrade availability at federal facilities not included in the HMI is assumed to be the HMI average of $8 \%$ of the rated capacity, and upgrade availability at non-federal facilities is assumed to be the NHAAP average of $10 \%$ of the rated capacity. Rather than making all upgrade potential available immediately, upgrade potential is made available over time at the earlier of either (1) the Federal Energy Regulatory Commission (FERC) license expiration (if applicable) or (2) the turbine age reaching 50 years. This feature better reflects institutional barriers and industry practices surrounding hydropower facility upgrades. The total upgrade potential from this methodology is $6.9 \mathrm{GW}(27 \mathrm{TWh} / \mathrm{yr})$.

${ }^{25}$ http://nhaap.ornl.gov/content/nhaap-data-sources 


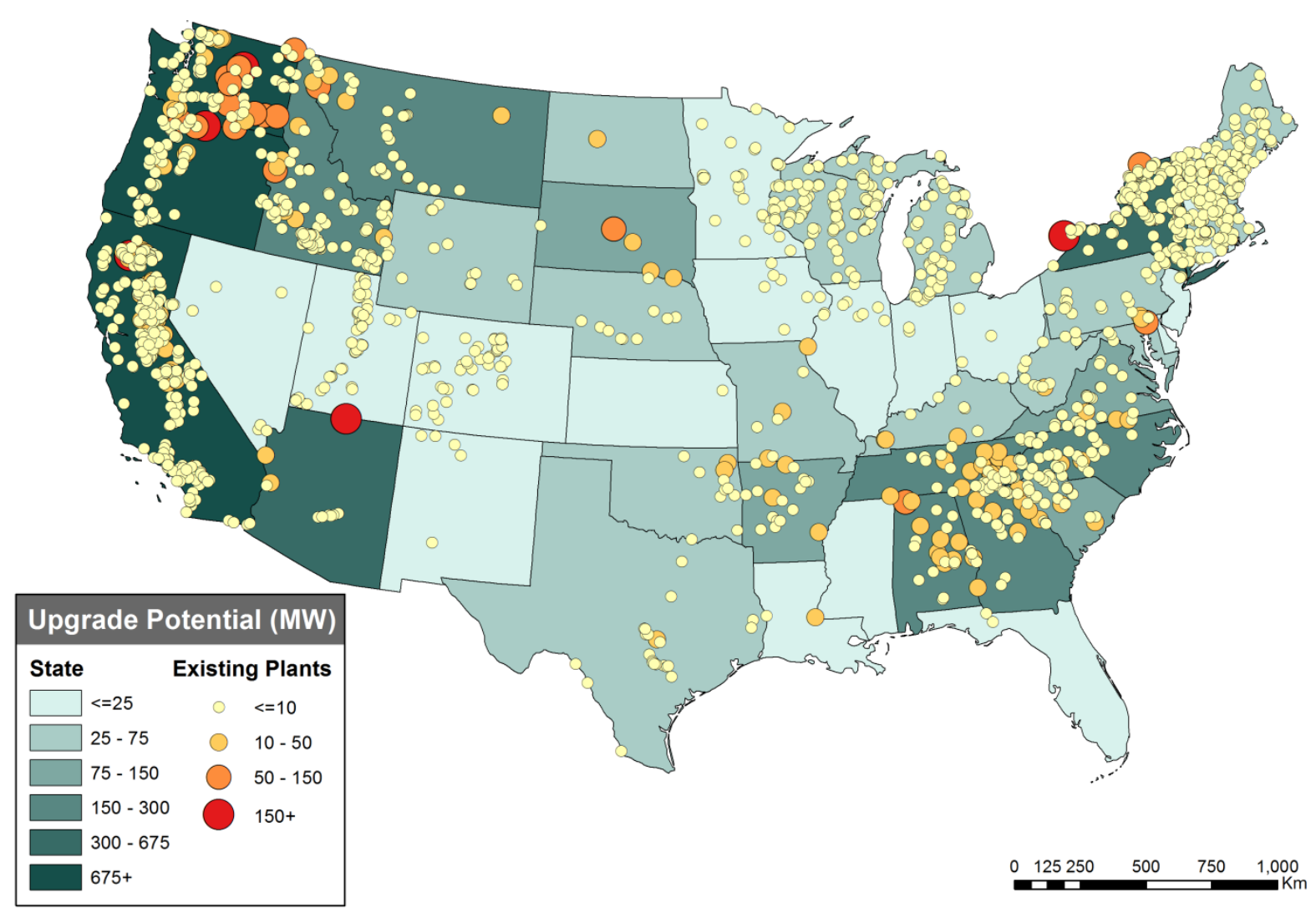

Figure 14. Modeled hydropower upgrade resource potential (DOE 2016b)

NPD resource is derived from the 2012 NHAAP NPD resource assessment (Hadjerioua, Wei, and Kao 2012; Hadjerioua et al. 2013), where the modeled resource of 5.0 GW (27 TWh/yr) reflects an updated site sizing methodology, data corrections, and an exclusion of sites under 500 $\mathrm{kW}$ to allow better model resolution for more economic sites. 


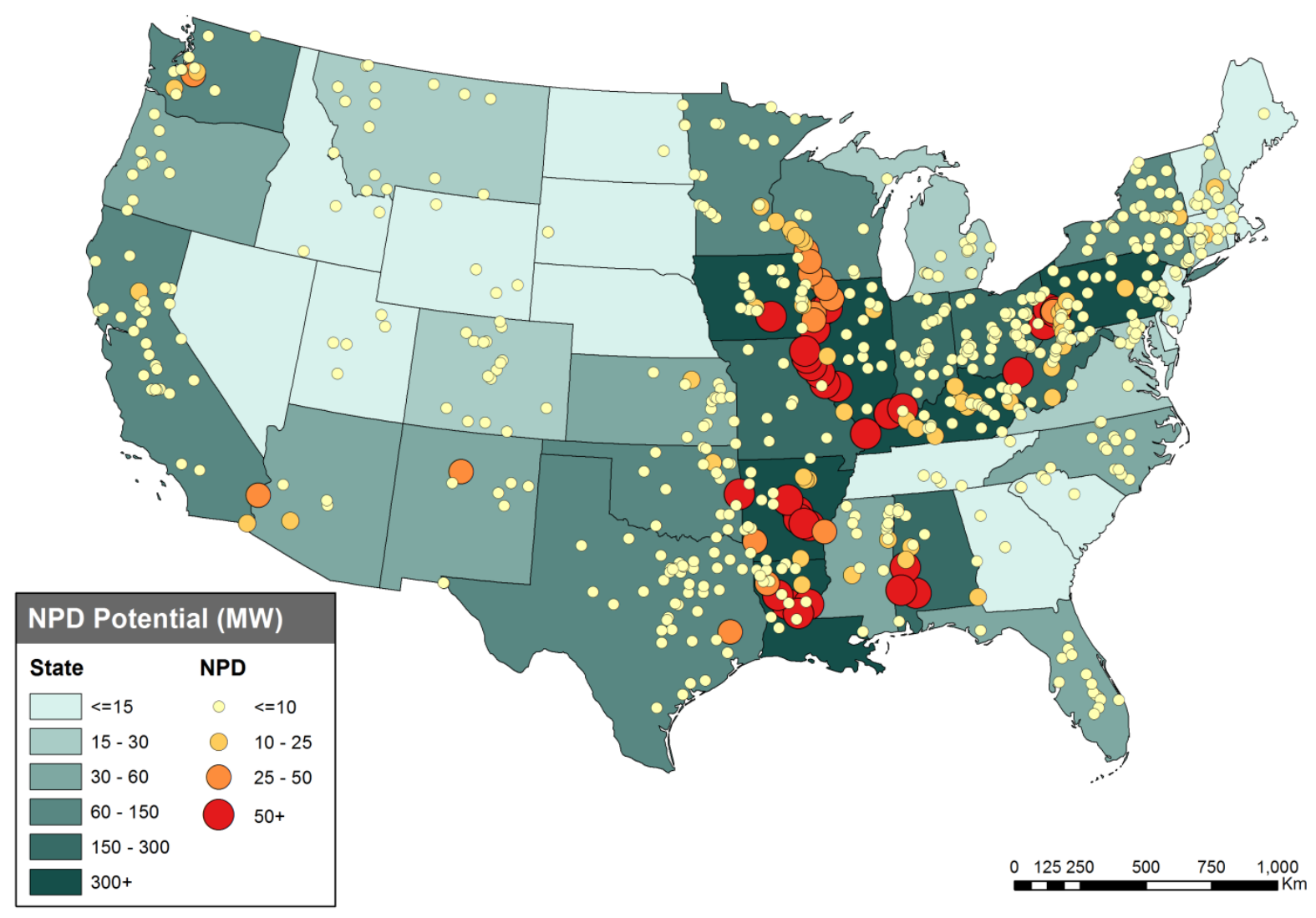

Figure 15. Modeled non-powered dam resource potential (DOE 2016b)

NSD resource is based on the 2014 NHAAP NSD resource assessment (Kao et al. 2014), where the modeled resource of $30.7 \mathrm{GW}(176 \mathrm{TWh} / \mathrm{yr})$ reflects the same sizing methodology as NPD and a sub-1 MW site exclusion, again to improve model resolution for lower-cost resource. The NSD resource assumes "low head" sites inundating no more than the 100-year flood plain and excludes sites within areas statutorily barred from development—national parks, wild and scenic rivers, and wilderness areas. 


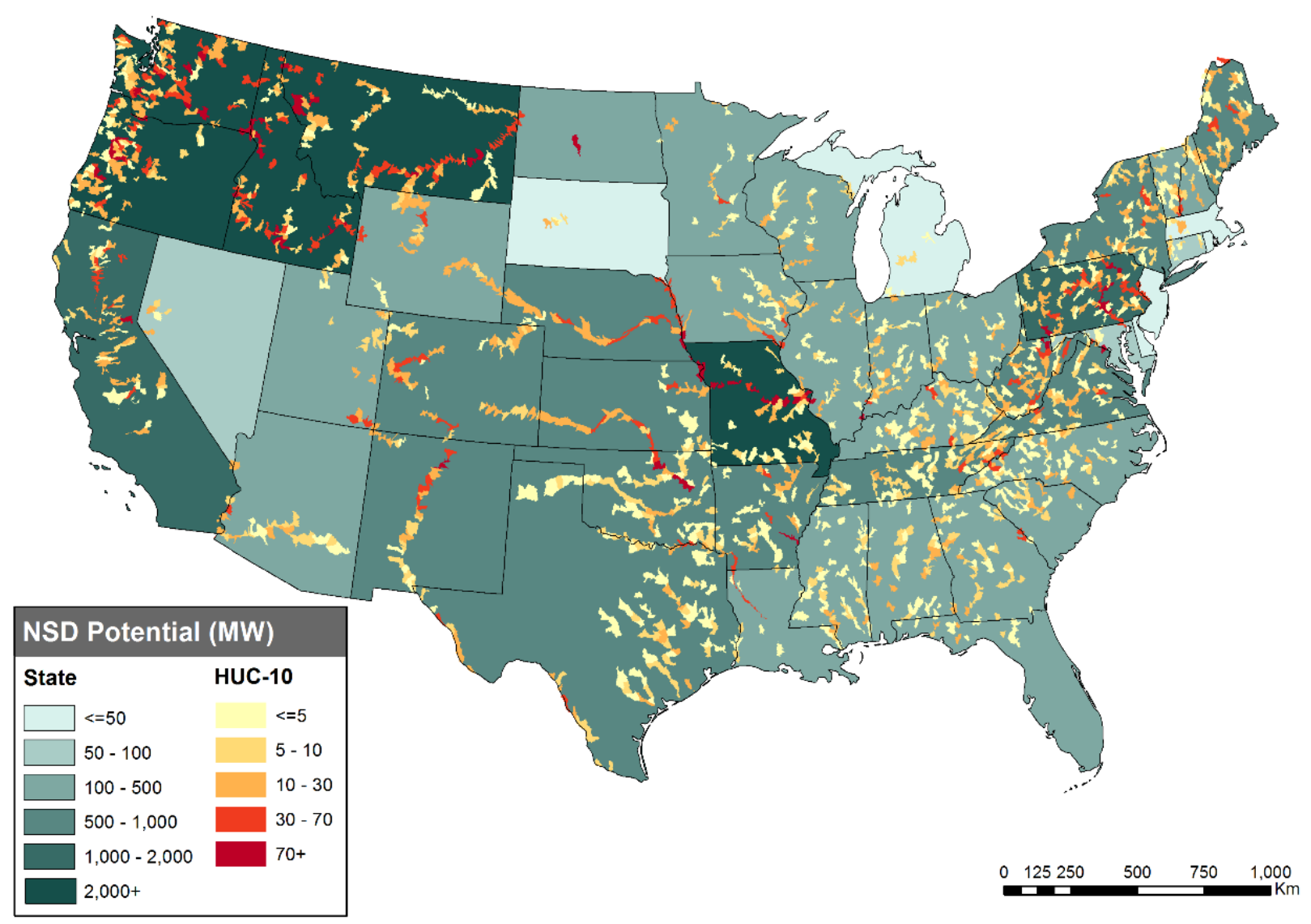

Figure 16. Modeled new stream-reach development resource potential (DOE 2016b)

The combined hydropower capacity coupled with the costs from the ATB (NREL 2018a) results in the supply curve shown in Figure 16.

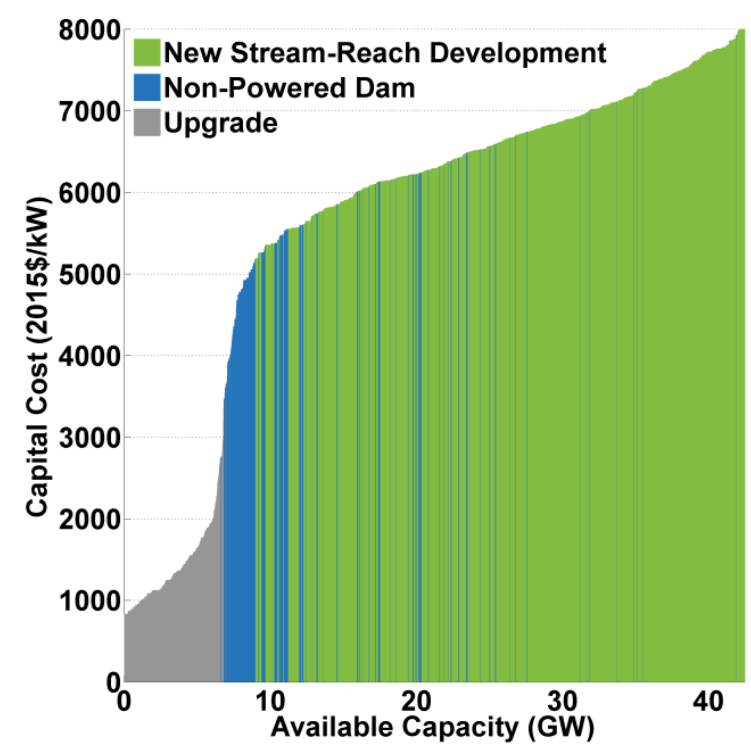

Figure 17. National hydropower supply curve of capital cost versus cumulative capacity potential 
The hydropower operating parameters and constraints included in ReEDS do not fully reflect the complex set of operating constraints on hydropower in the real world. Detailed site-specific considerations involving a full set of water management challenges are not easily represented in a model with the scale and scope of ReEDS, but several available parameters allow a stylized representation of actual hydropower operating constraints (Stoll et al. 2017).

Each hydropower category can be differentiated into "dispatchable" or "non-dispatchable" capacity, with "dispatchable" defined in ReEDS as the ability to provide the following services:

1. Diurnal load following within the capacity and average daily energy limits for each season

2. Planning (adequacy) reserves with full rated capacity

3. Operating reserves up to a specified fraction of rated capacity if the capacity is not currently being utilized for energy production.

"Non-dispatchable" capacity, on the other hand, provides:

1. Constant energy output in each season such that all available energy is utilized

2. Planning reserves equal to the output power for each season

3. No operating reserves.

Dispatchable capacity is also parameterized by a fractional minimum load, with the maximum fractional capacity available for operating reserves as one minus the fractional minimum load. The existing fleet and its corresponding upgrade potential are differentiated by dispatchability using data from the TEPPC 2024 Common Case for WECC and the NHAAP Hydropower Market Report for other regions (WECC 2013, 2015; Uria-Martinez, O'Connor, and Johnson 2015). All WECC facilities that do not follow load are assumed non-dispatchable, and all nonWECC facilities in the following NHAAP categories are non-dispatchable: run-of-river, run-ofriver/peaking (downstream), and regulating. This methodology chooses only the most obvious facilities as non-dispatchable while leaving all other existing and upgrade capacity as dispatchable. In total, $43 \%$ of existing capacity and $49 \%$ of upgrade potential is assumed nondispatchable.

The same TEPPC database is used to define region-specific fractional minimum capacity for dispatchable existing and upgrade hydropower in WECC. Lacking minimum capacity data for non-WECC regions, 0.5 is chosen as a reasonable fractional minimum capacity.

Both the NPD and NSD resource assessments implicitly assume inflexible, run-of-river hydropower, so all NPD and NSD resource potential is assumed non-dispatchable. Additional site-specific analysis could allow re-categorizing portions of these resources as dispatchable, but $100 \%$ non-dispatchable remains the default assumption. 


\subsubsection{Biopower}

ReEDS can generate electricity from biomass either in dedicated biomass integrated gasification combined cycle (IGCC) plants or cofired with coal in facilities that have been retrofitted with an auxiliary fuel feed. These cofire-ready coal plants can use biomass in place of coal to supply the fuel for up to $15 \%$ of the plant's electricity generation. A cofire retrofit costs $305 \$ 2017 / \mathrm{kW}$ based on EIA's Electricity Market Module assumptions (EIA 2017, 101).

Dedicated and cofired plants source feedstock from the same biomass supply curves, which are derived from the U.S. Billion-Ton Update report (DOE 2011). The biomass types from this study included in ReEDS supply curves are crop and forest residues (including forest residues from federal lands) and energy crops. Figure 17 shows the national supply curve for biomass feedstock through the 2012 solve year, after which both supply and prices are adjusted each year through 2030 to follow projections in the U.S. Billion-Ton Update report (DOE 2011).

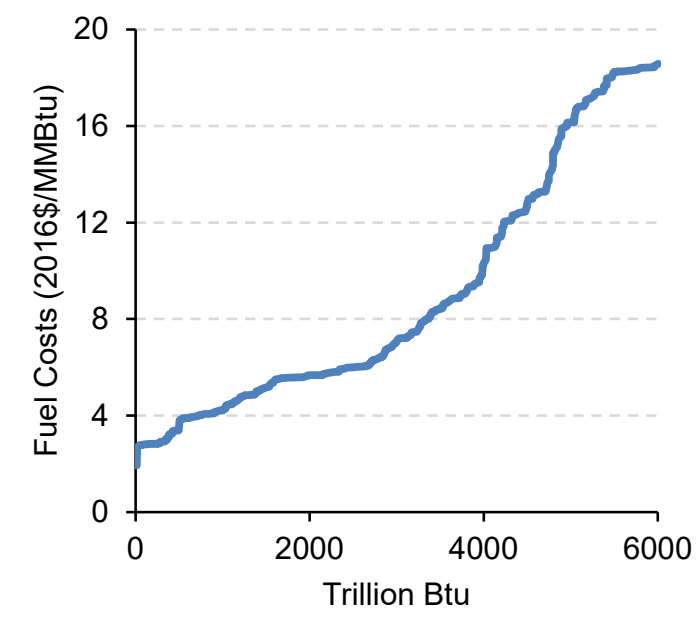

Figure 18. National supply curve for biomass feedstock through the 2012 solve year

\subsubsection{Marine Hydrokinetic Wave}

ReEDS does have a representation of marine hydrokinetic wave technologies, but this capability is not utilized in any of the recent or current ReEDS modeling work.

\subsection{Conventional Energy Technologies}

ReEDS includes all major categories of conventional generation technologies within its operating fleet or its investment choices. In the context of ReEDS, "conventional" is defined as thermal generating technologies driven by coal, gas, oil, or nuclear fuel. Coal technologies are subdivided into pulverized and gasified (IGCC) categories, with the pulverized plants further distinguished by 1) whether or not $\mathrm{SO}_{2}$ scrubbers are installed and 2) their vintage ${ }^{26}$ as pre- or post-1995. Pulverized coal plants have the option of adding a second fuel feed for biomass. New

\footnotetext{
${ }^{26}$ While differentiating pre- and post-1995 is somewhat arbitrary, it allows the model to better represent performance differences between relatively old and new coal technologies.
} 
IGCC plants can only be constructed with CCS technology. ${ }^{27}$ Existing coal units built after 1995 with $\mathrm{SO}_{2}$ scrubbers installed also have the option of retrofitting CCS capability.

Natural gas generators are categorized as combustion turbine (CT), combined cycle (CC), or gas$\mathrm{CC}$ with CCS. ${ }^{28}$ There are also nuclear (steam) generators, landfill gas generators, ${ }^{29}$ and oil/gas steam generators, though the latter two are not offered as options for new construction unless prescribed as a known unit expected to come online. The model distinguishes each conventionalgenerating technology by costs, efficiency, and operational constraints.

Where renewable energy technologies have many unique characteristics, ReEDS conventional technologies are characterized more generally by the following parameters:

- Capital cost $(\$ / \mathrm{MW})$

- $\quad$ Fixed and variable operating costs (dollars per megawatt-hour [\$/MWh])

- Fuel costs (dollars per million British thermal units [\$/MMBtu])

- Heat rate (MMBtu/MWh)

- Construction period (years) and expenses

- Equipment lifetime (years)

- Financing costs (such as interest rate, loan period, debt fraction, and debt-servicecoverage ratio)

- Tax credits (investment or production)

- Minimum turndown ratio (\%)

- Quick-start capability and cost $(\%, \$ / M W)$

- Spinning reserve capability

- Planned and unplanned outage rates (\%).

Cost and performance assumptions for all new conventional technologies are taken from the ATB (NREL 2018a), which are based on the projections from the AEO2018 Reference scenario. ${ }^{30}$ The National Energy Modeling System (NEMS) Electricity Market Module, which is used for AEO analyses, represents technological learning endogenously, with costs falling as more capacity of that type is built. Because ReEDS does not include endogenous learning, the

\footnotetext{
${ }^{27}$ New coal plants without CCS plants are not allowed by default due the U.S. Environmental Protection Agency's proposed New Source Performance Standard. There is currently no option for partial $\mathrm{CO}_{2}$ capture technologies in ReEDS, so CCS plants in ReEDS are assumed to be $90 \%$ capture plants, meaning that they capture $90 \%$ of the $\mathrm{CO}_{2}$ emissions in the flue gas. Thus the technology representation is more conservative than allowed under proposed EPA regulations. Transportation and sequestration of the $\mathrm{CO}_{2}$ is not modeled, but an $\$ 11 /$ tonne (2011\$) costs is assumed based on (Timothy Fout 2015). No revenue from the potential use of $\mathrm{CO}_{2}$ is currently captured in ReEDS.

${ }^{28}$ Retrofits from Gas-CC to Gas-CC-CCS are not currently an option in the model.

${ }^{29}$ Landfill gas generators are classified as conventional generators but can count toward renewable portfolio standard requirements.

${ }^{30}$ Where AEO includes two separate projections (advanced and conventional) for any single ReEDS technology, ReEDS uses an average of those figures to represent a medium level of technological advancement.
} 
technology cost projections used in ReEDS reflect technology growth in the AEO Reference scenario. The AEO assumptions include a projected materials price index (MPI) that also influences capital costs over time; we remove the MPI from our projections for better consistency of ReEDS technology representations across both renewable and conventional energy sources. Regional variations and adjustments are included and described in Section 2.4.

In addition to the performance parameters listed above, technologies are differentiated by their ability to provide operating reserves. In general, natural gas plants, especially combustion turbines, are better suited for ramping and reserve provision, while coal and nuclear plants are designed for steady, baseload operation.

The existing fleet in ReEDS is extracted from the ABB unit database. In particular, ReEDS uses summer nameplate capacity, location, and heat rate to characterize the existing fleet. ReEDS uses a modified "average" heat rate for existing stock: a small, technology-specific increase on the full-load heat rate is applied to accommodate for units not always operating at their design point. The modifiers, shown in Table 5, are based on the relationship between full-load and average heat rates for generators in the Ventyx database. Coal adjustment factors also take into account the historical observed fleet-wide heat-rates, which are calculated using EIA form 923.

\section{Table 7. Multipliers Applied to Full-Load Heat Rates to Approximate Heat Rates for Part-} Load Operation

\begin{tabular}{lc}
\hline Technology & Adjustment Factor \\
\hline Coal (all) & 1.0674 \\
Gas-CC & 1.0545 \\
Gas-CT & 1.1502 \\
OGS & 1.1704 \\
\hline
\end{tabular}

Emissions rates from conventional plants are a function of the fuel emission rate and the plant heat rate. Burner-tip emissions rates are shown in Table 6. Because ReEDS does not differentiate coal types, the coal $\mathrm{CO}_{2}$ emissions rate in the model is the average of the bituminous and subbituminous emissions rate. ${ }^{31}$

\footnotetext{
${ }^{31}$ See https://www.eia.gov/tools/faqs/faq.cfm?id=74\&t=11, accessed November 11, 2016.
} 
Table 8. Emissions Rate by Generator Type in Pounds per MMBtua

\begin{tabular}{lllll}
\hline Generator & $\begin{array}{l}\mathrm{SO}_{2} \\
\text { Emissions } \\
\text { Rate }\end{array}$ & $\begin{array}{l}\mathrm{NO}_{\mathbf{x}} \\
\text { Emissions } \\
\text { Rate }\end{array}$ & $\begin{array}{l}\text { Mercury } \\
\text { Emissions } \\
\text { Rate }\end{array}$ & $\begin{array}{l}\mathrm{CO}_{2} \\
\text { Emissions } \\
\text { Rate }\end{array}$ \\
\hline Hydropower & 0 & 0 & 0 & 0 \\
\hline Gas-CT & 0.0098 & 0.15 & 0 & 117.00 \\
\hline Gas-CC & 0.0033 & 0.02 & 0 & 117.00 \\
\hline Gas-CC-CCS & 0.0033 & 0.02 & 0 & 11.70 \\
\hline $\begin{array}{l}\text { Pulverized Coal with } \\
\text { Scrubbers (pre-1995) }\end{array}$ & 0.2 & 0.19 & $4.3612 \mathrm{E}-06$ & 210.55 \\
\hline $\begin{array}{l}\text { Pulverized Coal with } \\
\text { Scrubbers (post-1995) }\end{array}$ & 0.1 & 0.08 & $4.3612 \mathrm{E}-06$ & 210.55 \\
\hline Pulverized Coal & 1.11 & 0.19 & $5.30785 \mathrm{E}-06$ & 210.55 \\
without Scrubbers & 0.0555 & 0.085 & $4.3612 \mathrm{E}-07$ & 210.55 \\
\hline IGCC Coal & 0.0555 & 0.085 & $4.3612 \mathrm{E}-07$ & 21.06 \\
\hline Coal-CCS & 0.299 & 0.1723 & 0 & 137.00 \\
\hline Oil/Gas Steam & 0 & 0 & 0 & 0 \\
\hline Nuclear & 0 & 0 & 0 & 0 \\
\hline Geothermal & 0.08 & 0 & 0 & 0 \\
\hline Biopower & 0 & 0 & 0 & 0 \\
\hline
\end{tabular}

a The assumed $\mathrm{CO}_{2}$ pollutant rate for land-fill gas is zero, so the optimization does not see the emissions benefits of land-fill gas. However, ReEDS can track land-fill gas emissions and the associated benefits as a post-processing calculation. Land-fill gas is assumed to have negative effective carbon emissions because the methane gas would be flared otherwise, thereby it produces the less potent greenhouse gas.

Not all parameter data are given in this document. For those values not included here, see the NREL ATB (NREL 2018a) as well as Short et al. (2011). Financing parameters and calculations are discussed in Section 9.1.

\subsection{Storage and Demand-ide Technologies}

\subsubsection{Storage}

ReEDS includes three utility-scale energy storage options: PSH, batteries, and CAES. All three storage options are capable of load shifting (arbitrage), providing planning and operating reserves, and reducing curtailment of VRE. Load shifting can be done only within a season's representative day, and it is accomplished by charging the reservoir during inexpensive lowdemand time-slices and discharging at peak times. The nameplate capacity of storage is assumed to contribute to planning reserves, and capacity not otherwise committed can be utilized to provide any of the operating reserves products represented in ReEDS (see Section 6 on how reserves are differentiated in ReEDS). 
The ReEDS framework also allows for standalone thermal energy storage, though this technology is inactive by default because its site-specific nature makes it difficult to include in a nationwide optimization framework. This technology is representative of chilled water and ice storage units in buildings where, during the summer, cold water or ice is produced during cooler hours when loads are lower and used to replace or supplement the air conditioning during the warmer hours. Only units for commercial buildings are considered. A supply curve for thermal energy storage units was developed at the NERC subregions level. The model restricts the use of thermal energy storage devices by the regional cooling load profile, with power delivered from thermal energy storage available only during times of high cooling load (e.g., summer afternoons). Thermal energy storage technologies can contribute to operating and planning reserves and reduce curtailment.

Although storage is neither directly linked nor assumed co-located with renewable energy technologies in ReEDS, it can play an important role in reducing curtailed electricity from variable generation resources by charging during time-slices with excess renewable generation. The ability of storage to reduce curtailment is calibrated using the REFlex model (Denholm et al. 2010). For batteries, the curtailment calculation in ReEDS takes into account a finite storage duration $^{32}$, while CAES and PSH are assumed to have sufficient storage to operate as needed within the diurnal variations represented in the model. Similarly, CAES and PSH are not energylimited in performing energy arbitrage across time-slices within a season; thus, there is no explicit storage duration defined for these technologies.

Existing PSH totals $22.2 \mathrm{GW}$, and ReEDS includes the existing 100 MW CAES facility in Alabama. New PSH and CAES are location-restricted due to hydrology and topography (for PSH) and geology (for CAES). In contrast, utility-scale batteries are not restricted to any subset of regions. New PSH potential is derived from FERC license applications since $1980^{33}$ with an additional $750 \mathrm{MW}$ of high-cost "artificial" resource placed in each region to prevent overconstraining PSH expansion in regions without FERC applications while remaining consistent across all regions. In total, there is 108.7 GW FERC-based PSH resource and $100.5 \mathrm{GW}$ artificial PSH resource in ReEDS. FERC-based PSH capital costs are based on O'Connor et al. (2015), and artificial capacity is assumed to be $\$ 3,500 / \mathrm{kW},{ }^{34}$ which is near the upper bound of greenfield PSH resource sized at $750 \mathrm{MW}$ (Figure 19). PSH fixed O\&M costs are also based on O'Connor et al. 2015, and round-trip efficiency is assumed to be $80 \%$ for all existing and new capacity. CAES site development costs are estimated based on the underground geology, where domal salt is the least costly resource at $\$ 1170 / \mathrm{kW}(22.6 \mathrm{GW}$ available), bedded salt is the next most costly resource at $\$ 1,420 / \mathrm{kW}(37.0 \mathrm{GW})$, and aquifers (porous rock) are the most costly resource at $\$ 1,680 / \mathrm{kW}(61.6 \mathrm{GW})$ (Black \& Veatch 2012; Lazard 2016). ${ }^{35}$ CAES requires a natural gas fuel input when supplying power output, and its heat rate is assumed to be $4.91 \mathrm{MMBtu} / \mathrm{MWh}$. This additional fuel input (to the electrical power input during compression) results in a roundtrip efficiency of $125 \%$.

\footnotetext{
${ }^{32}$ The default storage duration is 4 hours but can be specified by the user.

${ }^{33}$ See "Preliminary Permits," FERC, updated October 11, 2016, http://www.ferc.gov/industries/hydropower/geninfo/licensing/pre-permits.asp.

${ }^{34}$ In $2015 \$$

${ }^{35}$ Values in $2016 \$$
} 


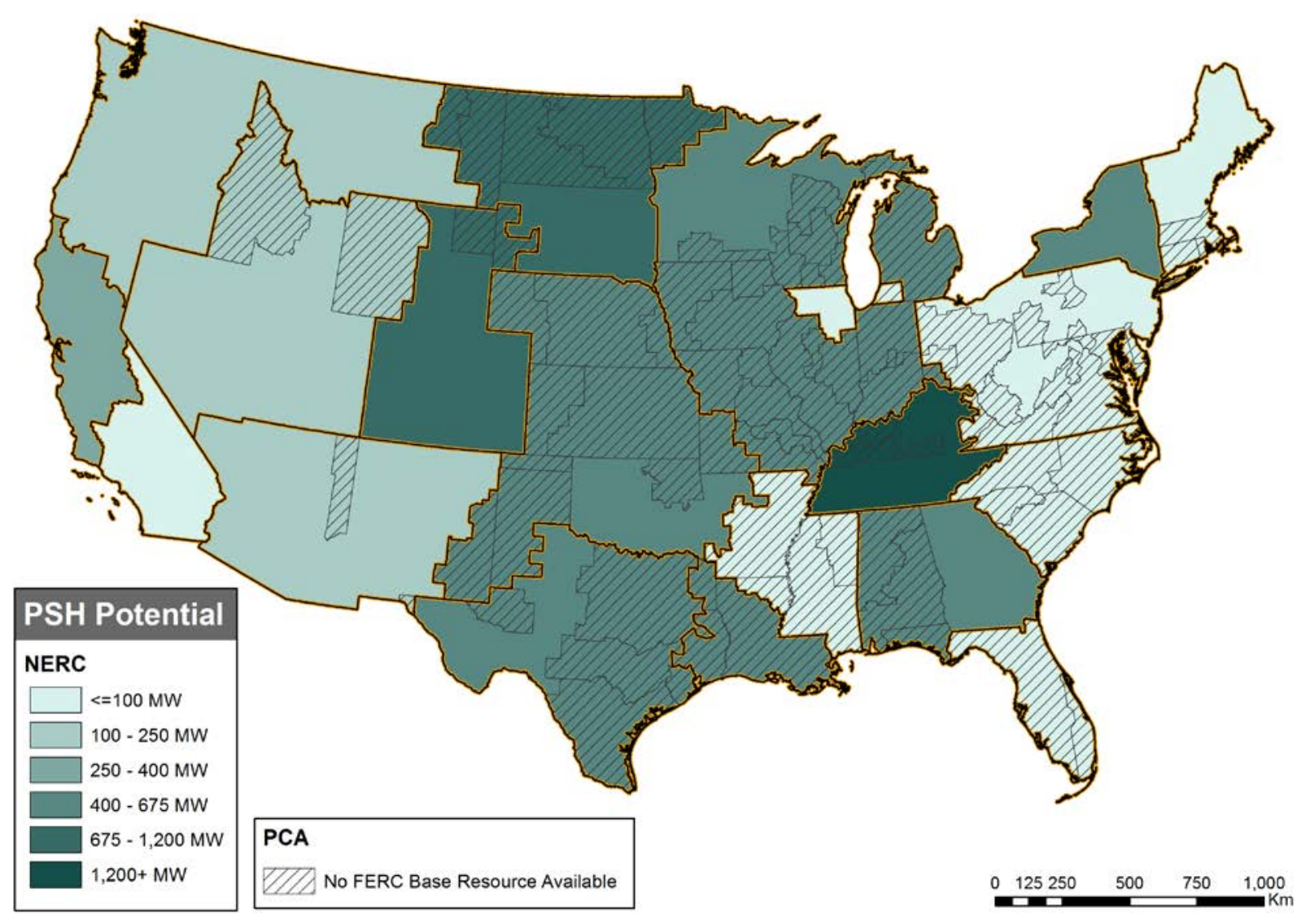

Figure 19. Modeled new PSH resource potential (DOE 2016b)

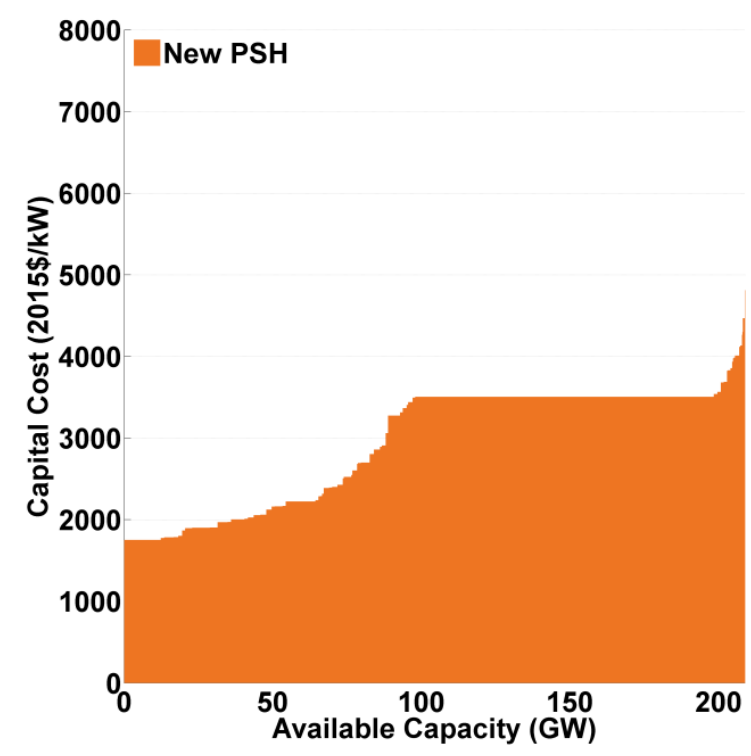

Figure 20. National PSH supply curve of capital cost versus cumulative capacity potential 
Battery cost and performance assumptions are based on lithium-ion battery systems, with costs taken from Cole, Marcy, et al. (2016). Low, mid, and high cost projections are available and will scale with the user-defined battery duration. In contrast to all other generator technologies in ReEDS, which outlast the 20-year evaluation window of the model, the battery is assumed to last 15 years. As a result, its capital cost is uprated by 1.14 to account for the equipment lifetime shortfall. The 1.14 uprate is based on a cash-flow calculation using the default ReEDS financing assumptions. The batteries are assumed to have a round-trip efficiency of 85\% (Lazard 2017). The contribution of storage toward the reserve margin requirement is discussed in Section 6.2.

\subsubsection{Demand Response}

Demand response is not typically active in ReEDS due to the difficulty defining cost and availability for demand response technologies at the resolution available in ReEDS. When active, however, demand response in ReEDS allows shifting of electricity use during hours with high electricity prices or peak load. Demand response is limited by a fraction of electricity load that grows from grows from $2 \%$ in 2018 to $10 \%$ in 2050. In addition to load shifting, demand response can also provide operating reserves.

\subsubsection{Plug-In Electric Vehicles}

Because ReEDS does not include vehicle choice or transportation sector modeling, the deployment of plug-in electric vehicles or plug-in hybrid electric vehicles (and their associated charging infrastructure) is input into ReEDS. ${ }^{36}$ The number of plug-in vehicles is simply translated in the model into additional annual demand for electricity. This annual demand can be met through either a fixed charging profile over the 17 time-slices within a year in ReEDS, an endogenously determined dynamic profile, or some combination of the two. The endogenous profile allows for time-of-day flexibility within seasons but does not allow for load shifting across seasons. Ultimately, this profile is driven by the net load and is determined simultaneously with investment and operation of dispatchable and non-dispatchable resources within each timeslice of ReEDS.

In addition to not modeling vehicle deployment, the ReEDS model does not consider vehicle-togrid or reserve services from vehicles. Plug-in vehicles cannot be used to meet the planning reserve requirements, and, in fact, can increase the reserve requirements through increasing peak demand. Likewise, these vehicles cannot contribute to meeting operating reserve requirements. However, dynamically charged plug-in vehicles are allowed one operational benefit in ReEDSadjusting load to better match generation profiles.

\subsubsection{Energy Efficiency}

Energy efficiency investment decisions are not modeled endogenously, although, past efforts have used exogenously specified trajectories (Bird et al. 2011).

\footnotetext{
${ }^{36}$ For details and an example of how transportation electrification can be represented in ReEDS, see Appendix K of (NREL 2012).
} 


\subsection{Capital Stock}

\subsubsection{Initial Capital Stock, Prescribed Builds and Restrictions}

Existing electricity generation capacity is taken from the ABB Velocity Suite unit database (ABB 2018), unless specific unit information has been determined to be more accurate. Units are mapped to ReEDS technologies based on a combination of fuel source and prime mover of the generation technology, and they are then aggregated to a total capacity for each modeled region ${ }^{37}$ based on net summer capacity of the units. For conventional technologies, cooling technologies are also assigned as described in Section 4.1. Hydropower has additional subcategories to differentiate dispatchability as discussed in Section 2.1.6. In addition, any plants that are listed as under construction or in testing phases in the unit database become prescribed builds. In other words, ReEDS builds any under-construction units, with the units coming online in the anticipated online year listed in the database.

For wind technologies, there are near-term regional growth restrictions to reflect the difficulty of immediately scaling the wind industry. Specifically, regional wind plant construction in the 2018 solve year (which represents 2017-2018) is limited to plants that are planned to be installed before the end of 2018 and are currently designated in the ABB database as "under construction", "permitted", "testing", "undergoing feasibility studies", or "on standby". Wind plant construction in the 2020 solve year (which represents 2019-2020) is limited similarly, except plants designated as "proposed" are allowed in addition to the other categories. The result of these restrictions is that no more than $21 \mathrm{GW}$ of cumulative wind capacity is permitted in the contiguous US in the 2018 solve year, and no more than $83 \mathrm{GW}$ is permitted in the 2018 plus 2020 solve years. This treatment is intended to bound model decisions due to the complex factors and tax incentive rules associated with the wind production tax credit (PTC) (see Section 8.2). After 2020, no wind capacity limits are implemented.

\subsubsection{Retirements}

Renewable energy generator and battery retirements are based on assumed lifetimes. Once a generator has reached its lifetime, it is retired. Renewable energy and battery lifetime assumptions are shown in Table 7 . When renewable energy capacity is retired, the resource associated with that capacity is made available, and ReEDS can choose to rebuild a renewable energy generator using the newly available resource, without the need to rebuild the grid interconnection infrastructure. A consequence of this assumption is that retired renewable capacity can be replaced without incurring interconnection costs and, with all other considerations being equal, re-powered or re-built renewable capacity has lower cost than new "green-field" capacity of the same type ${ }^{38}$ One exception to this procedure is hydropower, which due to assumed non-power requirements is never retired unless there is an announced hydropower capacity retirement listed in the ABB Velocity Suite database (ABB 2018).

\footnotetext{
${ }^{37}$ Plant locations are determined by the county specified in the ABB database or, when county is unavailable, the intersection of the plant location with GIS shapefiles for the ReEDS regions.

${ }^{38}$ ReEDS does not account for any decommissioning costs for renewable or any other capacity type.
} 
Table 9. Lifetimes of Renewable Energy Generators and Batteries

\begin{tabular}{lcl}
\hline Technology & $\begin{array}{c}\text { Lifetime } \\
\text { (Years) }\end{array}$ & Source \\
\hline Land-based Wind & 24 & Wind Vision (DOE 2015) \\
Offshore Wind & 24 & Wind Vision (DOE 2015) \\
Solar Photovoltaic & 30 & SunShot Vision (DOE 2012) \\
Concentrating Solar Power & 30 & SunShot Vision (DOE 2012) \\
Geothermal & 30 & Renewable Electricity Futures Study, Vol. 1 (Mai et \\
& & al. 2012) \\
Hydropower & 100 & Hydropower Vision (DOE 2016b) \\
Biopower & 50 & ABB (2010) \\
Marine Hydrokinetic & 20 & Previsic et al. (2012) \\
Battery & 15 & (Cole, Marcy, et al. 2016) \\
\hline
\end{tabular}

Retirements of existing conventional energy generators in ReEDS are primarily a function of announced retirement dates and technology-specific estimated lifetimes, taken from the ABB Velocity Suite database that seeds ReEDS (ABB 2018). Estimated retirement dates depend on the size of the unit, and the most common lifetimes are shown in Table 8 for plants that are smaller or larger than $100 \mathrm{MW}$. Nuclear plants are assumed to have a mix of 60 and 80 year lifetimes as explained below. All conventional generators that are economically built in ReEDS are given the lifetime of plants greater than $100 \mathrm{MW}$, and these lifetimes are used as necessary when the solution period extends beyond 2050. No refurbishment costs or increased O\&M costs can be applied endogenously to extend the life of nuclear or fossil facilities.

Table 10. Most Common Estimated Lifetimes of Conventional Energy Generators (ABB 2018)

\begin{tabular}{lcc}
\hline Technology & $\begin{array}{c}\text { Lifetime less than } \\
\text { (Years) }\end{array}$ & $\begin{array}{c}\text { Lifetime greater or equal } \\
\text { to 100 } \mathbf{~ M W ~ ( Y e a r s ) ~}\end{array}$ \\
\hline Gas Combustion Turbine & 50 & 50 \\
Gas Combined Cycle and CCS & 60 & 60 \\
Coal, all techs, including cofired & 65 & 75 \\
Oil-Gas-Steam & 50 & 75 \\
Biopower & 50 & 50 \\
Compressed-Air Energy Storage & 100 & 100 \\
\hline
\end{tabular}

In addition to age-based retirements, additional retirements can occur for coal technologies based on plant utilization. ReEDS does not have a generalized framework for endogenous retirements, so modeled utilization-based coal retirements represent a proxy for economic considerations that might accelerate coal retirements. Utilization-based retirements are implemented by comparing each BA's coal annual capacity factor to a minimum utilization threshold. If the capacity factor is beneath the threshold in a given year, capacity is retired such that the remaining BA capacity, assuming the same annual production, would operate at the capacity factor threshold. 
The utilization-based retirement is not active until 2020 and becomes increasingly stringent over time. ${ }^{39}$ The oldest and least efficient extant units are retired preferentially in this scheme.

ReEDS includes four exogenous nuclear retirement scenario settings. The four settings are defined by first dividing the currently operating reactors into two bins. Any plants participating in a restructured market and all single-reactor plants are assigned to Bin 1. The remaining plants, which are all multi-reactor plants in a traditional regulated environment, are assigned to Bin 2. The only exception to these categorizations is that plants that have announced their intent to seek a second operating license renewal from the Nuclear Regulatory Commission (NRC) are included in Bin 2. Table 9 breaks down the bins and shows total capacity in each case. These bins are categorizations that reflect the current discussion pointing to more economic pressure on restructured and single-reactor units (Haratyk 2017; Steckler 2017).

Table 11. Amount of Nuclear Power Plant Capacity (in GW) in Each Bin

\begin{tabular}{|l|r|r} 
Plant Category & Bin 1 & Bin 2 \\
\hline Restructured, Single Reactor & 8.7 & \\
\hline Restructured, Multi Reactor & 27.5 & $2.0^{\mathrm{a}}$ \\
\hline Regulated, Single Reactor & 15.7 & \\
\hline Regulated, Multi Reactor & & 42.1 \\
\hline Total & $\mathbf{5 1 . 9}$ & $\mathbf{4 4 . 1}$ \\
\hline
\end{tabular}

a The Peach Bottom plant $(2.0 \mathrm{GW})$ has announced its intent to seek a second license renewal. Therefore, it is moved from Bin 1 to Bin 2 even though it is in a restructured market.

The four nuclear retirement scenarios are: (1) Early Retirement, (2) 60-Year Lifetime, (3) MidCase (mix of 60 and 80-year lifetimes), and (4) 80-Year Lifetime (see Table 10). The Early Retirement scenario retires nuclear capacity in Bin 1 when its lifetime reaches 50 years, and capacity in Bin 2 at 60 years. The 50-year lifetime emulates the retirements of recent plants that did have a renewed operating license but retired before they reached the end of their license. The 60 -Year Lifetime scenario retires all plants at 60 years, which would be at the end of their first operating license renewal. The 80 -Year Lifetime scenario retires all plants at 80 years, simulating a successful completion of a second operating license renewal from the NRC. The Mid-Case scenario serves as the default setting in ReEDS and retires capacity in Bin 1 at 60 years and capacity in Bin 2 at 80 years.

Table 12. Nuclear Power Plant Lifetime for Each Scenario by Bin (years)

\begin{tabular}{|l|c|c|}
\hline Scenario Name & Bin 1 & Bin 2 \\
\hline Early Retirement & 50 & 60 \\
\hline 60-Year Lifetime & 60 & 60 \\
\hline Mid-Case & 60 & 80 \\
\hline 80-Year Lifetime & 80 & 80 \\
\hline
\end{tabular}

\footnotetext{
39 The capacity factor threshold starts at 0.01 in 2020 , increases linearly to 0.50 in 2040 , and stays at that value until 2050.
} 


\subsubsection{Growth Penalties}

We impose penalties on (1) component capital costs for all technologies based on excessive national growth and (2) installation costs for wind, CSP, and utility-scale PV based on excessive regional growth. ${ }^{40}$ The growth penalties are functions of the nominal installed capital cost and the increase in new construction over previous years.

Similar to EIA (EIA 2017), we use a step-wise growth penalty cost function shown in Figure 20. The rate of installations can increase by $44 \%$ of the base capacity in every model year before growth cost penalties apply. The base capacity is defined as the maximum of (1) $90 \%$ of the previous base, (2) the minimum base, and (3) installations and upgrades from the previous model year. Table 11 summarizes the minimum base values used.

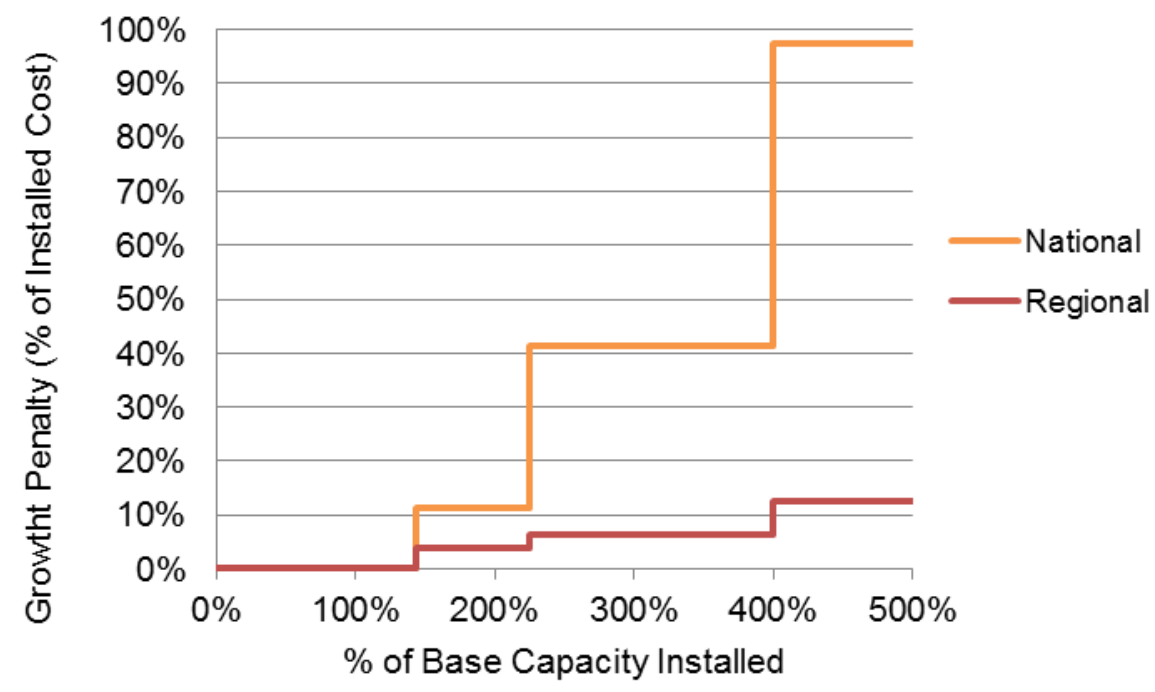

Figure 21. National and regional growth penalty cost curve

\footnotetext{
${ }^{40}$ For wind, CSP, and UPV, we assume the breakdown of total cost is $75 \%$ for components and $25 \%$ for installation.
} 
Table 13. Minimum Base Values for Assessing Excessive Growth

\begin{tabular}{|c|c|c|c|}
\hline \multirow{2}{*}{$\begin{array}{l}\text { Technology } \\
\text { Conventionala }\end{array}$} & \multirow{2}{*}{$\begin{array}{l}\text { Region } \\
\text { National }\end{array}$} & \multicolumn{2}{|c|}{ Minimum Base (MW) } \\
\hline & & 400: & Geothermal \\
\hline & & 500: & $\begin{array}{l}\text { Natural gas combustion turbine, } \\
\text { natural gas combined cycle with } \\
\text { CCS, coal with CCS, and marine } \\
\text { hydrokinetic }\end{array}$ \\
\hline & & 1,000: & $\begin{array}{l}\text { natural gas combined cycle, } \\
\text { hydro, biopower }\end{array}$ \\
\hline & & 2,000: & Nuclear \\
\hline \multirow[t]{2}{*}{ Wind } & National & $1,000^{\mathrm{b}}$ & \\
\hline & $\begin{array}{l}\text { Resource } \\
\text { region }\end{array}$ & $200^{c}$ & \\
\hline \multirow[t]{2}{*}{ CSP } & National & $1,000^{d}$ & \\
\hline & $\begin{array}{l}\text { Resource } \\
\text { region }\end{array}$ & $200^{e}$ & \\
\hline \multirow[t]{2}{*}{ Utility-scale PV } & National & $1,000^{d}$ & \\
\hline & BA & $600^{f}$ & \\
\hline
\end{tabular}

a Minimum base for conventional plants based on the approximate size of a new plant

${ }^{b}$ Roughly based on the average size of annual wind installations in the United States from 1999 to 2005

c Assuming one wind farm built in a single wind resource region is typically about $200 \mathrm{MW}$

d Using the same value as wind

e Assuming one CSP system built in a single CSP resource region is typically about $200 \mathrm{MW}$

${ }^{f}$ Assuming three PV systems, about $200 \mathrm{MW}$ each, built in a single BA

\subsection{Regional Parameter Variations and Adjustments}

For most generation technologies, regional cost multipliers are applied to reflect variations in installation costs across the United States (see Figure 22). These regional multipliers are applied to the base overnight capital cost presented in earlier sections. The regional multipliers are technology-specific and are derived primarily from the EIA/Leidos Engineering report (EIA 2016) that is the source of capital cost assumptions for the NEMS model. While the regional costs presented in the EIA/Leidos Engineering report are based on particular cities, the regional multipliers for ReEDS are calculated by interpolating between these cities and using the average value over the ReEDS regions for each technology. For technologies such as CSP that are not included in the newer report, we rely on the older EIA/Science Applications International Corporation report (EIA 2013). 


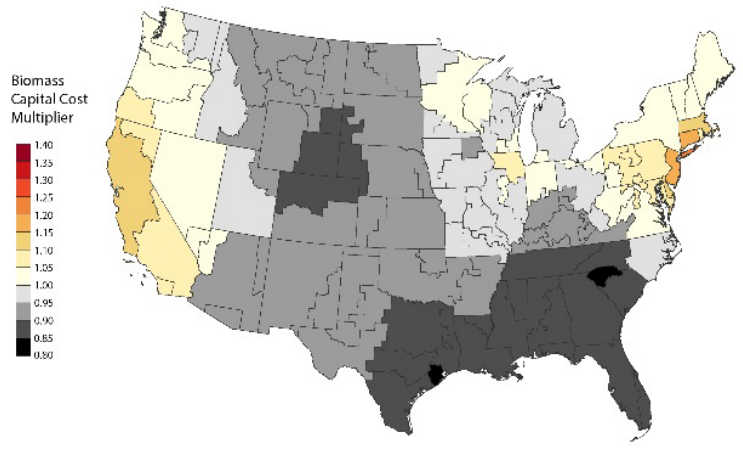

(a)

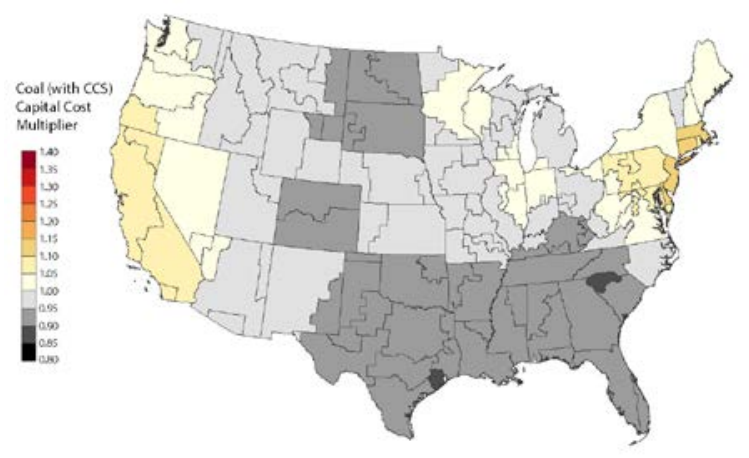

(c)

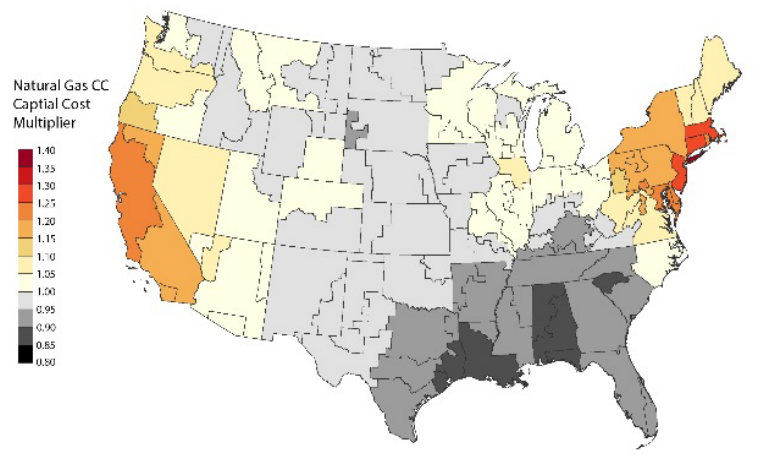

(e)

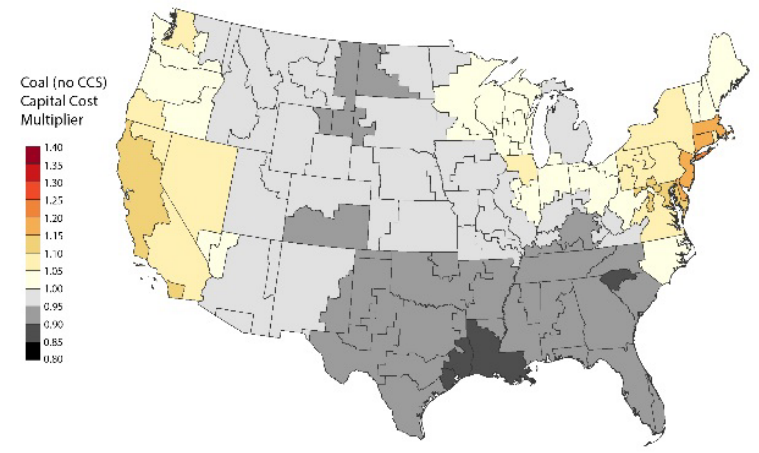

(b)

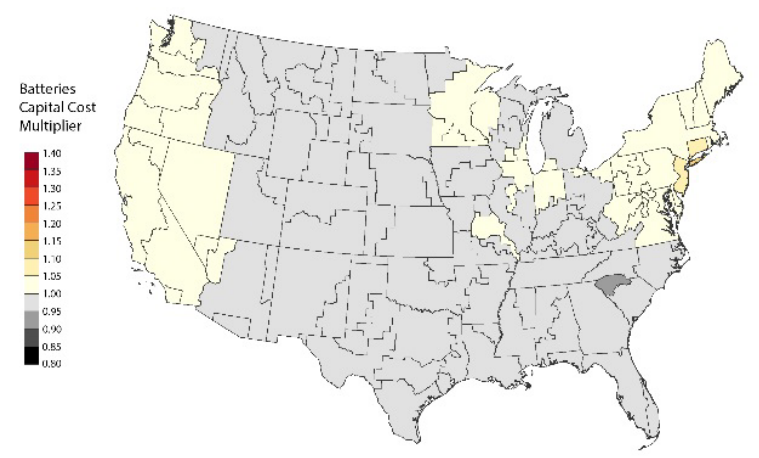

(d)

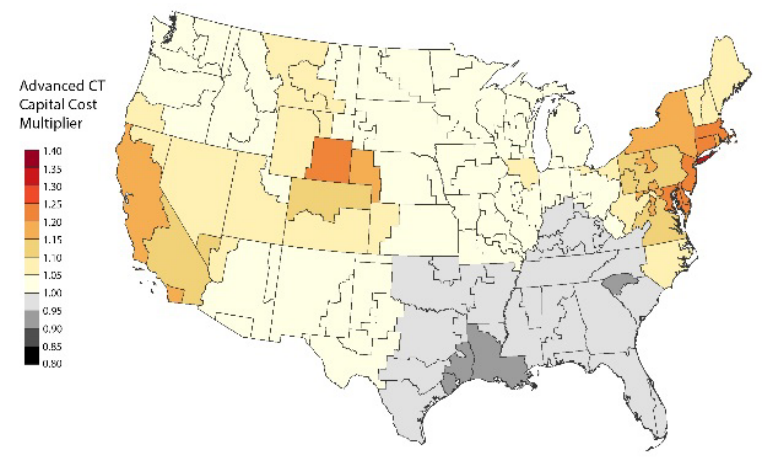

(f) 


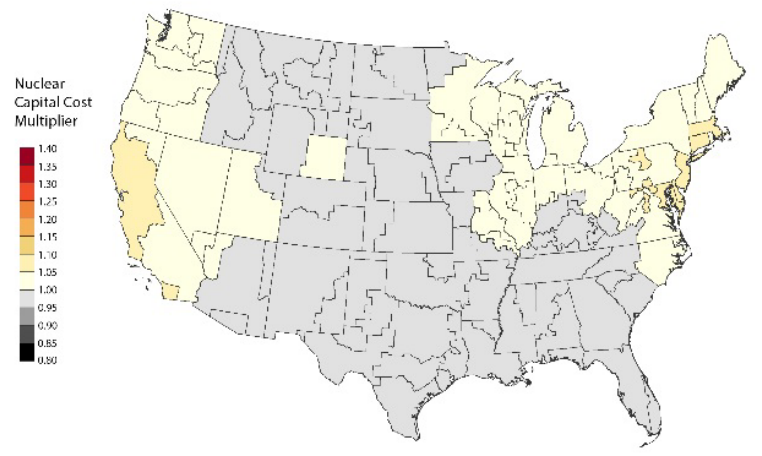

(g)

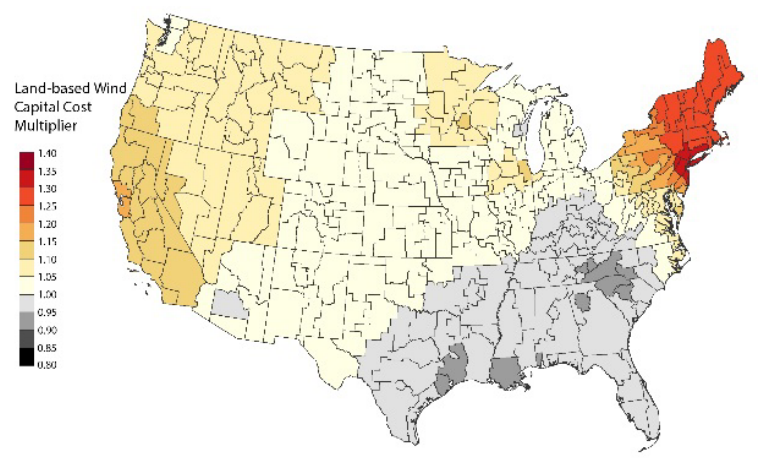

(i)

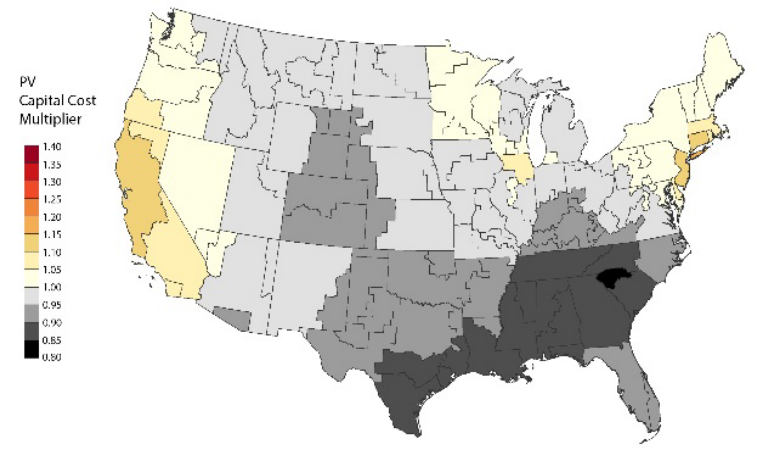

(h)

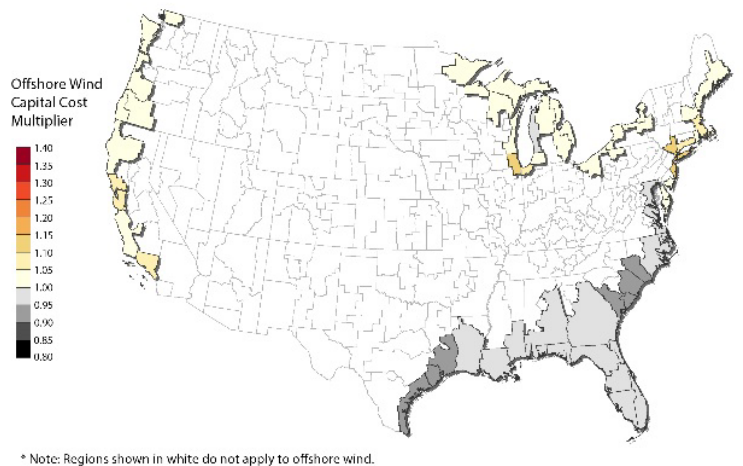

(j)

Figure 22. Maps of regional capital cost multipliers for the various technology types

Regions shown in white in (j) do not apply to offshore wind. 


\section{Fuel Prices}

Natural gas, coal, and uranium prices in ReEDS are based on the most recent AEO. Coal prices are provided for each of the nine EIA census divisions. Low and high natural gas price alternatives are taken from the Low and High Oil and Gas Resource and Technology scenarios. ReEDS includes only a single national uranium price trajectory. Base fuel price trajectories are shown in Figure 22 for the AEO2018 (EIA 2018). Biomass fuel prices are represented using supply curves with five bins in each region. The costs and resource availability are based on the U.S. Billion-Ton Update study (DOE 2011). Biomass costs range from \$1.91/MMBtu to \$18.33/MMBtu (in 2014\$).
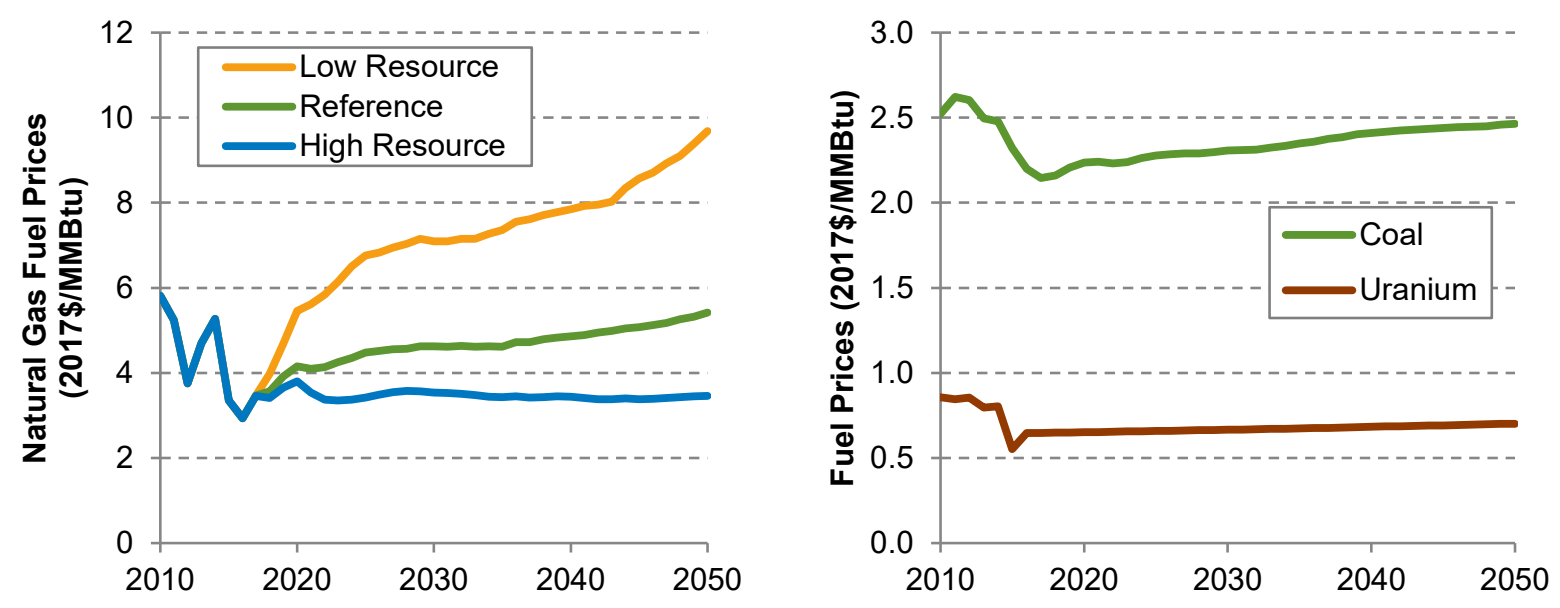

Figure 23. Fuel price assumptions

Coal and uranium are assumed to be perfectly inelastic; the price is pre-determined and insensitive to the ReEDS demand for the fuel. With natural gas, however, the price and demand are linked. Actual natural gas prices in ReEDS are based on the AEO scenario prices but are not exactly the same; instead, they are price-responsive to ReEDS natural gas demand. In each year, each census division is characterized by a price-demand "set point" taken from the AEO Reference scenario but also by two elasticity coefficients: regional $\left(\beta_{\mathrm{r}}\right)$ and national $\left(\beta_{\mathrm{n}}\right)$ elasticity coefficients for the rate of regional price change with respect to (1) the change in the regional gas demand from its setpoint and (2) the overall change in the national gas demand from the national price-demand set point respectively. The set of regional and national elasticity coefficients are developed through a linear regression analysis across an ensemble of AEO scenarios ${ }^{41,42}$ to estimate changes in fuel prices driven solely by electric sector natural gas demand (as described in Logan et al. (2013) and Cole, Medlock III, and Jani (2016), though the coefficients have since been updated for the latest AEO data). Though there is no explicit representation of natural gas demand beyond the electricity sector, the regional supply curves reflect natural gas resource, infrastructure, and nonelectric sector demand assumptions embedded within the AEO modeling. For details, see the section in the appendix titled, Natural Gas Supply Curves.

\footnotetext{
${ }^{41}$ Supply curves are nonlinear in practice, but a linear regression approximation has been observed to be satisfactory under most conditions.

42 The elasticity coefficients are derived from all scenarios of AEO 2018, but the price-demand set points are taken from any one single scenario of the AEO.
} 
In addition to the natural gas supply curve representation, ReEDS includes targeted fuel price foresight for new natural gas capacity investments. Specifically, the effective investment cost for new natural gas combined cycle capacity includes an extra term representing the present value of the difference between flat natural gas prices and expected future natural gas prices.

Finally, the natural gas fuel prices include a seasonal price adjustor, making winter prices higher than the natural gas prices seen during the other seasons of the year. For details, see the section in the appendix titled, Seasonal Natural Gas Price Adjustments. 


\section{Thermal Cooling Water}

In addition to representing a full suite of power generation technologies, ReEDS further differentiates power technologies by cooling system type to better characterize and constrain electric sector water requirements. The cooling system impacts the cost and performance of the thermal generators, and water withdrawal and consumption rates are used in conjunction with water availability and cost to appropriately constrain and track the water requirements of new capacity expansion. The ReEDS cooling water formulation is discussed in Macknick et al. (2015), which forms the basis of this section.

\subsection{Cooling System Characteristics}

Cooling systems implemented in the ReEDS model fall into one of four categories: oncethrough, pond, recirculating, and dry cooling systems. ${ }^{43}$ ReEDS can then select the optimal cooling technology amongst allowable power-cooling technology combinations for any new thermal generating capacity it chooses to build. Individual power plant cooling systems are derived from a database developed by the (Union of Concerned Scientists 2012). Within each ReEDS BA, existing generation capacity by power generation technology is disaggregated into power-cooling system technology categories based on 2008 generation data from the database. When the database does not contain information on cooling systems for certain fuel types within a particular BA, cooling technology is assumed using the following rules:

1. If there are other units of the same fuel type at the same plant with assigned cooling technology, assume the same cooling technology.

2. If (1) does not apply and there are other thermal units at the same plant with assigned cooling technology, assume the same cooling technology.

3. If neither (1) nor (2) apply, and no additional information is available, assume recirculating cooling.

Table 12 lists the allowable power-cooling technology combinations under the current cooling technology representation. Allowed combinations must be consistent with the existing fleet and reflect allowed cooling technologies for new builds. New builds in ReEDS are not permitted to use once-through cooling due to pending U.S. Environmental Protection Agency (EPA) regulations and industry trends, so technologies that do not exist using once-through cooling (e.g., CCS technologies) are not allowed to use once-through cooling. In addition, new capacity cannot choose to use cooling ponds because designs are too site-specific for a reasonable general model representation. Only existing pond cooling facilities are characterized. Dry cooling is not allowed for nuclear or CCS due to their exceptionally large cooling requirements.

\footnotetext{
${ }^{43}$ Once-through cooling uses water as a medium to exchange heat without the water undergoing a phase change (i.e., evaporation), with most withdrawn water returned to the water source. Pond cooling use a similar process but with a static cooling pond as a thermal reservoir instead of a flowing water source. Recirculating cooling uses evaporative cooling with water to reduce water withdrawal needs, but most withdrawn water is "consumed", as it evaporates to the atmosphere without being returned directly to the water source. Dry cooling uses air instead of water as a heat exchange medium.
} 
Table 14. Allowed Power and Cooling Technology Combinations in ReEDS

\begin{tabular}{|c|c|c|c|c|c|}
\hline \multirow[b]{2}{*}{ Power Technology } & \multicolumn{5}{|c|}{ Cooling Technology Allowed } \\
\hline & $\begin{array}{l}\text { Once- } \\
\text { Through }\end{array}$ & Recirculating & Dry & $\begin{array}{l}\text { Cooling } \\
\text { Pond } \\
\text { (existing } \\
\text { fleet only) }\end{array}$ & None \\
\hline Hydropower & No & No & No & No & Yes \\
\hline Gas-CT & No & No & No & No & Yes \\
\hline Gas-CC & Yes & Yes & Yes & Yes & No \\
\hline Gas-CC-CCS & No & Yes & Yes & No & No \\
\hline $\begin{array}{l}\text { Pulverized coal } \\
\text { with scrubbers } \\
\text { (pre-1995) }\end{array}$ & Yes & Yes & Yes & Yes & No \\
\hline $\begin{array}{l}\text { Pulverized coal } \\
\text { without scrubbers }\end{array}$ & Yes & Yes & Yes & Yes & No \\
\hline $\begin{array}{l}\text { Pulverized coal } \\
\text { with scrubbers (post- } \\
\text { 1995) }\end{array}$ & Yes & Yes & Yes & Yes & No \\
\hline IGCC coal & Yes & Yes & Yes & Yes & No \\
\hline Coal-CCS & Yes & Yes & No & No & No \\
\hline Oil/gas steam & Yes & Yes & Yes & Yes & No \\
\hline Nuclear & Yes & Yes & No & Yes & No \\
\hline Geothermal ${ }^{44}$ & No & No & No & No & Yes \\
\hline Biopower & Yes & Yes & Yes & Yes & No \\
\hline $\begin{array}{l}\text { Cofired coal } \\
\text { (pre-1995) }\end{array}$ & Yes & Yes & Yes & Yes & No \\
\hline $\begin{array}{l}\text { Cofired coal } \\
\text { (post-1995) }\end{array}$ & Yes & Yes & Yes & Yes & No \\
\hline Landfill gas & No & No & No & No & Yes \\
\hline PV & No & No & No & No & Yes \\
\hline Wind & No & No & No & No & Yes \\
\hline CSP & No & Yes & Yes & No & No \\
\hline
\end{tabular}

${ }^{4444}$ Geothermal capacity uses the 'none' cooling technology designation because its cooling requirements are defined instead by the geothermal resource subcategory (see Section 2.1.5) and whether the resource is assumed to use a binary or flash system configuration. 
The cooling system affects capital and O\&M costs through cost multipliers, and performance effects are implemented using heat rate multipliers. Cost and performance characteristics are derived from Woldeyesus, Macknick, and Colman (forthcoming), and apply to baseline input data assuming recirculating cooling (Black \& Veatch 2012). In general, once-through cooling systems are the least expensive and have the highest efficiencies. Recirculating cooling systems generally have higher capital and operating costs and are less efficient than once-through cooling systems, but they are less expensive and more efficient than dry cooling systems. Pond-cooled systems have various configurations that can resemble either recirculating or once-through cooling systems; thus, they generally have characteristics that fall between those of recirculating and once-through systems. Table 13- Table 17 summarize the cooling technology parameterization by generation technology type.

Table 15. Capital Cost Multipliers for Power-Cooling Technology Combinations

\begin{tabular}{lllll}
\hline & $\begin{array}{l}\text { Once- } \\
\text { Through }\end{array}$ & Recirculating & Dry & $\begin{array}{l}\text { Cooling } \\
\text { Pond }\end{array}$ \\
\hline Gas-CC & 0.978 & 1.000 & 1.102 & 0.978 \\
Gas-CC-CCS & $\mathrm{n} / \mathrm{a}$ & 1.000 & $\mathrm{n} / \mathrm{a}$ & $\mathrm{n} / \mathrm{a}$ \\
Pulverized coal with scrubbers (pre-1995) & 0.981 & 1.000 & 1.045 & 0.981 \\
Pulverized coal without scrubbers & 0.981 & 1.000 & 1.045 & 0.981 \\
Pulverized coal with scrubbers & 0.981 & 1.000 & 1.045 & 0.981 \\
(post-1995) & 0.988 & 1.000 & 1.033 & 0.988 \\
IGCC coal & 0.982 & 1.000 & $\mathrm{n} / \mathrm{a}$ & $\mathrm{n} / \mathrm{a}$ \\
Coal-CCS & 0.981 & 1.000 & 1.045 & 0.981 \\
Oil/gas steam & 0.981 & 1.000 & $\mathrm{n} / \mathrm{a}$ & 0.981 \\
Nuclear & 0.981 & 1.000 & 1.045 & 0.981 \\
Biopower & 0.981 & 1.000 & 1.045 & 0.981 \\
Cofired coal (pre-1995) & 0.981 & 1.000 & 1.045 & 0.981 \\
Cofired coal (post-1995) & $\mathrm{n} / \mathrm{a}$ & 1.000 & 1.050 & $\mathrm{n} / \mathrm{a}$ \\
\hline CSP & & &
\end{tabular}


Table 16. Operations and Maintenance Cost Multipliers for Power-Cooling Technology Combinations

\begin{tabular}{lllll}
\hline & $\begin{array}{l}\text { Once- } \\
\text { Through }\end{array}$ & Recirculating & Dry & $\begin{array}{l}\text { Cooling } \\
\text { Pond }\end{array}$ \\
\hline Gas-CC & 0.996 & 1.000 & 1.021 & 0.996 \\
Gas-CC-CCS & $\mathrm{n} / \mathrm{a}$ & 1.000 & $\mathrm{n} / \mathrm{a}$ & $\mathrm{n} / \mathrm{a}$ \\
Pulverized coal with scrubbers (pre-1995) & 0.989 & 1.000 & 1.051 & 0.989 \\
Pulverized coal without scrubbers & 0.989 & 1.000 & 1.051 & 0.989 \\
Pulverized coal without scrubbers (post-1995) & 0.989 & 1.000 & 1.051 & 0.989 \\
IGCC coal & 0.996 & 1.000 & 1.021 & 0.996 \\
Coal-CCS & 0.993 & 1.000 & $\mathrm{n} / \mathrm{a}$ & $\mathrm{n} / \mathrm{a}$ \\
Oil/gas steam & 0.989 & 1.000 & 1.051 & 0.989 \\
Nuclear & 0.989 & 1.000 & $\mathrm{n} / \mathrm{a}$ & 0.989 \\
Biopower & 0.989 & 1.000 & 1.051 & 0.989 \\
Cofired coal (pre-1995) & 0.989 & 1.000 & 1.051 & 0.989 \\
Cofired coal (post-1995) & 0.989 & 1.000 & 1.051 & 0.989 \\
CSP & $\mathrm{n} / \mathrm{a}$ & 1.000 & 1.050 & $\mathrm{n} / \mathrm{a}$ \\
\hline
\end{tabular}

Table 17. Heat Rate Multipliers for Power-Cooling Technology Combinations

\begin{tabular}{lllll}
\hline & $\begin{array}{l}\text { Once- } \\
\text { Through }\end{array}$ & Recirculating & Dry & $\begin{array}{l}\text { Cooling } \\
\text { Pond }\end{array}$ \\
\hline Gas-CC & 0.980 & 1.000 & 1.050 & 0.980 \\
Gas-CC-CCS & $\mathrm{n} / \mathrm{a}$ & 1.000 & $\mathrm{n} / \mathrm{a}$ & $\mathrm{n} / \mathrm{a}$ \\
Pulverized coal with scrubbers (pre-1995) & 0.985 & 1.000 & 1.050 & 0.985 \\
Pulverized coal without scrubbers & 0.985 & 1.000 & 1.050 & 0.985 \\
Pulverized coal with scrubbers (post-1995) & 0.985 & 1.000 & 1.050 & 0.985 \\
IGCC Coal & 0.980 & 1.000 & 1.050 & 0.98 \\
Coal-CCS & 0.800 & 1.000 & $\mathrm{n} / \mathrm{a}$ & $\mathrm{n} / \mathrm{a}$ \\
Oil/Gas Steam & 0.985 & 1.000 & 1.050 & 0.985 \\
Nuclear & 0.973 & 1.000 & $\mathrm{n} / \mathrm{a}$ & 0.973 \\
Biopower & 0.985 & 1.000 & 1.050 & 0.985 \\
Cofired Coal (pre-1995) & 0.985 & 1.000 & 1.050 & 0.985 \\
Cofired Coal (post-1995) & 0.985 & 1.000 & 1.050 & 0.985 \\
CSP & $\mathrm{n} / \mathrm{a}$ & 1.000 & $1.000^{\mathrm{a}}$ & $\mathrm{n} / \mathrm{a}$ \\
\hline
\end{tabular}

a There are currently no data to inform a heat rate multiplier for CSP.

Water withdrawal and consumption rates for power technology-cooling system combinations are defined by volumes of water withdrawn and consumed per unit of electricity generation (i.e., gallons per MWh of electricity generated) (Macknick et al. 2012). 
Table 18. Water Withdrawal Rates for Power-Cooling Technology Combinations (gal/MWh)

\begin{tabular}{lllll}
\hline & $\begin{array}{l}\text { Once- } \\
\text { Through }\end{array}$ & Recirculating & Dry & $\begin{array}{l}\text { Cooling } \\
\text { Pond }\end{array}$ \\
\hline Gas-CC & 11,380 & 255 & 2 & 5950 \\
Gas-CC-CCS & $\mathrm{n} / \mathrm{a}$ & 506 & $\mathrm{n} / \mathrm{a}$ & $\mathrm{n} / \mathrm{a}$ \\
Pulverized coal with scrubbers (pre-1995) & 36,350 & 1,005 & 0 & 12,225 \\
Pulverized coal without scrubbers & 36,350 & 1,005 & 0 & 12,225 \\
Pulverized coal with scrubbers (post-1995) & 27,088 & 587 & 0 & 17,914 \\
IGCC Coal & 18,136 & 393 & 0 & 9,635 \\
Coal-CCS & 56,483 & 1,224 & $\mathrm{n} / \mathrm{a}$ & $\mathrm{n} / \mathrm{a}$ \\
Oil/gas steam & 35,000 & 1,203 & 0 & 5,950 \\
Nuclear & 44,350 & 1,101 & $\mathrm{n} / \mathrm{a}$ & 7,050 \\
Biopower & 35,000 & 878 & 0 & 450 \\
Cofired coal (pre-1995) & 35,000 & 878 & 0 & 450 \\
Cofired coal (post-1995) & 35,000 & 878 & 0 & 450 \\
CSP trough/tower & $\mathrm{n} / \mathrm{a}$ & $906 / 786$ & $78 / 26$ & $\mathrm{n} / \mathrm{a}$ \\
\hline
\end{tabular}

Table 19. Water Consumption Rates for Power-Cooling Technology Combinations (gal/MWh)

\begin{tabular}{lllll}
\hline & $\begin{array}{l}\text { Once- } \\
\text { Through }\end{array}$ & Recirculating & Dry & $\begin{array}{l}\text { Cooling } \\
\text { Pond }\end{array}$ \\
\hline Gas-CC & 100 & 205 & 2 & 240 \\
Gas-CC-CCS & $\mathrm{n} / \mathrm{a}$ & 378 & $\mathrm{n} / \mathrm{a}$ & $\mathrm{n} / \mathrm{a}$ \\
Pulverized coal with scrubbers (pre-1995) & 250 & 687 & 0 & 545 \\
Pulverized coal without scrubbers & 250 & 687 & 0 & 545 \\
Pulverized coal with scrubbers (post-1995) & 113 & 479 & 0 & 545 \\
IGCC coal & 90 & 380 & 0 & 32 \\
Coal-CCS & 217 & 921 & $\mathrm{n} / \mathrm{a}$ & $\mathrm{n} / \mathrm{a}$ \\
Oil/gas steam & 240 & 826 & 0 & 240 \\
Nuclear & 269 & 672 & $\mathrm{n} / \mathrm{a}$ & 610 \\
Biopower & 300 & 553 & 0 & 390 \\
Cofired coal (pre-1995) & 300 & 553 & 0 & 390 \\
Cofired coal (post-1995) & 300 & 553 & 0 & 390 \\
CSP trough/tower & $\mathrm{n} / \mathrm{a}$ & $906 / 786$ & $78 / 26$ & $\mathrm{n} / \mathrm{a}$ \\
\hline
\end{tabular}

ReEDS also allows capacity to upgrade from more withdrawal-intensive cooling technologies to less withdrawal-intensive technologies. Doing so could be advantageous if the value of reducing water needs in water-constrained regions offsets any cost and performance penalty. 


\subsection{Water Access Constraints}

Water availability is constrained in each BA through a requirement for new capacity to purchase sufficient water access to satisfy the withdrawal requirements of the power technology-cooling system combination and the size of the facility (Macknick et al. 2015). Sufficient water access is defined as enough water for a power plant to operate at full capacity at any time throughout the year. This conservative method ensures new power plant builds have secured more than enough water than they would realistically use in a year so that they can operate at maximum output during the annual low-flow condition. The ReEDS model calculates actual water withdrawals and consumption separately from the purchases of water access based on the actual operation of the power fleet. It is important to distinguish between constraining water access, which affects capacity expansion only, and constraining operational water availability, which would influence operation. Additional constraints described below are designed to represent operational water availability limits.

All water constraints in ReEDS are implemented on withdrawals but not consumption. Though consumption is important to physical water availability downstream and overall impacts on the water system, water withdrawals are used to define legal availability of water to the power sector, which is assumed to be an important driver of capacity expansion decisions. Furthermore, baseline water availability data are defined as water available for future power sector water withdrawal, so enforcing constraints on withdrawal is the most internally consistent use of this data set. Future analysis could explore constraints on consumption, but doing so comprehensively and consistently would require new data development.

\subsection{Cooling Water Availability and Cost}

Each BA has unique water access availability and cost for up to five resource categories: unappropriated freshwater, appropriated freshwater (western United States only), fresh groundwater, brackish groundwater, and wastewater. ${ }^{45}$ Multiple types of water resources can be purchased to meet the demand for new generation capacity. Water access availability of retiring power plants is returned to the pool of available water access for new power plants at the price of appropriated water access.

Water availability and cost are defined using supply curves developed by Tidwell, Zemlick, and Klise (2013). Resource assessment methodologies are unique to each water category as detailed in that report as well as by Macknick et al. (2015). Water access costs include capital and O\&M costs necessary to procure each water type. Where available, unappropriated freshwater is the lowest-cost resource, typically followed by fresh groundwater, appropriated freshwater, wastewater, and brackish groundwater. Many regions in the West have no unappropriated freshwater and limited fresh groundwater and appropriated freshwater, making these regions more likely to require higher-cost wastewater or brackish groundwater resources. Figure 23 shows regional water availability and cost for each type of water represented in ReEDS.

\footnotetext{
${ }^{45}$ Unappropriated freshwater is fresh surface water not previously assigned by a prior rights or access agreement. Appropriated freshwater is fresh surface water where water rights are presently owned, but the resource has been identified by Tidwell et al. (2013) as low-value and thus potentially available for sale to the power sector. Groundwater is defined as fresh or brackish based on salinity, with brackish groundwater typically deeper underground and more expensive to access. Wastewater resource is the identified portion of wastewater treatment plant discharge that is available for power plant cooling.
} 
Unappropriated Freshwater Availability

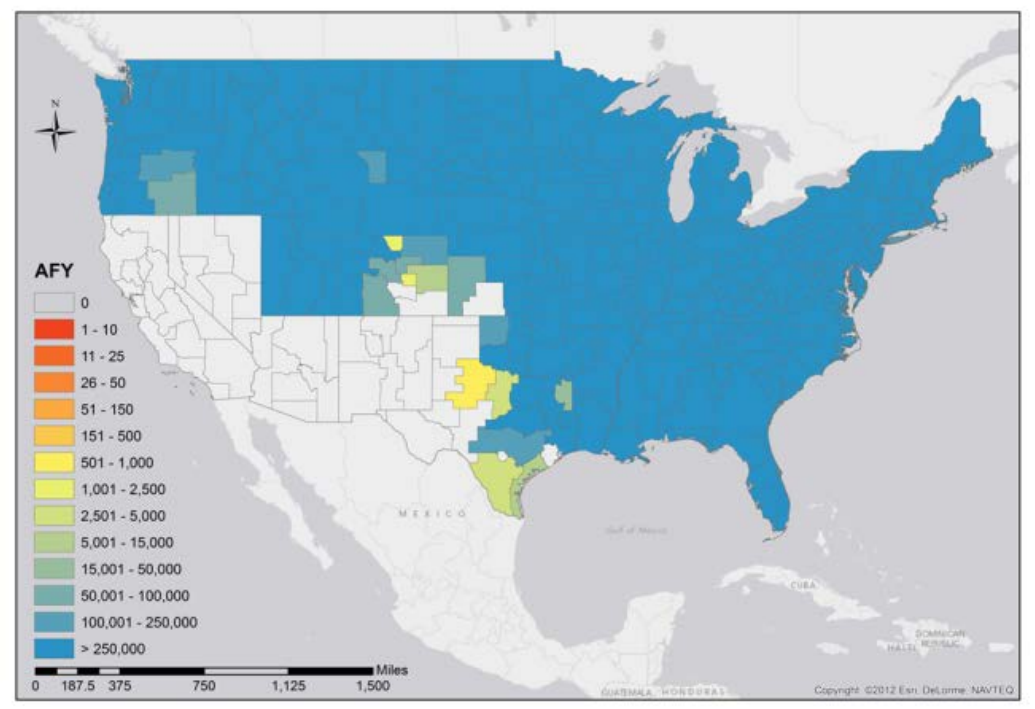

Fresh Groundwater Availability
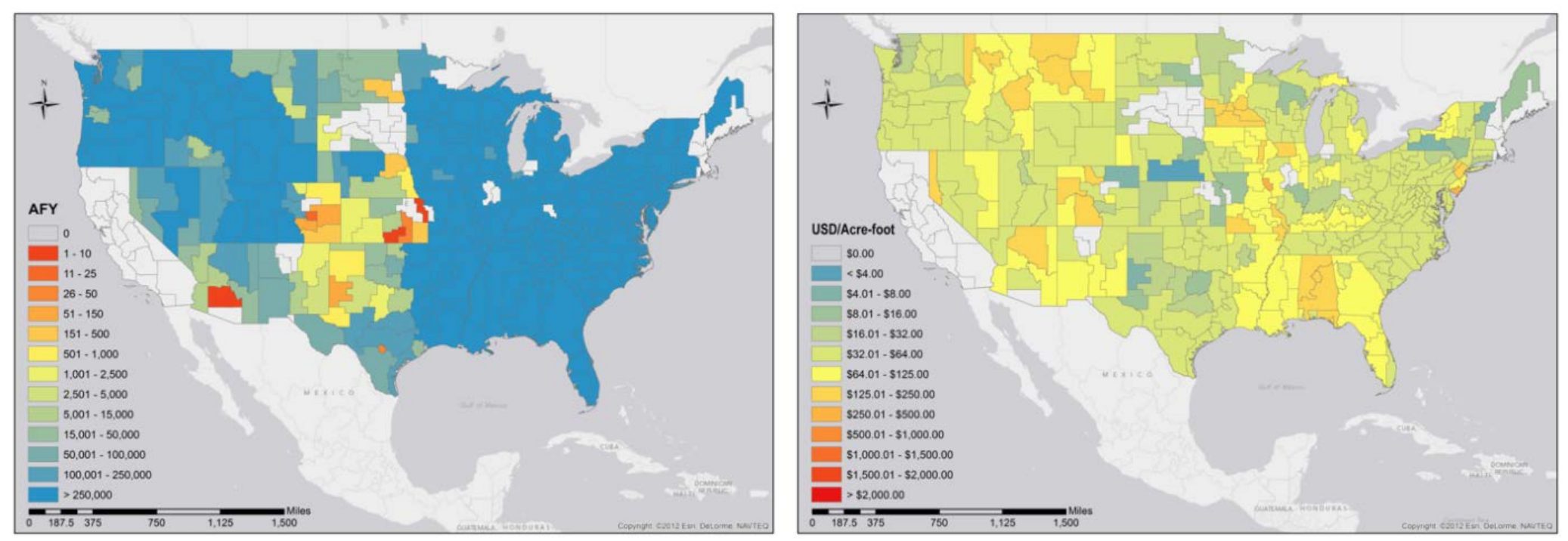
Appropriated Freshwater Availability

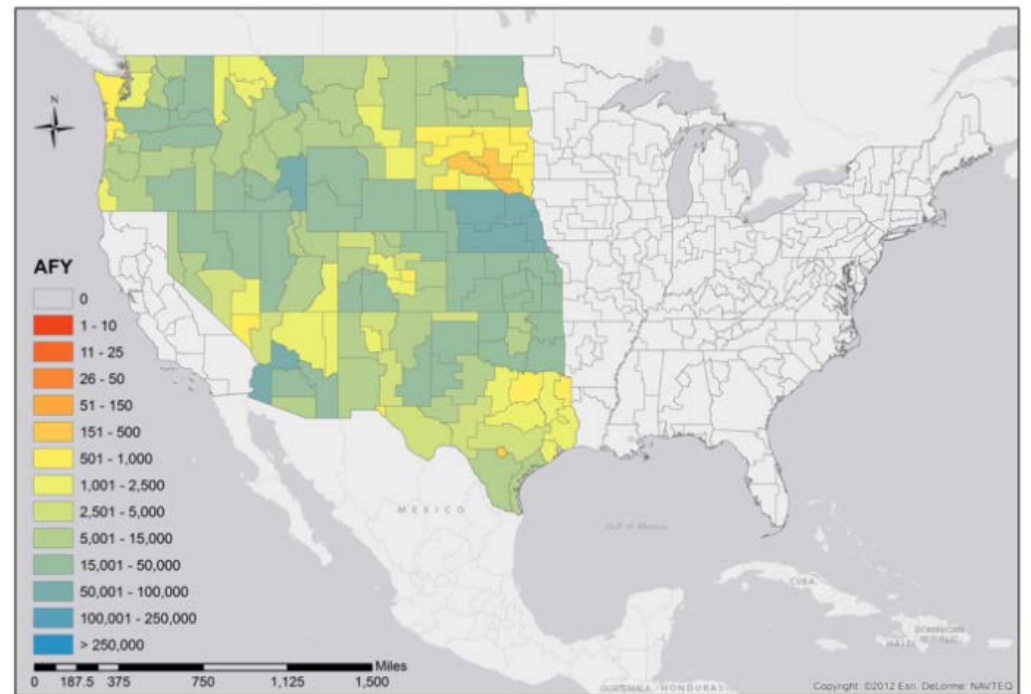

Wastewater Availability

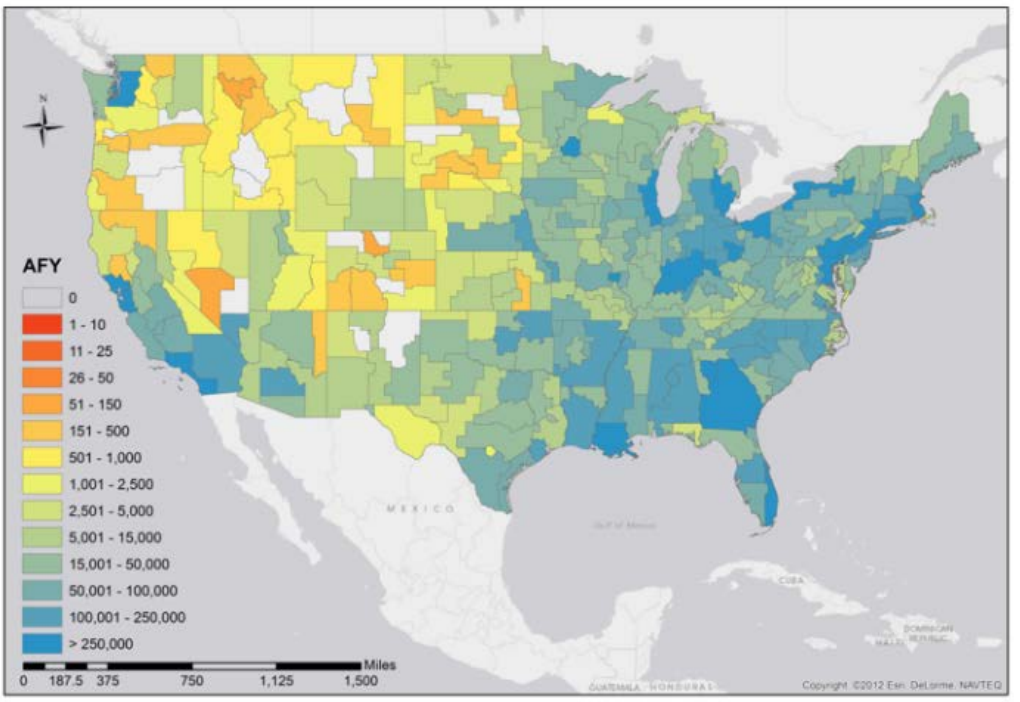

Appropriated Freshwater Cost

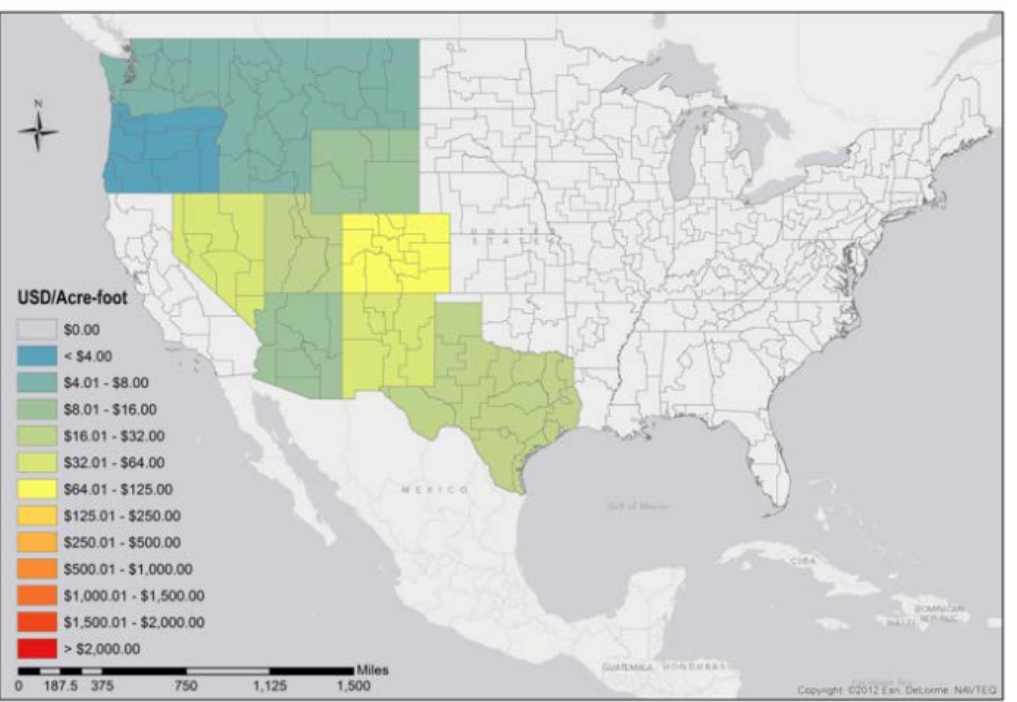

\section{Wastewater Cost}

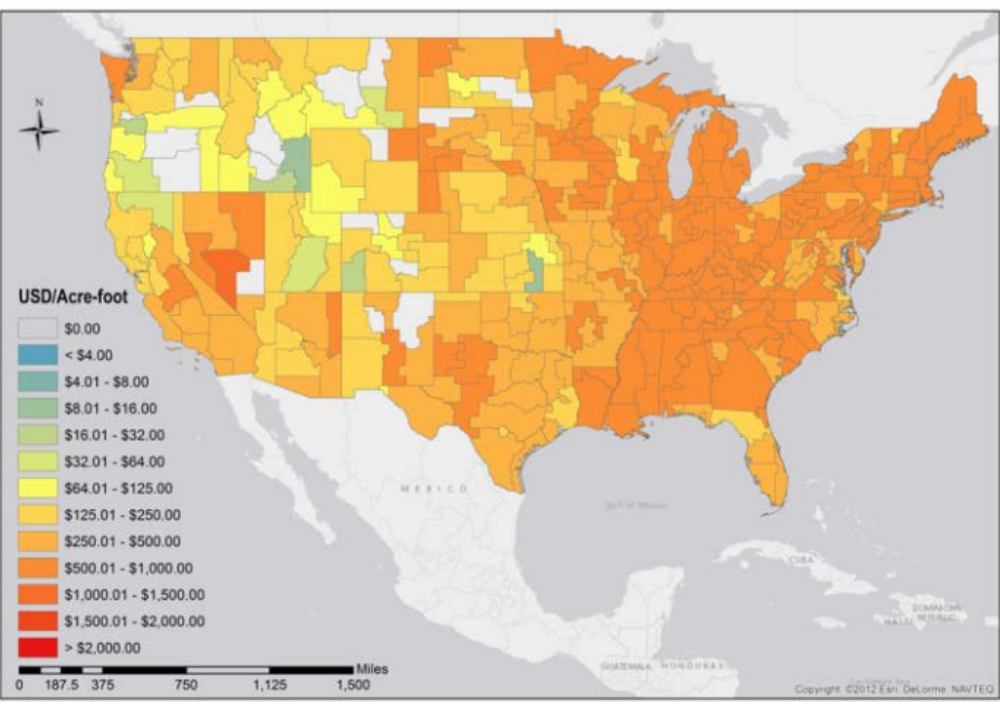


Brackish Groundwater Availability

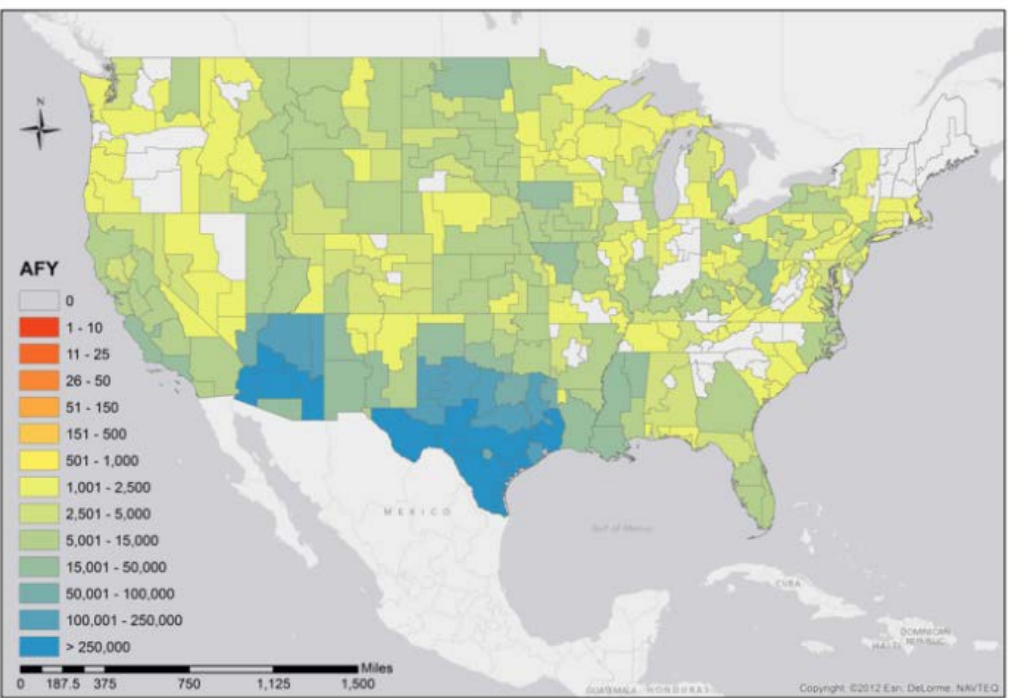

Brackish Groundwater Cost

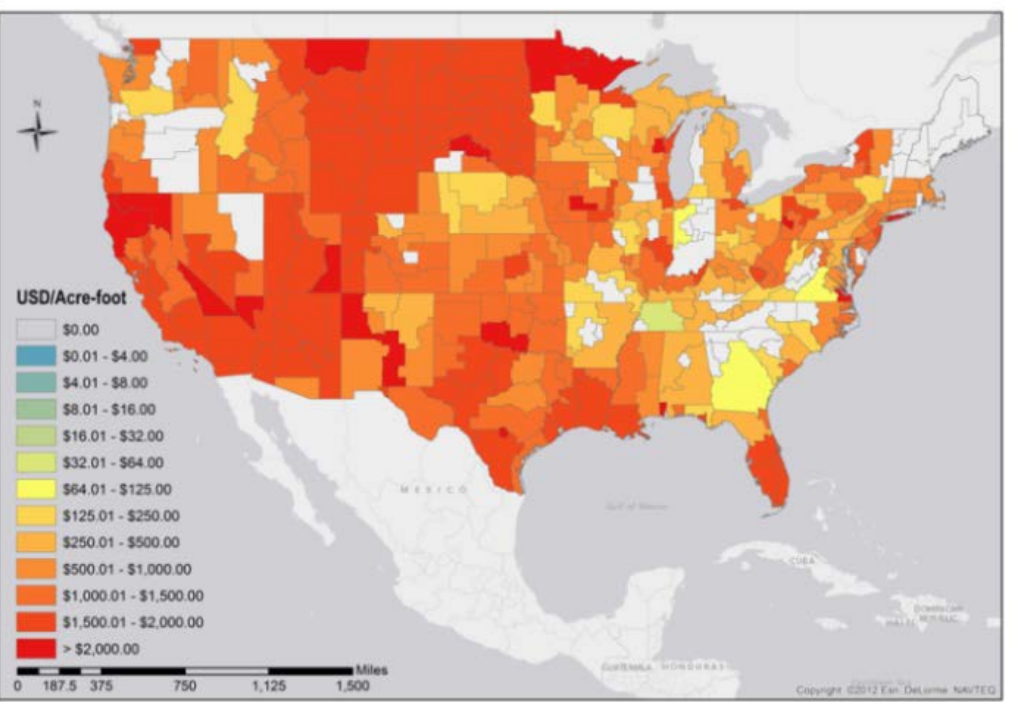

Figure 24. Water availability and cost for each water type

$$
\mathrm{AFY}=\text { acre-feet per year }
$$

Source: Tidwell, Zemlick, and Klise 2013 


\subsection{Operational Water Constraints}

ReEDS also constrains physical quantities of water withdrawn in each season and balancing area, with a less restrictive option that constrains annual water withdraws. The water availability data described in Section 4.3 apply to new capacity only, and because there is no comprehensive water resource data set for the existing fleet, total available water is initialized in 2010 solve as the quantity of water withdrawn in that year when operational water constraints are inactive. This method implicitly assumes that known historical generation accounts for any historical constraints on generation due to limited water availability. When new capacity and associated water access are purchased, total water availability is updated by adding purchased amounts from the Tidwell et al. (2013) supply curves. Annual quantities of unappropriated freshwater are distributed seasonally using the 2010 seasonal distribution, and all other water categories are assumed available uniformly throughout the year (Cohen et al. [in review]). This framework can create disincentives for purchasing unappropriated water if it is unavailable in certain seasons (and thus does not support generation in that season). There could also be an added incentive for less water-intensive technologies that avoid operational water constraints. Though operational water availability is linked to water access purchased for specific generating capacity, ReEDS aggregates capacity of a given generating technology across a BA, so operational water in a BA is not constrained for each generation technology. Available operational water of all types within a BA is available to all generating capacity in that BA. Additional discussion of operational water constraints and their application can be found in (Cohen et al. [in review]). 


\section{Transmission}

\subsection{Transmission System}

ReEDS uses a reduced network with 134 nodes (at the centroids of ReEDS BAs) connected by roughly 300 aggregate lines, as shown in Figure 24. Each line has a nominal carrying capacity limit that is determined for the start-year (2010) based on power-flow analysis using ABB's GridView model and NERC-reported line limits (NERC 2010). In later years, ReEDS can expand these carrying capacities, though the model cannot build new node-to-node pathways. Transmission expansion is limited before 2020 to lines for which new construction is already planned (EEI 2010). After 2020, that limitation is dropped. ReEDS constrains transmission flows in each of the 17 time-slices when dispatching generation and contracting operating reserves, and available transmission capacity can also be used for firm capacity to meet system adequacy needs.

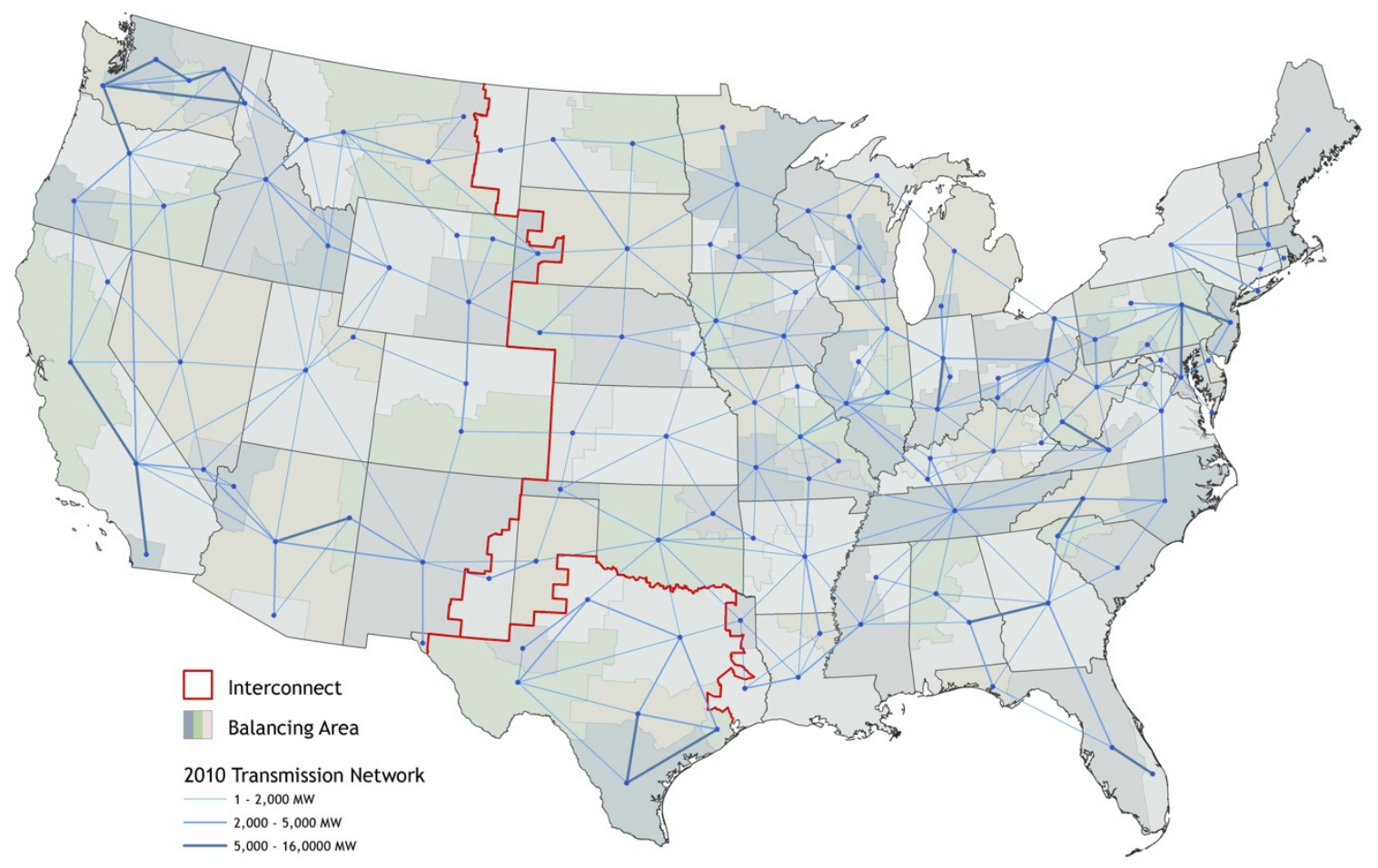

Figure 25. Existing long-distance transmission infrastructure as represented in ReEDS

Transmission network flows in ReEDS are determined by a linearized DC power-flow model (Stott, Jardim, and Alsaç 2009). The power-flow model is a linear approximation of DC power flow using effective line susceptance ${ }^{46}$ to distribute power injected at a node, with susceptance approximated as transmission capacity over distance. As in a real power system, flows are interdependent and determined by the topology of the network, including the generators, loads, and lines. Changing the pattern of generation affects the flows on all loop-forming alternating

\footnotetext{
${ }^{46}$ Susceptances are approximated as a proportionality of line capacity divided by distance. Specifically in ReEDS, susceptances are (10*Line Capacity in MW)/Distance (as measured using a Cartesian distance approximation).
} 
current (AC) lines within an interconnect. A few notable DC transmission connections in the U.S. power system are distinguished from the AC networks in ReEDS by granting them flow control, as they are not subject to Kirchhoff's voltage laws. ${ }^{47}$

ReEDS can choose to build additional transmission capacity on the existing network to reduce congestion. ${ }^{48}$ Adding capacity on a transmission corridor will also increase that line's susceptance in subsequent years and thus increase the proportion of a power injection that takes that route. ${ }^{49}$

ReEDS does not represent reactive power and does not address AC-power-flow issues of voltage, frequency, or limiting phase angle differences. Intra-BA transmission and distribution networks are similarly ignored, effectively ignoring the effects of transmission congestion within each region.

Transmission and distribution losses are considered in the model. There are bulk transmission losses of $1 \%$ per 100 miles for power that flows between BAs. In addition, distribution losses of $5.3 \%$ are assumed and thus added to the end-use demand (Section 6.1) to scale end-use demand to busbar load. Distribution losses do not apply to rooftop PV, as they are assumed to be downstream within distribution networks, but they do apply at a lower rate to DUPV systems, which are assumed to connect directly to low-voltage distribution substations (Section 6.1).

Wind, CSP, and PV technologies are highly sensitive to location and often require spur lines to connect remote locations to the bulk transmission system. The GIS supply curve algorithm described in Section 5.3 estimates spur line distances and costs for potential development sites for these technologies, which are then grouped into supply curve bins. These spur lines, which are distinct from the inter-BA bulk transmission system for ReEDS, are assumed to link remote sites to the larger transmission system and to load centers. All other technologies are assumed to be built close to existing transmission infrastructure, and they therefore need only a nominaldistance spur line. Because the plant envelope used to determine technology capital cost assumptions includes the onsite switchyard, a short spur line, and relevant upgrades at the substation (EIA 2013), those technologies incur no additional grid interconnection cost.

\subsection{Transmission Cost}

The long-distance and spur-line transmission costs in ReEDS are based on regional line voltage and cost premium assumptions. For long-distance interregional transmission lines, an assumed voltage $(345 \mathrm{kV}, 500 \mathrm{kV}$, or $765 \mathrm{kV})$ is applied for each region. The voltage assumption in each BA for long-distance transmission is taken from the highest voltage line currently operating in the BA from the Homeland Security Infrastructure Project (HSIP 2012). For BAs where the highest voltage of currently operating transmission lines is less than $500 \mathrm{kV}$, the voltage in the future is assumed to be $765 \mathrm{kV}$, and the associated costs for $765-\mathrm{kV}$ lines are used for all years. For BAs where the highest voltage of currently operating transmission lines is $500 \mathrm{kV}$, the costs

\footnotetext{
47 Those DC connections include the nine AC-DC-AC interconnect interties, the Pacific DC Intertie that links Columbia River hydropower to Southern California loads, the Intermountain HVDC line between Utah and Southern California, as well as future DC projects along defined corridors.

48 The Renewable Electricity Futures Study includes sample ReEDS transmission flows. (NREL 2012)

${ }^{49}$ ReEDS includes scenario options that make transmission more expensive and/or increase transmission losses, with both options aimed at representing additional unmodeled barriers to transmission. See Cole, Mai, et al. (2016).
} 
for $500-\mathrm{kV}$ lines are used. The only exception to these rules for voltages in the Eastern Interconnection are for BAs in New England (Connecticut, Maine, Massachusetts, New Hampshire, Rhode Island, and Vermont), which are assumed to use $345-\mathrm{kV}$ transmission lines for all years.

Each voltage class is associated with a base capital cost sourced from the Phase II Eastern Interconnection Planning Collaborative (EIPC) report: \$2,333/MW-mile, \$1,347/MW-mile, and $\$ 1,400 / \mathrm{MW}-\mathrm{mile}$ for $345-\mathrm{kV}, 500-\mathrm{kV}$, and $765-\mathrm{kV}$ transmission lines respectively (EIPC 2012) ${ }^{50}$ All wind and solar spur line costs are based on $230-\mathrm{kV}$ line costs, assumed to be $\$ 3,667 / \mathrm{MW}$-mile (ibid). ${ }^{51}$ For DC transmission lines, an additional cost of $\$ 253,000 / \mathrm{MW}$ (in $2015 \$$ ) is applied to account for the cost of the converter stations.

In addition to the base transmission costs, regional multipliers are also applied and are largely based on assumptions from EIPC (2012). Regional transmission cost multipliers are the average of the EIPC report's high and low multipliers in each North American Electricity and Environmental Model region, and they are associated with the assumed voltage within the region. BAs in ERCOT and the Western Interconnection (excluding Canada and California) are assumed to have a regional transmission multiplier of one (1). Long-distance transmission costs in BAs in the California Independent System Operator are 2.25 times the cost of the other baseline costs for the rest of the Western Interconnection. For long-distance transmission between BAs with different transmission costs, the average cost is used. The same process is applied to wind and solar spur line costs.

Figure 25 and Figure 26 show the regional long-distance and spur-line transmission costs, respectively, that result from the previously described steps and assumptions.

\footnotetext{
${ }^{50}$ The base transmission costs for ReEDS are converted to \$/MW-mile according to new transmission line cost and capacity assumptions for single circuit conductors for each voltage in EIPC (2012). The costs reported are in 2010\$ as used by the EIPC.

${ }^{51}$ Wind and solar spur line costs are applied within the development of the resource supply curves.
} 


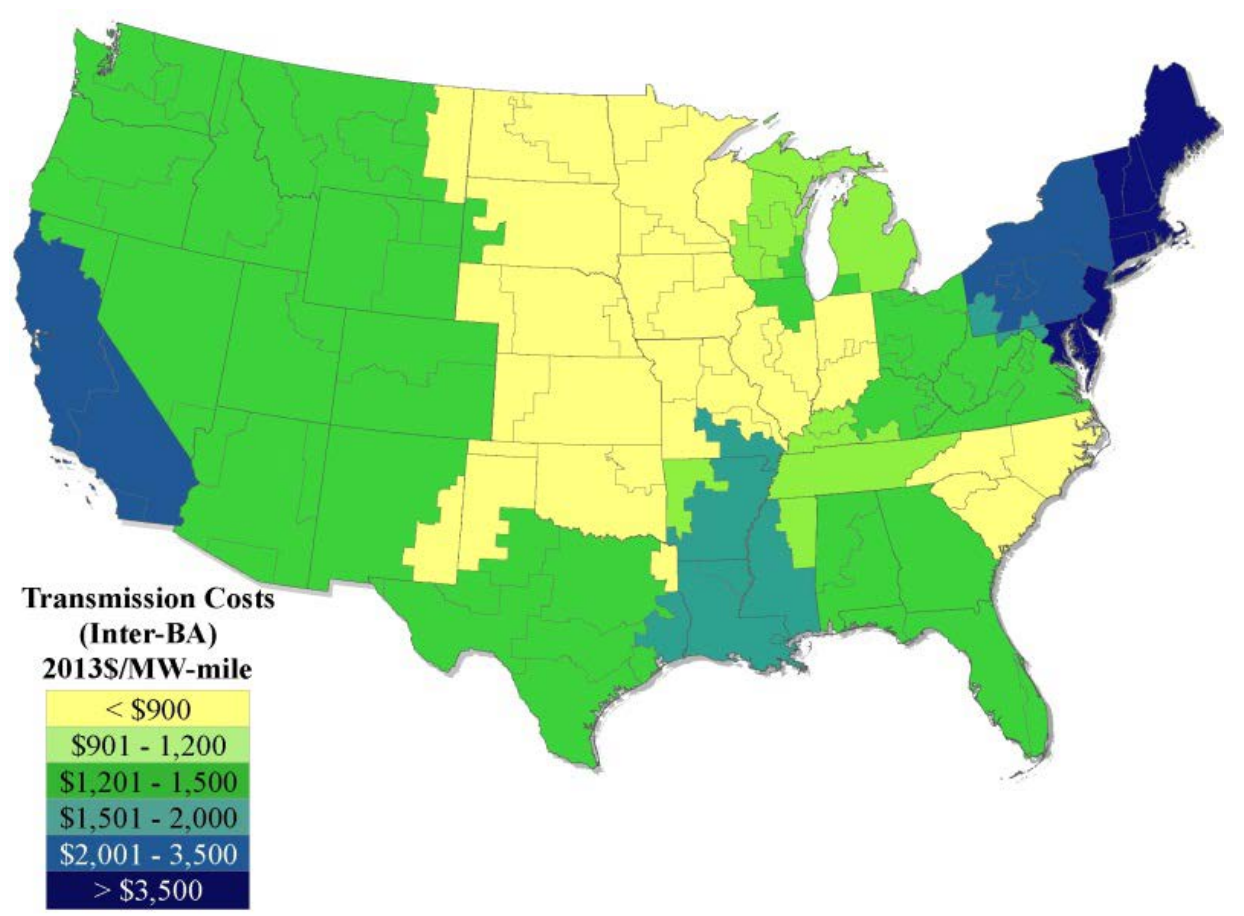

Figure 26. Map of long-distance transmission costs

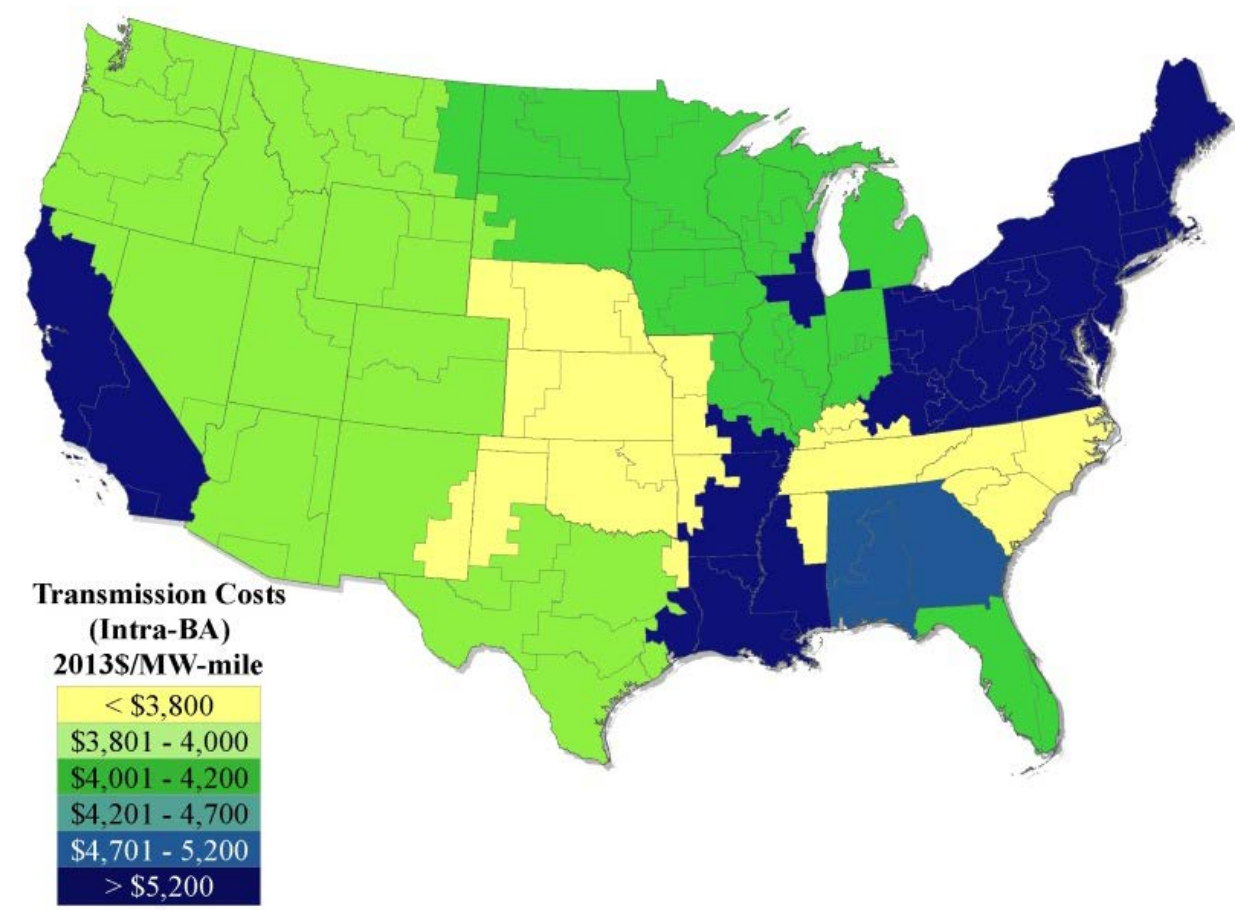

Figure 27. Map of spur-line transmission costs 


\subsection{Spur Lines}

To supplement the resource assessments that seed ReEDS with renewable potential, GIS analysis adds an accessibility dimension to the supply curves for wind, PV, and CSP technologies based on the expected cost of linking renewable resource sites to the transmission network. Coupled with supply curves for the renewable resource itself, the resulting two-dimensional supply curves allow ReEDS to make internal decisions about tradeoffs between resource quality and interconnection cost.

The geospatial site-connection algorithm evaluates each potential link from a wind or solar resource site to an electricity infrastructure feature, and the model assigns to the link a cost of development. For the algorithm, wind resource assessed at $2-\mathrm{km}$ resolution are downscaled to 90 $\mathrm{m}$ resolution for the purpose of identifying developable and non-developable locations based on numerous land cover, land use, and protected areas GIS data sets. The $90 \mathrm{~m}$ resolution pixels are then aggregated to a grid of roughly $5.7 \mathrm{~km}$ resolution to reduce the number of points to be used in additional analyses downstream. CSP sites are similarly grouped into $1.35 \mathrm{~km} \times 1.35 \mathrm{~km}$ cells, and PV sites are grouped into $3.15 \mathrm{~km} \times 3.15 \mathrm{~km}$ cells. Each resource site and each link is characterized by a LCOE that includes the expected cost of interconnection.

The resource supply curves are the result of successively selecting the least-cost site-toinfrastructure link and allocating that site to the infrastructure component until the transmission lines are saturated. At the start, each transmission line is assumed to have $10 \%$ of its nominal carrying capacity available for renewable connections, and each time a link is added, the remaining headroom is decremented by the capacity of the site being tied in. As the available capacity at transmission infrastructure features decreases, resource sites have to look farther afield for available linkages.

The resource supply curves are described in detail in (Galen Maclaurin et al. [in review]) (DOE 2015), Previsic et al. (2012), and (C. Murphy et al. 2019).

\subsection{International Electricity Trade}

ReEDS is capable of endogenously representing Canada and Mexico (Section 10), but our default model configuration only covers the contiguous United States and represents electricity trade with Canada exogenously. In the default configuration, imports and exports are specified by Canadian province based on the National Energy Board's (NEB) Canadian Electricity Futures Reference Scenario (NEB 2016), with net exports across all regions shown in Figure 27 (values beyond NEB projections to 2040 are held constant at the 2040 value). Each province is required to send electricity to or receive electricity from any of the ReEDS BAs that have connecting transmission lines to that province. Thus, while the total amount of energy imported from and exported to each Canadian province is exogenous, the model can choose which BAs supply or receive that electricity. Electricity flows in 2010-2014 are taken from historical data (Canadian Electricity Association 2015). Canadian imports are assumed to be from hydropower and are counted toward RPS requirements where allowed by state RPS regulations. Canadian imports also count toward reserve margin requirements. 


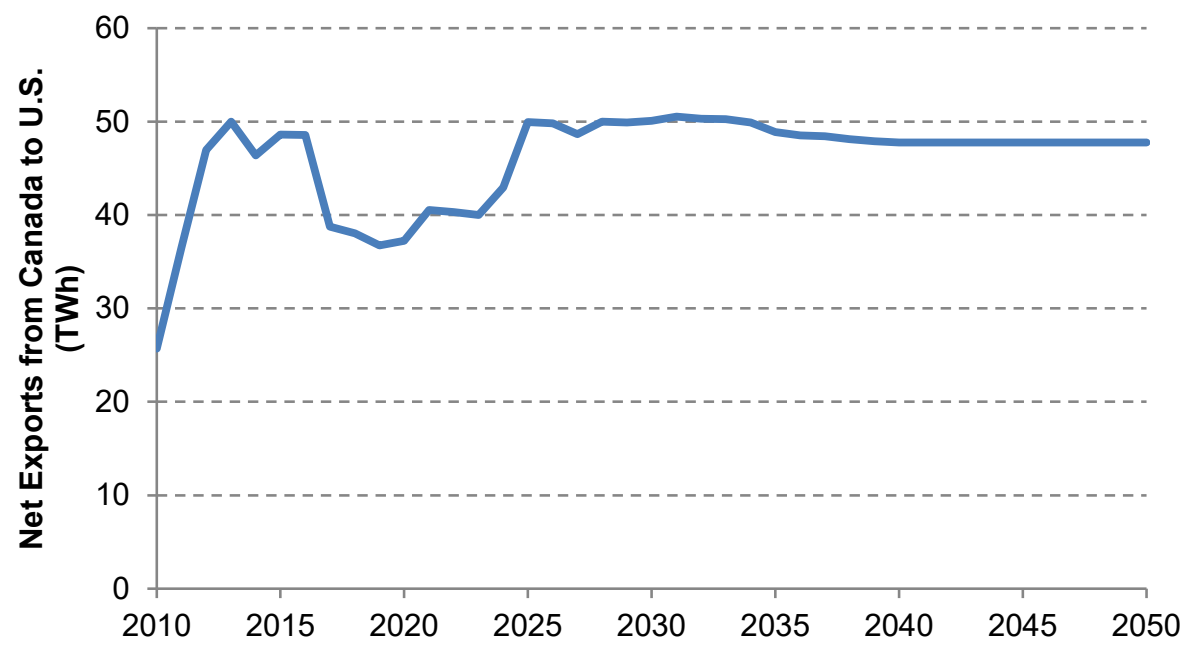

Figure 28. Net exports from Canada to the United States

A limited amount of trade with Mexico is represented endogenously in that several Mexican plants along the Mexico-California border are included in ReEDS with transmission lines that connect to the southern California BAs. These plants are operated using the same framework as all other plants in ReEDS and can send power into California. ReEDS is not allowed to build new plants in Mexico to serve U.S. load except for plants that are already under construction and are under contract to send their power to the United States. Renewable energy generated in Mexico and sent to California is eligible for the California RPS. Other than these interties between Mexico and California, all other U.S.-Mexico interties are not currently included in the U.S.-only model. In Section 10, we discuss separate model versions that explicitly include the Canadian and Mexican electricity systems. 


\section{Electricity System Operation and Reliability}

ReEDS finds the least-cost way of building and operating the electricity system while meeting certain requirements that are dominated by the need to meet electricity load while maintaining system adequacy and operational reliability.

\subsection{Electricity Load}

The primary constraint in ReEDS is to serve electricity load in each BA and time-slice. The enduse electricity load projection used in ReEDS is exogenously defined, based on scenarios from AEO2018 (EIA 2018) and calibrated in 2010 to load data from Ventyx (2014). Hourly load profiles from Ventyx transmission zones are summarized and averaged to the 17 time-slice load profiles for the model BAs. These 2010 profiles are then scaled to ensure a match with the state-level annual load data from EIA's "Electricity Data Browser" (EIA 2015). The regional growth factors for years after 2010 are calculated from the AEO scenario electricity consumption by census division. ${ }^{52}$ For each model year in ReEDS, the regional load profiles are scaled by regional growth factors, but the shape of the load profile is assumed constant throughout the study period. ${ }^{53}$

The end-use load, described in the previous paragraph, is defined at the meter level. ReEDS includes inter-BA transmission system losses in the optimization but does not represent distribution losses, so the end-use load must be scaled up to busbar load to account for distribution losses. The $5.3 \%$ distribution loss factor used for this conversion is estimated based on a combination of EIA and ReEDS numbers. ReEDS is required to generate sufficient power in each time-slice and BA (allowing for transmission of power but accounting for losses) to meet this busbar load. ${ }^{54}$

\subsection{Resource Adequacy}

Resource adequacy is "the ability of supply- and demand-side resources to meet the aggregate electrical demand" (NERC 2016). Planning reserve requirements in ReEDS ensure adequate resource is available at all times, within an acceptable probability of failing to do so. In practice, this constraint is enforced by requiring the system to have sufficient firm capacity to meet the forecasted peak demand plus a reserve margin. This constraint is enforced for each season to accommodate the potential for peak net load to shift seasons as renewable penetration increases.

\footnotetext{
${ }^{52}$ The demand growth factors from AEO's census divisions are applied to the ReEDS NERC-level regions. Due to differences in AEO's census divisions and the similarly sized NERC regions in ReEDS, the projected national load in ReEDS does not agree exactly with AEO's demand projections, but the differences are small.

${ }^{53}$ Demand profiles and annual consumption can be altered with different plug-in hybrid electric vehicle and rooftop PV scenarios; however, absent these demand-side technologies, the profiles are assumed to be the same as those from 2010.

${ }^{54}$ Load balancing is implemented with equality constraints, so there is no physical representation of lost load and an associated cost.
} 
Each technology is assigned a capacity value $(\mathrm{CV})^{55}$ reflecting its expected availability when power is needed, typically during the highest-risk hours, which are ideally identified as the hours with highest loss of load probability (LOLP) ${ }^{56}$. For conventional generators in ReEDS, the CV matches the nameplate capacity.

\subsubsection{VRE Capacity Value}

For VRE technologies (i.e., wind and solar), ReEDS estimates a seasonal CV for each region/class bin via an hourly LDC approximation of expected load carrying capability (ELCC) ${ }^{57}$ performed between solve years. ELCC can be described as the amount of additional load that can be accommodated by adding those generators while maintaining a constant reliability level. Prior to ReEDS v.2017, a statistical approximation was used to calculate this ELCC by time-slice, region, and bin (Walter Short et al. 2011). The new 8760-based methodology is better able to capture the highest load and net load hours, which typically represent the highest risk hours, thereby supporting a more accurate representation of CV. Details of this new LDC approach, as well as a comparison against the former statistical method, can be found in Frew et al. (2017).

The LDC approach for calculating CV is based on explicit hourly (8760) tracking of timesynchronous load and VRE resources. The CV method uses a capacity factor proxy that is applied to top hours in load and net load-duration curves (LDCs and NLDCs) to estimate ELCC. Figure 28 is a graphic representation of the ReEDS CV methodology. The LDC reflects the total load in a given modeling region, which is sorted from the hours of highest load to lowest load and is shown by the blue line. The NLDC represents the total load minus the time-synchronous contribution from VRE, where the resulting net load is then sorted from highest to lowest, as shown by the solid red line. ${ }^{58}$ The $\operatorname{NLDC}(\delta)$, which represents further addition of VRE resources, can be created by subtracting the time-synchronous generation of an incremental capacity addition from the NLDC, where the resulting time series is again sorted from highest to lowest; this is shown by the dashed red line.

\footnotetext{
${ }^{55}$ In ReEDS, CV is defined as the fraction of nameplate capacity that contributes to the top peak net load hours.

${ }^{56}$ LOLP is defined as the probability of a loss-of-load event in which the system load is greater than available generating capacity during a given period.

${ }^{57} \mathrm{ELCC}$ is the contribution (units of MW that can then be reported as a fraction of the installed capacity to represent $\mathrm{CV}$ ) that an additional resource provides toward meeting the system's load while maintaining a fixed system-wide reliability level.

${ }^{58}$ Residual LDC (RLDC) is an equivalent term to NLDC used in the literature.
} 


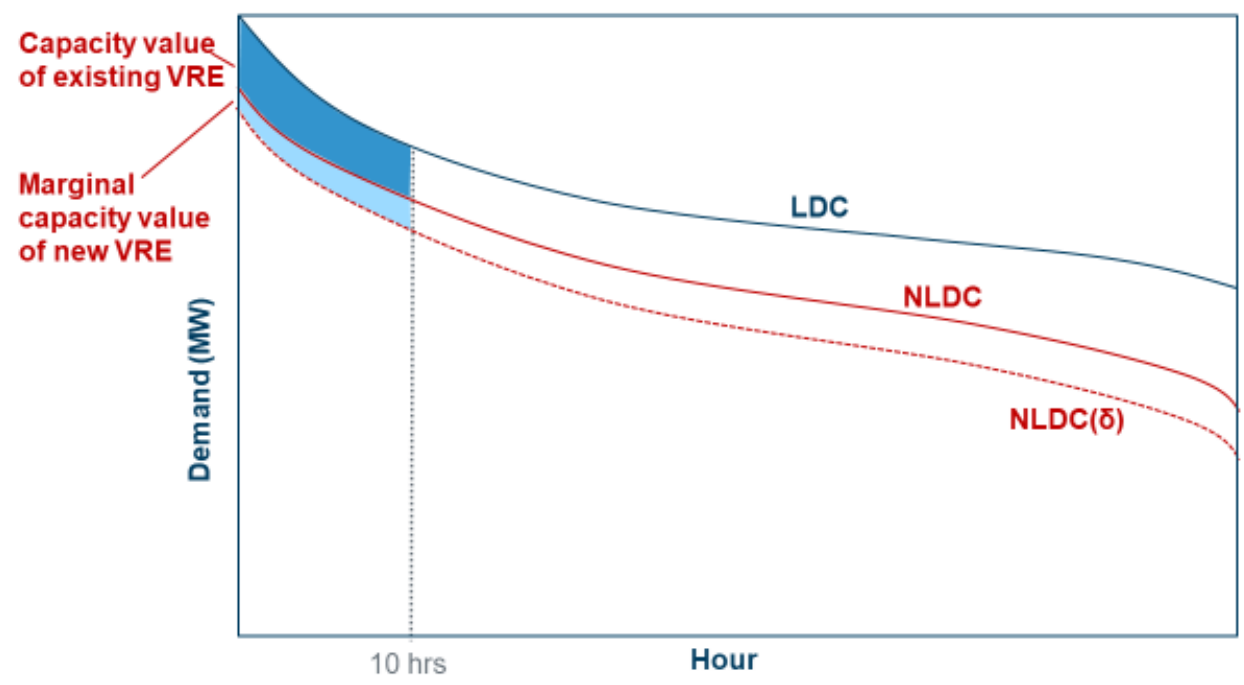

Figure 29. LDC-based approach to calculating CV

ReEDS calculates the ELCC as the difference in the areas between the LDC and NLDC during the top 10 hours of the duration curves in each season, as represented by the dark blue shaded area in Figure 28. These 10 hours are a proxy for the hours with the highest risk for loss of load, i.e., the LOLP. ${ }^{59}$ Similarly, the contribution of an additional unit of capacity to meeting peak load is the difference in the areas between the NLDC and the $\operatorname{NLDC}(\delta)$, as shown by the light blue shaded area in Figure 28. To ensure resource adequacy, ReEDS calculates CV based on a 1,000-MW incremental capacity size of new solar and wind builds. These areas are then divided by the corresponding installed capacity and number of top hours ( 10 hours per season in this case, although the number of hours can be adjusted by the user) to obtain a fractional seasonalbased CV.

The resulting existing and marginal $\mathrm{CV}^{60}$ values then feed into ReEDS to quantify each VRE resource's capacity contribution to the planning reserve requirement. Existing VRE CV calculations are performed by region and technology. For all candidate VRE resources that might be built in the coming year, the marginal $\mathrm{CV}$ is calculated by region, technology, and resource class. In all cases, the VRE profile is compared against the Regional Transmission Organization (RTO)-level load profile for determining the CV (Figure 29). We use the RTO-level load profile to simplify the challenge of representing the ability of transmission to wheel VRE capacity from one BA to another. In essence we have assumed a copper plate within each RTO for the purpose of sharing VRE capacity. We use RTO regions rather than NERC regions for this assumption because transmission and trading tend to be closely related to RTO regions than NERC regions.

\footnotetext{
${ }^{59}$ We currently use only a single year of wind, solar, and load data to calculate CV. Expansion of this method to use multiple years of data would increase the robustness of this calculation.

${ }^{60}$ We refer to "existing" CV as the reliable capacity contribution from resources that have already been deployed in the model prior to the buildout of additional "marginal" resources.
} 


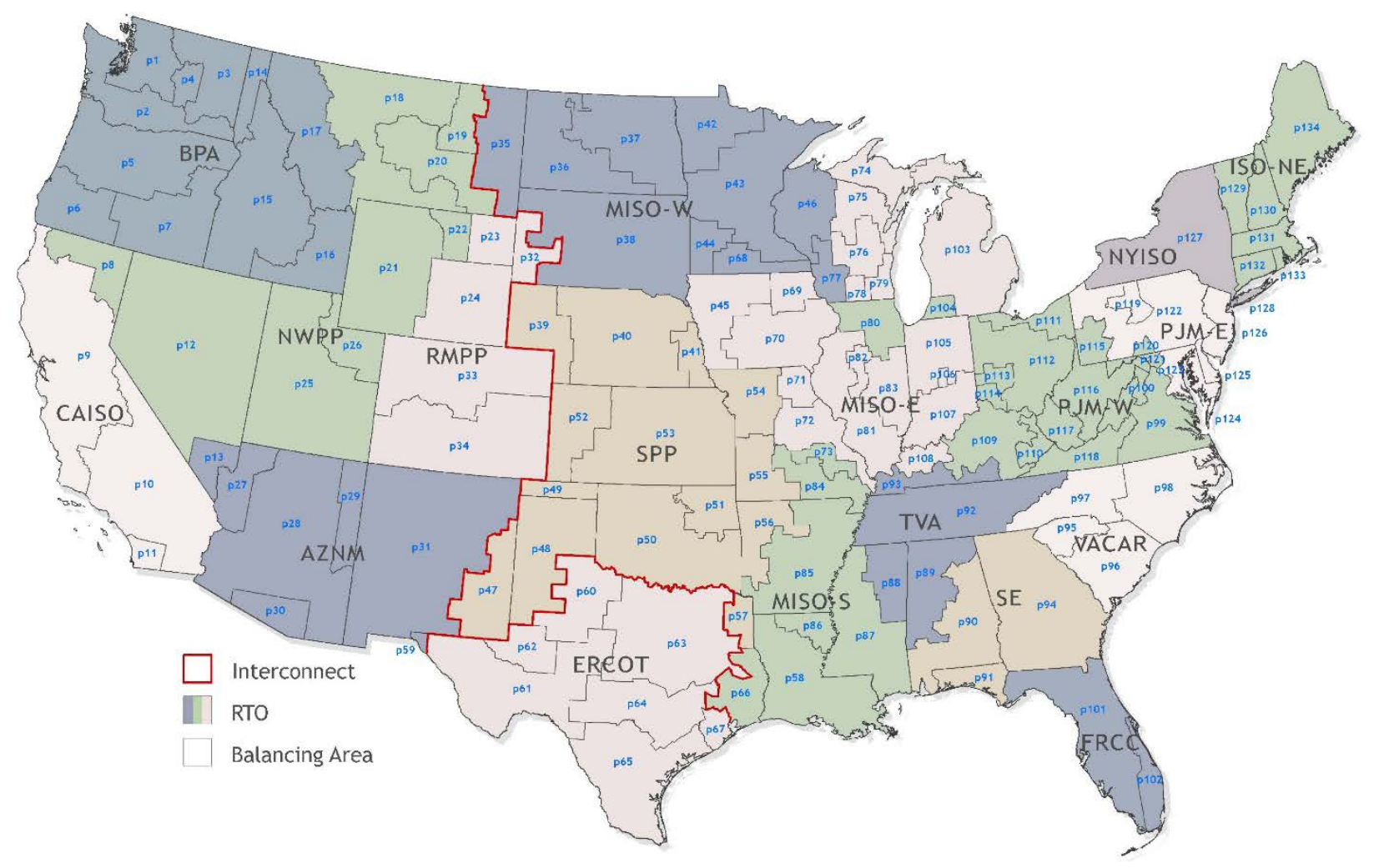

Figure 30. Map of ReEDS 134 BA regions and 18 RTO subregions

\subsubsection{Storage Capacity Value}

For storage, the $\mathrm{CV}$ is assumed to be 1 for PSH and CAES. For battery storage, ReEDS estimates CVs based on curves fitted to results from NREL's REFlex model using multiple years of input load and solar data for California (Denholm and Margolis 2018). This approach approximates the $\mathrm{CV}$ of storage as the potential of storage to reduce the peak net load. The battery storage CV curves assume a piecewise nonlinear fit as a function of storage penetration, PV penetration, and storage duration. To be consistent with the method used in REFlex, storage penetration is calculated as the battery power capacity divided by the instantaneous peak load, and PV penetration is calculated as the total annual PV generation energy divided by the total annual load. Thus, a storage penetration of 2 means that the total storage power capacity is double the peak load, and a PV penetration of 0.3 means that the annual generation from PV that serves load is $30 \%$ of the total annual load. A detailed description of these curves and the implementation in ReEDS is provided in (B. A. Frew et al. 2018).

The battery storage $\mathrm{CV}$ is calculated for battery storage capacity that is already deployed along with marginal battery storage available for new deployment in the subsequent ReEDS solve period. Existing storage $\mathrm{CV}$ is calculated by integrating along the given $\mathrm{PV}$ penetration curve from 0 to the current storage penetration (purple area in Figure 30). This integration value is then divided by the storage penetration to return an average existing storage $\mathrm{CV}$ that is then applied to all existing storage (dashed red line in Figure 30). The marginal storage CV is the rightmost value along the storage CV curve (red point in Figure 30). Both the existing and marginal battery storage CV are calculated at the ReEDS RTO level and then mapped to the BA level for implementation within ReEDS. 


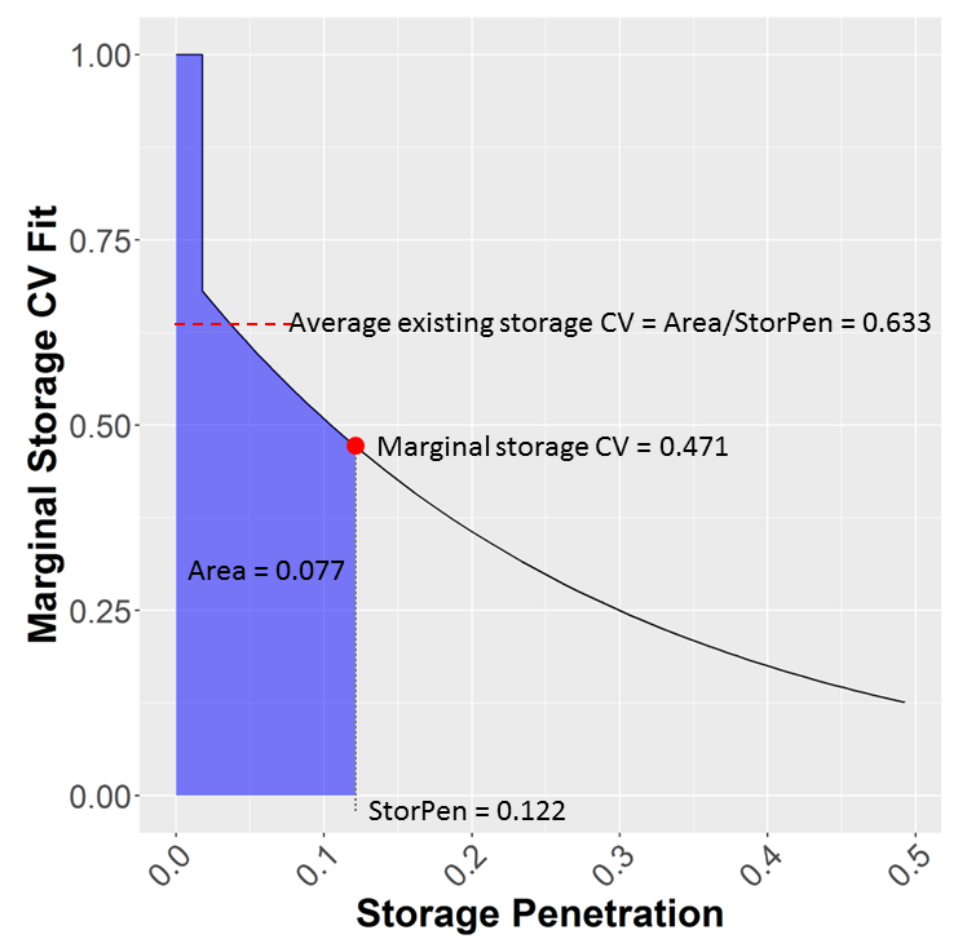

Figure 31. Illustration of the calculation of marginal and existing storage $\mathrm{CV}$ with the functional form curve fit for PV penetration of $7 \%$ and storage duration of four hours

The battery storage CVs estimated by the fitted curves are then multiplied by an availability factor, which accounts for uncertainty in electricity demand, storage dispatch, and generator outages that could all lead to supply scarcity. These availability factors are a function of duration, as shown in Figure 31, which was derived from Sioshansi, Madaeni, and Denholm (2014). The resulting adjusted battery storage CV parameters are included in the planning reserve constraint, similar to the treatment for VRE technologies.

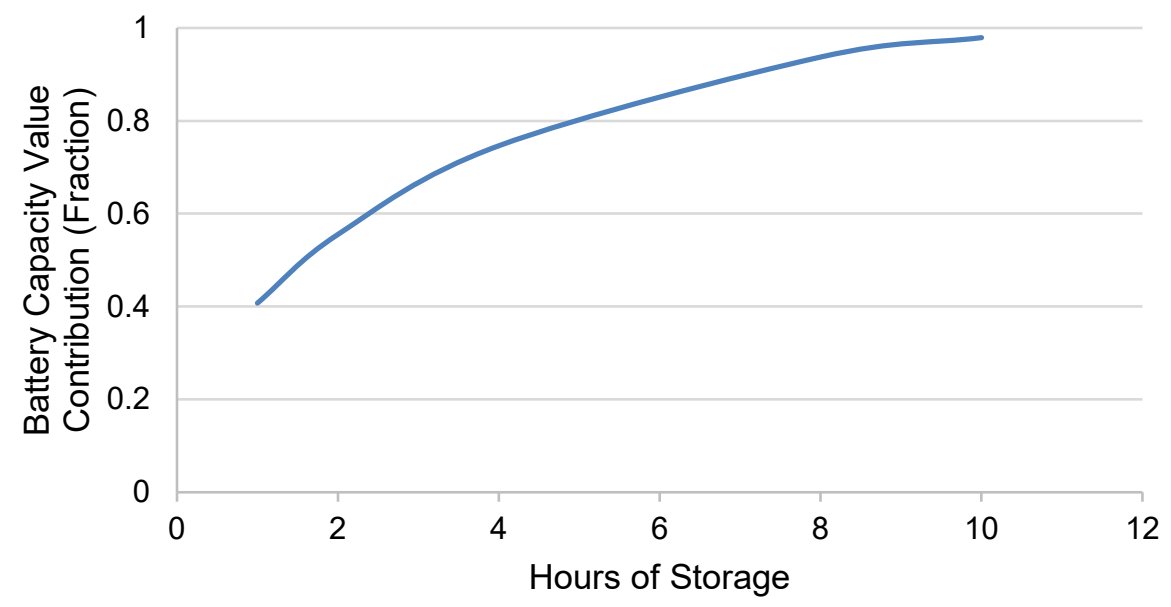

Figure 32. Battery capacity value availability factor as a function of battery duration 


\subsubsection{Planning Reserve Margins}

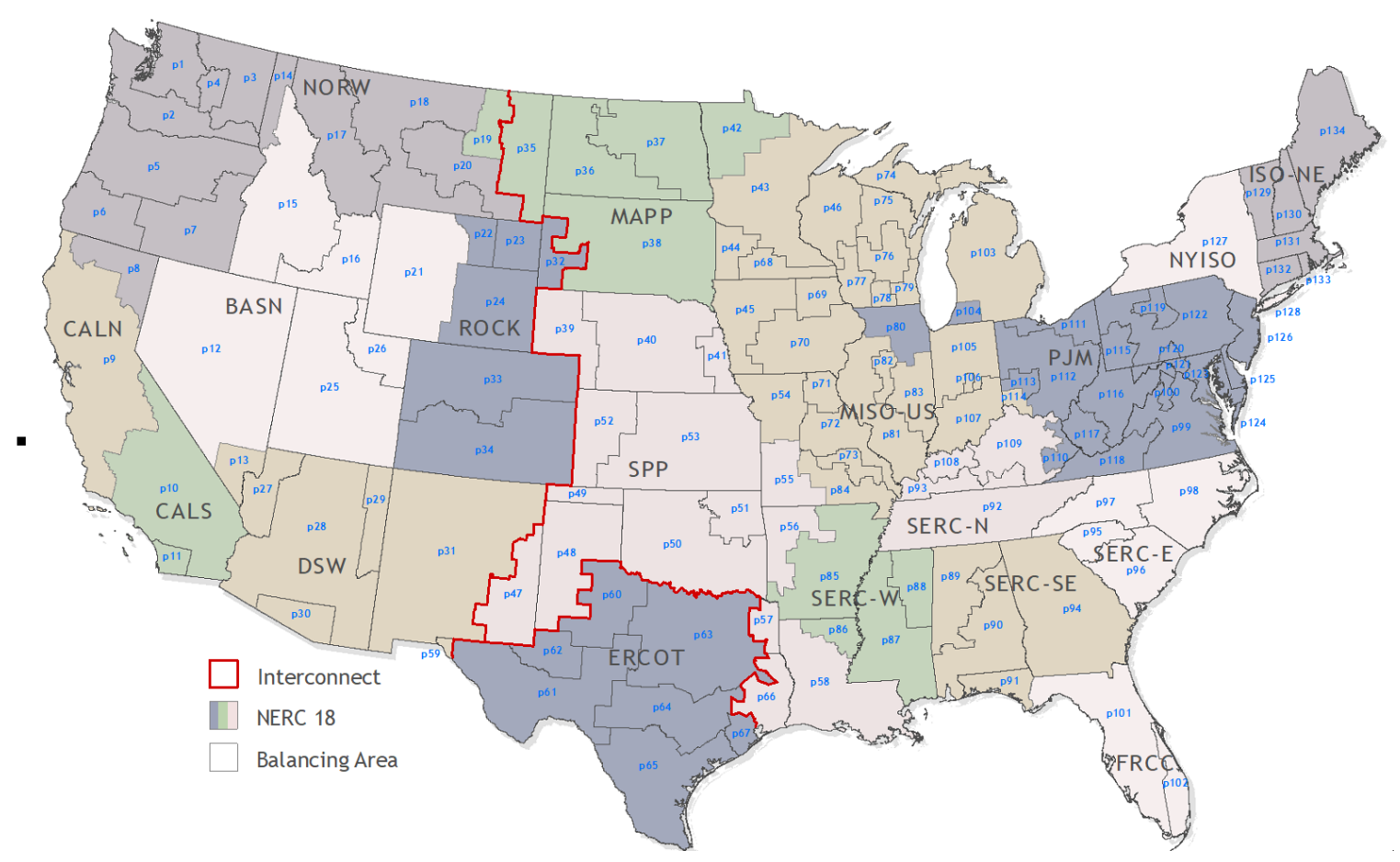

Figure 33. Map of ReEDS 134 BA regions and 18 NERC reliability subregions.

The reserve margin fractions applied in ReEDS are based on reserve margin requirements for NERC reliability subregions (NERC 2010). Each ReEDS BA must meet the requirement, but regions can engage in bilateral contracts for firm capacity subject to transmission limits on $\mathrm{AC}$ or DC corridors.

The minimum reserve margin required in each ReEDS region varies over time. The 2018 reserve margin is set by taking the minimum of the average actual long-term interconnect-wide reserve margin from 1990 to 2016 and the average actual short-term regional reserve margin from 2010 to $2016 .{ }^{61}$ However, if the minimum of those two values is lower than the NERC-recommended level, the NERC-recommended level is taken instead. Figure 33 shows the resulting planning reserve margins used in 2018 (under the "Combined" label). The minimum reserve margin requirement in 2025 in ReEDS is then set to the NERC-recommended level, and intermediate years between 2018 and 2025 are a linear interpolation between the two values. This dynamic treatment gives the model some incentive to maintain reserve margins above the NERCrecommended levels until 2025.

\footnotetext{
${ }^{61}$ A long-term regional value could not be calculated because of how often the NERC region definitions have changed.
} 


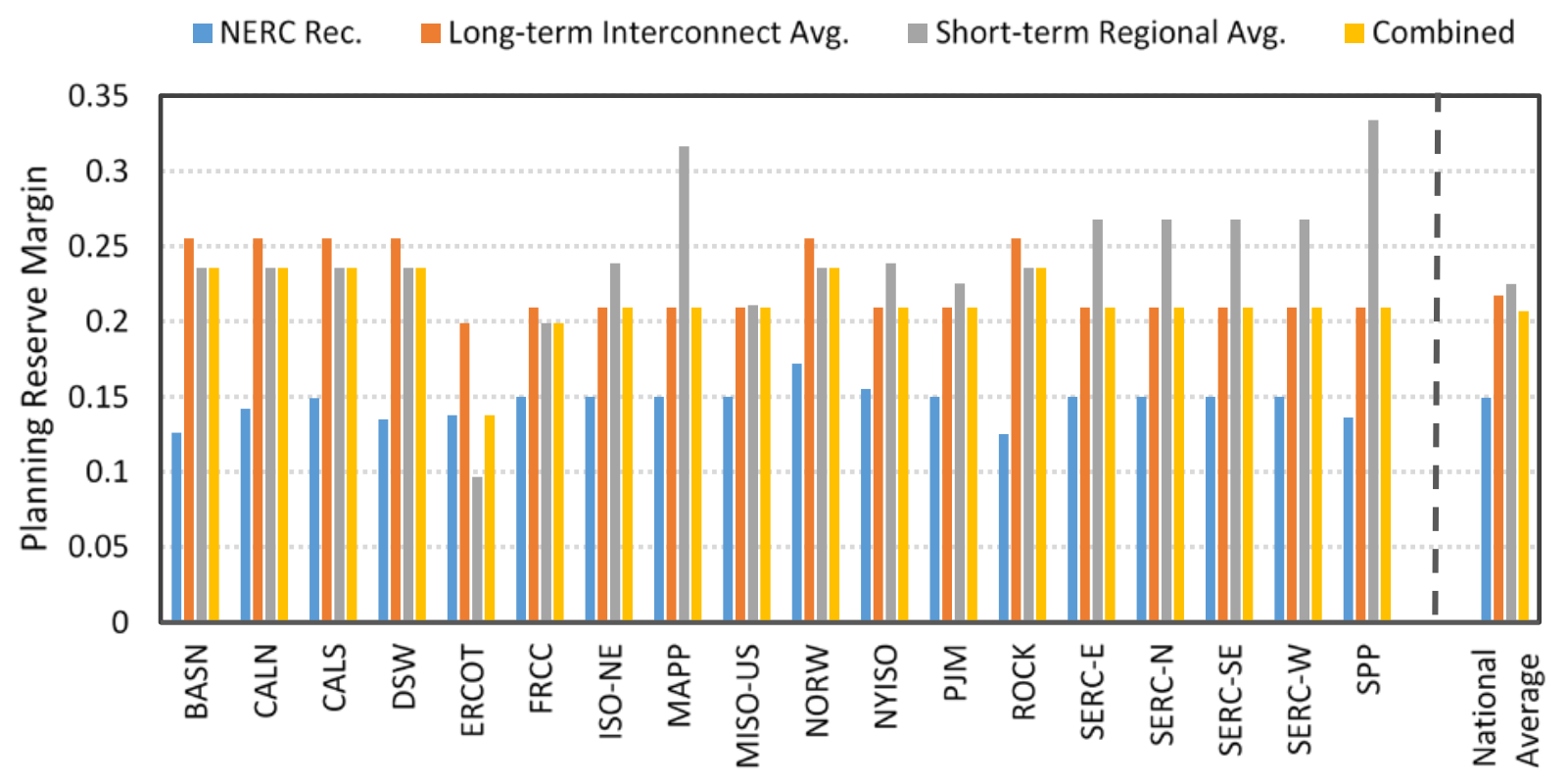

Figure 34. Planning reserve margin by NERC region.

NERC Rec. are the NERC-recommended levels, Long-term Interconnect Avg. is the average by interconnect from 1990 to 2016, Short-term Region Avg. is the average by NERC region from 2010 to 2016, and combined is the minimum of the short-term and long-term average, unless that values falls below the NERC-recommended level, in which case it is set to the NERC-recommended level.

\subsection{Operational Reliability}

In addition to ensuring adequate capacity to satisfy long-term planning reserve requirements, ReEDS requires operational reliability - that is, the ability to continue operating the bulk-power system in the event of a sudden disturbance (NERC 2016). In practice, ancillary reserve requirements ensure there is sufficient flexibility from supply-side and demand-side technologies to rebalance fluctuations in generation and demand.

ReEDS represents three type of operating reserve products, including, spinning, regulation, and flexibility reserves. The requirement specified for each product in each time-slice is a function of load, wind generation, and photovoltaic capacity (during daytime hours). ${ }^{62}$ Technologies providing these reserve products must be able to ramp their output within a certain amount of time (Table 18).

\footnotetext{
${ }^{62}$ The PV reserve requirement is only valid during daytime hours when the PV systems are operating. In addition, the requirement is a function of capacity rather than generation because reserves are especially important around sunrise and sunset when PV generation is low.
} 
Table 20. Summary of Operating Reserve Requirements

\begin{tabular}{|l|c|r|r|r|}
\hline $\begin{array}{l}\text { Reserve } \\
\text { Product }\end{array}$ & $\begin{array}{l}\text { Load Requirement } \\
\text { (\% of load) a }\end{array}$ & $\begin{array}{l}\text { Wind Requirement } \\
\text { (\% of generation) b }\end{array}$ & $\begin{array}{l}\text { PV Requirement } \\
\text { (\% of capacity) b }\end{array}$ & $\begin{array}{l}\text { Time Requirement } \\
\text { to Ramp (minutes) }\end{array}$ \\
\hline Spinning & $3 \%$ & & & 10 \\
\hline Regulation & $1 \%$ & $0.5 \% \mathrm{c}$ & $0.3 \% \mathrm{c}$ & 5 \\
\hline Flexibility & & $10 \%$ & $4 \%$ & 60 \\
\hline
\end{tabular}

a See Lew et al. 2013, Section 5.3.4.

${ }^{b}$ Reserve requirements for wind and PV were derived from the outcomes from (Lew et al. 2013). The flexibility requirement for wind was estimated as the ratio of the change in the reserve requirement to the change in wind generation from the Lew et al. "High Wind" scenario; the requirement was estimated similarly for PV using the Lew et al. "High Solar" scenario.

${ }^{c}$ The estimated regulation requirements $(0.5 \%$ wind generation and $0.3 \% \mathrm{PV}$ capacity) are based on incremental increases in regulation reserves across all scenarios in (Lew et al. 2013).

All ancillary reserve requirements must be satisfied in each BA for each time-slice; however, reserve provision can be traded between BAs using AC transmission corridors. Trades are only allowed within an RTO and not across RTO boundaries. The amount of reserves that can be traded is limited by the amount of carrying capacity of an AC transmission corridor that is not already being used for trading energy.

The ability of technologies to contribute to reserves is limited by the ramping requirement for a given reserve product, the plant ramp rate, and online capacity (Table 19). Online capacity is approximated in ReEDS as the maximum generation from all time-slices within a modeled day. Reserves can be provided by generation and storage technologies that are turned on but not fully dispatched in a time-slice. In addition, demand-side interruptible load can also contribute to reserve requirements, if enabled in a scenario. Neither nuclear, PV, nor wind can contribute toward the supply of reserves.

The cost for providing regulation reserves is represented in ReEDS using data from (Hummon et al. 2013); see Table 20. Because ReEDS does not clearly distinguish between coal fuel types, $\$ 12.5 / \mathrm{MWh}$ is the assumed regulation cost for all coal technologies. The cost of providing regulation reserves from Gas-CT, geothermal, biopower, land-fill gas, and CAES is assumed to be the same as oil/gas steam. 
Table 21. Flexibility Parameters of the ReEDS Generation Technologies

\begin{tabular}{lcccc}
\hline & $\begin{array}{c}\text { Assumed } \\
\text { Ramp } \\
\text { Rate } \\
(\% / m i n)\end{array}$ & Upper Bound (\% of online capacity) = Ramp Rate (\%/min) $\times$ \\
Ramp Requirement (min)
\end{tabular}

a See (Bloom et al. 2016b).

b Geothermal and biopower values are assumed to be the same as oil/gas steam units. In practice, geothermal plants typically do not ramp given their zero or near-zero variable costs, and therefore only provide energy and not operating reserves.

c. See (Jorgenson et al. 2013).

Table 22. Cost of Regulation Reserves

\begin{tabular}{|l|c|}
\hline Generator Type & $\begin{array}{c}\text { Cost of Regulation } \\
\text { Reserves (2013\$/MWh) }\end{array}$ \\
\hline Supercritical Coal & 15 \\
\hline Subcritical Coal & 10 \\
\hline Combined Cycle & 6 \\
\hline Gas/Oil Steam & 4 \\
\hline Hydro & 2 \\
\hline Pumped Storage Hydropower & 2 \\
\hline
\end{tabular}

\subsection{Curtailment}

Curtailment is a reduction in the output of a generator from what it could otherwise produce given available resources. Most renewable generators, being resource dependent and lacking fuel costs, are subject to curtailment that reduces plant revenue, in particular, when there is ample generating capacity committed, insufficient load to absorb it locally, and limited options to export surplus power via the transmission network. The economics of investment in renewable generators can be impacted by the amount of curtailment to which a plant will be subjected, so ReEDS estimates curtailment fractions for both existing renewable generators and candidate sites. 
The ReEDS curtailment calculation is a statistical estimate of expected surplus generation in each balancing area and time-slice given the expected load level, expected VRE output, expected minimum turndown level for committed thermal units (see Table 19), and the variances and correlations of the preceding factors. Recommitting thermal capacity from one year to the next can change curtailment patterns by changing the minimum stable output level of the thermal fleet. Similarly, adding new storage capacity can reduce curtailment levels by effectively increasing the available load.

Short et al. (2011) describe the calculation details for curtailment in ReEDS. The only difference in the current version of ReEDS is that storage is no longer explicitly included in the statistical calculations for the existing and marginal VRE curtailments. Instead, the contribution of all storage toward reducing curtailment via charging by region and time-slice is captured within a storage effectiveness parameter. This parameter is nominally set to 1 , which assumes full reduction in curtailment for energy placed into storage, for all load and renewable energy generation levels. Details about this parameter can be found in Cole, Marcy, et al. (2016). 


\section{Climate Impacts}

ReEDS nominally assumes a constant climate throughout the study period; however, it has the capability to represent several impacts, both combined and isolated, that climate change could have on the electricity system. These include temperature impacts on electricity load and power system performance, changes to thermal cooling water availability, and changes to hydropower availability. The effect of changing water temperature on operation and reliability is not included, but we have explored ways to incorporate such effects through linking with detailed hydrological models (Vorosmarty et al. 2017). There is also no representation of climate impacts on future wind and solar resource availability, though ongoing work is exploring these effects.

\subsection{Temperature Impacts on Load}

Temperature changes influence electricity load primarily through their effects on heating and cooling demands. Modeled climate impacts on load are based on projected changes in heating and cooling degree days from the Coupled Model Intercomparison Project Phase 5 (CMIP5) climate model results (Wood 2014). Degree days are calculated directly from temperature data. Data are either derived from a single simulation of a general circulation model (GCM) for a specific representative concentration pathway (RCP), or scenario data are aggregated across several GCM-RCP scenarios with features relevant to the present analysis. Because ReEDS is not inter-temporally optimized and has limited foresight, raw degree day data with a high degree of inter-annual variability must be smoothed before use in the model to avoid skewing decisions. Smoothed degree day data are aggregated for each BA and season, and the resulting impacts on electricity load are based on temperature-load relationships developed by Sullivan et al. for each ReEDS time slice (Sullivan, Colman, and Kalendra 2015).

\subsection{Temperature Impacts on Power System Performance}

Temperature change can also affect the efficiency of thermodynamic cycles used in power generation. Higher air temperature reduces cycle efficiency and maximum power output capacity. ReEDS imposes temperature-performance relationships during summer time slices that increase thermal power plant heat rate by $0.1-0.2 \%$ and reduce available capacity by $0.5-0.75 \%$ per $1{ }^{\circ} \mathrm{C}$ increase (ICF 1995; Jaglom et al. 2014). Heat rate and generation capacity impacts in other time slices are assumed negligible.

Air temperature changes also affect cooling system performance. The relationships between temperature and water withdrawal and consumption rates in Rutberg et al. (2011) are assumed valid for all cooling technologies despite their derivation only for recirculating cooling (Rutberg et al. 2011). Though performance of once-through and pond cooling technologies will not necessarily respond to temperature in the same way as recirculating cooling, we use air temperature change as a proxy for water temperature change for these cooling systems. The result is the following functional relationship between temperature $T\left({ }^{\circ} \mathrm{C}\right)$ and fractional change in withdrawal or consumption rate $y$. This equation allows cooling system performance to be adjusted for temperature in a consistent manner with power plant capacity and efficiency.

$$
y=-1.04 \times 10^{-7} T^{3}+1.19 \times 10^{-5} T^{2}-3.62 \times 10^{-5} T+4.46 \times 10^{-3}
$$


Higher temperatures can also reduce transmission capacity by increasing electrical resistance. This effect is simulated for summer afternoon time slices with a $0.55 \%$ reduction in transmission capacity per $1{ }^{\circ} \mathrm{C}$ increase.

\subsection{Precipitation Impacts on Cooling Water Availability}

Climate change can also influence both how much water is available and when it is available. To assess climate impacts on unappropriated freshwater supplies, external collaborators in partnership with NREL have developed data specifying the changes across solve years to unappropriated freshwater available in each BA and season, accounting for changes both to total precipitation and its seasonal distribution. This procedure requires downscaling CMIP5 climate model precipitation projections, modeling the resultant effects on surface water runoff in hydrological modeling frameworks, and relating runoff changes to power sector water availability. As with temperature data, inter-annual smoothing is required to avoid biasing optimal decisions. Ongoing work has utilized multiple approaches for projecting changes to unappropriated freshwater availability, and these approaches are discussed in greater detail by Cohen et al. and EPA (Cohen et al. [in review]; EPA 2017).

Climate impacts are not imposed on any other water resource types. Appropriated surface water availability is assumed static with climate due to its legally binding nature. Climate change could also affect groundwater resources, but there are no robust methods for characterizing how precipitation and surface water runoff under alternative climate regimes affect groundwater resources across the entire United States. Applying climate impacts to other water resource categories requires new methodology and data.

\subsection{Precipitation Impacts on Hydropower}

Climate impacts on hydropower energy availability are determined using similar methodology as with thermal cooling water, where precipitation-runoff relationships are assumed applicable to water available to hydropower facilities. Impacts are represented as fractional changes to hydropower capacity factors, which are applied differently for dispatchable and non-dispatchable resources. Dispatchable hydropower is assumed to have sufficient reservoir size to maintain the same seasonal distribution of energy availability, so changes are applied on an annual basis. Season-specific changes to energy availability are applied to non-dispatchable hydropower. This capability was first exercised in the DOE Hydropower Vision report, with subsequent use for the $4^{\text {th }}$ National Climate Assessment (DOE 2016b; EPA 2017). 


\subsection{Climate Scenarios}

Several sets of climate impacts data have been developed for use in ReEDS. These include the following GCM-RCP combinations:

\begin{tabular}{ll}
\hline GCM & $\mathbf{R C P}(\mathbf{s})$ \\
\hline BCC-CSM-1.1(m) & 4.5 \\
CanESM2 & $4.5,8.5$ \\
CCSM4 & $4.5,8.5$ \\
GFDL-CM3 & 4.5 \\
GFDL-ESM2M & $2.6,4.5,6.0,8.5$ \\
GISS-E2-R & $4.5,8.5$ \\
HadGEM2-ES & $2.6,4.5,6.0,8.5$ \\
IPSL-CM5A-LR & $2.6,4.5,6.0,8.5$ \\
MIROC5 & $4.5,8.5$ \\
MIROC-ESM-CHEM & $2.6,4.5,6.0,8.5$ \\
NorESM1-M & $2.6,4.5,6.0,8.5$ \\
\hline
\end{tabular}

In addition to climate scenarios generated from specific GCM-RCP combinations, three aggregate scenarios represent temperature-precipitation futures based on summer-fall conditions in the Southwestern United States. The Southwestern United States is already water-stressed and at risk of becoming more so in hotter, dryer climate conditions, so focusing on the Southwest in the summer-fall allows exploration of particularly challenging future climate conditions. The three scenarios defined in this way include (1) ModNone: moderate warming, no precipitation change, (2) HotDry: significant warming, less precipitation, and (3) HotWet: significant warming, more precipitation. 


\section{Policy Descriptions}

Policies modeled in ReEDS include federal and state-level emission regulations, tax incentives, and portfolio standards. This section primarily focuses on existing policies, but Section 8.4 does discuss additional frameworks that exist in the model.

\subsection{Federal and State Emission Standards}

\subsubsection{New Source Performance Standards}

The U.S. EPA's New Source Performance Standards (promulgated through Section 111(b) of the Clean Air Act) require that new capacity have annual average $\mathrm{CO}_{2}$ emissions below 1,400 pounds $\mathrm{CO}_{2} / \mathrm{MWh}$ (at least as low as those of new natural gas combined cycle technology). Therefore, we do not allow ReEDS to build new coal without CCS because ReEDS does not have any non-CCS coal technologies represented that can meet this emission limit.

The existing source performance standard under the Clean Power Plan and the associated Clean Energy Incentive Program are excluded by default but can be modeled as discussed in the Appendix.

\subsubsection{Cross-State Air Pollution Rule}

ReEDS applies the Clean Air Interstate Rule (CAIR) and Cross-State Air Pollution Rule (CSAPR) using caps on power plant emissions to the states in the eastern half of the United States over which the rules are imposed. CAIR annual emission caps for $\mathrm{SO}_{2}$ and $\mathrm{NO}_{\mathrm{x}}$ are applied for 27 states in the entire eastern United States from 2010 to 2014. From 2016 onward, CSAPR annual emission allowance budgets for $\mathrm{SO}_{2}$ and $\mathrm{NO}_{\mathrm{x}}$ are applied at the state level, with CSAPR Phase 1 caps applied in 2016 and relatively more stringent Phase 2 caps applied from 2018 (EPA 2016). In addition to the annual $\mathrm{NO}_{\mathrm{x}}$ caps, CSAPR also applies an ozone-seasonspecific cap for few states. ReEDS applies an annual estimate of these ozone season caps. ReEDS also models the interstate cap and trade for $\mathrm{SO}_{2}$ and $\mathrm{NO}_{\mathrm{x}}$ allowance budgets within the respective $\mathrm{SO}_{2}$ and $\mathrm{NO}_{x}$ groups. States can only purchase additional emission credits up to their assurance limits, which is fixed at $18 \%$ of state allowance budget. Even though states can go up to $118 \%$ of their allowance budget, the total emissions allowance at the group level must be respected.

\subsubsection{Mercury and Air Toxic Standards}

In addition to these air pollution control policies, ReEDS also considers the impact of the EPA's Mercury and Air Toxic Standards (MATS) that limit pollutants from individual power plants. In contrast to the CAIR and CSAPR implementations that apply at regional scale, MATS is implemented by prescribing compliance retrofits or retirements of each unit in the coal fleet in the 2016 solve year. All these retrofit decisions are taken outside the ReEDS and are appropriately represented by:

- Re-estimating the available coal fleet capacity in each category after accounting for the retrofits (i.e., coal-unscrubbed and coal-scrubbed capacities post-MATS)

- Accounting for the appropriate retrofit costs and their impacts on the system planning costs and electricity prices 
- Accounting for the change in generation emission factors (i.e., estimating average coal fleet $\mathrm{SO}_{2}$ emission factors after plants comply with MATS limits [0.2 lb/MMBtu]).

Though MATS is primarily designed to limit mercury, hydrogen chloride and particulate matter, there are also alternate limits to other metallic/non-metallic pollutants, including $\mathrm{SO}_{2}$. Therefore, ReEDS also models the change in $\mathrm{SO}_{2}$ emissions factor for units retrofitted to comply with MATS. Though ReEDS does not constrain mercury emissions, it does track them over the planning horizon, and the MATS compliance effects are incorporated by reducing mercury emission factors for these generation technologies by $90 \%$ during post-MATS period.

The following logic is applied to each coal unit in the ABB Velocity Suite database for making exogenous retrofit decisions and fleet updates in the 2016 model year:

- Low-cost option: Do not retrofit if (1) the coal plant is set to retire before or during 2016 or (2) its $\mathrm{SO}_{2}$ emission factor is within $20 \%$ of the MATS limit (to accommodate coal switching or other low-cost strategies)

- Mid-cost option: Retrofit with dry sorbent injection if (1) the plant is set to retire before 2025 or is small in size ( $<200 \mathrm{MW})$, (2) the plant is $<300 \mathrm{MW}$ and its $\mathrm{SO}_{2}$ emission factor is within $200 \%$ of the MATS limit, (3) the plant already has a flue-gas desulfurization system, or (4) there is a planned dry sorbent injection retrofit as per the ABB Velocity Suite database.

- High-cost option: retrofit with flue-gas desulfurization if (1) the plant does not meet any of the criteria above (i.e., it is large and will retire after 2025) or (2) there is a planned flue-gas desulfurization retrofit as per the ABB Velocity Suite database.

These upgrades are mandated in ReEDS. The appropriate capacity-weighted retrofit costswhich are estimated based on the capital and operational costs ${ }^{63}$ of the flue-gas desulfurization and dry sorbent injection retrofits - are applied to the system cost and the calculated electricity price. ${ }^{64}$ The above assumptions and representation of MATS in ReEDS have at least three broad caveats:

1. The national-scale $\mathrm{SO}_{2}$ emissions could be lower than in practice, as the alternative $\mathrm{SO}_{2}$ limit of MATS has been targeted for compliance. In reality, units may comply with primary mercury and hydrogen chloride limits while still having $\mathrm{SO}_{2}$ above the MATS alternate limits.

2. Alternative low-cost compliance strategies, such as adopting low-sulfur or low-hydrogen chloride coal switching, are not considered.

3. The retrofit decisions are not based on a full-fledged economic analysis considering unit size, lifetime, O\&M cost, or other factors.

\footnotetext{
${ }^{63} \mathrm{O} \& \mathrm{M}$ costs are estimated for individual retrofits as a function of unit size (MW), heat rate, pre-MATS emission rate, removal efficiency, limestone or sorbent injection rate, waste rate, limestone cost, waste disposal cost, auxiliary power cost, water cost, labor rate, and other factors.

${ }^{64}$ The O\&M costs were taken from documentation of EPA's Integrated Planning Model (IPM) Versions 5.1, 5.2, and 5.5, which are no longer available online.
} 


\subsubsection{California Carbon Cap}

California's Global Warming Solution Act of 2016 (referred to as Assembly Bill 398 or AB 398) established a program to reduce economy-wide greenhouse gas emissions to 1990 levels by 2020. In 2016, legislation was passed that codified the 2030 greenhouse gas target to $40 \%$ below 1990 levels. In ReEDS, these state carbon caps are modeled as a cap on electricity-system $\mathrm{CO}_{2}$ emissions from generators either located in California or serving load in the state. Direct $\mathrm{CO}_{2}$ emissions from generators located in California count toward the cap. $\mathrm{CO}_{2}$ from imported electricity is estimated through an accounting of imported energy and the carbon intensity of the states from which that energy originated. The default representation in ReEDS estimates the imported carbon intensities at the state level and updates the intensities over time based on the prior year's emissions.

Because California's greenhouse gas reduction targets are legislated for all economic sectors while ReEDS only models the electricity sector, we rely on published economy-wide modeling results to estimate electric sector-specific caps that are used in ReEDS. In particular, we apply power sector caps based on the annual CA electric sector emissions (from in-state and imported electricity) from California Public Utilities Commission (CPUC 2018), which provides guidance for a 42 million $\mathrm{tCO}_{2}$ cap by 2030. We enforce that cap from 2030 to 2050. The pre-2030 cap ramps linearly from 60 million $\mathrm{tCO}_{2}$ in 2020 to the 42 million $\mathrm{tCO}_{2}$ in 2030. Note that we also model California's RPS policy.

\subsubsection{Regional Greenhouse Gas Initiative}

The Regional Greenhouse Gas Initiative cap-and-trade program limits the $\mathrm{CO}_{2}$ emissions for fossil fuel-fired power plants in nine states: Connecticut, Delaware, Maine, Maryland, Massachusetts, New Hampshire, New York, Rhode, Island, and, Vermont.

We enforce allowance budgets from the update model rule adopted in $2017 .{ }^{65}$ We ignore the provision for privately banked allowances and therefore use the unadjusted budgets: 165 million short tons in 2012 declining to 91 million by 2014, then declining 2.5\% per year from 2015 to 2020. According to the 2017 Model Rule, the 2021 cap is set at 75 million short tons and decreases by 2.275 million tons per year until 2030. We assume the budget remains constant beyond 2030. We do not model banking of allowances, emissions offsets, or recycling of initiative allowance revenues. A price floor is implemented starting in 2014 at $\$ 2$ per short ton and increases $2.5 \%$ per year thereafter.

65 “2017 Model Rule," accessed April 26, 2018, https://www.rggi.org/program-overview-and-design/programreview. For more information, see:

- "About the Regional Greenhouse Gas Initiative (RGGI)," fact sheet updated August 2016, https://www.rggi.org/docs/Documents/RGGI_Fact_Sheet.pdf

- “The RGGI $\mathrm{CO}_{2}$ Cap,” https://www.rggi.org/design/overview/cap

- "Regional Greenhouse Gas Initiative,” December 2013, http://www.c2es.org/docUploads/rggi-brief-12-1813-updated.pdf. 


\subsection{Federal and State Tax Incentives}

\subsubsection{Renewable Production and Investment Tax Credits}

Existing federal tax incentives for renewable energy are included in ReEDS. These include the PTC and the ITC - and the Modified Accelerated Cost Recovery System (MACRS) depreciation schedules. ${ }^{66}$ The most recent renewable tax credit extensions were passed in December 2015 as part of the Consolidated Appropriations Act, 2016. Our representations of the PTC and ITC are based on this act, including tax credit values, schedules, expirations, and technology eligibility (Mai et al. 2016). Current technology-specific depreciation schedules are modeled for all years, as we assume they are permanent parts of the tax code.

Model representations of the latest tax credit extensions are complicated by the "commencedconstruction" provision in these policies, the annual ramp-down in tax credit value, and the twoyear modeling intervals used in ReEDS. Because ReEDS accounts for when plants come online rather than when they begin construction, we represent the commenced-construction provision by assuming the tax credit received by facilities corresponds to the value of the tax credits at the time the plant would typically start construction. For most purposes, we assume construction starts two years prior to the commercial operation date for utility-scale solar and wind and one year prior for commercial rooftop PV. However, guidance from the Internal Revenue Service (IRS) ${ }^{67}$ allows for a longer construction period and equipment warehousing for wind projects to qualify for the PTC. It is unclear how the wind industry and wind deployment will react to this unprecedented IRS guidance. As a result, we conservatively represent a three-year period for wind in our PTC representation, meaning a project with a commercial online date of 2019 would qualify for the PTC value in 2016, for example.

For utility solar, facilities must be placed in service before the end of 2023 to qualify for a tax credit greater than $10 \%$. To simplify representation in the model, we assume a two-year construction period. ${ }^{68}$ For residential PV, the ITC is a placed-in-service tax credit, meaning the commenced-construction provision does not apply. Furthermore, the effective value of the tax credit during each two-year model period is based on the average value of the tax credit available after accounting for these under construction periods. For example, an effective $28 \%$ ITC is modeled for utility-scale solar during the 2022 ReEDS model year (representing 2021-2022) based on the average of the $30 \%$ ITC available in 2019 and the $26 \%$ ITC available in $2020 .{ }^{69}$ Table 21 presents the effective wind PTC and solar ITC schedules modeled in ReEDS compared with the nominal schedule listed by the policy.

\footnotetext{
${ }^{66}$ Note that the eligible cost basis for MACRS is reduced by one-half the value of the tax credit.

67 "Beginning of Construction for Sections 45 and 48: Notice 2016-31," IRS 2016, https://www.irs.gov/pub/irsdrop/n-16-31.pdf.

${ }^{68}$ This is justified by the typically shorter construction periods for utility PV. Also, these assumptions are largely consistent with IRS guidance for commenced-construction provisions in earlier tax credit policies; see "Beginning of Construction for Sections 45 and 48: Notice 2015-25," Internal Revenue Service, U.S. Dept. of the Treasury, accessed January 28, 2016, https://www.irs.gov/pub/irs-drop/n-15-25.pdf.

${ }^{69}$ This representation may underestimate the impact of the tax credit on near-term deployment, as more projects may be moved forward to gain the higher tax credit value in earlier years. However, we conducted test scenarios and found little impact in renewable energy capacity deployment results when shifting the effective tax credit schedule slightly to account for this behavior.
} 
Though they are not shown in Table 21, we also include tax credits for other renewable energy technologies in the modeled scenarios. The model representation of the tax credit extensions includes effective PTCs for biopower, geothermal, and hydropower lasting through the 20172018 model period to account for the commenced-construction deadline at the end of 2016. A PTC value of $2.3 \phi / \mathrm{kWh}$ is applied to biopower and geothermal, and a PTC of $1.2 \phi / \mathrm{kWh}^{70}$ is applied to new hydropower during this period. No tax credits are assumed for biopower and hydropower after 2018. A geothermal ITC of $10 \%$ is modeled for all years after 2018. Another nuance not shown on Table 21 is the ITC option in lieu of the PTC for certain qualifying facilities, including offshore wind. For offshore wind, we include an effective ITC through the 2020 model year. $^{71}$

Due to these complexities and the required simplifications, we also limit near-term wind capacity deployment as discussed in section 2.4.1.

\footnotetext{
${ }^{70}$ These values in implemented in ReEDS in 2015\$.

${ }^{71}$ The current legislation specifies a ramp-down schedule for the ITC that is available to offshore wind wherein a $30 \%$ ITC is available in 2016 and reduces by six percentage points annually through 2019 . However, we have not implemented the ability to model ITC ramp-downs for offshore wind. We include a full $30 \%$ offshore wind ITC for all model years from 2016 to 2020, but in most scenarios, no new offshore wind capacity is endogenously added during this period by the model. For this reason, we conclude that a more accurate representation of the ramp-down schedule would yield the same result.
} 
Table 23. Actual and Modeled Schedule of Wind and Solar Tax Credits from the Consolidated Appropriations Act, 2016

\begin{tabular}{|c|c|c|c|c|c|c|c|c|c|c|c|c|c|}
\hline \multicolumn{2}{|c|}{ Consolidated Appropriations Act, 2016} & 2015 & 2016 & 2017 & 2018 & 2019 & 2020 & 2021 & 2022 & 2023 & 2024 & 2025 & Future \\
\hline \multicolumn{2}{|l|}{ Wind PTC } & Full & Full & $80 \%$ & $60 \%$ & $40 \%$ & $0 \%$ & $0 \%$ & $0 \%$ & $0 \%$ & $0 \%$ & $0 \%$ & $0 \%$ \\
\hline \multirow{3}{*}{ Solar ITC } & Utility & $30 \%$ & $30 \%$ & $30 \%$ & $30 \%$ & $30 \%$ & $26 \%$ & $22 \%$ & $10 \%$ & $10 \%$ & $10 \%$ & $10 \%$ & $10 \%$ \\
\hline & Commercial/Third-Party-Owned & $30 \%$ & $30 \%$ & $30 \%$ & $30 \%$ & $30 \%$ & $26 \%$ & $22 \%$ & $10 \%$ & $10 \%$ & $10 \%$ & $10 \%$ & $10 \%$ \\
\hline & Residential Host-Owned & $30 \%$ & $30 \%$ & $30 \%$ & $30 \%$ & $30 \%$ & $26 \%$ & $22 \%$ & $0 \%$ & $0 \%$ & $0 \%$ & $0 \%$ & $0 \%$ \\
\hline & Model Representation & \multicolumn{2}{|c|}{$2015-16$} & \multicolumn{2}{|c|}{ 2017-18 } & \multicolumn{2}{|c|}{ 2019-20 } & \multicolumn{2}{|c|}{ 2021-22 } & \multicolumn{2}{|c|}{ 2023-24 } & \multicolumn{2}{|c|}{ Future } \\
\hline \multicolumn{2}{|l|}{ Wind PTC } & \multicolumn{2}{|c|}{ Full } & \multicolumn{2}{|c|}{ Full } & \multicolumn{2}{|c|}{$90 \%$} & \multicolumn{2}{|c|}{$50 \%$} & \multicolumn{2}{|c|}{$0 \%$} & \multicolumn{2}{|c|}{$0 \%$} \\
\hline \multirow{3}{*}{ Solar ITC } & Utility & $30 \%$ & & $30 \%$ & & $30 \%$ & & $28 \%$ & & $16 \%$ & & $10 \%$ & \\
\hline & Commercial/Third-Party-Owned & $30 \%$ & & $30 \%$ & & $30 \%$ & & $24 \%$ & & $10 \%$ & & $10 \%$ & \\
\hline & Residential Host-Owned & $30 \%$ & & $30 \%$ & & $28 \%$ & & $11 \%$ & & $0 \%$ & & $0 \%$ & \\
\hline
\end{tabular}

Table is adapted from Mai et al. (2016) but is updated to reflect the longer construction periods allowed for qualifying wind facilities. 
Several states also have production and investment incentives for renewable energy sources. The default values used in these states are listed in Table 22. Though other states have tax credit policies in place, those programs are for small system installations and have dollar amount limits that render them of limited value for ReEDS utility-scale investments.

Table 24. Default State Tax Incentives

\begin{tabular}{lccc}
\hline State & $\begin{array}{l}\text { PTC } \\
\mathbf{( 2 0 1 3 \$ / M W h )}\end{array}$ & ITC (\%) & End Year \\
\hline North Dakota $^{72}$ & - & 12.6 & 2017 \\
Oklahoma & 5.0 & - & 2023 \\
Utah & 3.5 & - & - \\
\hline
\end{tabular}

\subsubsection{Carbon Oxide Sequestration Tax Credit}

The Bipartisan Budget Act of 2018 included expanded the IRS Tax Code Section 45Q Credit for Carbon Oxide Sequestration (26 USC 45Q: Credit for Carbon Oxide Sequestration 2018). Though this policy existed prior to the 2018 Budget Act, it was not previously included in ReEDS because it had a limited impact on the electricity system due to a stipulation that only 75 million tons of $\mathrm{CO}_{2}$ was eligible for the tax credit across all facilities and time. The 2018 policy update removes this restriction and raises the credit value ${ }^{73}$ to $\$ 22.66 / \mathrm{tCO}_{2}$ in 2016 increasing linearly to $\$ 50 / \mathrm{tCO}_{2}$ in 2026 for $\mathrm{CO}_{2}$ sequestered without previously being used for enhanced oil or gas recovery (EOR/EGR); $\mathrm{CO}_{2}$ sequestered after use in $\mathrm{EOR} / \mathrm{EGR}$ has a value of $\$ 12.83 / \mathrm{tCO}_{2}$ in 2016 increasingly linearly to $\$ 35 / \mathrm{tCO}_{2}$ in 2026 . In both cases, the credit value remains constant thereafter (in nominal terms) without a planned expiration date for the policy. Any qualified facility beginning construction after January 1, 2018 is eligible to receive the credit for the first 12 years of operation.

ReEDS implements a simplified version of this policy given its current representation of CCS technologies. CCS capacity is made eligible for the policy beginning in the 2018 solve year. GasCC-CCS constructed through 2028 is eligible based on its 3-year construction time, and CoalCCS constructed through 2030 is eligible based on a 6-year construction time. ReEDS does not characterize EOR/EGR opportunities, so all captured $\mathrm{CO}_{2}$ is assumed sequestered without $\mathrm{EOR} / \mathrm{EGR}$. The $\$ / \mathrm{tCO}$ credit is converted to a $\$ / \mathrm{MWh}$ value using fuel $\mathrm{CO}_{2}$ content, heat rate, and $\mathrm{CO}_{2}$ capture rate, and this $\$ / \mathrm{MWh}$ value is then applied in a similar manner as the renewable PTC. To account for the difference in marginal generating costs beyond the 12-year availability period, O\&M costs for CCS technologies are increased 12 years after any new CCS construction so that operating costs of CCS capacity no longer receiving the credit are properly reflected in ReEDS dispatch decisions.

\subsection{State Renewable Portfolio Standards}

ReEDS models state RPSs, including technology set-asides and renewable energy certificate (RECs) that can count toward RPS compliance. RPS rules are complex and can vary significantly between states. The RPS representation in ReEDS attempts to model the primary

\footnotetext{
${ }^{72}$ The policy allows a credit of $3 \%$ per year for five years, which is discounted to $12.6 \%$ in ReEDS.

${ }^{73} \mathrm{All} \mathrm{CO}_{2}$ credit values in this section are in 2008 U.S. dollars.
} 
impacts of these RPS rules but includes many simplifying assumptions. In addition, in recent years there have been numerous changes to RPS legislation. We periodically update our representation to capture the recent changes to the legislation; however, the numerous and frequent changes to state laws create challenges to having a current representation of all RPS legislation.

Table 23 shows the respective RPS targets and technology set-asides for years 2020, 2025 and 2030 as a percentage of state electricity sales as modeled within ReEDS. These values - along with many other data that we use to represent nuanced RPS rules - are based on data compiled by Lawrence Berkeley National Laboratory, which takes into account the in-state REC multiplier incentives and load adjustments (e.g., sales-weighted RPS targets considering different load serving entities subject to compliance, such as investor owned utilities, municipal utility, and cooperatives). ${ }^{74}$ Solar includes UPV and rooftop PV, wind includes both land-based and offshore technologies, and DG includes rooftop PV and ground-mounted PV systems located within the distribution network. ${ }^{75}$ ReEDS also models alternative compliance payments for unmet RPS requirement for both main RPS targets and solar set-asides as is consistent with the available data. $^{75}$

Technology eligibility for state RPS requirements is appropriately modeled for each state. ${ }^{75}$ For instance, California's RPS does not allow in-state rooftop solar technologies to contribute toward its RPS. ${ }^{76}$ Additionally, every state has specific rules regarding hydropower generation's eligibility toward contributing RECs, which are usually based on each unit's vintage and size (e.g., small hydro with specific capacity cut-offs are eligible in some states). ReEDS models these as allowable capacity fractions (estimated from ABB Velocity Suite database (ABB 2018)), which is imposed on each state's total hydropower generation thereby limiting the amount of hydropower RECs that each state could generate. Additionally, ReEDS also imposes an upper limit on the total hydropower RECs that a state can use toward its RPS based on historical data as compiled and estimated by Lawrence Berkeley National Laboratory.

We also model restricted eligibility of existing renewable capacity to contribute to future RPS targets. In other words, while the amount of renewable generation in 2014 exceeds RPS requirements in that year, some of this renewable generation has contractual or other obligations that prevent it from being eligible to meet RPS requirements. This eligibility restriction, estimated by region and technology type, was estimated by Lawrence Berkeley National Laboratory. For the contiguous United States, we estimate that $25 \%$ of renewable generation in excess of RPS demand in 2014 is eligible to meet RPS demand after 2014. The eligibility restriction is also reduced when capacity is retired by an amount equal to the restricted generation multiplied by the ratio of retired capacity to the capacity operating in 2014 . We do not model banking or borrowing of RECs.

\footnotetext{
${ }^{74}$ See Barbose (2017) and https://emp.lbl.gov/projects/renewables-portfolio. Spreadsheet accessed January, 2017.

${ }^{75}$ See Database of State Incentives for Renewables \& Efficiency (DSIRE) website at dsireusa.org . If data are unavailable, ReEDS forces RPS target to be met by using a default alternative compliance payments and solar alternative compliance payments of $\$ 200 / \mathrm{MWh}$ and $\$ 400 / \mathrm{MWh}$ respectively.

${ }^{76}$ This version of ReEDS does not include CA Senate Bill 100 requiring $100 \%$ carbon-free electricity by 2045 , as this bill was passed too recently to be included in this model version. The CA Senate Bill 100 policy will be included in future ReEDS versions.
} 
Table 23 also lists the allowable states from which each state may import RECs; interstate REC transactions that are required to be bundled with energy are marked with an asterisk. With the exception of California, ReEDS enforces an upper limit on the total RECs (both bundled and unbundled) that can be imported for that state's RPS compliance. For California alone, due to its unique out-of-state rules, ReEDS enforces two upper limits, one on the total unbundled REC imports and the other on the total bundled REC imports. There are a myriad of possibilities of interstate REC transactions, in terms of both which two states can transact and the quantity of those transactions. To constrain the solution space of ReEDS to credible values, the interstate REC trading modeling is based on historical observations (Holt 2016), as shown in the final two columns of Table 23. The out-of-state total REC import percentages for each state in are limited to those observed in 2012-2013 (Heeter 2015).

Three states (NJ, MA, MD) have implemented carveouts for offshore wind. These carveouts are fulfilled through planned projects. NJ and MA have capacity based carveouts of 3,500 and 1,600 MW, respectively, by 2030. MD has a retail sales-based requirement $(2.5 \%)$ that we assume will be fulfilled by previously planned projects. These projects are assumed to be rebuilt once they are retired. 
Table 25. Effective State RPS Requirements in ReEDS

\begin{tabular}{|c|c|c|c|c|c|}
\hline \multirow[b]{2}{*}{ State } & \multicolumn{3}{|c|}{ RPS target / Solar / DG / Wind set-asides (\%) } & \multirow{2}{*}{$\begin{array}{l}\text { Allowable states for REC import, includes } \\
\text { Canadian provinces ('bundling requirement) }\end{array}$} & \multirow{2}{*}{$\begin{array}{l}\text { REC import limit } \\
\text { (\% of RPS } \\
\text { target) }\end{array}$} \\
\hline & 2020 & 2025 & 2030 & & \\
\hline$A Z$ & $5.9 /-/ 1.8 /-$ & 8.8/-/2.6/- & 8.8/-/2.6/- & $\mathrm{CA}^{*}, \mathrm{CO}^{*}, \mathrm{NM}^{*}$ & 100 \\
\hline CA & $32.2 /-/-/-$ & $39 /-/-/-$ & $48.8 /-/-/-$ & $A Z^{*}, I D, M T, N M, N V^{*}, \mathrm{OR}^{*}, \mathrm{UT}^{*}, \mathrm{WA}, \mathrm{WY}^{*}, \mathrm{MEX}^{*}$ & $\begin{array}{l}25<2013 \\
15<2016 \\
10>2017 \\
\text { (only unbundled, } \\
100 \% \text { for } \\
\text { bundled) }\end{array}$ \\
\hline $\mathrm{CO}^{\mathrm{a}}$ & 19.1/-/0.8/- & 19.5/-/0.8/- & 19.6/-/0.8/- & WY & 8 \\
\hline CT & 23/-/-/- & 23/-/-/- & 23/-/-/- & $\begin{array}{l}\mathrm{MA}, \mathrm{ME}, \mathrm{NH}, \mathrm{NY}^{*}, \mathrm{RI}, \mathrm{VT}, \mathrm{NB}^{*}, \mathrm{NL}^{*}, \mathrm{NS}^{*}, \mathrm{QC}^{*} \text {, } \\
\mathrm{NFI}^{*}, \mathrm{PEI}^{*}\end{array}$ & 59 \\
\hline $\mathrm{DE}^{\mathrm{b}}$ & 14.4/-/1.9/- & 19/-/3/- & 19/-/3/- & $\mathrm{IL}^{*}, \mathrm{IN}^{*}, \mathrm{MD}, \mathrm{PA}^{*}, \mathrm{VA}^{*}, \mathrm{WV}^{*}$ & 94 \\
\hline$I^{\mathrm{b}, \mathrm{c}}$ & 13.6/-/1.5/1.5 & $20.3 /-/ 2.2 / 2.2$ & 21.1/-/3.1/3.1 & $\begin{array}{l}\text { IA, IN, MD, MN, MO, ND, NY, OH, PA, SD, VA, WI, } \\
\text { WV }\end{array}$ & 60 \\
\hline $\mathrm{MA}^{\mathrm{b}}$ & $14.8 /-/ 3.5 /-$ & 19.1/-/3.6/- & 23.5/-/3.7/- & $\begin{array}{l}\mathrm{CT}, \mathrm{ME}, \mathrm{NH}, \mathrm{NY}^{*}, \mathrm{RI}, \mathrm{VT}, \mathrm{NB}^{*}, \mathrm{NL}^{*}, \mathrm{NS}^{*}, \mathrm{QC}^{*} \text {, } \\
\mathrm{NFI}^{*}, \mathrm{PEI}^{*}\end{array}$ & 62 \\
\hline$M D^{b, d}$ & 18/-/1.9/- & 20.6/-/2.1/- & 23.1/-/2.4/- & $\begin{array}{l}\mathrm{DE}, \mathrm{IA}, \mathrm{IL}, \mathrm{IN}^{*}, \mathrm{NC}^{*}, \mathrm{NY}^{*}, \mathrm{OH}^{*}, \mathrm{PA}^{*}, \mathrm{TN}^{*}, \mathrm{VA}^{*}, \mathrm{WI}^{*} \\
\mathrm{WV}^{*}\end{array}$ & 70 \\
\hline ME & 33.5/-/-/- & 33.5/-/-/- & 33.5/-/-/- & $\begin{array}{l}\text { CT, MA, NH, RI, VT, NB* }{ }^{*} \mathrm{NL}^{*}, \mathrm{NS}^{*}, \mathrm{QC}^{*}, \mathrm{NFI}^{*} \text {, } \\
\mathrm{PEI}^{*}\end{array}$ & 18 \\
\hline MI & $10.9 /-/-/-$ & 13.0/-/-/- & $12.9 /-/-/-$ & IA, IN, MN, WI & 0 \\
\hline $\mathrm{MN}$ & 25.3/0.8/-/11.4 & 28.1/0.8/-/11.4 & 28.1/0.8/-/11.4 & IA, MI, ND, SD, WI, MB, ON, SK & 24 \\
\hline $\mathrm{MO}^{\mathrm{b}}$ & 6.8/-/0.1/- & $10.1 /-/ 0.2 /-$ & $10.1 /-/ 0.2 /-$ & $\mathrm{IA}, \mathrm{KS}$, & 94 \\
\hline MT & $10.7 /-/-/-$ & 10.7/-/-/- & $10.7 /-/-/-$ & $\mathrm{ND}^{*}, \mathrm{OR}^{*}, \mathrm{WA}^{*}, \mathrm{BC}^{*}$ & 6 \\
\hline NC & $4.1 / 0.2 /-/-$ & $5 / 0.2 /-/-$ & $4.8 / 0.2 /-/-$ & $\begin{array}{l}\mathrm{AL}^{*}, \mathrm{FL}^{*}, \mathrm{GA}^{*}, \mathrm{LA}^{*}, \mathrm{MS}^{*}, \mathrm{OH}^{*}, \mathrm{PA}^{*}, \mathrm{SC}^{*}, \mathrm{TN}^{*}, \mathrm{VA}^{*}, \\
\mathrm{WV}^{*}\end{array}$ & 43 \\
\hline
\end{tabular}




\begin{tabular}{|c|c|c|c|c|c|}
\hline \multirow[b]{2}{*}{ State } & \multicolumn{3}{|c|}{ RPS target / Solar / DG / Wind set-asides (\%) } & \multirow{2}{*}{$\begin{array}{l}\text { Allowable states for REC import, includes } \\
\text { Canadian provinces (*bundling requirement) }\end{array}$} & \multirow{2}{*}{$\begin{array}{l}\text { REC import limi } \\
\text { (\% of RPS } \\
\text { target) }\end{array}$} \\
\hline & 2020 & 2025 & 2030 & & \\
\hline $\mathrm{NH}^{\mathrm{b}}$ & 20/-/0.3/- & 24.3/-/0.3/- & 24.3/-/0.3/- & $\begin{array}{l}\mathrm{CT}, \mathrm{MA}, \mathrm{ME}, \mathrm{NY}^{*}, \mathrm{RI}, \mathrm{VT}, \mathrm{NB}^{*}, \mathrm{NL}^{*}, \mathrm{NS}^{*}, \mathrm{QC}^{*} \text {, } \\
\mathrm{NFI}^{*}, \mathrm{PEI}^{*}\end{array}$ & 35 \\
\hline$N J^{b}$ & 23.4/-/3.4/- & 23.9/-/4.3/- & 24.1/-/6.8/- & $\mathrm{DE}, \mathrm{IL}^{*}, \mathrm{IN}^{*}, \mathrm{MD}, \mathrm{OH}^{*}, \mathrm{PA}^{*} \mathrm{VA}^{*}, \mathrm{WV}^{*}$ & 76 \\
\hline NM & $16 / 2.8 / 0.4 / 4.1$ & $16 / 2.8 / 0.4 / 4.1$ & $16 / 2.8 / 0.4 / 4.1$ & - & 0 \\
\hline NV & $16.4 / 0.5 /-/-$ & 21.1/0.6/-/- & 21.2/0.6/-/- & - & 100 \\
\hline NY & 7.9/-/0.7/- & 16.3/-/0.7/- & 25.4/-/0.7/- & $\mathrm{RI}^{*}, \mathrm{ON}^{*}, \mathrm{QC}^{*}$ & 4 \\
\hline $\mathrm{OH}^{\mathrm{b}}$ & $5.7 /-/ 0.2 /-$ & $10.1 /-/ 0.4 /-$ & $11.1 /-/ 0.4 /-$ & $\mathrm{IN}^{*}, \mathrm{KY}^{*}, \mathrm{MI}^{*}, \mathrm{PA}^{*}, \mathrm{WV}^{*}$ & 57 \\
\hline $\mathrm{OR}^{\mathrm{b}}$ & $14.2 /-/ 0 /-$ & $20.2 /-/ 0 /-$ & 25.9/-/0/- & $\mathrm{CA}^{*}, \mathrm{ID}^{*}, \mathrm{MT}^{*}, \mathrm{UT}^{*}, \mathrm{WA}^{*}, \mathrm{WY}^{*}, \mathrm{BC}^{*}$ & 42 \\
\hline $\mathrm{PA}^{\mathrm{b}}$ & $7.8 /-/ 0.5 /-$ & $7.8 /-/ 0.5 /-$ & 7.8/-/0.5/- & $\mathrm{DE}, \mathrm{IL}, \mathrm{IN}, \mathrm{MD}, \mathrm{NC}, \mathrm{NJ}, \mathrm{OH}, \mathrm{VA}, \mathrm{WV}$ & 47 \\
\hline RI & 15.9/-/-/- & 23.3/-/-/- & $30.8 /-/-/-$ & $\begin{array}{l}\mathrm{CT}, \mathrm{MA}, \mathrm{ME}, \mathrm{NH}, \mathrm{NY}^{*}, \mathrm{VT}, \mathrm{NB}^{*}, \mathrm{NL}^{*}, \mathrm{NS}^{*}, \mathrm{QC}^{*} \text {, } \\
\mathrm{NFI}^{*}, \mathrm{PEI}^{*}\end{array}$ & 77 \\
\hline TX & $4.4 /-/-/-$ & $4.2 /-/-/-$ & $4 /-/-/-$ & - & 0 \\
\hline VT & $59 /-/ 2.8 /-$ & 63/-/5.8/- & 71/-/8.8/- & $\mathrm{CT}, \mathrm{MA}, \mathrm{ME}^{*}, \mathrm{NH}, \mathrm{RI}$ & 100 \\
\hline WA & $12.2 /-/-/-$ & $12.2 /-/-/-$ & $12.2 /-/-/-$ & ID, MT, OR, BC* & 43 \\
\hline WI & $10 /-/-/-$ & 9.9/-/-/- & $10 /-/-/-$ & $\mathrm{IA}^{*}, \mathrm{MI}^{*}, \mathrm{MN}^{*}, \mathrm{ND}^{*}, \mathrm{SD}^{*}, \mathrm{MB}^{*}, \mathrm{SK}^{*}$ & 41 \\
\hline
\end{tabular}

"Interstate REC transactions that are required to be bundled with energy are marked with an asterisk.

a Based on historical observation, only $50 \%$ of the actual DG carve out for Colorado is assumed to be met using distributed solar technologies (DUPV and distributed PV).

${ }^{b}$ Based on historical observation, the solar carve out in these states are seen to be met only using distribution side solar technologies. Hence the solar carve out in these states are modeled as a DG carve out in ReEDS.

c Illinois allows for $50 \%$ of its RPS target to be met using alternative compliance payments, and hence ReEDS targets are adjusted to reflect this.

dWashington, D.C. RPS targets are rolled into Maryland (Washington D.C. load also rolled into Maryland). 


\subsection{Storage Mandates}

Three state storage mandates are represented in ReEDS. ${ }^{77}$ These include a 1,125 MW storage requirement in California by 2022, a 50 MW storage requirement in Massachusetts by 2020, and a $2.5 \mathrm{MW}$ storage requirement in Oregon by 2020. These are enforced through prescribed builds of 4-hour battery storage in each of the states, and the mandates are required to be maintained throughout the model horizon (i.e., once a battery is retired it must be rebuilt if the retirement causes the capacity to fall below the mandate).

\subsection{Other Policy Capabilities}

In addition to the existing policies described above, ReEDS also includes several optional policy implementations that are useful for exploring alternative futures or the impact of existing policies. These additional policy frameworks include

- National Clean Energy Standard: This framework allows the user to specify which technologies count as "clean energy" and enforce a minimum limit for the penetration of these clean energy technologies.

- National Renewable Portfolio Standard: This standard enforces a national RPS, with the RPS trajectory defined by the user.

- Carbon Tax: This feature implements a user-specified carbon tax on burner-tip emissions from the power sector.

- National Emissions Limit: This framework limits the total national emissions according to user-specified values. The limit is often referred to as a carbon cap or $\mathrm{CO}_{2}$ cap.

- Alternative ITC and PTC Schedules: In addition to the ITC and PTC schedules described in Section 8.2, the ITC and PTC can be modified to apply for any number of years and to any technology.

- Alternative Financing Measures: Policy-related financing impacts such as MACRS or the under-construction provisions for the ITC and PTC can be modified as specified by the user.

${ }^{77}$ Additional storage policies will be evaluated for inclusion in future model versions. 


\section{Capital Financing, System Cost, and Electricity Rates}

\subsection{Financing of Capital Stock}

The financing assumptions used in ReEDS are taken directly from the 2018 ATB spreadsheet (NREL 2018b), using the "Market Factor Financials" and the 20-year capital recovery period options. The ATB has technology-specific and time-varying financing parameters, including interest rate, rate of return on equity, debt fraction, and tax rate. Other elements of the ATB included in ReEDS include construction schedules, MACRS depreciation schedules, and inflation rates. These values are further defined and explained in the ATB, with additional explanation of our financing implementation detailed in the Capital Cost Financial Multipliers appendix of this document. The only deviation in ReEDS from the ATB is associated with the MACRS implementation. Because of the bonus depreciation opportunities in the most recent tax law, the MACRS schedules for all technologies use the 5-year MACRS schedule through 2023, then those schedules ramp back up to the schedules specified in the ATB by 2026.

Tax credits are assumed to impact financing costs. We assume lower debt fractions are available to technologies receiving tax credits to reflect some of the higher costs associated with financing these projects. The result is a higher weighted average cost of capital (WACC) when a tax credit (ITC or PTC) is available. Bolinger (2015) summarizes these considerations, and Mai et al. (2015) describe this implementation in detail.

\subsection{Electric Sector Costs}

Two system-wide cost metrics are calculated from each ReEDS run: a present value of direct electric sector system costs and electricity price. These cost calculations are not part of the ReEDS optimization process; they are calculated after the ReEDS optimizations have been conducted. The cost metrics provided directly from ReEDS do not include any environmental or health externalities (e.g., social cost of carbon emissions).

\subsubsection{Present Value of Direct Electric Sector Cost}

The present value system cost metric accounts for capital and operating expenditures incurred over the entire study horizon for all technology types considered, including generation, transmission, and storage. The cost in each future year is discounted by a $3 \%$ social discount rate. Not to be confused with the discount rate used in the optimization for investment decisions, the social discount rate is selected to represent private-sector investment decisions for electric system infrastructure and approximates the expected market rate of return of investors. All costs incurred prior to the start of the specified economic horizon are assumed to be sunk. The costs incurred from investments made near the end of the economic horizon are prorated to account for only the years in which the investment is used.

\subsubsection{Electricity Price}

One electricity price metric is a cost-of-service price with a 30-year rate base or amortization of all investments to 30 equal annual payments. Investments include costs for new generation capacity, replaced generation capacity, and new transmission lines. The output electricity pricereported by BA - is a weighted average of the electricity prices for each time-slice, which are calculated differently depending on whether the region is a net importer or net exporter. 
Electricity produced from rooftop PV systems are subtracted from the load for this calculation. The methodology uses a calibration step to match historical (2010) retail rates to consider distribution costs and/or the markup between wholesale and retail rates for regions with competitive wholesale markets. This additional cost is assumed to be uniform across all years. Though this metric is not indicative of actual retail prices in all regions (e.g., price impacts for competitive markets are not evaluated with ReEDS), it provides an indication of the price impacts over time. Details about how the cost-of-service prices are calculated in ReEDS can be found in the appendix under the "Cost-of-Service Electricity Prices" section.

There is also another methodology within ReEDS to calculate a "competitive"78 electricity price (F. H. Murphy and Smeers 2005; Ventosa et al. 2005; EIA 2017). This calculation takes advantage of the linear programming formulation of the model. Specifically, the marginal price on a model constraint represents how much the objective function would change given a change in the right-hand side of the constraint. Each constraint can be viewed as a market with a marginal price and quantity. At optimality, the total revenue (the product of price and quantity) across all constraints is equal to the objective function value.

The constraints within ReEDS are written such that the marginal values from the load constraints can be used as a proxy for the competitive electricity price. The load constraints are linked to the supply-demand balance constraints, capacity constraints, operating reserve constraints, and others ${ }^{79}$ through load variables. Taking the marginal value from the load balance constraint, we can find the marginal value of an additional unit of load (e.g., MWh) to the system, accounting for the additional energy, capacity, and operating reserves required. In other words, the reported competitive prices in ReEDS capture energy and capacity value. It is assumed that this methodology mimics a competitive electricity market's behavior better than the cost-of-service electricity price. The user can choose to use the competitive price, the regulated price, or a blending of the two to calculate national or regional electricity prices.

\footnotetext{
${ }^{78}$ See Murphy and Smeers (2005), Ventosa et al. (2005), and EIA (2017).

${ }^{79}$ Specifically, state RPS constraints
} 


\section{ReEDS North American Expansion}

As discussed in Section 5.4, ReEDS includes an exogenous representation of Canada and a limited endogenous representation of the Baja California region of Mexico when ReEDS is run only for the continental United States. However, the ReEDS model also includes the capability to model both Canada and Mexico endogenously. This continental version of the ReEDS model, which is referred to as ReEDS-North America, is described here. Country specific models can be run separate from the continental model as ReEDS-Canada and ReEDS-Mexico. The ReEDSCanada model includes 20 additional BAs, regions as shown in Figure 34, and 47 new wind/CSP resource. The Canadian BAs only cover areas where the grid is directly connected to the U.S. system and therefore do not include the Yukon, Northwest Territories, and Nunavut. The ReEDS-Mexico model includes 49 additional BAs, which are also used for defining wind/CSP resource regions. This representation directly aligns with the transmission regions used by Secretaría de Energía for Mexico (SENER) in their annual report Programa de Desarrollo del Sistema Eléctrico Nacional (PRODESEN). The Mexican BAs cover all regions in Mexico but do not include exporting generators on the Mexico-California border, which are modeled endogenously when modeling the United States. 


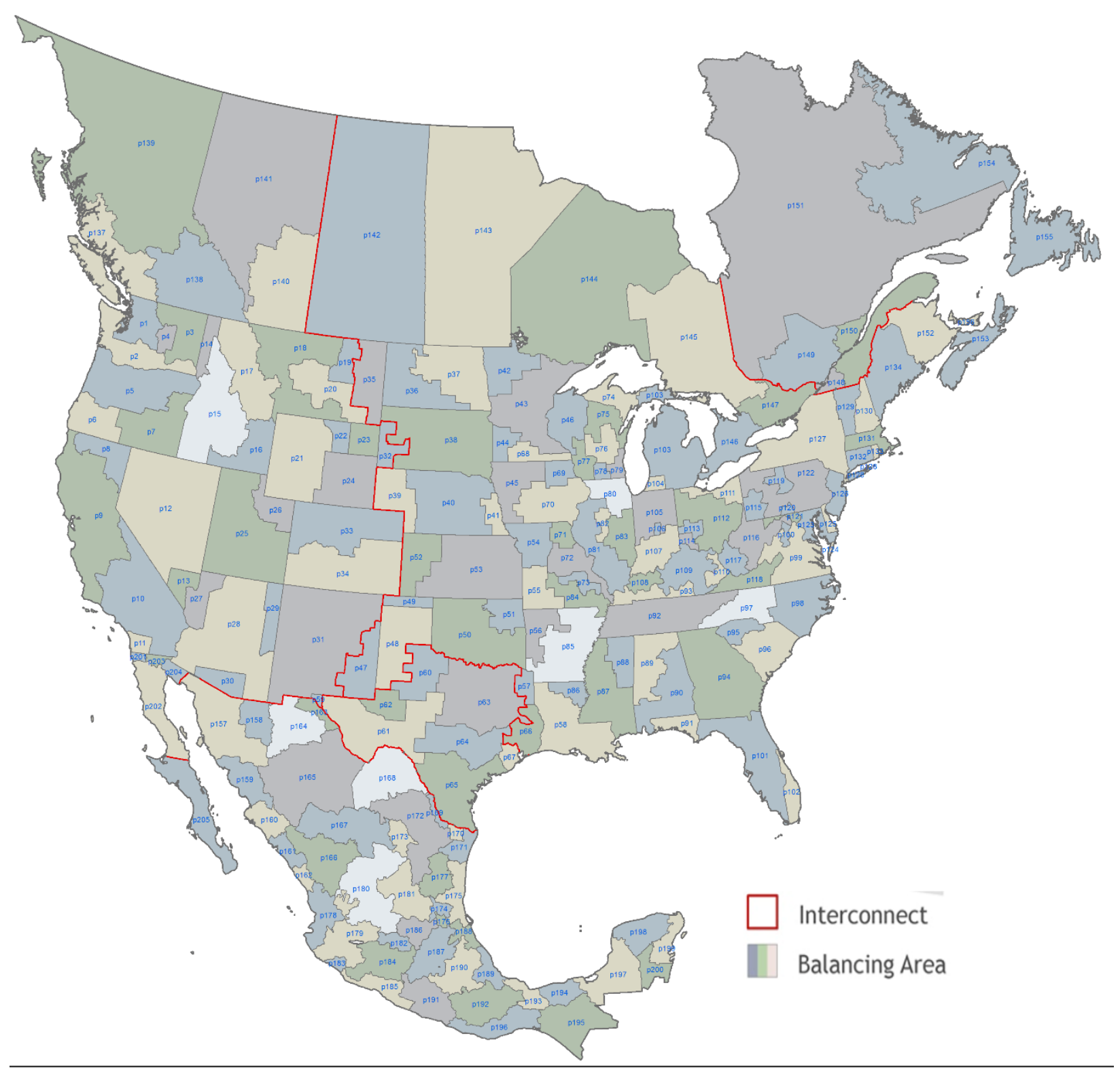

Figure 35. Regions defined in the ReEDS-Canada model

\subsection{Fuel Price and Availability}

Natural gas supply and demand dynamics are represented in ReEDS through regional supply curves along EIA Census Division boundaries (see the section titled, Natural Gas Supply Curves in the appendix). For Canadian provinces, the U.S.-only regional supply curves are modified based on consumption projections from the National Energy Board's Canada's Energy Future 2016 (NEB 2016). Natural gas supply curves are modified to capture the additional supply and demand for natural gas in Canadian regions; adjacent Canadian provinces are assigned to EIA census divisions. A map of this allocation is shown in Figure 35. 


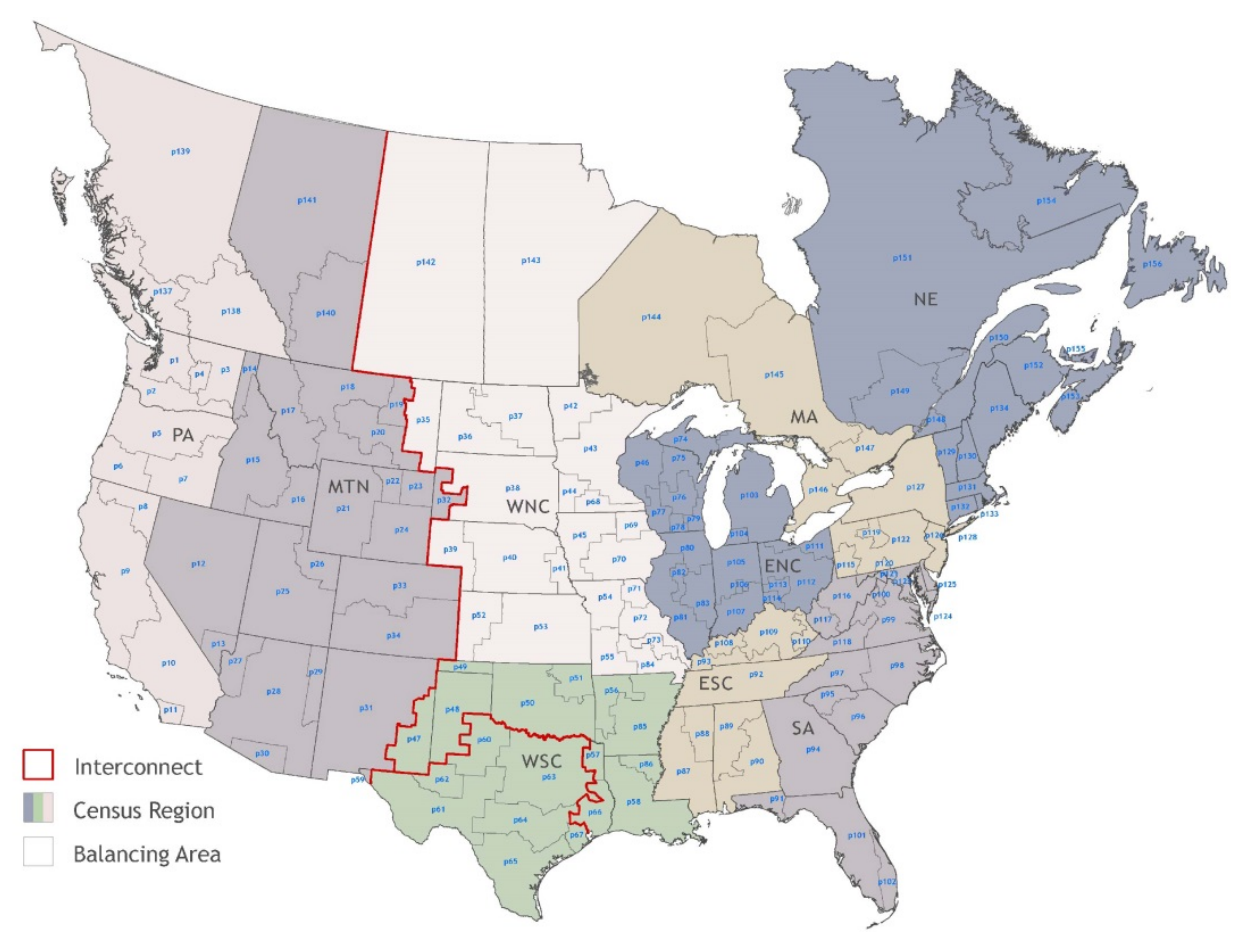

Figure 36. Map of EIA Census Division boundaries extended to Canadian provinces

A single Mexican natural gas curve is adapted from the WSC census division in the AEO. Mexico-specific natural gas consumption is taken from PRODESEN 2018 and incorporated in the new gas curve. Prices were inflated by $9 \%$ for Mexico relative to WSC to reflect the higher price of natural gas in Mexico, based on Henry Hub prices from 2010 to 2015.

Canadian coal prices are provincial and represented as inelastic to changes in consumption; they are consistent with Canadian provincial coal price projections from NEB (2016). The price of nuclear fuel for Canadian units is assumed to be same as those for nuclear units in the United States.

Mexican coal and uranium prices are matched with the WSC census division in the AEO and are inelastic.

\subsection{Electricity Demand}

Canadian annual electricity demand projections are based on the NEB (2016) reference scenario, and they reflect annual provincial load reduced by customer-sited electricity cogeneration. Provincial and zonal load shapes are described in Martinez et al. (2013). For provinces composed of multiple ReEDS BAs (Alberta, British Columbia, Ontario, and Quebec), the spatial distribution of annual provincial electricity demand among BAs is also described in Martinez et al. (2013).

Mexican load shapes and annual demand projections are based on 2016 PRODESEN. The PRODESEN load projection extends through 2030. For projections beyond 2030 load growth is projected based on the average load growth for the years 2020-2030. Load shape data in PRODESEN are available for nine regions that were mapped to the ReEDS BA representation through provided load participation factors. 


\subsection{Generation Fleet Representation}

Consistent with the ReEDS representation of the generation fleet in the contiguous United States, the ABB Velocity Suite is used as a basis for Canadian and Mexican generation units (ABB 2018). This data set is then cross-referenced with NEB (2016) for Canada, PRODESEN for Mexico, and any Canadian provincial energy plans to represent the Canadian fleet. The existing fleet, prescribed new builds, and prescribed retirements are based on the ABB Velocity Suite database. Additionally, any new hydropower or geothermal capacity projected in NEB (2016) and PRODESEN is also included in ReEDS (ReEDS does not include hydropower or geothermal resource supply curves for Canada or Mexico, and thus cannot represent new builds of those technologies endogenously).

There are currently 18,215 MW of existing transmission capacity between the United States and Canada from a combination of AC and DC lines dispersed across the border. Potential new transmission lines between the United States and Canada are derived from a list of pending applications as of January 2016 (DOE 2016a). Lines that are not yet under construction are allowed to be built in the ReEDS-Canada model, but they are not prescribed.

There are currently 2,238 MW of existing transmission capacity between the United States and Mexico, which include DC lines connecting Texas and Mexico and the AC lines connecting southern California to Mexico. Potential new transmission lines between the United States and Mexico are limited to reinforcements of existing cross-border connections. New connections specified in PRODESEN, including the DC interconnection between the main Mexican system asynchronous Baja California system and the Baja California Sur system, are allowed but not forced to be built in the ReEDS-Mexico model.

Transmission lines in Canada and Mexico are assumed to have the same cost as their neighboring regions in the United States. Table 24 summarizes pending cross-border transmission lines as of January 2016. 
Table 26. Pending Cross-Border Transmission Lines as of January 2016 (DOE 2016a)

\begin{tabular}{|c|c|c|c|c|c|c|c|}
\hline Name & Sponsor & State-Province & $\begin{array}{l}\text { Length } \\
\text { (miles) }\end{array}$ & $\begin{array}{l}\text { Voltage and } \\
\text { Capacity }\end{array}$ & Purpose & $\begin{array}{l}\text { In-service } \\
\text { Date }\end{array}$ & Permit Status \\
\hline $\begin{array}{l}\text { Champlain } \\
\text { Hudson Power } \\
\text { Express }\end{array}$ & $\begin{array}{l}\text { Transmission } \\
\text { Developers Inc. }\end{array}$ & $\begin{array}{l}\text { New York- } \\
\text { Québec }\end{array}$ & 333 & $\begin{array}{l}\text { 1,000 MW, } \\
\text { HVDC }^{\mathrm{a}} \\
\text { (underwater, } \\
\text { underground, } \\
\text { merchant) }\end{array}$ & $\begin{array}{l}\text { Deliver hydro and } \\
\text { wind energy from } \\
\text { QC to New York } \\
\text { City area }\end{array}$ & $\begin{array}{l}\text { Fall } 2017 \\
\text { (expected) }\end{array}$ & $\begin{array}{l}\text { Permit issued } \\
\text { October } 2014\end{array}$ \\
\hline $\begin{array}{l}\text { Great Northern } \\
\text { Transmission } \\
\text { Line }\end{array}$ & $\begin{array}{l}\text { Minnesota } \\
\text { Power (MP) }\end{array}$ & $\begin{array}{l}\text { Minnesota- } \\
\text { Manitoba }\end{array}$ & 220 & $\begin{array}{l}500 \mathrm{kV} \\
750 \mathrm{MW}, \mathrm{AC}\end{array}$ & $\begin{array}{l}\text { Part of MP-MB } \\
\text { Hydro PPA; } \\
\text { supports building } \\
\text { wind in North } \\
\text { Dakota }\end{array}$ & $\begin{array}{l}\text { June } 2020 \\
\text { (expected) }\end{array}$ & $\begin{array}{l}\text { Application filed } \\
\text { April } 2014\end{array}$ \\
\hline $\begin{array}{l}\text { Lake Erie } \\
\text { Connector }\end{array}$ & ITC & $\begin{array}{l}\text { Pennsylvania- } \\
\text { Ontario }\end{array}$ & 72.4 & $\begin{array}{l}\text { 1,000 MW, } \\
\text { HVDC } \\
\text { (underwater, } \\
\text { merchant) }\end{array}$ & $\begin{array}{l}\text { Deliver surplus ON } \\
\text { renewable energy, } \\
\text { enhance service } \\
\text { reliability }\end{array}$ & Q4 2019 & $\begin{array}{l}\text { Application filed } \\
\text { May } 2015\end{array}$ \\
\hline $\begin{array}{l}\text { New England } \\
\text { Clean Power } \\
\text { Link }\end{array}$ & $\begin{array}{l}\text { TDI-New } \\
\text { England }\end{array}$ & $\begin{array}{l}\text { Vermont- } \\
\text { Québec }\end{array}$ & 154 & $\begin{array}{l}\text { 1,000 MW, } \\
\text { HVDC } \\
\text { (underwater, } \\
\text { underground, } \\
\text { merchant) }\end{array}$ & $\begin{array}{l}\text { Deliver renewable } \\
\text { energy from QC into } \\
\text { VT and New } \\
\text { England }\end{array}$ & $\begin{array}{l}2019 \\
\text { (expected) }\end{array}$ & $\begin{array}{l}\text { Application filed } \\
\text { May } 2014\end{array}$ \\
\hline Northern Pass & $\begin{array}{l}\text { Northern Pass } \\
\text { Transmission } \\
\text { LLC }\end{array}$ & $\begin{array}{l}\text { New Hampshire- } \\
\text { Québec }\end{array}$ & 187 & $\begin{array}{l}1,200 \mathrm{MW} \\
\text { HVDC line with } \\
345 \mathrm{kV} \text { AC spur }\end{array}$ & $\begin{array}{l}\text { Deliver QC hydro } \\
\text { into NH and New } \\
\text { England }\end{array}$ & $\begin{array}{l}2017 \\
\text { (expected) }\end{array}$ & $\begin{array}{l}\text { Application filed } \\
\text { October } 2010 ; \\
\text { re-filed with new } \\
\text { route July } 2013\end{array}$ \\
\hline $\begin{array}{l}\text { Soule River } \\
\text { Hydroelectric } \\
\text { Project }\end{array}$ & $\begin{array}{l}\text { Soule Hydro, } \\
\text { LLC }\end{array}$ & $\begin{array}{l}\text { Alaska-British } \\
\text { Columbia }\end{array}$ & 10 & $\begin{array}{l}138 \mathrm{kV}, \mathrm{HVAC} \\
\text { (submarine) }\end{array}$ & $\begin{array}{l}\text { Support } 77 \mathrm{MW} \\
\text { hydro project in AK } \\
\text { (sales to BC or } \\
\text { Pacific NW) }\end{array}$ & $\begin{array}{l}\text { To be } \\
\text { determined }\end{array}$ & $\begin{array}{l}\text { Application filed } \\
\text { March } 2013\end{array}$ \\
\hline
\end{tabular}

a high-voltage, direct current 


\subsection{Renewable Energy Representation}

\subsubsection{Hydropower Generation Capacity}

ReEDS is not allowed to endogenously build new hydropower capacity in Canada or Mexico due to a lack of available hydropower supply curves that are compatible with those developed for the United States. Instead, we rely on a schedule of expected builds from NEB (2016) for new Canadian hydropower units. Though annual hydropower output can fluctuate significantly from year to year based on precipitation and other weather patterns, we assume there is no inter-annual variation in available hydropower generation in ReEDS; rather, average capacity factors are assumed that reflect long-run historical averages. Seasonal hydropower capacity factors are specified for each Canadian province and are derived from NEB (2013).

In Mexico, existing hydropower capacity is represented, but no new prescribed capacity is added to the system. Operating characteristics are determined from the historical fleetwide capacity factor from PRODESEN.

\subsubsection{Wind Resource}

For Canada and Mexico the onshore-wind resource is represented using the same methodology described in Section 2.1.1. Using reV, the quality, capacity, and spur line costs are calculated and represented within the model at the wind resource region level. Wind turbine performance is modeled using results from the WIND Toolkit. Toolkit data include complete coverage of Mexico and Southern Canada. Meteorological data for northern Canada are supplemented using NASA's MEERA-2 data set. Resource calculations are preformed using 2012 data; however, the methodology flexibly supports alternate weather years.

Offshore-wind technology is not represented as an available resource for Canada or Mexico because a comprehensive resource assessment has not been completed.

\subsubsection{Solar Resource}

UPV and DUPV resources are calculated for Canada and Mexico using the same approach described in Section 2.1.3. The quality, capacity, and spur line costs are calculated using reV and represented within the model for BA regions. The performance of PV panels is based on insolation data from the NSRDB 2.0 using a 2012 metrological year.

The deployment of residential and commercial rooftop PV systems is exogenously defined in for the United States using output from NREL's dGen model (see Section 2.1.3). Because this model is not currently designed to capture consumer behavioral dynamics in Canada and Mexico, we assume no rooftop PV deployment outside the United States. Direct normal irradiance throughout Canada is below the threshold necessary to produce economic CSP generation, and thus is not represented in Canada. Though the direct normal irradiance is high in Mexico, comprehensive resource data for CSP in Mexico have not been developed due to its expected competitive disadvantage relative to PV. Thus CSP is not represented as an available resource in Mexico.

\subsubsection{Geothermal Resource}

Geothermal technologies are not available for development outside the United States due to a lack of sufficient information on the location and potential of geothermal resources. Mexico does 
currently produce electricity from geothermal technology, and any existing capacity is included in ReEDS-Mexico.

\subsubsection{Biomass Resource}

The biomass feedstock supply curve for each Canadian BA is assumed to be the same as that of the contiguous BAs in the United States (scaling to account for differences in area). Biomass is not available as a resource or generation technology in Mexico because resource data are unavailable. Future resource assessments for biomass feedstocks are needed to improve these representations.

\subsection{Policy and Regulation}

ReEDS represents existing RPS requirements for:

- New Brunswick: $40 \%$ by $2020^{80}$

- Nova Scotia: $5 \%$ by $2011,10 \%$ by $2013,25 \%$ by 2015 , and $40 \%$ by 2020 (Nova Scotia Department of Energy 2010)

- Prince Edward Island: 15\% by 2010 (Department of Environment, Energy and Forestry, n.d.).

Canadian contributions to U.S. state RPS (and vice versa) are permitted in alignment with existing laws, regulations, and practices as of October 2014. We list the rules for U.S.-Canada REC trading in Table 25, focusing on U.S. states that are physically or electrically adjacent to a Canadian province, or where international REC trading activity has been observed in practice.

80 "Provincial Government Strengthens its Commitment to Renewable Energy," news release dated August 7, 2014 http://www2.gnb.ca/content/gnb/en/news/news release.2014.08.1007.html. 
Table 27. International REC Trading Rules Implemented in ReEDS

\begin{tabular}{lll}
\hline State/Province & $\begin{array}{l}\text { Canadian RECs } \\
\text { Accepted? }\end{array}$ & Notes \\
\hline California & Yes & Power must be delivered to state \\
Colorado & No & - \\
Massachusetts & Yes & Power must be delivered to ISO-New Englanda \\
Maine & No & - \\
Michigan & No & - \\
Minnesota & Yes & Power must be delivered to state from Manitoba \\
Montana & No & - \\
Nevada & No & - \\
New Hampshire & No & - \\
New York & No & - \\
Nova Scotia & Yes & RECs accepted from New England Power Pool \\
Ohio & No & - \\
Oregon & Yes & Subject to same bundling rules as U.S. states \\
Pennsylvania & No & - \\
Rhode Island & Yes & Power must be delivered to ISO-New England \\
Washington & Yes & Power must be delivered to state \\
Wisconsin & Yes & Power must be delivered to state \\
\hline & &
\end{tabular}

British Columbia has a carbon tax that is applied to in-province electricity generation (British Columbia Ministry of Finance 2015). This tax is also applied to imported electricity; in this case, the average carbon intensity of delivered electricity is endogenously calculated from the imported generation mix in the previous solve year ${ }^{81}$ and taxed appropriately. We also implement the British Columbia 2016 requirement for electricity self-sufficiency ${ }^{82}$ (Clean Energy Act of 2010 2010).

New Canadian coal units that do not have carbon capture and storage are not in allowed in the model beginning in the 2016 solve year. Any early retirements of existing coal units are reflected in the exogenous retirements of Canadian coal units. ${ }^{83}$

The Mexico clean energy standard of 35\% of load by 2024 is also modeled. (Presidencia de la República 2016) Renewable energy and nuclear power are allowed to contribute to this policy, while CCS is excluded.

\footnotetext{
${ }^{81}$ This calculation uses a proportional sharing construct adapted from Bialek (1996).

${ }^{82}$ The requirement is structured such that plants within British Columbia must generate as much energy as is required to serve load within the province.

${ }^{83}$ For details about the electricity regulations for coal units in Canada, see "Coal-Fired Electricity Generation Regulations: Overview," Government of Canada, modified December 16, 2013, https://ec.gc.ca/cc/default.asp?lang=En\&n=C94FABDA-1.
} 


\section{Model Linkages}

\subsection{ReEDS-dGen}

All ReEDS scenarios utilize dGen to project rooftop PV deployment, but the two models are also capable of operating in a more tightly coupled manner with two-way feedback in each solve year. Under this arrangement, ReEDS provides dGen with estimated curtailment of rooftop PV resources, which dGen uses to update its projected rooftop PV deployment for the following solve year. This coupled configuration improves rooftop PV projections by disincentivizing new capacity that would achieve low utilization within the interconnected bulk system modeled in ReEDS. Additional details on this linkage and its influence on results can be found in (Cole, Lewis, et al. 2016).

\subsection{ReEDS-PLEXOS}

The ReEDS reduced-form dispatch and variable renewable parameterization aims to represent enough operational detail for realistic capacity expansion decisions, but the model cannot explicitly represent detailed power system operations. To verify the feasibility of ReEDS solutions and better inform its representation of system operation, NREL has developed utilities to implement a ReEDS capacity expansion solution for any solve year in the PLEXOS production-cost model (PCM).

PLEXOS is a commercial PCM tool capable of representing individual generating units and transmission nodes for least-cost dispatch optimization at hourly or subhourly time resolution. It can incorporate unit-commitment decisions and detailed operating constraints (e.g., ramp rates, minimum runtime) to simulate realistic power system operations. NREL has previously used PLEXOS in several analyses such as the Western Wind and Solar Renewable Integration Study and the Eastern Renewable Grid Integration Study (Lew et al. 2013; Bloom et al. 2016a).

The ReEDS-PLEXOS linkage involves disaggregating the ReEDS solution and adding necessary parameters for to the resolution necessary for PLEXOS. To facilitate the translation, the existing linkage maintains the spatial resolution of ReEDS and operates PLEXOS as a zonal model matching ReEDS BAs to PLEXOS transmission zones. PLEXOS uses the ReEDS transmission line capacity, and reactance and resistance are calculated from ReEDS transmission properties to represent the aggregated transmission system. Generating capacity within each zone is, however, converted from aggregate ReEDS capacity to individual units in PLEXOS using a characteristic unit size for each technology. For consistency, ReEDS cost and performance parameters are used when possible and reasonable, but values are taken from the average across WECC data when parameters are not available from ReEDS or are available but used inconsistently in ReEDS due to structural differences between the models. ${ }^{84}$

Once the ReEDS solution is converted to a PLEXOS database, we can simulate hourly dispatch over a full year and compare results with ReEDS outcomes. A consistent solution builds confidence in the effectiveness of ReEDS capacity expansion decisions, while inconsistencies

\footnotetext{
${ }^{84}$ Minimum load is an example of one such parameter. The aggregate representation of minimum load in ReEDS at the technology-BA level does not effectively reflect unit-level operating constraints used in PLEXOS, so PLEXOS uses native assumptions for minimum load.
} 
and reliability concerns such as load shedding indicate the need for improving capacity expansion model structures.

Additional discussion of this capability is forthcoming in ongoing analyses where detailed mechanics and results will be discussed.

\subsection{ReEDS-JEDI}

A linkage between ReEDS outputs and the Jobs and Economic Development Impact Models (JEDI) allows the analysis of technology-specific economic results (jobs, earnings, value added, total output) to ReEDS scenarios ("NREL: Energy Analysis - Jobs and Economic Development Impact (JEDI) Models" n.d.). Currently, linkages have been built for the JEDI land-based wind, photovoltaics, natural gas, and coal models, so economic results are limited to these technologies alone. ReEDS outputs of capacity, generation, fuel use, capital cost, O\&M cost, and fuel cost by BA are processed through the JEDI models to produce state-level economic results. 


\section{References}

26 USC 45Q: Credit for Carbon Oxide Sequestration. 2018. 26 USC 45Q.

http://uscode.house.gov/view.xhtml?req=(title:26\%20section:45Q\%20edition:prelim).

ABB. 2018. “ABB Velocity Suite.” 2018. http://new.abb.com/enterprise-software/energyportfolio-management/market-intelligence-services/velocity-suite.

Arora, Vipin. 2014. "Estimates of the Price Elasticities of Natural Gas Supply and Demand in the United States." MPRA Paper No. 54232. U.S. Energy Information Administration.

http://mpra.ub.uni-muenchen.de/54232/.

Augustine, C. 2011. "Updated US Geothermal Supply Characterization and Representation for Market Penetration Model Input." NREL/TP-6A20-47459. Golden, CO: National Renewable Energy Laboratory.

Beiter, Philipp, Walter Musial, Levi Kilcher, Michael Maness, and Aaron Smith. 2017. “An Assessment of the Economic Potential of Offshore Wind in the United States from 2015 to 2030.” NREL/TP-6A20-67675. National Renewable Energy Lab. (NREL), Golden, CO (United States). https://doi.org/10.2172/1349721.

Beiter, Philipp, and Tyler Stehly. 2016. "A Spatial-Economic Cost-Reduction Pathway Analysis for U.S. Offshore Wind Energy Development from 2015-2030.” NREL/PR-6A20-67204. National Renewable Energy Lab. (NREL), Golden, CO (United States). https://www.osti.gov/biblio/1330939-spatial-economic-cost-reduction-pathway-analysisoffshore-wind-energy-development-from.

Bernstein, Mark A., and James M. Griffin. 2006. "Regional Differences in the Price-Elasticity of Demand for Energy.” NREL/SR-620-39512. Golden, CO: National Renewable Energy Laboratory. http://www.nrel.gov/docs/fy06osti/39512.pdf.

Bird, Lori, Caroline Chapman, Jeff Logan, Jenny Sumner, and Walter Short. 2011. "Evaluating Renewable Portfolio Standards and Carbon Cap Scenarios in the U.S. Electric Sector." Energy Policy 39 (5): 2573-85. https://doi.org/10.1016/j.enpol.2011.02.025.

Black \& Veatch. 2012. "Cost and Performance Data for Power Generation Technologies." Overland Park, KS: Black \& Veatch Corporation.

Bloom, Aaron, Aaron Townsend, David Palchak, Joshua Novacheck, Jack King, Clayton Barrows, Eduardo Ibanez, et al. 2016a. "Eastern Renewable Generation Integration Study." NREL/TP-6A20-64472. Golden, CO: National Renewable Energy Laboratory, RePPAE LLC, GE. http://www.nrel.gov/docs/fy16osti/64472.pdf.

_. 2016b. "Eastern Renewable Generation Integration Study." NREL/TP-6A20-64472. National Renewable Energy Lab. (NREL), Golden, CO (United States). https://doi.org/10.2172/1318192. 
British Columbia Ministry of Finance. 2015. "Carbon Tax: Overview of the Revenue-Neutral Carbon Tax.” 2015. http://www.fin.gov.bc.ca/tbs/tp/climate/carbon_tax.htm.

Bureau of Reclamation. 2011. "Hydropower Resource Assessment at Existing Reclamation Facilities.” Denver, CO: U.S. Department of the Interior, Bureau of Reclamation, Power Resources Office.

http://www.usbr.gov/power/AssessmentReport/USBRHydroAssessmentFinalReportMarch2011. pdf.

C. Van Atten. 2017. "Coal-Fired Electricity Generation in the United States and Future Outlook.” MJB\&A Issue Brief. Concord, MA: M.J. Bradley \& Associates LLC.

https://www.mjbradley.com/reports/coal-fired-electricity-generation-united-states-and-futureoutlook.

Canadian Electricity Association. 2015. “Canada’s Electricity System.” 2015.

http://www.electricity.ca/media/Electricity101/Electricity101.pdf.

Clean Energy Act of 2010. 2010. https://www.leg.bc.ca/pages/bclasslegacy.aspx\#/content/legacy/web/39th2nd/1st_read/gov17-1.htm.

Clemmer, Steve, John Rogers, Sandra Sattler, Jordan Macknick, and Trieu Mai. 2013. "Modeling Low-Carbon US Electricity Futures to Explore Impacts on National and Regional Water Use.” Environmental Research Letters 8 (1): 015004. https://doi.org/10.1088/17489326/8/1/015004.

Cohen, Stuart M., James R. Meldrum, Jordan Macknick, Kristen Averyt, and Imtiaz Rangwala. [in review]. "Climate-Water-Electricity: Evaluating Climate-Induced Changes to the Future Development of the U.S. Electricity Sector."

Cole, Wesley, Bethany Frew, Pieter Gagnon, Andrew Reimers, Jarett Zuboy, and Robert Margolis. 2018. "Envisioning a Low-Cost Solar Future: Exploring the Potential Impact of Achieving the SunShot 2030 Targets for Photovoltaics." Energy 155 (July): 690-704. https://doi.org/10.1016/j.energy.2018.04.166.

Cole, Wesley J., Allister Frazier, Paritosh Das, Trieu T. Mai, and Paul Donohoo-Vallett. 2018. "2018 Standard Scenarios Report: A U.S. Electricity Sector Outlook." NREL/TP-6A20-71913. National Renewable Energy Lab. (NREL), Golden, CO (United States). https://doi.org/10.2172/1481848.

Cole, Wesley, Haley Lewis, Ben Sigrin, and Robert Margolis. 2016. "Interactions of Rooftop PV Deployment with the Capacity Expansion of the Bulk Power System." Applied Energy 168 (April): 473-81. https://doi.org/10.1016/j.apenergy.2016.02.004.

Cole, Wesley, Trieu Mai, Paul Donohoo-Vallett, James Richards, and Paritosh Das. 2017. "2017 Standard Scenarios Report: A U.S. Electricity Sector Outlook.” Technical Report NREL/TP6A20-68548. Golden, CO: National Renewable Energy Laboratory. https://www.nrel.gov/docs/fy18osti/68548.pdf. 
Cole, Wesley, Trieu Mai, Kelly Eurek, Daniel C. Steinberg, and Robert Margolis. 2015. "Considering the Role of Solar Generation under Rate-Based Targets in the EPA's Proposed Clean Power Plan.” The Electricity Journal 28 (8): 20-28.

https://doi.org/10.1016/j.tej.2015.09.002.

Cole, Wesley, Trieu Mai, Jeffrey Logan, Daniel Steinberg, James McCall, James Richards, Benjamin Sigrin, and Gian Porro. 2016. "2016 Standard Scenarios Report: A U.S. Electricity Sector Outlook." NREL/TP-6A20-66939. Golden, CO: National Renewable Energy Laboratory. http://www.nrel.gov/docs/fy17osti/66939.pdf.

Cole, Wesley, Cara Marcy, Venkat Krishnan, and Robert Margolis. 2016. "Utility-Scale Lithium-Ion Storage Cost Projections for Use in Capacity Expansion Models." In 2016 North American Power Symposium (NAPS), 1-6. Denver, CO, United States: IEEE. https://doi.org/10.1109/NAPS.2016.7747866.

Cole, Wesley, Kenneth B. Medlock III, and Aditya Jani. 2016. "A View to the Future of Natural Gas and Electricity: An Integrated Modeling Approach." Energy Economics 60 (November): 486-96. https://doi.org/10.1016/j.eneco.2016.03.005.

CPUC. 2018. DECISION SETTING REQUIREMENTS FOR LOAD SERVING ENTITIES FILING INTEGRATED RESOURCE PLANS. Vol. 16-02-007. http://docs.cpuc.ca.gov/PublishedDocs/Published/G000/M209/K771/209771632.PDF.

Denholm, Paul, Erik Ela, Brendan Kirby, and Michael Milligan. 2010. "The Role of Energy Storage with Renewable Electricity Generation." NREL/TP-6A2-47187. Golden, CO: National Renewable Energy Laboratory. http://www.nrel.gov/docs/fy10osti/47187.pdf.

Department of Environment, Energy and Forestry. n.d. "Energy Strategy Securing Our Future: Energy Efficiency and Conservation." Charlottetown, Prince Edward Island, Canada: Department of Environment, Energy and Forestry. http://www.gov.pe.ca/photos/original/env_snergystr.pdf.

DOE. 2008. “20\% Wind Energy by 2030: Increasing Wind Energy's Contribution to U.S. Electricity Supply.” Technical Report DOE/GO-102008-2567. Washington, D.C.: U. S. Department of Energy. http://www.nrel.gov/docs/fy08osti/41869.pdf.

- 2011. "US Billion-Ton Update: Biomass Supply for a Bioenergy and Bioproducts Industry." ORNL/TM-2011/224. Agricultural and Biosystems Engineering Technical Reports and White Papers. Oak Ridge, TN: Oak Ridge National Laboratory. https://www1.eere.energy.gov/bioenergy/pdfs/billion_ton_update.pdf.

—. 2012. "SunShot Vision Study." DOE/GO-102012-3037. Washington, D.C.: U.S. Department of Energy. http://www.nrel.gov/docs/fy12osti/47927.pdfDOE/GO-102012-3037.

- 2015. "Wind Vision: A New Era for Wind Power in the United States." DOE/GO102015-4557. Washington, D.C.: U.S. Department of Energy.

http://www.energy.gov/sites/prod/files/WindVision_Report_final.pdf. 
—. 2016a. "Pending Applications | Department of Energy." 2016.

http:/energy.gov/oe/services/electricity-policy-coordination-and-implementation/internationalelectricity-regulation/pending-applications.

- 2016b. "Hydropower Vision: A New Chapter for America's 1st Renewable Electricity Source.” Technical Report DOE/GO-102016-4869. Washington, D.C.: U. S. Department of Energy. http://energy.gov/eere/water/articles/hydropower-vision-new-chapter-america-s-1strenewable-electricity-source.

EEI. 2010. “Transmission Project: At a Glance.” Edison Electric Institute with assistance from Navigant Consulting, Inc.

EIA. 2013. "Updated Capital Cost Estimates for Utility Scale Electricity Generating Plants." Washington, D.C.: U.S. DOE Energy Information Administration. http://www.eia.gov/forecasts/capitalcost/pdf/updated_capcost.pdf.

—. 2014. “Annual Energy Outlook 2014.” DOE/EIA-0383(2014). Washington, D.C.: U.S. DOE Energy Information Administration.

_. 2015. "Electric Power Detailed State Data." 2015. http://www.eia.gov/electricity/data/state/.

- 2016. "Capital Cost Estimates for Utility Scale Electricity Generating Plants." Washington, D.C.: U.S. DOE Energy Information Administration. http://www.eia.gov/analysis/studies/powerplants/capitalcost/pdf/capcost_assumption.pdf.

- 2017. "The Electricity Market Module of the National Energy Modeling System: Model Documentation 2016." Washington, D.C.: U.S. Energy Information Administration. https:/www.eia.gov/outlooks/aeo/nems/documentation/electricity/pdf/m068(2016).pdf.

—. 2018. “Annual Energy Outlook 2018.” DOE/EIA-0383(2017). Washington, D.C.: U.S. DOE Energy Information Administration. https://www.eia.gov/outlooks/aeo/pdf/AEO2018.pdf.

EIPC. 2012. "Phase 2 Report: DOE Draft - Parts 2-7 Interregional Transmission Development and Analysis for Three Stakeholder Selected Scenarios.” Eastern Interconnect Planning Collaborative.

http://nebula.wsimg.com/2964d965b867c8786028b950057c7e52?AccessKeyId=E28DFA42F06 A3AC21303\&disposition=0\&alloworigin $=1$.

EPA. 2016. "Resources for Implementation | Air Transport | US EPA.” 2016. https://www3.epa.gov/crossstaterule/stateinfo.html\#states.

- 2017. "Avoiding and Reducing Long-term Risks of Climate Change: A Technical Report for the Fourth National Climate Assessment.” EPA 430-R-17-001. U.S. Environmental Protection Agency, Office of Atmospheric Programs.

Fischer, Carolyn. 2001. "Rebating Environmental Policy Revenues: Output-Based Allocations and Tradable Performance Standards.” 01-22. RFF Discussion Paper. Washington, DC: 
Resources for the Future. http://www.rff.org/files/sharepoint/WorkImages/Download/RFF-DP01-22.pdf.

Frew, Bethany A., Wesley J. Cole, Nina M. (ORCID:0000000221442954) Vincent, Andrew Reimers, and Robert M. Margolis. 2018. "Impact of Dynamic Storage Capacity Valuation in Capacity Expansion Models: Preprint.” NREL/CP-6A20-71462. National Renewable Energy Lab. (NREL), Golden, CO (United States). https://www.osti.gov/biblio/1464451-impactdynamic-storage-capacity-valuation-capacity-expansion-models-preprint.

Frew, Bethany, Wesley Cole, Yinong Sun, James Richards, and Trieu Mai. 2017. "8760-Based Method for Representing Variable Generation Capacity Value in Capacity Expansion Models." NREL/CP-6A20-68869. Golden, CO: National Renewable Energy Laboratory. https://www.nrel.gov/docs/fy17osti/68869.pdf.

Fry, Joyce, George Xian, Suming Jin, Jon Dewitz, Collin Homer, Limin Yang, Christopher Barnes, Nathaniel Herold, and James Wickham. 2011. "Completion of the 2006 National Land Cover Database for the Conterminous United States." Photogrammetric Engineering \& Remote Sensing 77 (9): 858-64.

Fu, Ran, T.L. James, D. Chung, D. Gagne, A. Lopez, and A. Dobos. 2015. "Economic Competitiveness of U.S. Utility-Scale Photovoltaics Systems in 2015: Regional Cost Modeling of Installed Cost (\$/W) and LCOE (\$/KWh)." In Photovoltaic Specialist Conference (PVSC), 2015 IEEE 42nd, 1-11. https://doi.org/10.1109/PVSC.2015.7356261.

Gagnon, Pieter, Wesley J. Cole, Bethany Frew, and Robert Margolis. 2017. "The Impact of Retail Electricity Tariff Evolution on Solar Photovoltaic Deployment." The Electricity Journal, Energy Policy Institute's Seventh Annual Energy Policy Research Conference, 30 (9): 22-28. https://doi.org/10.1016/j.tej.2017.10.003.

Galen Maclaurin, Nick Grue, Anthony Lopez, and Donna Heimiller. [in review]. "The Renewable Energy Potential (ReV) Model: A Geospatial Platform for Technical Potential and Supply Curve Modeling."

Hadjerioua, B., S.-C. Kao, R.A. McManamay, M.F.K. Pasha, D. Yeasmin, A.A. Oubeidillah, N.M. Samu, et al. 2013. "An Assessment of Energy Potential from New Stream-Reach Development in the United States: Initial Report on Methodology." Oak Ridge, TN: Oak Ridge National Laboratory.

Hadjerioua, B., Yaxing Wei, and Shih-Chieh Kao. 2012. "An Assessment of Energy Potential at Non-Powered Dams in the United States.” GPO DOE/EE-0711. Oak Ridge, TN: Oak Ridge National Laboratory.

Haratyk, Geoffrey. 2017. "Early Nuclear Retirements in Deregulated US Markets: Causes, Implications and Policy Options." https://assets.documentcloud.org/documents/3723775/MITEarly-Nuclear-Retirement-3-2017.pdf.

Heeter, Jenny. 2015. “Cross-State RPS Visualization.” 2015. http://www.nrel.gov/analysis/docs/index.html. 
Holt, Ed. 2016. "Potential RPS Markets for Renewable Energy Generators." Ed Holt \& Associates, Inc. http://www.cesa.org/assets/2016-Files/Potential-RPS-Markets-Report-Holt.pdf.

HSIP. 2012. "Homeland Security Infrastructure Project."

Hummon, Marissa, Paul Denholm, Jennie Jorgenson, David Palchak, Brendan Kirby, and Ookie Ma. 2013. "Fundamental Drivers of the Cost and Price of Operating Reserves." NREL/TP-6A2058491 .

Huntington, Hillard. 2013. "EMF 26: Changing the Game? Emissions and Market Implications of New Natural Gas Supplies." Stanford, CA: Energy Modeling Forum, Stanford University. https://web.stanford.edu/group/emf-research/docs/emf26/Summary26.pdf.

ICF. 1995. "Potential Effects of Climate Change on Electric Utilities." EPRI TR-105005.

Jaglom, Wendy S., James R. McFarland, Michelle F. Colley, Charlotte B. Mack, Boddu Venkatesh, Rawlings L. Miller, Juanita Haydel, et al. 2014. "Assessment of Projected Temperature Impacts from Climate Change on the U.S. Electric Power Sector Using the Integrated Planning Model ${ }^{\circledR} . ”$ Energy Policy 73 (October): 524-39. https://doi.org/10.1016/j.enpol.2014.04.032.

John Larsen, Kate Larsen, Whitney Herndon, Peter Marsters, Hannah Pitt, and Shashank Mohan. 2018. "Taking Stock 2018." New York, NY: Rhodium Group. https://rhg.com/research/takingstock-2018/.

Jordan, Dirk C., and Sarah R. Kurtz. 2013. "Photovoltaic Degradation Rates—an Analytical Review.” NREL/JA-5200-51664. Golden, CO: National Renewable Energy Laboratory. http://onlinelibrary.wiley.com/doi/10.1002/pip.1182/full.

Jorgenson, Jennie, Paul Denholm, Mark Mehos, and Craig Turchi. 2013. "Estimating the Performance and Economic Value of Multiple Concentrating Solar Power Technologies in a Production Cost Model.” NREL/TP-6A20-58645. National Renewable Energy Lab. (NREL), Golden, CO (United States). https://doi.org/10.2172/1260920.

Kao, Shih Chieh, Ryan A. McManamay, Kevin M. Stewart, Nicole M. Samu, Boualem Hadjerioua, Scott T. DeNeale, Dilruba Yeasmin, et al. 2014. "New Stream-Reach Development: A Comprehensive Assessment of Hydropower Energy Potential in the United States." GPO DOE/EE-1063. U.S. Department of Energy Wind \& Water Power Technologies Office, prepared by Oak Ridge National Laboratory.

http://nhaap.ornl.gov/sites/default/files/ORNL_NSD_FY14_Final_Report.pdf.

Lantz, Eric, Daniel Steinberg, Michael Mendelsohn, Owen Zinaman, Ted James, Gian Porro, Maureen Hand, et al. 2014. "Implications of a PTC Extension on U.S. Wind Deployment." Technical Report NREL/TP-6A20-61663. Golden, CO: National Renewable Energy Laboratory. http://www.nrel.gov/docs/fy14osti/61663.pdf.

Lazard. 2016. "Lazard's Levelized Cost of Storage - Version 2.0." https://www.lazard.com/media/438042/lazard-levelized-cost-of-storage-v20.pdf. 
—. 2017. "Levelized Cost of Storage: Version 3.0." /perspective/levelized-cost-of-storage$2017 /$.

Lew, D., G. Brinkman, E. Ibanez, A. Florita, M. Heaney, B.-M. Hodge, M. Hummon, G. Stark, J. King, and S. A. Lefton. 2013. "The Western Wind and Solar Integration Study Phase 2." NREL/TP-5500-55588. Golden, CO: National Renewable Energy Laboratory. http://www.osti.gov/scitech/servlets/purl/1095399.

Logan, Jeffrey, Anthony Lopez, Trieu Mai, Carolyn Davidson, Morgan Bazilian, and Douglas Arent. 2013. "Natural Gas Scenarios in the US Power Sector." Energy Economics 40: 183-95.

Lopez, Anthony, Billy Roberts, Donna Heimiller, Nate Blair, and Gian Porro. 2012. "US Renewable Energy Technical Potentials: A GIS-Based Analysis.” NREL/TP-6A20-51946. Golden, CO: National Renewable Energy Laboratory. http://cdn.decarboni.se/sites/default/files/publications/138258/US-renewable-energy-technicalpotentials-GIS-based-analysis.pdf.

Macknick, Jordan, Stuart Cohen, Robin Newmark, Andrew Martinez, Patrick Sullivan, and Vince Tidwell. 2015. "Water Constraints in an Electric Sector Capacity Expansion Model." NREL/TP-6A20-64270. Golden, CO: National Renewable Energy Laboratory. http://www.nrel.gov/docs/fy15osti/64270.pdf.

Macknick, Jordan, Robin Newmark, Garvin Heath, and Kathleen C. Hallett. 2012. "Operational Water Consumption and Withdrawal Factors for Electricity Generating Technologies: A Review of Existing Literature." Environmental Research Letters 7 (4): 045802. https://doi.org/10.1088/1748-9326/7/4/045802.

Mai, Trieu, Wesley Cole, Venkat Krishnana, and Mark Bolinger. 2015. "Impact of Federal Tax Policy on Utility-Scale Solar Deployment Given Financing Interactions." NREL/PR-6A2065014. Golden, CO: National Renewable Energy Laboratory.

Mai, Trieu, David Mulcahy, M. Maureen Hand, and Samuel F. Baldwin. 2014. "Envisioning a Renewable Electricity Future for the United States." Energy 65 (February): 374-86. https://doi.org/10.1016/j.energy.2013.11.029.

Mai, Trieu, R. Wiser, D. Sandor, G. Brinkman, G. Heath, P. Denholm, D. J. Hostick, N. Darghouth, A. Schlosser, and K. Strzepek. 2012. "Exploration of High-Penetration Renewable Electricity Futures. Vol. 1 of Renewable Electricity Futures Study." NREL/TP-6A20-52409-1. Golden, CO: National Renewable Energy Laboratory.

Martinez, Andrew, Kelly Eurek, Trieu Mai, and Andrew Perry. 2013. "Integrated Canada-US Power Sector Modeling with the Regional Energy Deployment System (ReEDS)." NREL/TP6A20-56724. Golden, CO: National Renewable Energy Laboratory.

Mignone, Bryan K., Thomas Alfstad, Aaron Bergman, Kenneth Dubin, Richard Duke, Paul Friley, Andrew Martinez, et al. 2012. "Cost-Effectiveness and Economic Incidence of a Clean Energy Standard." Economics of Energy \& Environmental Policy 1 (3). https://doi.org/10.5547/2160-5890.1.3.5. 
Montgomery, Watson, and Harza. 2009. "Hydropower Modernization Initiative, Phase I, Needs and Opportunities Evaluation and Ranking. Report Prepared for the U.S. Army Corps of Engineers Northwest Division Hydroelectric Design Center.” Contract No. W9127N-08-D-0003, Task Order 0013.

Murphy, Caitlin, Yinong Sun, Wesley Cole, Galen Maclaurin, Craig Turchi, and Mark Mehos. 2019. "The Potential Role of Concentrating Solar Power within the Context of DOE's 2030 Solar Cost Targets.” NREL/TP-6A20-71912. Golden, CO: National Renewable Energy Laboratory.

Murphy, Frederic H., and Yves Smeers. 2005. "Generation Capacity Expansion in Imperfectly Competitive Restructured Electricity Markets.” Operations Research 53 (4): 646-661.

NEB. 2013. "Canada's Energy Futures 2013: Energy Supply and Demand Projections through 2035.” NE2-12/2013E-PDF. National Energy Board. http://www.nebone.gc.ca/nrg/ntgrtd/ftr/2016/2016nrgftr-eng.pdf.

—. 2016. “Canada's Energy Futures 2016: Energy Supply and Demand Projections through 2040.” NE2-12/2015E-PDF. National Energy Board. http://www.nebone.gc.ca/nrg/ntgrtd/ftr/2016/2016nrgftr-eng.pdf.

NERC. 2010. “2010 Long-Term Reliability Assessment.” North American Electric Reliability Corporation (NERC). http://www.nerc.com/files/2010\%20LTRA.pdf.

—. 2016. "Glossary of Terms Used in NERC Reliability Standards.” North American Electric Reliability Corporation. http://www.nerc.com/files/glossary_of_terms.pdf.

Nova Scotia Department of Energy. 2010. "Renewable Electricity Plan: A Path to Good Jobs, Stable Prices, and a Cleaner Environment." Halifax, Nova Scotia, Canada: Province of Nova Scotia. http://energy.novascotia.ca/sites/default/files/renewable-electricity-plan.pdf.

NREL. 2012. "Renewable Electricity Futures Study." NREL/TP-6A20-52409. Golden, CO: National Renewable Energy Laboratory.

—. 2018a. "2018 Annual Technology Baseline.” Golden, CO: National Renewable Energy Laboratory. https://atb.nrel.gov/.

_. 2018b. “2018 Annual Technology Baseline.” Golden, CO: National Renewable Energy Laboratory. https://atb.nrel.gov/.

"NREL: Energy Analysis - Jobs and Economic Development Impact (JEDI) Models." n.d. Accessed November 21, 2013. http://www.nrel.gov/analysis/jedi/.

O’Connor, Patrick, Qin Fen Zhang, Scott T. Deneale, Dol Raj Chalise, and Emma Centurion. 2015. "Hydropower Baseline Cost Modeling." ORNL/TM-2015/14. Oak Ridge, TN: Oak Ridge National Laboratory. http://hydropower.ornl.gov/docs/pubs/Hydropower_Baseline_Cost_Modeling.pdf. 
Previsic, Mirko, Jeff Epler, Maureen Hand, Donna Heimiller, Walter Short, and Kelly Eurek. 2012. "The Future Potential of Wave Power in the United States." RE Vision Consulting. http://www.re-vision.net/documents/The\%20Future\%20of\%20Wave\%20Power\%20MP\%20920-12\%20V2.pdf.

Richards, James, and Wesley J. Cole. 2017. "Assessing the Impact of Nuclear Retirements on the U.S. Power Sector.” The Electricity Journal, Energy Policy Institute's Seventh Annual Energy Policy Research Conference, 30 (9): 14-21. https://doi.org/10.1016/j.tej.2017.10.007.

Rutberg, Michael J., Anna Delgado, Howard J. Herzog, and Ahmed F. Ghoniem. 2011. “A System-Level Generic Model of Water Use at Power Plants and Its Application to Regional Water Use Estimation,” January, 513-23. https://doi.org/10.1115/IMECE2011-63786.

Scott Jell, and Michelle Bowman. 2018. "Almost All Power Plants That Retired in the Past Decade Were Powered by Fossil Fuels.” Today in Energy - U.S. Energy Information Administration (EIA). January 9, 2018. https://www.eia.gov/todayinenergy/detail.php?id=34452.

Sengupta, Manajit, Yu Xie, Anthony Lopez, Aron Habte, Galen Maclaurin, and James Shelby. 2018. "The National Solar Radiation Data Base (NSRDB)." Renewable and Sustainable Energy Reviews 89 (June): 51-60. https://doi.org/10.1016/j.rser.2018.03.003.

Short, W., D. J. Packey, and T. Holt. 1995. “A Manual for the Economic Evaluation of Energy Efficiency and Renewable Energy Technologies." NREL/TP-462-5173. National Renewable Energy Lab., Golden, CO (United States). https://doi.org/10.2172/35391.

Short, Walter, Nate Blair, Donna Heimiller, and Vikram Singh. 2003. "Modeling the Long-Term Market Penetration of Wind in the United States." NREL/CP-620-34469. Golden, CO: National Renewable Energy Laboratory. http://www.nrel.gov/docs/fy03osti/34469.pdf.

Short, Walter, Nate Blair, Patrick Sullivan, and Trieu Mai. 2009. "ReEDS Model Documentation: Base Case Data and Model Description." Golden, CO: National Renewable Energy Laboratory.

Short, Walter, Patrick Sullivan, Trieu Mai, Matthew Mowers, Caroline Uriarte, Nate Blair, Donna Heimiller, and Andrew Martinez. 2011. "Regional Energy Deployment System (ReEDS).” NREL/TP-6A20-46534. Golden, CO: National Renewable Energy Laboratory.

Sigrin, Benjamin, Michael Gleason, Robert Preus, Ian Baring-Gould, and Robert Margolis. 2016. "The Distributed Generation Market Demand Model (DGen): Documentation." NREL/TP-6A2065231. Golden, CO: National Renewable Energy Laboratory.

http://www.nrel.gov/docs/fy16osti/65231.pdf.

Sioshansi, R., S.H. Madaeni, and P. Denholm. 2014. “A Dynamic Programming Approach to Estimate the Capacity Value of Energy Storage." IEEE Transactions on Power Systems 29 (1): 395-403. https://doi.org/10.1109/TPWRS.2013.2279839.

Smith, S. 2014. "EPA: Clean Power Plan Could Increase Power Sector Gas Use by 1.2 Tcf in 2020." SNL Financial, June 2, 2014. 
Steckler, Nicholas. 2017. "Half of U.S. Nuclear Power Plants Are Underwater." Bloomberg New Energy Finance.

Stoll, Brady, Juan Andrade, Stuart Cohen, Greg Brinkman, and Carlo Brancucci MartinezAnido. 2017. "Hydropower Modeling Challenges." NREL/TP-5D00-68231. Golden, CO: National Renewable Energy Laboratory. https://doi.org/10.2172/1353003.

Stott, Brian, Jorge Jardim, and Ongun Alsaç. 2009. "DC Power Flow Revisited.” Power Systems, IEEE Transactions On 24 (3): 1290-1300.

Sullivan, Patrick, Wesley Cole, Nate Blair, Eric Lantz, Venkat Krishnan, Trieu Mai, David Mulcahy, and Gian Porro. 2015a. "2015 Standard Scenarios Annual Report: U.S. Electric Sector Scenario Exploration.” NREL/TP-6A20-64072. Golden, CO: National Renewable Energy Laboratory.

—. 2015b. "2015 Standard Scenarios Annual Report: U.S. Electric Sector Scenario Exploration.” Technical Report NREL/TP-6A20-64072. Golden, CO: National Renewable Energy Laboratory. http://www.nrel.gov/docs/fy15osti/64072.pdf.

Sullivan, Patrick, Jesse Colman, and Eric Kalendra. 2015. "Predicting the Response of Electricity Load to Climate Change." NREL/TP-6A20-64297. Golden, CO: National Renewable Energy Laboratory. http://www.nrel.gov/docs/fy15osti/64297.pdf.

Tegen, S., M. Hand, B. Maples, E. Lantz, P. Schwabe, and A. Smith. 2012. "2010 Cost of Wind Energy." NREL/TP-5000-52920. Golden, CO: National Renewable Energy Laboratory. http://www.idmarch.org/document_cache/bf7e00e30c994eed0e244043d5f29acd.pdf.

Tester, Jefferson W., Brian J. Anderson, Anthony S. Batchelor, David D. Blackwell, Ronald DiPippo, Elisabeth M. Drake, John Garnish, et al. 2006. "The Future of Geothermal Energy." INL/EXT-06-11746. Idaho Falls, ID: Idaho National Laboratory. https://energy.mit.edu/wpcontent/uploads/2006/11/MITEI-The-Future-of-Geothermal-Energy.pdf.

Tidball, Rick, Joel Bluestein, Nick Rodriguez, and Stu Knoke. 2010. "Cost and Performance Assumptions for Modeling Electricity Generation Technologies.” NREL/SR-6A20-48595. Golden, CO: National Renewable Energy Laboratory. http://www.nrel.gov/docs/fy11 osti/48595.pdf.

Tidwell, Vince C., Katie Zemlick, and Geoff Klise. 2013. "Nationwide Water Availability Data for Energy-Water Modeling.” SAND2013-9968. Albuquerque, NM: Sandia National Laboratories.

Timothy Fout. 2015. "Cost and Performance Baseline for Fossil Energy Plants Volume 1a: Bituminous Coal (PC) and Natural Gas to Electricity Revision 3.” DOE/NETL-2015/1723. National Energy Technology Laboratory. https://www.netl.doe.gov/File\%20Library/Research/Energy\%20Analysis/Publications/Rev3Vol1 aPC_NGCC_final.pdf. 
Union of Concerned Scientists. 2012. "UCS EW3 Energy-Water Database V.1.3.” 2012. www.ucsusa.org/ew3database.

Uria-Martinez, Rocio, Patrick W. O’Connor, and Megan M. Johnson. 2015. "2014 Hydropower Market Report.” DOE/EE-1195. Washington, D.C.: U.S. Department of Energy Wind \& Water Power Technologies Office, prepared by Oak Ridge National Laboratory.

http://www.energy.gov/sites/prod/files/2015/04/f22/2014\%20Hydropower\%20Market\%20Repor t_20150424.pdf.

U.S. Environmental Protection Agency. 2015. "Data File: Goal Computation Appendix 1-5." https://www.epa.gov/cleanpowerplan/clean-power-plan-final-rule-technical-documents.

—. 2016. "Federal Plan Requirements.” Federal Register 80 (205): 64965-116.

Ventosa, Mariano, Álvaro Baíllo, Andrés Ramos, and Michel Rivier. 2005. "Electricity Market Modeling Trends." Energy Policy 33 (7): 897-913. https://doi.org/10.1016/j.enpol.2003.10.013.

Ventyx. 2014. "Ventyx Velocity Suite." 2014. http://www.ventyx.com/en/solutions/businessoperations/business-products/velocity-suite.

Vorosmarty, C. J., A. Miara, J. Macknick, R. L. Newmark, S. Cohen, Y. Sun, V. C. Tidwell, et al. 2017. "A National Energy-Water System Assessment Framework (NEWS): Synopsis of Stage 1 Research Strategy and Results.” AGU Fall Meeting Abstracts 23 (December). http://adsabs.harvard.edu/abs/2017AGUFMGC23F..03V.

WECC. 2013. “2013 Interconnection-Wide Plan Tools and Models.” Western Electricity Coordinating Council. https://www.wecc.biz/Reliability/2013Plan_ToolsandModels.docx.

—. 2015. “TEPPC Study Report - 2024 PC1 Common Case.” Western Electricity Coordinating Council. https://www.wecc.biz/Administrative/150805_2024\%20CCV1.5_StudyReport_draft.pdf.

Williams, Colin F., Marshall J. Reed, and Robert H. Mariner. 2008. "A Review of Methods Applied by the US Geological Survey in the Assessment of Identified Geothermal Resources." 1296.

Wiser, Ryan, and Mark Bolinger. 2017. "2016 Wind Technologies Market Report.” DOE/GO102917-5033. Lawrence Berkeley National Lab. (LBNL), Berkeley, CA (United States). https://doi.org/10.2172/1375677.

Woldeyesus, Tibebe, Jordan Macknick, and Jesse Colman. forthcoming. "A Review of Cost and Performance Characteristics of Cooling System Options at Thermoelectric Power Plants." NREL Technical Report. Golden, CO.

Wood, Mizukami. 2014. “CMIP5 1/8th Degree Daily Weather and VIC Hydrology Datasets for CONUS. Project Summary Report.” NCAR.

https://corpsclimate.us/docs/cmip5.hydrology.2014.final.report.pdf. 


\section{Appendix}

\section{Natural Gas Supply Curves}

The ReEDS model does not explicitly model the U.S. natural gas (NG) system, which involves multiple sectors of the economy and includes complex infrastructure and markets. Rather, a regional supply curve representation is a used to approximate the NG system as it interacts with the electric sector. For more information on the impact of natural gas representation in ReEDS, see Cole et al. (2016).

The premise of using regional supply curves is that the price in each region will be a function of both the regional and national NG demand. The supply curves are parameterized from AEO scenarios for each of the nine EIA census divisions (see Figure A-1).

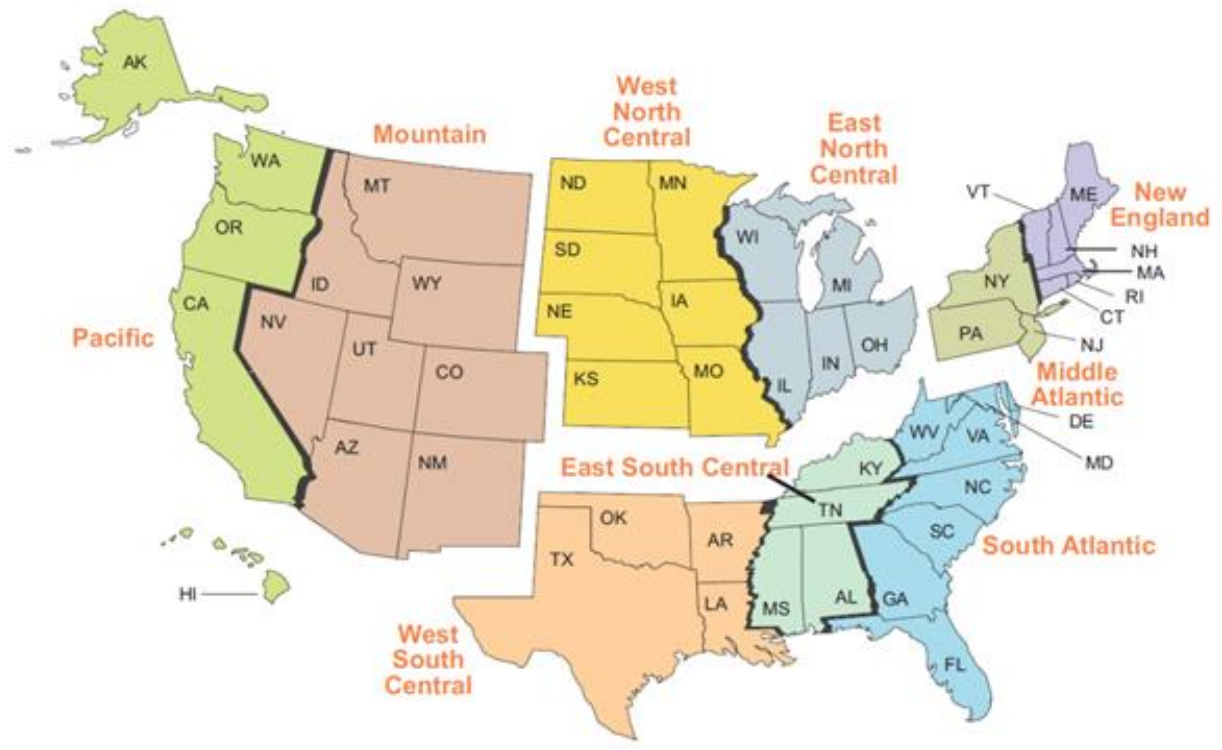

Figure A-1. The nine census divisions defined by EIA (EIA 2014)

A regional supply curve was created in ReEDS for each of these census divisions.

The AEO scenarios were used to estimate parameters for the following NG price-consumption model:

$$
P_{i, j}=\alpha+\alpha_{i}+\alpha_{j}+\alpha_{i, j}+\beta_{n a t} Q_{n a t_{j}}+\beta_{i} Q_{i, j}
$$

where $P_{i, j}$ is the price of natural gas (in $\$ / \mathrm{MMBtu}$ ) in region $i$ and year $j$, the $\alpha$ parameters are the intercept terms of the supply curves with adjustments made based on region $\left(\alpha_{i}\right)$, year $\left(\alpha_{j}\right)$, and the region-year interaction $\left(\alpha_{i, j}\right), \beta_{\text {nat }}$ is the coefficient for the national NG demand $\left(Q_{n a t}\right.$, in quads), $\beta_{i}$ is the coefficient for the regional NG demand $\left(Q_{i, j}\right)$ in region $i$. Note that the four $\alpha$ parameters in [1] can in practice be represented using only $\alpha_{i, j}$.

The $\beta$ terms are regressed from AEO2014 scenarios, with nine of the 31 AEO2014 scenarios removed as outliers (EIA 2014). These outlier scenarios typically include cases of very low or very high natural gas resource availability, which are useful for estimating NG price as a function of supply but not for estimating NG price as a function of demand - for given supply scenarios. The 
national and regional $\beta$ terms are reported in Figure A-2. We made a specific post-hoc adjustment to the regression model's outputs for one region; the $\beta_{i}$ term for the West North Central division was originally an order of magnitude higher than the other $\beta_{i}$ values because the West North Central usage in the electricity sector is so low $\left(0.05\right.$ quad $^{85}$ in 2013 , compared to $\sim 0.5$ quad or more in most regions). The overall natural gas usage (i.e., not just electricity sector usage) in West North Central is similar to the usage in East North Central, so intuitively it makes sense to have a $\beta_{i}$ for West North Central relatively close to that of East North Central. We therefore manually adjusted the West North Central $\beta_{i}$ term to be 0.6 (in 2004\$/MMBtu/quad) and recalculated the alpha terms with the new beta to achieve the AEO2014 target prices. The situation in West North Central whereby such a small fraction of NG demand goes to electricity is unique; we do not believe that the other regions warrant similar treatment.

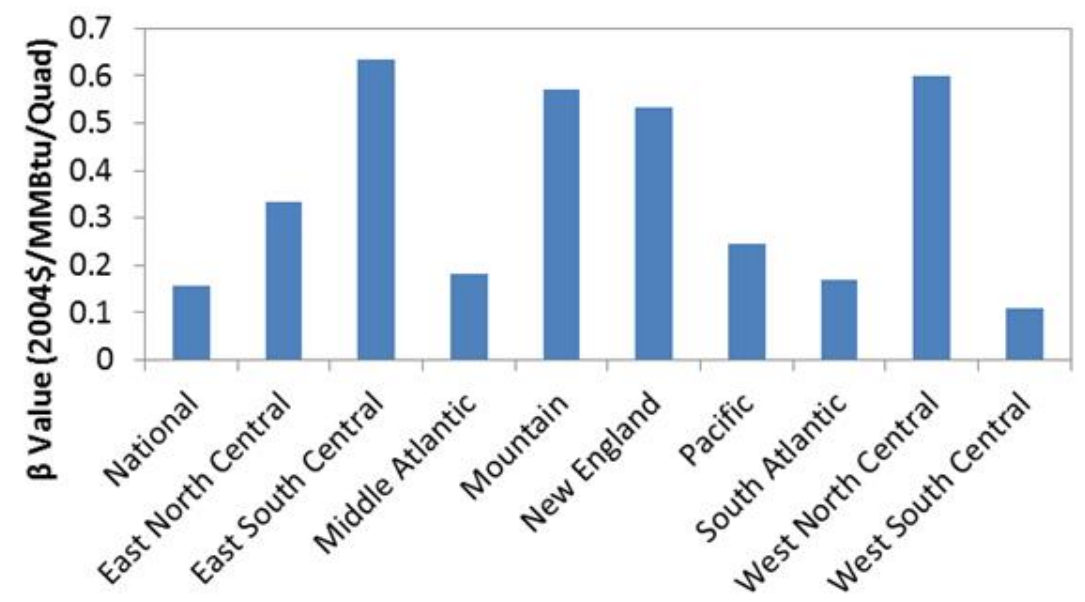

Figure A-2. $\beta$ values for the nine census divisions

The "National" value at the far left is $\beta_{\text {nat. }} A \beta$ of 0.2 means that if demand increases by one quad, the price will increase by $\$ 0.20 / \mathrm{MMBtu}$ (see Equation [1]).

The $\alpha$ terms are then regressed for each individual scenario assuming the same $\beta$ values for all scenarios. Although the $\beta$ terms are derived from AEO2014 data, $\alpha$ terms are regressed using AEO2018 data for the scenario they are intended to represent (EIA 2018). Thus, we assume natural gas price elasticity has remained constant while price projections shift over time as represented by the $\alpha$ values.

\section{Comparison to Literature Values}

Technical literature tends to report the price elasticity of supply and the price elasticity of demand, which are estimates of the supply and demand, respectively, of a good given a change in price. In the formulation given by Equation [1], we attempt to estimate a value that is similar to the price elasticity of demand - we estimate a change in price given a change in demand. Therefore we present here a comparison against the price elasticity of demand as the closest available proxy, noting however that it is not necessarily identical to estimates of $\beta$. Price elasticity of demand is typically negative but is reported here as a positive number for convenience.

${ }^{85}$ A quad is a quadrillion Btu, or $10^{15}$ Btu. 
External sources are varied and often vague in their estimates of price sensitivity of natural gas. Using the reported domestic NG market demand given for 2012 in AEO2014, the $\beta$ values reported here yield an overall NG sector elasticity value of $0.36-0.92$ (higher values of $\beta$ correspond to lower elasticity values). Arora (2014) estimated the price elasticity of demand for NG to be $0.11-0.70$, depending on the granularity and time horizon of the NG price data considered. Bernstein and Griffin (2006) examined the price elasticity of demand for residential NG usage, and they estimated the long-run elasticity to be $0.12-0.63$ depending on the region. The Energy Modeling Forum at Stanford University reports NG price elasticity of demand for 13 different energy models (Huntington 2013). The reported elasticity ranges from 0 to 2.20 depending on the year, model, and scenario considered. For the NEMS model, which is used for the AEO, the elasticity ranges from 0.22 to 0.81 depending on the year and scenario (Huntington 2013).

The EPA's proposed Clean Power Plan included a projection that natural gas usage will increase by 1.2 quads in 2020 , resulting in an $8 \%-12 \%$ increase in $\mathrm{NG}$ prices for the electric sector (Smith 2014). This corresponds to a $\beta_{\text {nat }}$ of $0.38-0.51$ in $2004 \$ / M M B t u / q u a d$.

\section{Seasonal Natural Gas Price Adjustments}

We use natural gas futures prices to estimate the ratio of winter to non-winter natural gas prices to implement seasonal gas price differences in ReEDS. We chose futures prices for two reasons: (1) ReEDS represents a system with no unforeseen disturbances, which is similar to futures prices and (2) historical natural gas prices have fluctuated greatly since the deregulation of natural gas prices.

Figure A-3 shows the cyclical nature of the natural gas futures prices. Figure A-4 breaks the same prices out into seasons, showing that the non-winter seasons have nearly the same price while wintertime prices are consistently higher. Wintertime prices are on average 1.054 times higher than non-winter prices. The standard deviation of this price ratio is 0.004 , indicating that the ratio shows very little year-to-year variation.

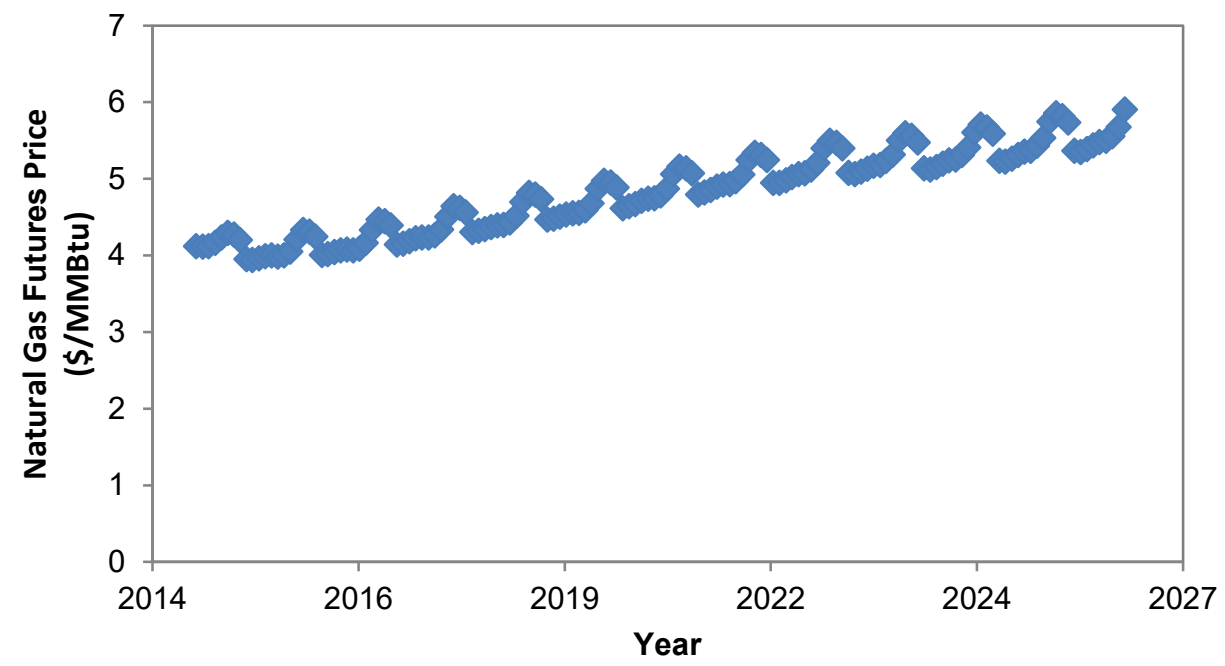

Figure A-3. Natural gas futures prices from the New York Mercantile Exchange for July 10, 2014

The prices show the higher wintertime prices and the cyclical nature of the prices. 


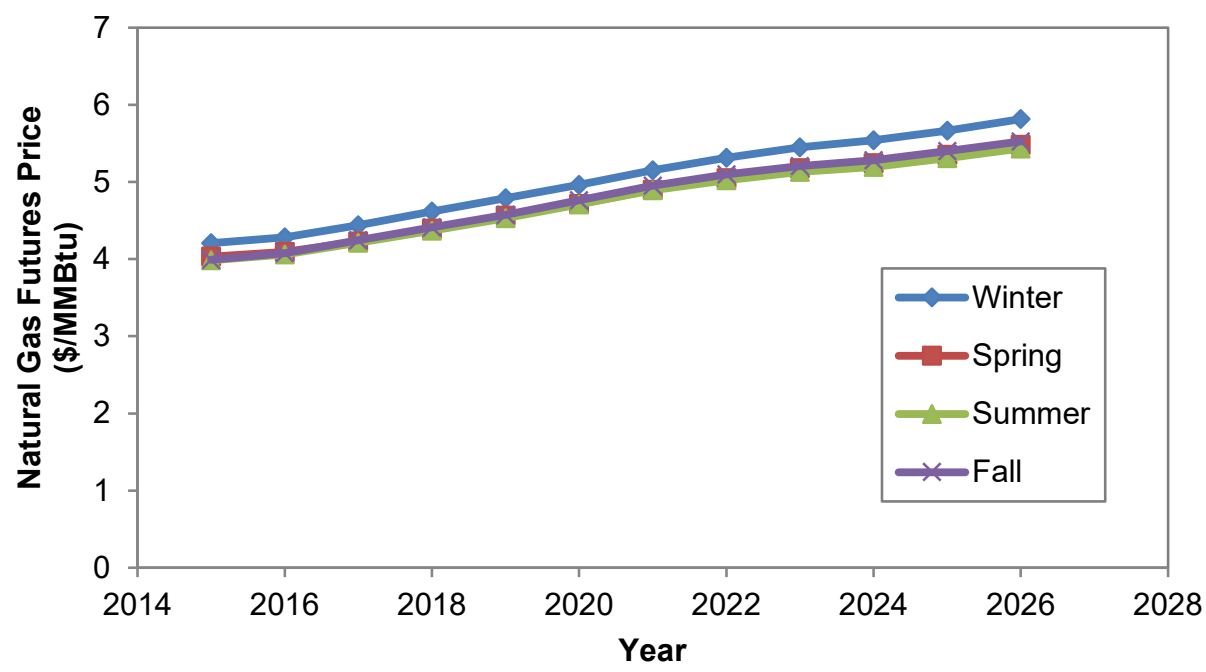

Figure A-4. Natural gas futures prices from Figure A-3 separated by season

Non-winter prices are nearly the same while wintertime prices are consistently higher.

A seasonal natural gas price multiplier is calculated in ReEDS based on the natural gas price ratio such that wintertime prices are 1.054 times higher than non-winter prices without changing the year-round average price. Mathematically, this can be expressed as

$$
\begin{gathered}
P_{\text {year-round }}=W_{\text {winter }} P_{\text {winter }}+\left(1-W_{\text {winter }}\right) P_{\text {non-winter }} \\
P_{\text {winter }}=1.054 P_{\text {non-winter }} \\
P_{\text {winter }}=\rho P_{\text {year-round }} \\
P_{\text {non-winter }}=\sigma P_{\text {year-round }}
\end{gathered}
$$

where $P$ is the natural gas price for the period indicated by the subscript, $W_{\text {winter }}$ is the fraction of natural gas consumption that occurs in the winter months, and $\rho$ and $\sigma$ are the seasonal multipliers for winter and non-winter, respectively. The multipliers $\rho$ and $\sigma$ are determined by solving Equations [2] through [5].

\section{Capital Cost Financial Multipliers}

The following equations are used to calculate the financial multipliers applied to ReEDS capital costs. The parameters may vary by technology or year as applicable. 


\section{Parameters}

- $d_{n}$ : nominal discount rate

- $d f$ : debt fraction

- $\operatorname{rore}_{n}$ : nominal rate of return on equity (RROE)

- $T$ : tax rate

- $I_{n}$ : nominal interest rate on debt

- $C C_{\text {mult }}$ : construction cost multiplier

- $I_{n}^{\text {const }}$ : nominal interest rate on debt for construction financing

- $f_{t}^{\text {const }}$ : construction fraction in year $\mathbf{t}$

- $P V_{\text {depr }}$ : present value of depreciation

- $f_{t}^{d e p r}:$ depreciation fraction in year $\mathbf{t}$

- ITC: investment tax credit

The financial multiplier represents the present value of revenue requirements necessary to finance a new investment, including construction financing, return to equity holders, interest on debt, taxes, and depreciation. The formula is based on (W. Short, Packey, and Holt 1995).

$$
\text { Financing Multiplier }=C C_{\text {mult }} * \frac{1-T * P V_{\text {depr }} *\left(1-\frac{I T C}{2}\right)-I T C}{1-T}
$$

The construction cost multiplier captures the cost to finance the construction of the plant. We use a mid-year discounting and account for the deduction of interest payments for taxes.

$$
C C_{\text {mult }}=\sum_{t} 1+(1-T) *\left(I_{n}^{\text {const }}{ }^{t+0.5}\right) * f_{t}^{\text {const }}
$$

The present value of depreciation is computed based on the fraction of the plant value that is depreciable in each year. All investments use a MACRS depreciation schedule.

$$
P V_{\text {depr }}=\sum_{t} \frac{1}{\left(1+d_{n}\right)^{t}} * f_{t}^{d e p r}
$$

The following term accounts for the fact that the eligible cost basis for MACRS is reduced by one-half the value of the tax credit:

$$
P V_{\text {depr }} *\left(1-\frac{I T C}{2}\right)
$$

The nominal discount rate is represented as the WACC.

$$
d_{n}=(1-d f) * \text { rore }_{n}+(1-T) * d f * I_{n}
$$




\section{Present Value of Direct Electric Sector Cost}

The following equations are used to calculate the present value cost of building and operating the system for some defined economic analysis period. The cost in each future year is discounted to the initial year of the economic analysis period, $t_{o}$, by a social discount rate, $d .^{86}$ In the equations, $P V_{o p}$ represents the present value cost to operate the system for the analysis period, including fixed and variable operating and maintenance costs, and fuel costs. ${ }^{87}$ The second term, $P V_{c 1}$, represents the cost of new capital investments made at least 20 years prior to the end of the analysis period, $t_{f}$. The third term, $P V_{c 2}$, represents the cost of new capital investments from the last 18 years of the analysis period. For investments that will last beyond the end of the model horizon, the cost is reduced by the weighting factor.

"New capacity" in $P V_{c 1}$ and $P V_{c 2}$ includes the capital cost ${ }^{88}$ for new generation and storage capacity installed in each year, including rebuilt renewable capacity. Grid interconnection costs for new generators are also included. ReEDS does not consider any lifetime-based replacement of existing or new transmission infrastructure.

\section{Parameters}

- $t_{o}$ : initial year of economic analysis

- $t_{f}$ : final year of economic analysis

- $\quad d$ : social discount rate $=0.03$

- $n$ : economic lifetime $=20$ years

- $C R F$ : capital recovery factor

- $C_{o p, t}$ : operational costs in year $\mathrm{t}$

- $C_{c a p, t}$ : capital costs in year $\mathrm{t}$

- $\quad P V_{o p}$ : present value of operational costs

- $P V_{c 1}$ : present value of capital investments made at least 20 years prior to tf

- $\quad P V_{c 2}$ : present value of capital investments made within 18 years of $\mathrm{tf}$

\section{Sets}

- $T$ : set of optimization years: $\{2010,2012, \ldots, 2100\}$

- $T_{o p} \subseteq T:\left\{t \mid t \geq t_{o} \cap t \leq t_{f}\right\}$ : set of years $t$ between to and tf

- $T_{c 1} \subseteq T:\left\{t \mid t \geq t_{o} \cap t \leq t_{f}-20\right\}$ : set of years $t$ that are at least 20 years prior to tf

- $T_{c 2} \subseteq T:\left\{t \mid t \leq t_{f}-18 \cap t \leq t_{f}\right\}$ : set of years t that are within 18 of $\boldsymbol{t}_{f}$

\footnotetext{
${ }^{86}$ The real discount rate used here represents the social discount rate and is not the same as the discount rate used in the investment decisions within the optimization.

${ }^{87}$ Operation costs include the marginal price of fuel.

${ }^{88}$ The capital costs are not overnight capital costs; the costs account for capital financing (e.g., construction financing, interest on debt, and return to equity), but they do not include investment tax credits.
} 
We discount operational costs from model year $t$ by $\frac{1}{(1+d)^{t-t_{o}}}$ for the all model years in $T_{o p}$ and we multiply by two to account for the operational costs of non-modeled years:

$$
P V_{o p}=2 \cdot \sum_{t \in T_{o p}}^{t_{f}} C_{o p, t} \cdot \frac{1}{(1+d)^{t-t_{o}}}
$$

We discount investments made at least 20 years prior to the $t_{f}$ by $\frac{1}{(1+d)^{t-t_{o}}}$ :

$$
P V_{c 1}=\sum_{t \in T_{c 1}} C_{c a p, t} \cdot \frac{1}{(1+d)^{t-t_{o}}}
$$

We scale investments made within 18 years of $t_{f}$ to only account for years that the investment is utilized. We then discount these scaled investments by $\frac{1}{(1+d)^{t-t_{o}}}$ :

$$
P V_{c 2}=\sum_{t \in T_{c 2}} C_{c a p, t} \cdot \text { scaling factor } \cdot \frac{1}{(1+d)^{t-t_{o}}}
$$

We define the scaling factor as the ratio of the capital recovery factor for the full economic lifetime $n$ to the capital recovery factor for the number of years that the investment is used (i.e., $\left.t_{f}+1-t\right)$. Note that we add 1 to $t_{f}$ to correctly calculate the number of years that the capacity is used. For example, assuming a 20-year economic lifetime and an analysis period out to 2050, investments made in 2031 will be paid off by 2050, which is represented by the 2050 solve year. So, $t_{f}+1-t=2050+1-2031=20$, gives the correct number of years the investments made in 2031 are utilized in the analysis horizon:

$$
\begin{aligned}
\text { scaling factor } & =\frac{\operatorname{CRF}(d, n)}{\operatorname{CRF}\left(d, t_{f}+1-t\right)} \\
\operatorname{CRF}(d, n) & =\frac{d}{1-\frac{1}{(1+d)^{n}}}
\end{aligned}
$$

\section{Cost-of-Service Electricity Prices}

\section{Sets}

- $\mathrm{n}, \mathrm{n}$ ': balancing area

- $\mathrm{m}, \mathrm{m}$ ': time-slice

- $\mathrm{q}$ : technology

- $\mathrm{t}$ : year 


\section{Parameters}

- $P_{n, m, t}^{e x}:$ cost-of service for net exporter region ' $\mathrm{n}$ ' in time-slice ' $\mathrm{m}$ ' in year ' $\mathrm{t}$ ' [\$/MWh]

- $\bar{c}_{n, m, t}^{g e n}$ : average cost of local generation in region' $n$ ' in time-slice ' $\mathrm{m}$ ' in year' $\mathrm{t}$ ' [\$/MWh]

- $n g t c_{n, t}$ : non-generation transaction cost in year ' $\mathrm{t}$ ' $[\$ / \mathrm{MWh}]$

- $P_{n, m, t}^{i m p}$ : cost-of service for net exporter region ' $\mathrm{n}$ ' in year ' $\mathrm{t}$ ' [\$/MWh]

- $\exp _{n, m, t}$ : exports from region ' $\mathrm{n}$ ' in time-slice ' $\mathrm{m}$ ' in year ' $\mathrm{t}$ ' [MWh]

- $g_{\text {en }} n_{n, m, t}$ : generation from technology ' $\mathrm{q}$ ' in region ' $\mathrm{n}$ ' in time-slice ' $\mathrm{m}$ ' in year ' $\mathrm{t}$ ' (note: generation from rooftop PV is not included in this term) [MWh]

- $\operatorname{load}_{n, m, t}$ : load in region ' $\mathrm{n}$ ' in time-slice ' $\mathrm{m}$ ' in year ' $\mathrm{t}$ ' (note: loadn,m,t is the total load minus rooftop PV generation) [MWh]

- $\bar{c}_{n, m, t}^{i m p}$ : average of cost of imported generation in year ' $\mathrm{t}$ ' [\$/MWh]

- $c_{n, t}^{r b}$ : total rate base cost in region ' $n$ ' in year ' $\mathrm{t}$ ' [\$]

- $c_{n, t}^{o m}$ : total O\&M cost in region ' $\mathrm{n}$ ' in year ' $\mathrm{t}$ ' [\$]

- $c_{n, t}^{\text {fuel }}$ : total fuel cost in region ' $\mathrm{n}$ ' in year ' $\mathrm{t}$ ' [\$]

- $c_{n, t}^{r p s}$ : total REC cost for state RPS compliance in region ' $\mathrm{n}$ ' in year ' $\mathrm{t}$ ' [\$]

- $c_{n, t}^{\text {water }}$ : total water cost in region ' $n$ ' in year ' $\mathrm{t}$ ' [\$]

- $c_{n, t}^{c p p}$ : total allowance/emissions rate credit (ERC) cost for Clean Power Plan (CPP) compliance in region ' $n$ ' in year ' $t$ ' $[\$] 89$

- $n t x_{\mathrm{n}^{\prime}, n, m, t}:=$ net transmission flow from Canada to region ' $\mathrm{n}$ ' in year ' $\mathrm{t}$ ' [\$]

- $c_{\mathrm{n}, n, t}^{t x}$ : cost of transmission from region $\mathrm{n}$ ' to region ' $\mathrm{n}$ ' in year ' $\mathrm{t}$ ' [ $\$ / \mathrm{MWh}$ ]

- $r b_{n, t}^{\text {owed }}$ : ratebase owed in region ' $\mathrm{n}$ ' in year ' $\mathrm{t}$ ' $[\$]$

- $r b_{n, t}^{\text {remain }}$ : ratebase remaining in region ' $n$ ' in year ' $\mathrm{t}$ ' $[\$]$

- $d$ : discount rate

- $r b^{\text {init }}$ : initial ratebase (in year to) [\$]

- invest $_{t}$ : investment made in region ' $\mathrm{n}$ ' in year ' $\mathrm{t}$ ' [\$]

- $\bar{c}_{n, m, t}^{\text {wheel }}$ : average wheel cost in region ' $\mathrm{n}$ ' in time-slice ' $\mathrm{m}$ ' in year ' $\mathrm{t}$ ' [\$/MWh]

- $u p f_{n, n^{\prime}, m}$ : upstream power fraction; fraction of power originating in region $\mathrm{n}$ ' that flows to region ' $n$ ' [unitless]

\footnotetext{
${ }^{89}$ This term is not included by default but contributes if the CPP policy representation is activated.
} 
The retail cost-of-service price for a net exporter region-where generation exceeds load-is the average cost of local generation, which is adjusted for non-generation transaction costs with a markup from wholesale to retail: ${ }^{90}$

$$
P_{n, m, t}^{e x}=\bar{c}_{n, m, t}^{g e n}+n g t c_{n, t}
$$

Alternatively, the retail cost-of-service price for a net importer region-where load exceeds generation - is a weighted average of costs from local and imported generation, which is also adjusted for non-generation transaction costs:

$$
P_{n, m, t}^{i m p}=\frac{\sum_{q}\left(g e n_{q, n, m, t}\right) \cdot \bar{c}_{n, m, t}^{g e n}+\exp _{n, m, t} \cdot \bar{c}_{n, m, t}^{i m p}}{\operatorname{load} d_{n, m, t}}+n g t c_{n, t}
$$

The average cost of local generation is the total cost of local generation averaged over the total electricity generated. Total costs include the rate base cost (additional cost to consumers to cover a utility's regulated rate of return), fixed and variable O\&M (including PTC), fuel (including $\mathrm{CO}_{2}$ tax), RPS shortfall compliance cost, water cost, Clean Power Plan compliance costs if applicable (allowances, ERCs), Canadian imports, and rooftop PV cost:

$$
\begin{gathered}
\bar{c}_{n, m, t}^{\text {gen }}=\frac{\left(c_{n, t}^{r b}+c_{n, t}^{o m}+c_{n, t}^{\text {fuel }}+c_{n, t}^{r p s}+c_{n, t}^{\text {water }}+c_{n, t}^{c p p}\right)}{\sum_{q, m^{\prime}}\left(g e n_{q, n, m^{\prime}}\right)} \\
+\frac{n t x_{\text {"can",n,m,t }} \cdot c_{\text {"can",n,t }}^{t x}}{\sum_{q}\left(g e n_{q, n, m, t}\right)}
\end{gathered}
$$

The costs associated with the rate base include the annual payments owed and the "interest" on the remaining rate base, which is based on the discount rate, $d$, corresponding to the investment discount rate:

$$
c_{r b, n, t}=r b_{n, t}^{\text {owed }}+r b_{n, t}^{\text {remain }} \cdot d
$$

The annual rate base payment owed includes the payment from initial rate base and payments from new investments since the initial year. We assume the investments for the initial rate base are spread equally from 1980 to 2009 . Therefore, by 2010, the investment in 1980 is fully depreciated by 2010; by 2040, the entire initial rate base is depreciated. The initial rate base is scale by $\left(1-\frac{t-t_{o}}{30}\right)$ to account for implicit payments made prior to 2010 :

$$
r b_{n, t}^{\text {owed }}=\frac{1}{30} \cdot r b^{\text {init }} \cdot\left(1-\frac{t-t_{o}}{30}\right)+\frac{1}{30} \cdot \sum_{t^{\prime}=\max \left(t_{o}, t-29\right)}^{t} \text { invest }_{t^{\prime}}^{t} \quad \forall t \leq t_{o}+30
$$

\footnotetext{
${ }^{90}$ The non-generation transaction cost defined as the difference between the 2010 historical retail price and the estimated wholesale cost-of-service price in the 2010 model year.
} 


$$
r b_{n, t}^{\text {owed }}=\frac{1}{30} * \sum_{t^{\prime}=\max \left(t_{o}, t-29\right)}^{t} \text { invest }_{t^{\prime}} \quad \forall t>t_{o}+30
$$

The remaining rate base is calculated from the remaining rate base in the prior year, adding in new investments, and deducting payment owed from initial rate base:

$$
r b_{n, t}^{\text {remain }}=r b_{n, t-1}^{\text {remain }}+\text { invest }_{t}-r b_{n, t}^{\text {owed }}
$$

The average cost of imports to region is the blending of the cost of Canadian power imports and the wheeling cost of all other imported generation, including the levelized cost of new transmission. ${ }^{91}$ These costs are weighted by net transmission flows:

$$
\bar{c}_{n, m, t}^{i m p}=\frac{n t x_{\text {"can",n,m,t}} \cdot c_{\text {can" }, n, t^{t x}}+\sum_{n^{\prime}}\left\{n t x_{n^{\prime}, n, m, t} \cdot\left(\bar{c}_{n, m, t}^{\text {wheel }}+c_{\mathrm{n}^{\prime}, n, t}^{t x}\right)\right\}}{n t x^{\prime \prime}{ }_{\mathrm{can}, n, m, t}+\sum_{n^{\prime}}\left(n t x_{n^{\prime}, n, m, t}\right)}+n g t c_{n, t}
$$

The weighted average wheeling cost of imported generation is the blending of local generation costs from all regions where the imports originate. The local generation costs are weighted by the fraction of the total imports that was generated at the upstream origin (i.e., upstream power fraction:

$$
\bar{c}_{n, m, t}^{\text {wheel }}=\sum_{n^{\prime}} \bar{c}_{n \prime, m, t}^{g e n} \cdot u p f_{n, n^{\prime}, m}
$$

\section{Marginal Electricity Prices}

ReEDS marginal "competitive" electricity prices are derived from the linear programming formulation.

In standard form, the primal formulation of a linear program is:

$$
\begin{aligned}
& \text { (P) } \quad \min c^{T} x \\
& \text { s.t. } \quad A x=b \\
& x \geq 0
\end{aligned}
$$

The associated dual formulation of the primal is:

$$
\begin{array}{cc}
\text { (D) } & \max y^{T} b \\
\text { s.t. } & y^{T} A \leq c^{T}
\end{array}
$$

Consider a simplified formulation of the ReEDS model with a subset of constraints: (1) resource limits, (2) capacity limits, (3) supply/demand balance, (4) planning reserve margin requirement, and (5) operating reserve requirement. The primal formulation is:

\footnotetext{
91 The levelized cost of new transmission connect two regions is the annualized cost of transmission (line + substation) connecting the regions averaged over the net energy flow across the line.
} 


\section{Parameters}

- $\operatorname{capcost}_{i}$ : capital cost of model plant i (\$/MW)

- vomcost $_{i}$ : variable O\&M cost of model plant i (\$/MWh)

- $S_{i}$ : available supply of model plant i (MW)

- load: electric load (MW)

- $\quad c v_{i}$ : capacity value of model plant i (MW)

- $f^{p r m}$ : planning reserve margin (unitless)

- $f^{o r}$ : operating reserve requirement (unitless)

\section{Variables}

- $C_{i}$ : capacity of model plant i (MW)

- $G_{i}$ : generation of model plant i (MWh)

- $O R_{i}$ : operating reserve allocation of plant $i(\mathrm{MWh})$

minimize $\sum_{i}$ capcost $_{i} \cdot C_{i}+$ vomcost $_{i} \cdot G_{i}$

Subject to:

$$
\begin{array}{r}
C_{i} \leq s_{i} \quad \forall i \\
\frac{G_{i}}{8760}+\frac{O R_{i}}{8760}-C_{i} \leq 0 \quad \forall i \\
\sum_{i} G_{i}=\text { load } \\
\sum_{i} c v_{i} \cdot C_{i} \geq \frac{\left(1+f^{p r m}\right)}{8760} \cdot \operatorname{load} \\
\sum_{i} O R_{i} \geq f^{\text {or }} \cdot \text { load } \\
C_{i}, G_{i}, O R_{i} \geq 0 \quad \forall i
\end{array}
$$

Constraints [1] define the resource limits for each model plant. Constraints [2] limit how capacity is allocated for each model plant (i.e., for energy or reserves). Constraint [3] requires the total generation supplied to equal the load. Constraint [4] ensures the total firm capacity meets the planning reserve margin requirement. Constraint [5] ensures the total operating reserves meet the operating reserve requirement.

From the dual formulation of the primal, the objective function is:

$$
y^{T} b=y_{1} \cdot s+y_{2} \cdot 0+y_{3} \cdot \operatorname{load}+y_{4} \cdot \frac{(1+\text { prm })}{8760} \cdot d+y_{5} \cdot f^{\text {or }} \cdot \text { load }
$$


Reformulating the primal with Constraints [3], [4], and [5] "linked" with a "load" variable, $L$, an alternative, but equivalent, primal formulation is the following:

minimize $_{\sum_{i}} \operatorname{capcost}_{i} \cdot C_{i}+$ vomcost $_{i} \cdot G_{i}$

Subject to:

$$
\begin{array}{r}
C_{i} \leq s_{i} \quad \forall i \quad[1] \\
\frac{G_{i}}{8760}+\frac{O R_{i}}{8760}-C_{i} \leq 0 \quad \forall i \quad[2] \\
\sum_{i} G_{i}-L \geq 0 \\
\sum_{i} c v_{i} \cdot C_{i}-\frac{\left[3^{\prime}\right]}{8760} \cdot L \geq 0 \\
\sum_{i} O R_{i}-f^{\text {or }} \cdot L \geq 0 \\
C_{i}, G_{i}, O R_{i} \geq 0 \\
L=\operatorname{load}
\end{array}
$$

From the dual formulation of the alternative primal, the objective function is:

$$
y^{T} b=y_{1} \cdot s+y_{2} \cdot 0+y_{3^{\prime}} \cdot 0+y_{4^{\prime}} \cdot 0+y_{5^{\prime}} \cdot 0+y_{7^{\prime}} \cdot \text { load }
$$

Equating the dual objective functions from the two equivalent primal formulations, we find that the marginal off the linking constraint [7'] is a blending of all constraints containing the "load" variable, including, constraints [3], [4], and [5]:

$$
\begin{gathered}
y_{7^{\prime}} \cdot \text { load }=y_{3} \cdot \text { load }+y_{4} \cdot \frac{\left(1+f^{\text {prm }}\right)}{8760} \cdot \operatorname{load}+y_{5} \cdot f^{\text {or }} \cdot \text { load } \\
y_{7^{\prime}}=y_{3}+y_{4} \cdot \frac{\left(1+f^{\text {prm }}\right)}{8760}+y_{5} \cdot f^{\text {or }}
\end{gathered}
$$

Therefore, we define the marginal off the linking constraint $\left[\mathrm{y}_{7^{\prime}}\right]$ as the "all-in" marginal price of electricity (i.e., change in total cost [objective function] given a small change in load). This marginal electricity price includes the energy price, capacity price and ancillary service price.

\section{Clean Power Plan}

As noted in Section 8.1.1, the Clean Power Plan and the associated Clean Energy Incentive Program are inactive by default. However, ReEDS is able to model these policies in detail if desired.

\section{Existing Source Performance Standard}

The EPA's Clean Power Plan, promulgated through Section 111(d) of the Clean Air Act, is designed to reduce $\mathrm{CO}_{2}$ emissions to $32 \%$ below 2005 levels by 2030 through rate- and massbased standards for existing sources. Existing sources are defined as any fossil fuel-fired steam- 
generating unit that commenced construction as of January 8, 2014. In ReEDS, we identify these affected fossil generators as existing source pollutant technologies. Generating units that commenced construction after January 8, 2014 (or are built endogenously by ReEDS) are considered new source pollutant technologies.

The $\mathrm{CO}_{2}$ emission targets for the interim (2022-2029) and final (2030) compliance periods are taken from the EPA technical support documents (U.S. Environmental Protection Agency 2015). For regulatory purposes, compliance with the Clean Power Plan with these emission targets must be met on the state level, though trading across states is permitted by the rule. ${ }^{92}$ No Clean Power Plan emissions limits are enforced in the pre-compliance years (prior to 2022); however, ReEDS uses foresight of the future cost of $\mathrm{CO}_{2}$ emissions to inform decisions for new investment. ${ }^{93}$ Beyond 2030, we assume the targets remain constant at the 2030 level (the Clean Power Plan does not specify what the targets will be post-2030).

For mass-based compliance ${ }^{94}$ in ReEDS, available allowances must meet or exceed $\mathrm{CO}_{2}$ emissions from sources that are covered by the Clean Power Plan. Total available allowances in a given year are the sum of the following allowance streams: (1) allowances initially allocated to generators (equal to the mass-based target for that year), (2) excess allowances from prior compliance years, and (3) early action allowances (described below). ${ }^{95} \mathrm{We}$ assume the allowances are purchased from an auction at the marginal $\mathrm{CO}_{2}$ price, which is equal to the shadow value of the model Clean Power Plan emissions constraint. The cost of allowances is incorporated into the electricity price.

For rate-based compliance in ReEDS, available ERC must offset the total ERCs required. Available ERCs are created from:

- Over-complying covered sources (i.e., sources with emission rates below their compliance targets)

- Shifts from coal to natural gas resources ${ }^{96}$

\footnotetext{
${ }^{92}$ The default representation of the Clean Power Plan in ReEDS allows for national trading so that some states can under-comply with the rule as long as other states over-comply (Cole, Mai, et al. 2016). Accordingly, this documentation focuses on that case. However, ReEDS has the capability to model any scope of compliance trading along spatial and technological dimensions.

${ }^{93}$ These future $\mathrm{CO}_{2}$ emissions costs are exogenously specified but were calibrated based on several iterations of model runs.

${ }^{94}$ Mass-based compliance is based on the mass of $\mathrm{CO}_{2}$ emitted, while rate-based compliance is based on the $\mathrm{CO}_{2}$ emission rate.

${ }^{95}$ We define excess allowances in this context to consist only of allowances allocated through the mass-based targets. In practice, early-action allowances are also banked for use in future model years and are treated equivalently to excess allowances. Banked allowances (both excess and early-action) are allocated equally over future model years through 2030.

${ }^{96}$ These ERCs are referred to as "gas-shift" ERCs in the EPA-proposed Federal Implementation Plan and are only applicable under subcategory rate compliance (U.S. Environmental Protection Agency 2016).
} 
- Qualifying zero-emitting resources ${ }^{97}$

- Energy efficiency in low-income communities (exogenously specific level of efficiency)

- Qualifying biomass ${ }^{98}$

- Biogenic portion of municipal solid waste ${ }^{99}$

- ERCs from prior years

- Early action credits.

We do not capture ERCs from non-affected combined heat and power plants, ERCs from transmission and distribution improvements, or ERCs from other sources. The total ERCs required is defined by the EPA as:

$$
\text { ERCs Req'd }=\frac{\sigma_{i}-s_{i}}{s_{i}} \cdot x_{i}
$$

where

- $\sigma_{i}$ : emission rate of source $\mathrm{i}$, (tons $\mathrm{CO} 2$ per MWh)

- $s_{i}$ : emission rate standard of source $\mathrm{i}$, (tons $\mathrm{CO} 2$ per $\mathrm{MWh}$ )

- $x_{i}$ : generation of source $i,(\mathrm{MWh})$.

For under-complying sources (i.e., $\sigma_{i}>s_{i}$ ), the amount of ERCs required is a positive number, meaning these sources must purchase ERCs. For over-complying sources (i.e., $\sigma_{i}<s_{i}$ ), the amount of ERCs required is a negative number, meaning these sources generate ERCs that can be sold. Gas-shift ERCs are defined as:

$$
E R C_{g s}=\frac{s_{\text {coal }}-\sigma_{i}}{s_{\text {coal }}} \cdot x_{i} \cdot I G F \quad \forall \quad i \in I_{\text {gas }} \text { s.t. } \sigma_{i}<s_{\text {coal }},
$$

where

- $\sigma_{i}$ : emission rate of source $\mathrm{i}$, (tons $\mathrm{CO} 2$ per MWh)

- $s_{\text {coal }}$ : emission rate standard of coal, (tons CO2 per MWh)

- $x_{i}$ : generation of source $\mathrm{i},(\mathrm{MWh})$

- IGF: incremental generation factor as specified by EPA.

We include the cost of ERCs in the electricity price, represented as tax and subsidy components (Fischer 2001), as follows:

\footnotetext{
${ }^{97}$ Qualifying zero-emitting resources include renewable and nuclear that was installed after 2012. For renewable resources, we do not track vintage; therefore, we exclude generation from those sources in 2012. Currently, we do not adjust the exclusions for retirements.

${ }^{98} \mathrm{We}$ assume every megawatt-hour generated from biomass qualifies as an ERC.

${ }^{99}$ We represent the combustion of the biogenic portion of municipal solid waste as the landfill gas technology.
} 
- $\operatorname{Tax}[\$ / \mathrm{MWh}]=\frac{\left(P_{e r c} \cdot \sigma \cdot x\right)}{x}=P_{e r c} \cdot \sigma$

- $\operatorname{Subsidy}[\$ / \mathrm{MWh}]=-\frac{\left(P_{e r c} \cdot s \cdot x\right)}{x}=-P_{e r c} \cdot s$

\section{Clean Energy Incentive Program}

The Clean Energy Incentive Program is a voluntary program under the Clean Power Plan that is intended to incentivize the early adoption of energy efficiency in low-income communities and the deployment of renewable energy. Early adoption of eligible projects ${ }^{100}$ creates early action credits (EACs) which are drawn from the pool of state allowances/ERCs from future compliance periods and matched by an EPA pool up to an equivalent of 300 million tons of $\mathrm{CO}_{2}$.

We convert EACs to allowances assuming a conversion rate of 0.8 ton/MWh as described in the EPA Federal Implementation Plan. This means that one megawatt-hour of generation/savings from eligible renewable energy/energy efficiency equals 0.8 ton of EACs for mass-based policy; and one megawatt hour of renewable energy/energy efficiency equals one megawatt-hour of EACs for rate-based policy. In total, the national EAC budget for a rate-based policy (in MWh) equals 300 million tons divided by 0.8 ton/MWh, or 375 million MWh.

Eligible energy efficiency/renewable energy projects earn EACs for energy saved and renewable energy generated in 2020 and 2021, ${ }^{101}$ which can be banked and used for compliance in any future year. Each megawatt-hour of energy generated from renewable energy gets one-half of an EAC each from the state pool and the EPA match pool. Each megawatt-hour of energy saved from energy efficiency gets one EAC each from the state pool and the EPA match pool.

To incentivize wind and solar under the Clean Energy Incentive Program, we apply a $\mathrm{CO}_{2}$ tax on new capacity that is not wind or solar to represent the expected advantage that wind and solar enjoy from acquiring (and eventually selling) early-action credits or allowances. Note that this tax does not incentivize the displacement of existing sources by wind or solar in the earlyaction period.

\footnotetext{
${ }^{100}$ Projects eligible for EACs include energy efficiency, wind, and solar projects constructed after the submittal of a state compliance plan. Assuming all states submit a state compliance plan by the end of 2016, renewable energy and energy efficiency projects built in the 2018 and 2020 model years are eligible for EACs.

${ }^{101}$ By convention, the 2022 model year represents 2022 and 2021 . Because we need to determine the amount of generation from eligible renewable energy from 2021 prior to the 2022 model year, we assume the dispatch in 2020 is representative of the 2021 dispatch.
} 